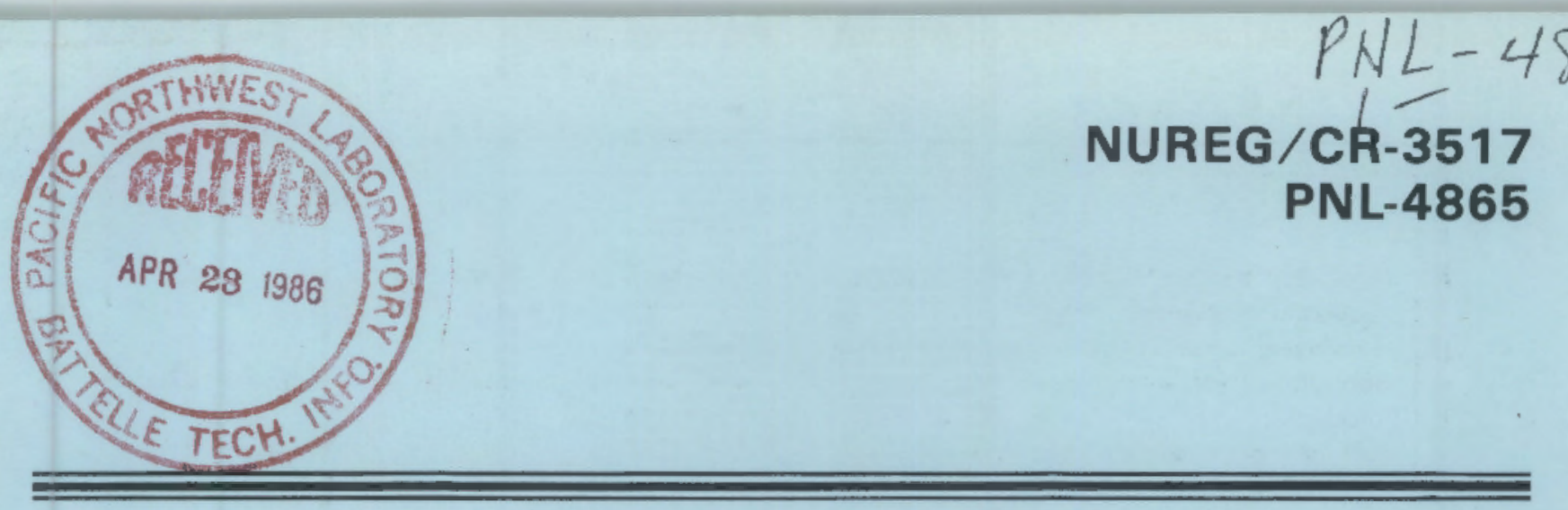

\title{
Recommendations to the NRC on Human Engineering Guidelines for Nuclear Power Plant Maintainability
}

March 1985

R. V. Badalamente

B. A. Fecht

D. E. Blahnik

J. D. Eklund

C. S. Hartley

Pacific Northwest Laboratory

Operated by

Battelle Memorial Institute

Prepared for

U.S. Nuclear Regulatory

Commission 


\section{NOTICE}

This report was prepared as an account of work sponsored by an agency of the United States Government. Neither the United States Government nor any agency thereof, or any of their employees, makes any warranty, expressed or implied, or assumes any legal liability of re. sponsibility for any third party's use, or the results of such use, of any information, apparatus, product or process disclosed in this report, or represents that its use by such third party would not infringe privately owned rights.

\section{NOTICE}

Availability of Reference Materials Cited in NRC Publications

Most documents cited in NRC publications will be available from one of the following sources:

1. The NRC Public Document Room, 1717 H Street, N.W. Washington, DC 20555

2. The Superintendent of Documents, U.S. Government Printing Office, Post Office Box 37082 , Washington, DC 20013-7082

3. The National Technical Information Service, Springfield, VA 22161

Although the listing that follows represents the majority of documents cited in NRC publications, it is not intended to be exhaustive.

Referenced documents available for inspection and copying for a fee from the NRC Public Docu. ment Room include NRC correspondence and internal NRC memoranda; NRC Office of Inspection and Enforcement bulletins, circulars, information notices, inspection and investigation notices: Licensee Event Reports; vendor reports and correspondence; Commission papers; and applicant and licensee documents and correspondence.

The following documents in the NUREG series are available for purchase from the GPO Sales Program: formal NRC staff and contractor reports, NRC-sponsored conference proceedings, and NRC booklets and brochures. Also available are Regulatory Guides, NRC regulations in the Code of Federal Regulations, and Nuclear Regulatory Commission /ssuances.

Documents available from the National Technical Information Service include NUREG series reports and technical reports prepared by other federal agencies and reports prepared by the Atomic Energy Commission, forerunner agency to the Nuclear Regulatory Commission.

Documents available from public and special technical libraries include all open literature items, such as books, journal and periodical articles, and transactions. Federal Register notices, federal and state legislation, and congressional reports can usually be obtained from these libraries.

Documents such as theses, dissertations, foreign reports and translations, and non-NRC conference proceedings are available for purchase from the organization sponsoring the publication cited.

Single copies of NRC draft reports are available free, to the extent of supply, upon written recpuest to the Division of Technical Information and Document Control, U.S. Nuclear Regulatory Com mission, Washington, DC 20555.

Copies of industry codes and standards used in a substantive manner in the NRC regulatory process are maintained at the NRC Library, 7920 Norfolk Avenue, Bethesda, Maryland, and are available there for reference use by the public. Codes and standards are usually copyrighted and may be purchased from the originating organization or, if they are American National Standards, from the American National Standards Institute, 1430 Broadway, New York, NY 10018. 


\section{Recommendations to the NRC on} Human Engineering Guidelines for Nuclear Power Plant Maintainability

Manuscript Completed: October 1985

Date Published: March 1986

R. V. Badalamente

B. A. Fecht

D. E. Blahnik

J. D. Eklund

C. S. Hartley

Pacific Northwest Laboratory

P. O. Box 999

Richland, WA 99352

Prepared for

Division of Human Factors Safety

Office of Nuclear Reactor Regulation

U.S. Nuclear Regulatory Commission

NRC FIN B2360 


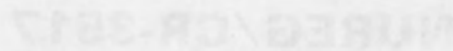

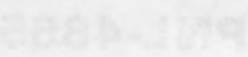

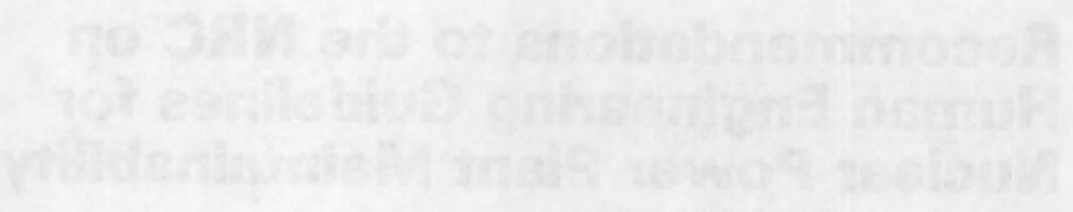

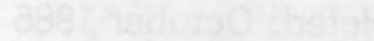

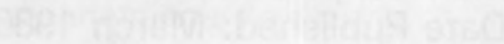

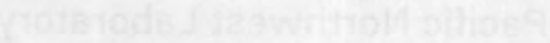

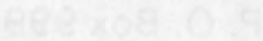

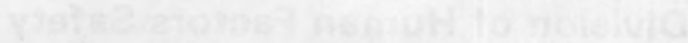

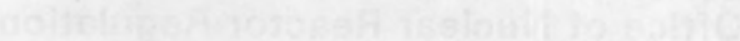

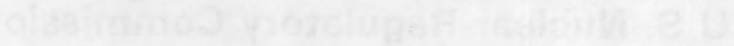




\section{FOREWORD}

Recent studies have identified deficiencies in nuclear power plant maintenance. One of the more important of those deficiencies was found to be maintainability. The potential impact of poor maintainability was stressed by the Human Factors Society report for the Nuclear Regulatory Commission (NRC). That report also indicated the need for development of a guideline document on maintainability similar to that for control room design.

In response to the indicated need, the NRC asked Pacific Northwest Laboratories to develop human engineering guidelines for enhancing nuclear power plant maintainability. This document is the result of that task. It contains human engineering guidelines drawn from a number of sources, both private and government. The NRC is aware that similar documents, based on many of the same sources, are being prepared by other organizations. The exact role for this and the other documents in any comprehensive NRC plan for addressing maintenance is undetermined. However, it is expected that the use of such documents can decrease the number of design-induced errors in nuclear power plants. Any decrease in maintenance errors is expected to have both safety and operational benefits.

Comments or questions concerning this document should be directed to Dennis Serig, U.S. Nuclear Regulatory Commission, Mail Stop AR-5209, Washington, DC 20555. Telephone: (301) 492-4887. 


\section{ACKNOWLEDGMENTS}

The authors wish to extend their appreciation to the personnel at nuclear power plants, architectengineers, and nuclear steam supply system (NSSS) vendors who assisted us in this endeavor. We also appreciate the cooperation we received from the Institute for Nuclear Power Operations (INPO) and the Electric Power Research Institute (EPRI). We are especially grateful for the efforts of Jolene Bruce, Rene Hinds, Sue Vickerman and Teresa Zinn of the Pacific Northwest Laboratory (PNL), whose efforts in manuscript illustration, editing and layout, and preparation were essential ingredients in the development of this document. Technical assistance from John Piatt of PNL and Jacques Faigenblum and Mike Morgenstern of Battelle's Human Affairs Research Center (HARC) are greatly appreciated, as are the numerous contributions from technical assistance to manuscript preparation that we received from other Battelle colleagues. Finally, we extend our appreciation to the many human factors engineers and scientists whose contributions to the field are represented, however imperfectly, in the maintainability design principles contained in this document. 


\section{ABSTRACT}

This document contains human engineering guidelines which can enhance the maintainability of nuclear power plants. The guidelines have been derived from general human engineering design principles, criteria, and data. The guidelines may be applied to existing plants as well as to plants under construction. They apply to nuclear power plant systems, equipment and facilities, as well as to maintenance tools and equipment. The guidelines are grouped into seven categories: accessibility and workspace, physical environment, loads and forces, maintenance facilities, maintenance tools and equipment, operating equipment design, and information needs. Each chapter of the document details specific maintainability problems encountered at nuclear power plants, the safety impact of these problems, and the specific maintainability design guidelines whose application can serve to avoid these problems in new or existing plants. Key words for this document should include: maintainability, human factors, human factors engineering, human engineering, nuclear power plant, reactor, maintenance. 


\section{EXECUTIVE SUMMARY}

\section{Background}

Recognizing the potential impact of maintenance on nuclear power plant safety, the Nuclear Regulatory Commission (NRC), Office of Nuclear Reactor Regulation (NRR), Division of Human Factors Safety (DHFS) contracted with Pacific Northwest Laboratory (PNL) in October 1981 to study the area and recommend a program for the development of maintenance guidelines for nuclear power plants. A program plan was submitted by PNL to NRR-DHFS in September 1982. A key recommendation in the plan was that the NRC develop guidelines for nuclear power plant (NPP) maintainability. In its recommendations to the NRC on critical human factors issues, the Human Factors Society stressed the importance of design for maintainability and recommended that a guideline document, similar to NUREG-0700 on control room design, be published for maintainability. The Electric Power Research Institute (EPRI) has also stressed the importance of this area.

In October 1982, NRR-DHFS contracted with PNL to develop and recommend maintainability design guidelines for nuclear power plants. This document is an output of that contract. It contains human engineering guidelines which can enhance the maintainability of nuclear power plants. The guidelines have been derived from general human engineering/design principles, criteria, and data, and represent a distillation of guidelines contained in numerous sources across both the civilian and government sectors. NUREG-0700 already contains some human engineering guidelines, which can increase nuclear power plant maintainability. For the most part guidelines in the current document provide a maintainability supplement to those in NUREG-0700. In areas of overlap (e.g., labeling) guidelines in the current document are consistent with those in NUREG-0700.

\section{Purpose of the Document}

The purpose of this document is to present selected human engineering guidelines, which can reduce the incidence of design-induced maintenance errors and thereby increase the operational safety of nuclear power plants. Relatively economical maintainability enhancements are included in the document, as well as guidelines that may be most appropriate as specifications for the procurement of new/replacement equipment. The guidelines may assist: (1) plant maintenance managers in evaluating plant/equipment design and recommending maintainability improvements; (2) utility project managers in ensuring that maintainability considerations are incorporated in plant/equipment contract specifications and implemented in plant design and construction; (3) nuclear steam supply system (NSSS) and balance of plant (BOP) equipment vendors in designing equipment that is maintainable; and (4) architect-engineers and facility designers in designing plants that incorporate equipment and workspace layouts, ambient environments and habitability provisions conducive to effective performance of maintenance personnel. The guidelines might also assist NRC personnel in the performance of regular inspections and audits, and in responding to operating reactor events.

\section{Organization and Format}

The guidelines are categorized into seven chapters: accessibility and workspace, physical environment, loads and forces, maintenance facilities, maintenance tools and equipment, operating equipment design, and information needs. Each of these chapters contains general definitions, related NPP maintainability problems, discussions of potential safety impact to the public and to plant personnel resulting from maintainability problems, and associated human engineering guidelines selected to help resolve the problems. 


\section{TABLE OF CONTENTS}

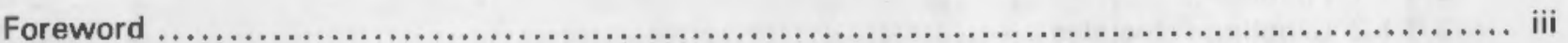

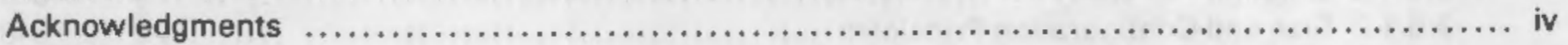

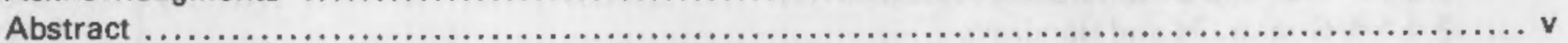

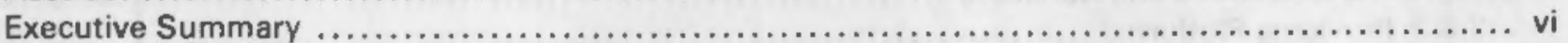

\section{Chapter 1}

\section{INTRODUCTION}

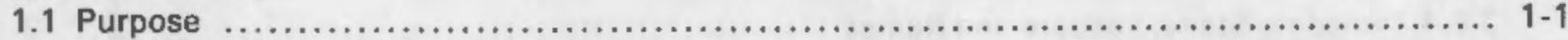

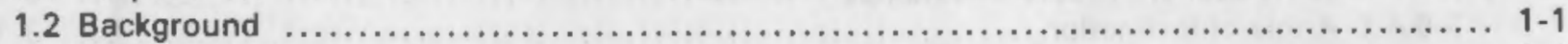

1.3 Impact of Maintenance on Safety $\ldots \ldots \ldots \ldots \ldots \ldots \ldots \ldots \ldots \ldots \ldots \ldots \ldots \ldots \ldots \ldots \ldots \ldots \ldots \ldots \ldots \ldots \ldots \ldots \ldots, 1$

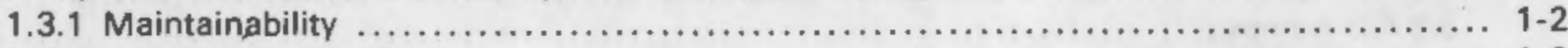

1.4 Organization and Format $\ldots \ldots \ldots \ldots \ldots \ldots \ldots \ldots \ldots \ldots \ldots \ldots \ldots \ldots \ldots \ldots \ldots \ldots \ldots \ldots \ldots \ldots, 2$

\section{Chapter 2}

\section{GENERAL PRINCIPLES}

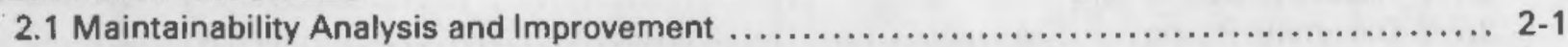

2.2 Design to Avoid Conditions That Increase Probability of Human Error ................... 2-1

2.3 Fool-Proof Design ......................................................... $2-2$

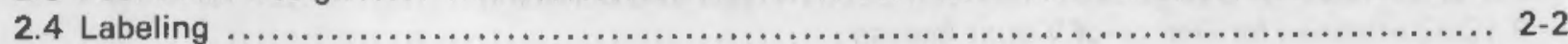

\section{Chapter 3}

\section{ACCESSIBILITY AND WORKSPACE}

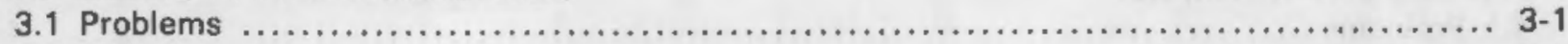

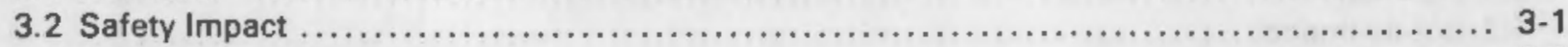

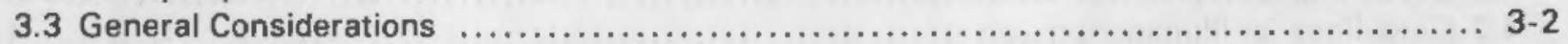

3.3.1 Decision Factors $\ldots \ldots \ldots \ldots \ldots \ldots \ldots \ldots \ldots \ldots \ldots \ldots \ldots \ldots \ldots \ldots \ldots \ldots \ldots \ldots \ldots \ldots \ldots \ldots \ldots \ldots, 2$

3.3.2 Types of Access (In Order of Preference) $\ldots \ldots \ldots \ldots \ldots \ldots \ldots \ldots \ldots \ldots \ldots \ldots \ldots \ldots \ldots \ldots \ldots \ldots \ldots \ldots, 3$

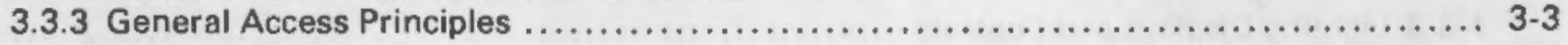

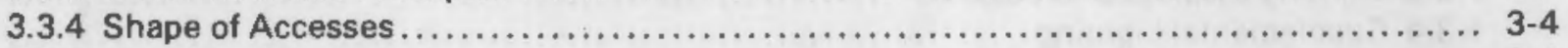

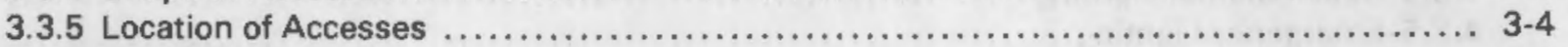

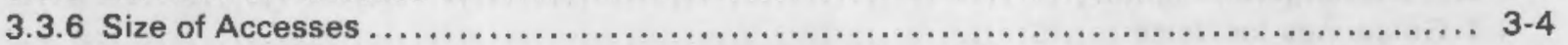

3.4 Guidelines for Designing Hatches and Manways for Whole Body Access ................. 3-4

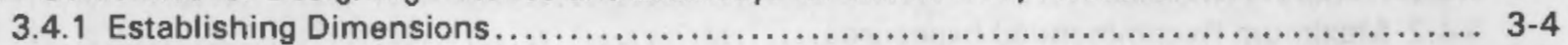

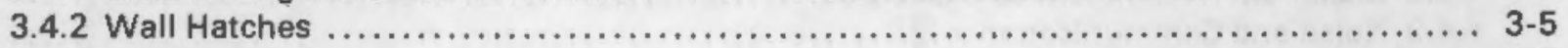

3.4.3 Sliding Doors $\ldots \ldots \ldots \ldots \ldots \ldots \ldots \ldots \ldots \ldots \ldots \ldots \ldots \ldots \ldots \ldots \ldots \ldots \ldots \ldots \ldots \ldots \ldots \ldots \ldots \ldots \ldots \ldots, 3-5$

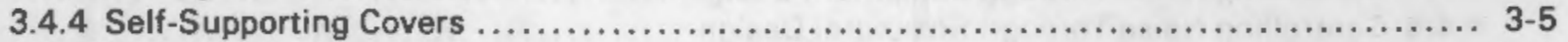

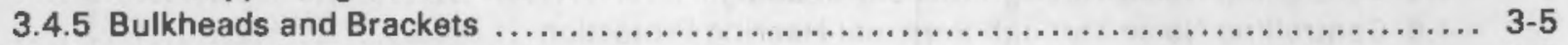

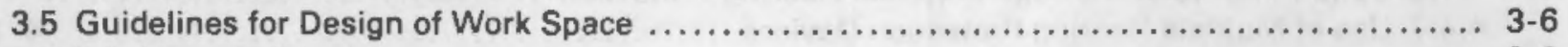

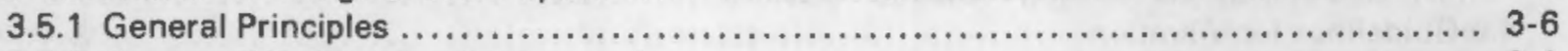

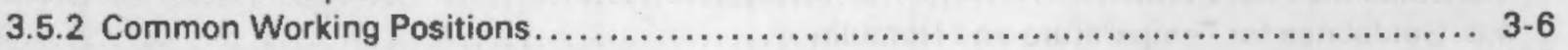

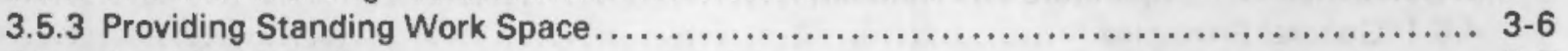

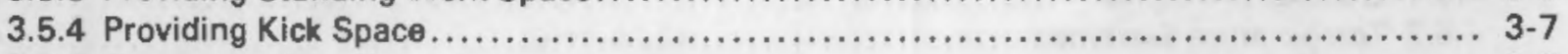

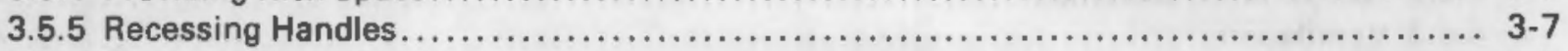

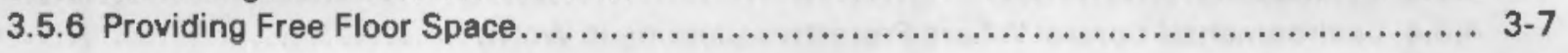




\section{Contents}

3.6 Guidelines for Design of Installed Platforms, Work Stands, and Ladders . . . . . . . . . . . . 3-7

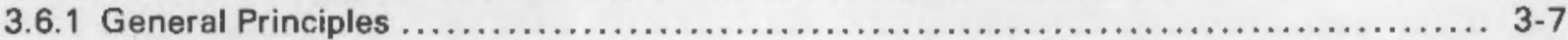

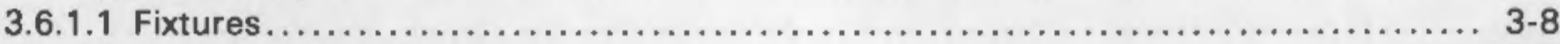

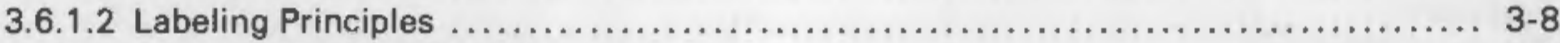

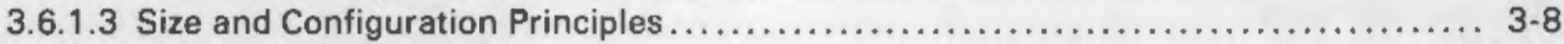

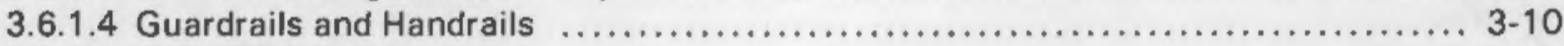

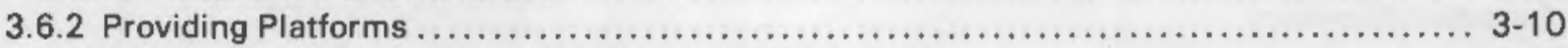

3.6.2.1 Constructing Personnel Platforms and Work Areas .......................... 3-10

3.6.2.2 Providing Elevators and Hydraulically Operated Work Platforms . . . . . . . . . . . $3-10$

3.6.3 Providing Stands ........................................................... $3-11$

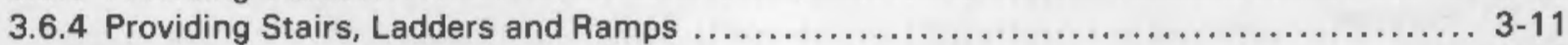

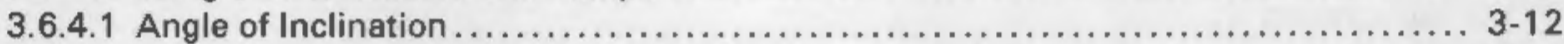

3.6.4.2 Types of Structures, In Order of Preference ................................ 3-12

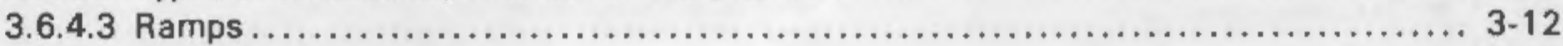

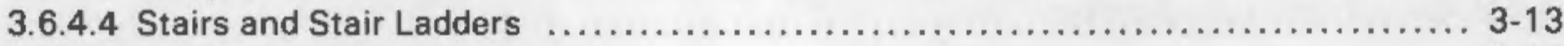

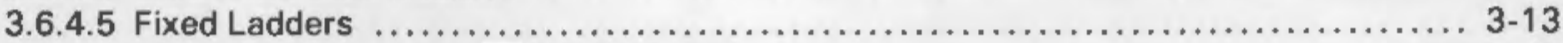

3.7 Guidelines for Design of Arm and Hand Access $\ldots \ldots \ldots \ldots \ldots \ldots \ldots \ldots \ldots \ldots \ldots \ldots \ldots \ldots \ldots \ldots \ldots \ldots \ldots, 13$

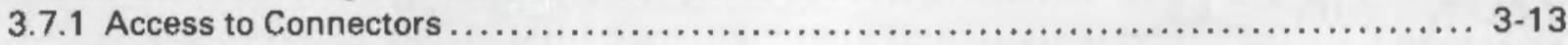

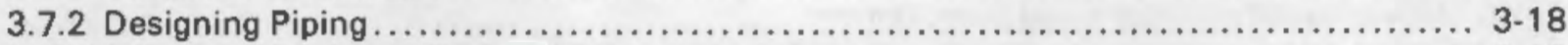

3.8 Guidelines for Design of Tool and Equipment Access $\ldots \ldots \ldots \ldots \ldots \ldots \ldots \ldots \ldots \ldots \ldots \ldots \ldots \ldots \ldots \ldots \ldots, 18$

3.9 Guidelines for Design to Facilitate Inspection, Test and Servicing $\ldots \ldots \ldots \ldots \ldots \ldots \ldots \ldots \ldots, 3-18$

3.10 Guidelines for Design of Visual Access ..................................... 19

\section{Chapter 4}

\section{PHYSICAL ENVIRONMENT}

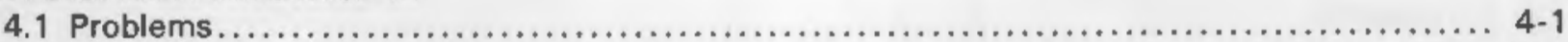

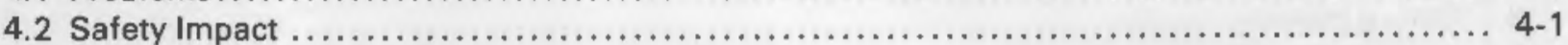

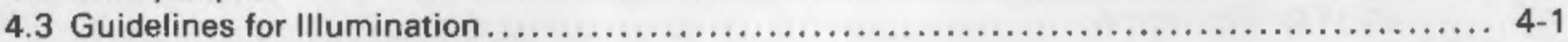

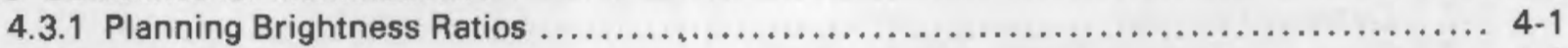

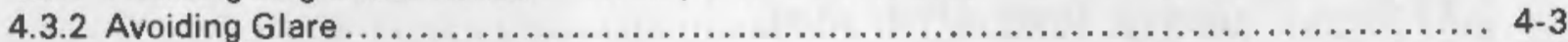

4.3.3 Lighting Displays and Controls $\ldots \ldots \ldots \ldots \ldots \ldots \ldots \ldots \ldots \ldots \ldots \ldots \ldots \ldots \ldots \ldots \ldots \ldots \ldots \ldots \ldots, 4$

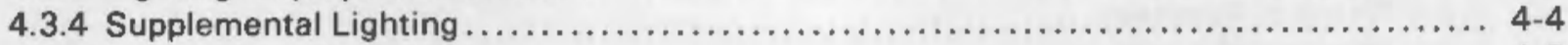

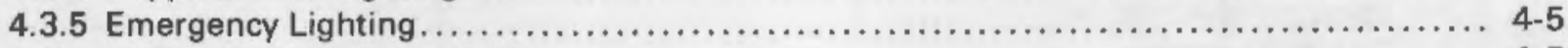

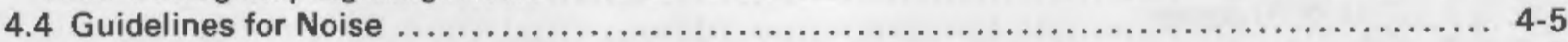

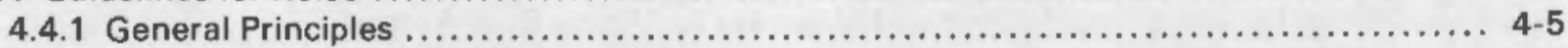

4.4.2 Maximum Recommended Exposures...................................... 4-5

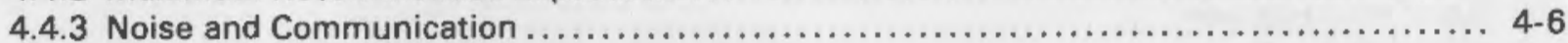

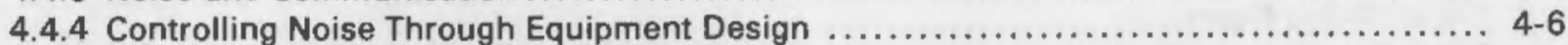

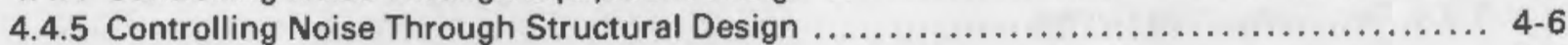

4.4.6 Controlling Noise Through Personal Hearing Protection ........................ 4-8

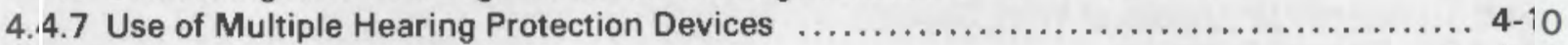

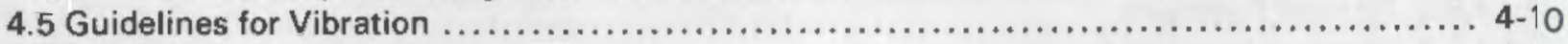

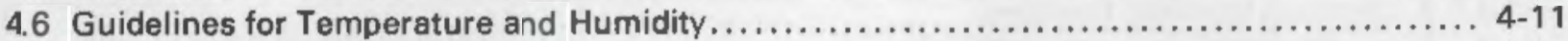

4.6.1 General Principles ................................................... 411

4.6.2 Temperature Extremes............................................... 411

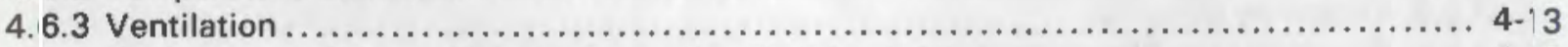

4.6.4 Environmental Control Where Protective Clothing is Worn.................... 4-13 


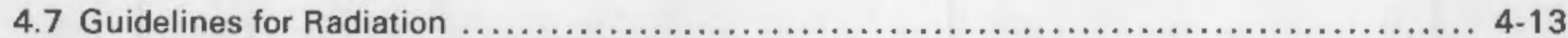

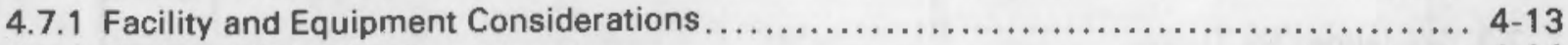

4.7.2 Tool and Shielding Considerations $\ldots \ldots \ldots \ldots \ldots \ldots \ldots \ldots \ldots \ldots \ldots \ldots \ldots \ldots \ldots \ldots \ldots \ldots, 4-14$

4.7.3 Protective Garments ............................................. 4-14

\section{Chapter 5}

LOADS AND FORCES

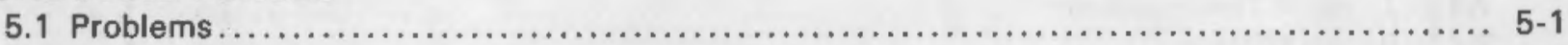

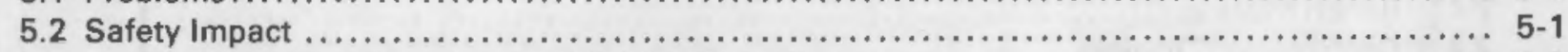

5.3 General Considerations for Establishing Guidelines. . . . . . . . .

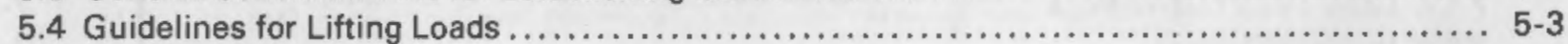

5.4 .1 One-Person Lifts . . . . . . . . . . . . . . . . . . . . .

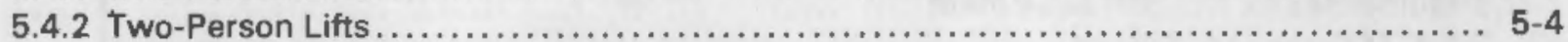

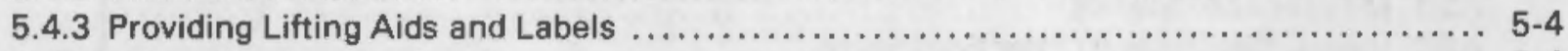

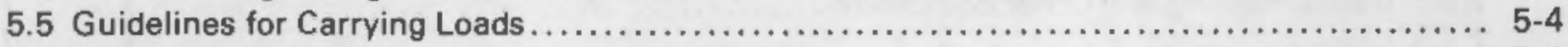

5.5 .1 Load Configuration ................................................... 5

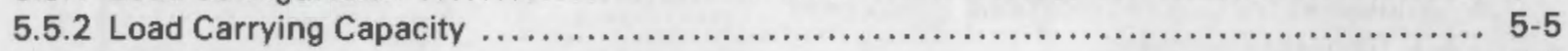

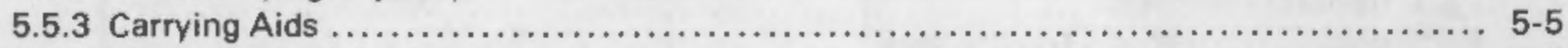

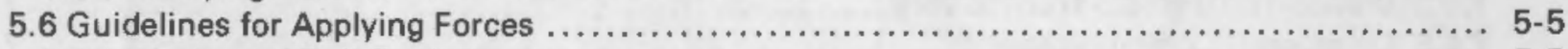

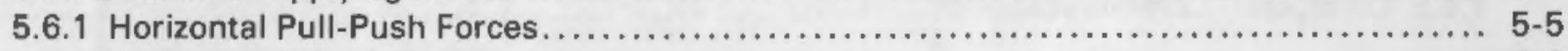

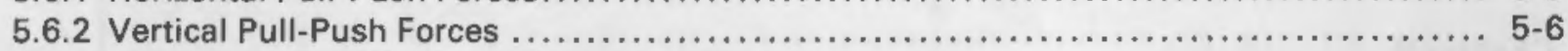

5.6.3 Arm, Hand, Thumb-Finger Control Forces .......................................

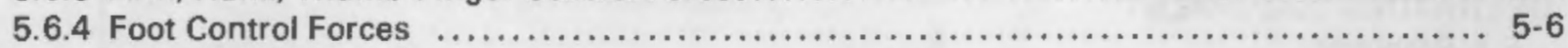

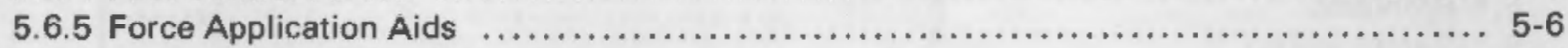

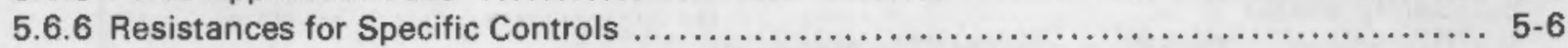

\section{Chapter 6}

MAINTENANCE FACILITIES

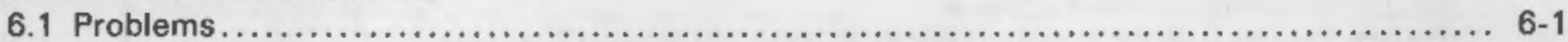

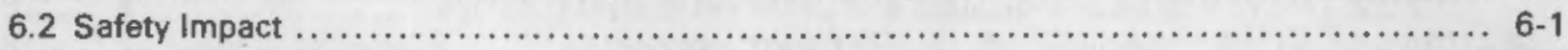

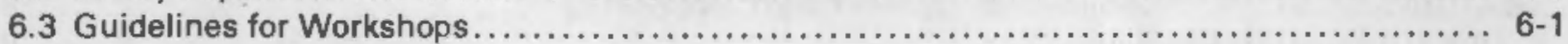

6.3 .1 Sizing and Arrangement $\ldots \ldots \ldots \ldots \ldots \ldots \ldots \ldots \ldots \ldots \ldots \ldots \ldots \ldots \ldots \ldots \ldots \ldots, 6,1$

6.3 .2 Location and Integration $\ldots \ldots \ldots \ldots \ldots \ldots \ldots \ldots \ldots \ldots \ldots \ldots \ldots \ldots \ldots \ldots \ldots \ldots \ldots \ldots \ldots \ldots \ldots \ldots \ldots, 2$

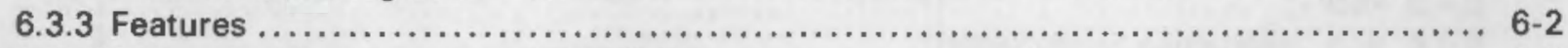

6.4 Guidelines for Warehouses and Tool Cribs . . . . . . . . . . . . .

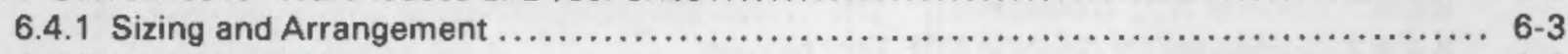

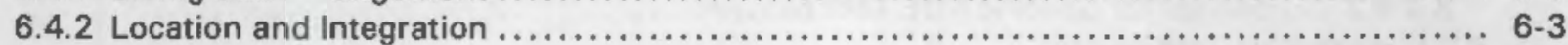

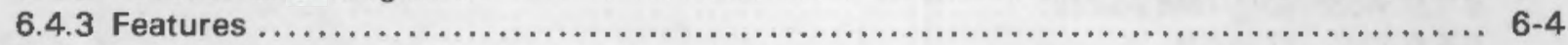

6.5 Guidelines for In-Plant Maintenance Work Space ................................. $6-4$

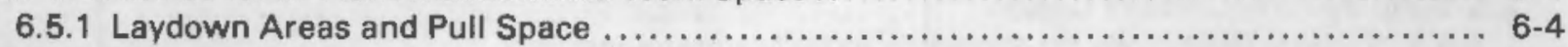

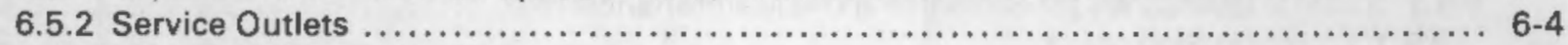

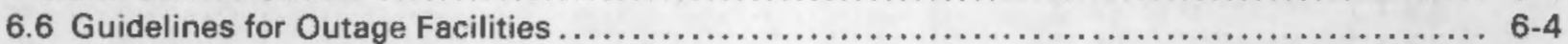

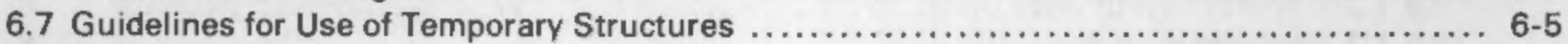

\section{Chapter 7 \\ MAINTENANCE TOOLS AND EQUIPMENT}

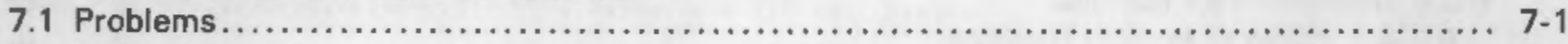

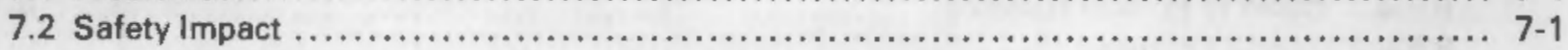




\section{Contents}

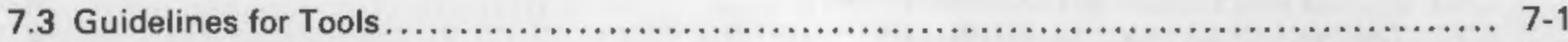

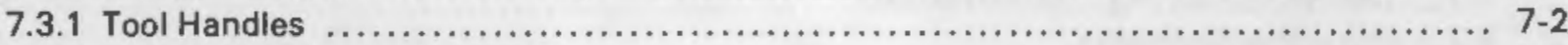

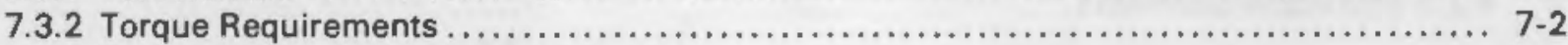

7.3.3 Tools for Use in Special Environments .........................................

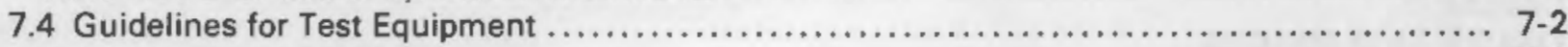

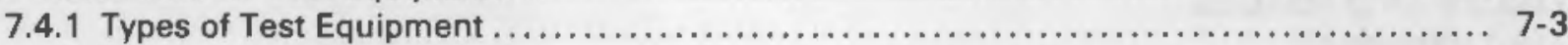

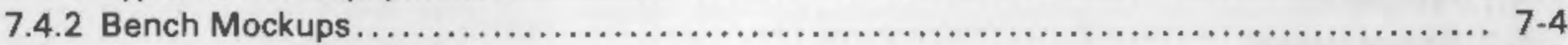

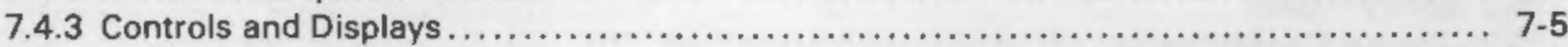

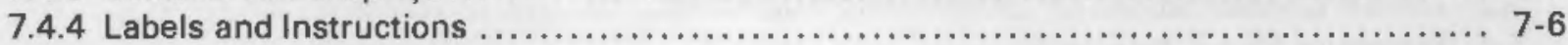

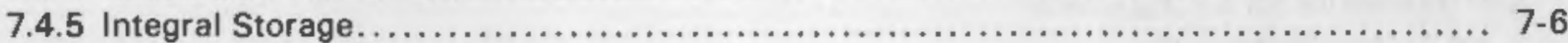

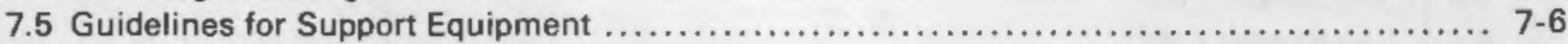

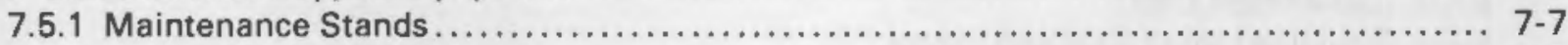

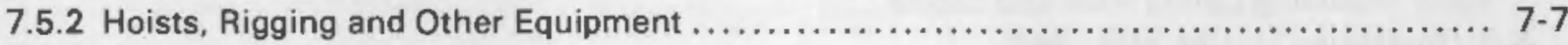

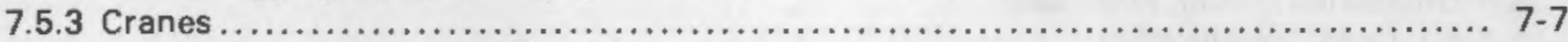

7.6 Guidelines for Communications Equipment $\ldots \ldots \ldots \ldots \ldots \ldots \ldots \ldots \ldots \ldots \ldots \ldots \ldots \ldots \ldots \ldots \ldots \ldots \ldots \ldots, 7,8$

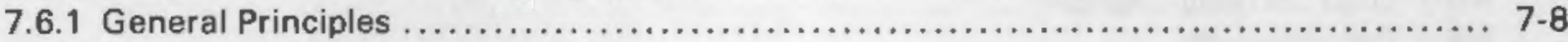

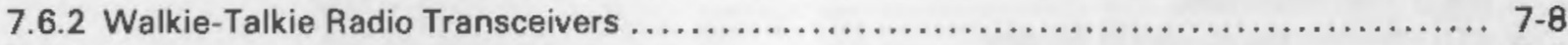

7.6.3 Emergency Communications $\ldots \ldots \ldots \ldots \ldots \ldots \ldots \ldots \ldots \ldots \ldots \ldots \ldots \ldots \ldots \ldots \ldots \ldots \ldots \ldots, 7-9$

\section{Chapter 8}

\section{OPERATING EQUIPMENT}

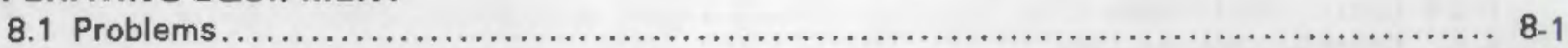

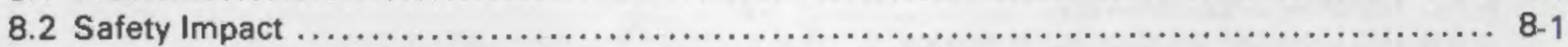

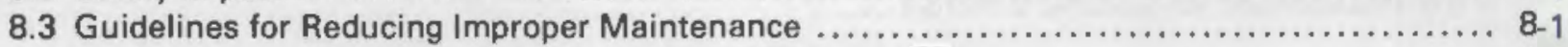

8.3.1 Physical Features to Preclude Improper Maintenance $\ldots \ldots \ldots \ldots \ldots \ldots \ldots \ldots \ldots \ldots \ldots, 8,2$

8.3.2 Information Necessary to Reduce the Probability of Errors ........................ $8-4$

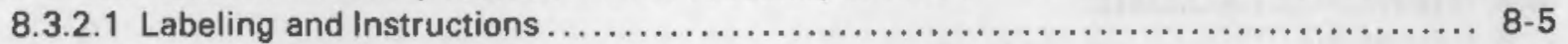

8.3.2.2 Test Points, Fault Indicators and Other Equipment Displays $\ldots \ldots \ldots \ldots \ldots \ldots \ldots \ldots$. 8-5

8.4 Guidelines for Accessibility to Equipment and Components $\ldots \ldots \ldots \ldots \ldots \ldots \ldots \ldots \ldots \ldots \ldots$. 8-6

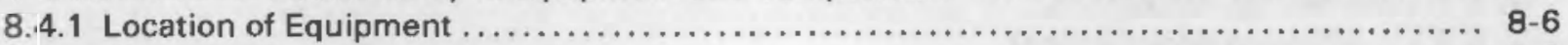

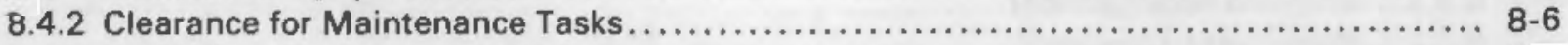

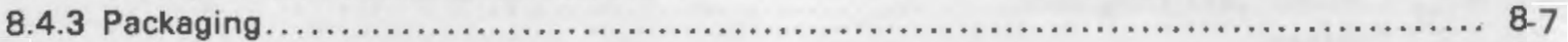

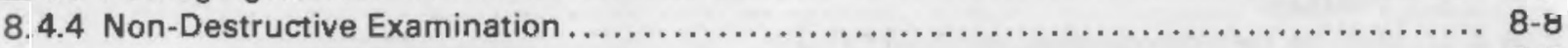

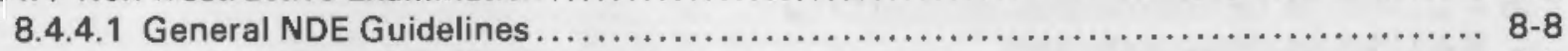

8.4.4.2 Guidelines for Specific NDE Techniques $\ldots \ldots \ldots \ldots \ldots \ldots \ldots \ldots \ldots \ldots \ldots \ldots \ldots \ldots \ldots \ldots$

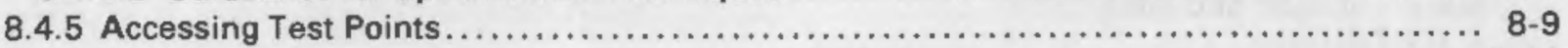

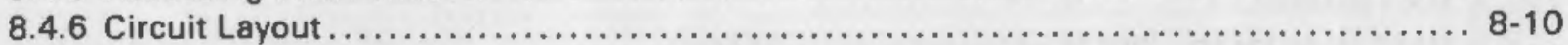

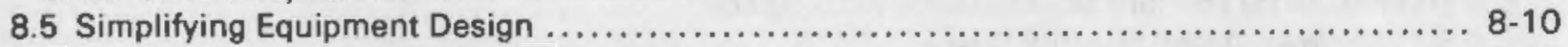

8.5.1 General Guidelines for Simplifying the Maintenance Task ...................... 8-10

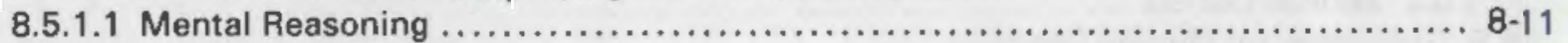

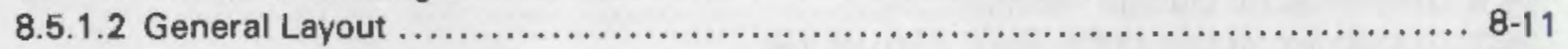

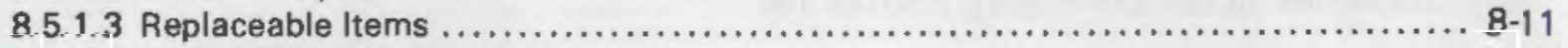

8.5.2 Guidelines for Modular Design ........................................ 8 812

8.5.3 Guidelines for Drawers, Racks and Slides ............................... 8-13

8.5.4 Guidelines for Handles $\ldots \ldots \ldots \ldots \ldots \ldots \ldots \ldots \ldots \ldots \ldots \ldots \ldots \ldots \ldots \ldots \ldots \ldots \ldots \ldots \ldots \ldots \ldots \ldots \ldots \ldots, 14$

8.5.4.1 When to Provide Handles $\ldots \ldots \ldots \ldots \ldots \ldots \ldots \ldots \ldots \ldots \ldots \ldots \ldots \ldots \ldots \ldots \ldots \ldots \ldots \ldots \ldots \ldots \ldots \ldots, 14$

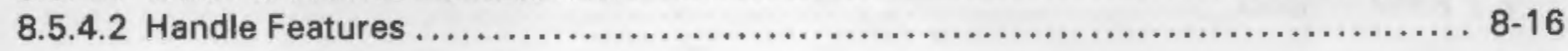


8.5.5 Guidelines for Cases and Covers....................................... 8-16

8.5.6 Guidelines for Cables and Connectors .................................... 8-16

8.5 .7 Guidelines for Fasteners $\ldots \ldots \ldots \ldots \ldots \ldots \ldots \ldots \ldots \ldots \ldots \ldots \ldots \ldots \ldots \ldots \ldots \ldots \ldots \ldots \ldots \ldots \ldots \ldots, 18$

8.5.8 Guidelines for Integrating Testing Needs with Equipment. $\ldots \ldots \ldots \ldots \ldots \ldots \ldots \ldots \ldots, 8-19$

8.5.8.1 Use of Automatic and Semi-Automatic Testing Methods .................... 8-19

8.5.8.2 Guidelines for Design of Equipment Testing Features $\ldots \ldots \ldots \ldots \ldots \ldots \ldots \ldots \ldots .8-20$

\section{Chapter 9}

INFORMATION NEEDS

9.1 Problems ..................... $9-1$

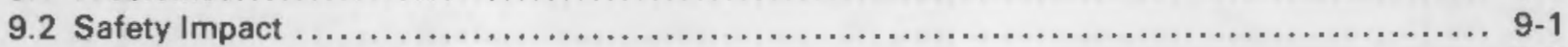

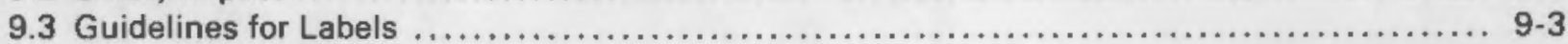

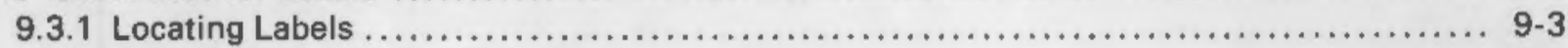

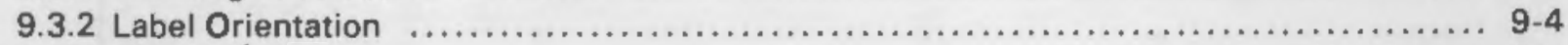

9.3.3 Label Viśsibility .......................................................... 9-4

9.3.4 Label Readability......................................................... 9-5

9.3.5 Label Content ........................................................... 9-6

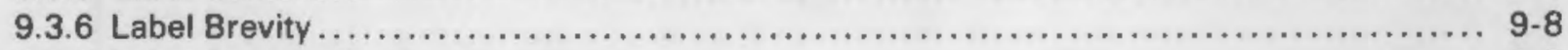

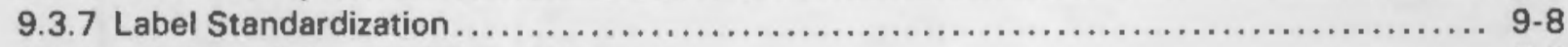

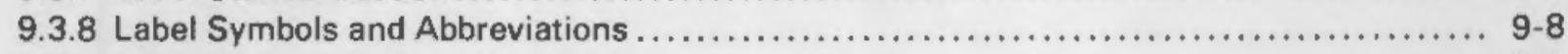

9.3.9 Color Coding Labels....................................................... 9-9

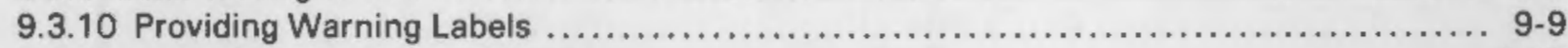

9.3.11 Indicating Lubrication Needs ......................................... 9-10

9.3.12 Providing Labels to Indicate Equipment Access .............................. 9-10

9.3.13 Labeling Test Points ................................................. 9-11

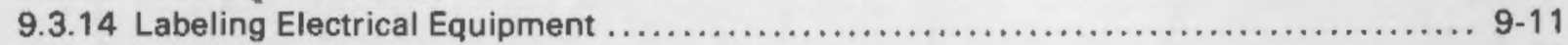

9.3.15 Labeling Disposable Modules.............................................. 9-12

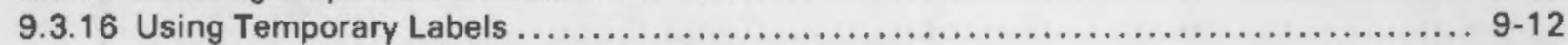

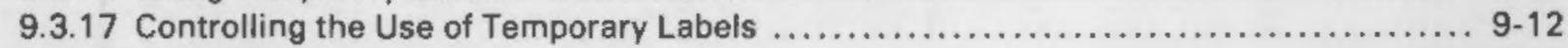

9.4 Guidelines for Visual Displays . . . . . . . . . .

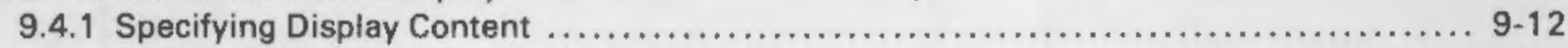

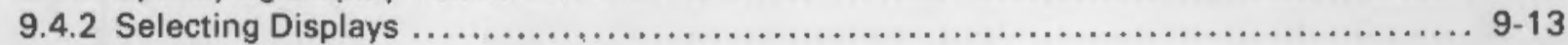

9.4.3 Locating and Arranging Displays........................................ 9

9.4.4 Integrating Displays and Controls ........................................... 9

9.4.5 Maintenance Displays ................................................... 9-17

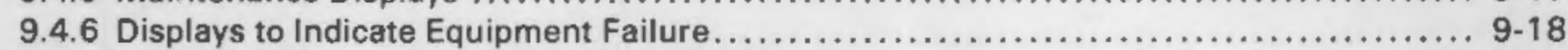

9.5 Guidelines for Tactile Sensation and Feedback $\ldots \ldots \ldots \ldots \ldots \ldots \ldots \ldots \ldots \ldots \ldots \ldots \ldots, 9,19$

9.5.1 Indicating Control Activation ................................................ 9-19

9.5.2 Shape Coding ............................................................. 9-19

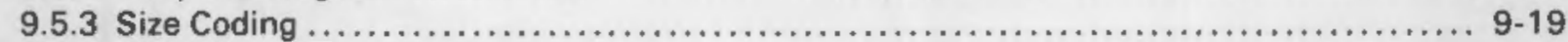

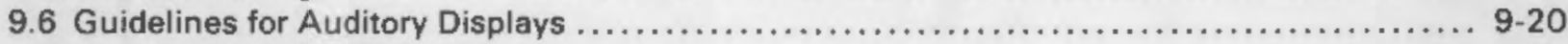

9.6.1 Use of Auditory Displays ................................................. 9-20

9.6.2 Choosing Visual vs. Auditory Displays ................................... 9-21

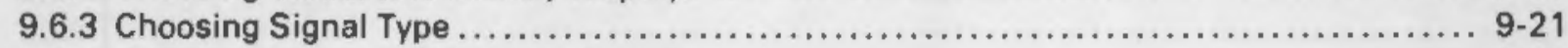

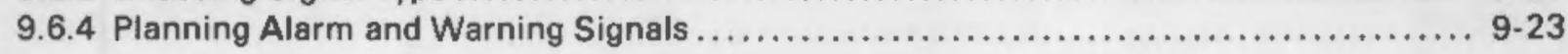




\section{Contents}

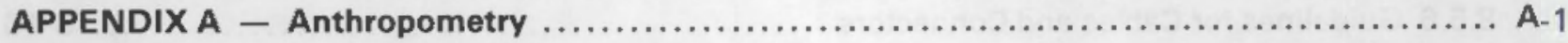

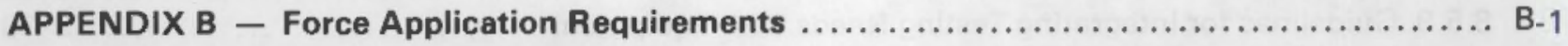

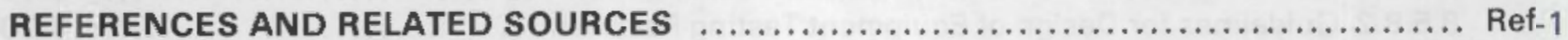




\section{LIST OF TABLES}

\section{Chapter 3}

\section{ACCESSIBILITY AND WORKSPACE}

3.1 Anthropometric Data for Common Working Positions $\ldots \ldots \ldots \ldots \ldots \ldots \ldots \ldots \ldots \ldots \ldots \ldots \ldots$

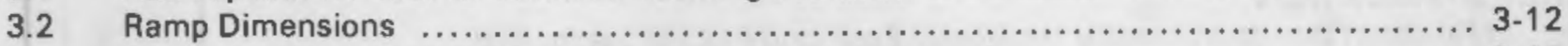

3.3 Dimensions for Fixed Ladders, Stairs and Stair Ladders ......................... 3-15

\section{Chapter 4}

\section{PHYSICAL ENVIRONMENT}

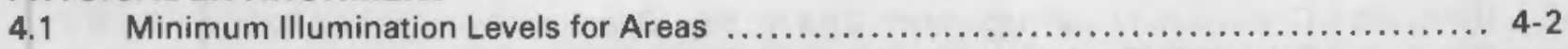

4.2 General Illumination Levels and Types of Illumination for Different Task Conditions

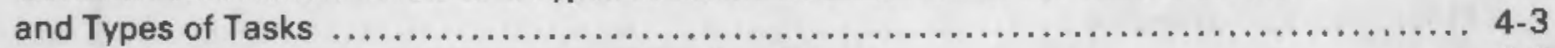

4.3 Maximum Brightness Ratios for Workplace Conditions $\ldots \ldots \ldots \ldots \ldots \ldots \ldots \ldots \ldots \ldots \ldots, 4,3$

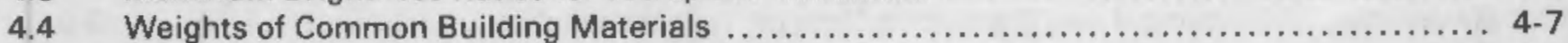

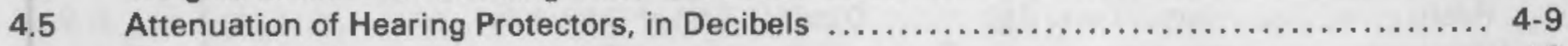

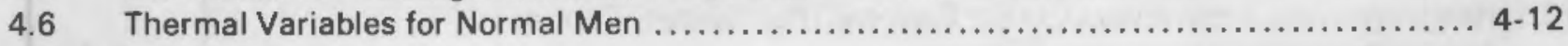

Chapter 5

LOADS AND FORCES

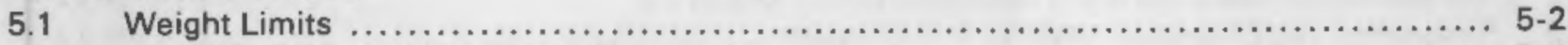

5.2 Design Weight Limits for Male Personnel ................................. $5-4$

Chapter 7

MAINTENANCE TOOLS AND EQUIPMENT

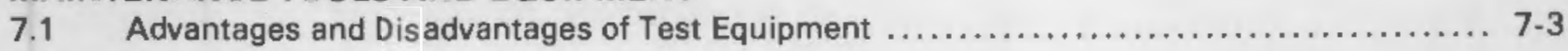

\section{Chapter 8}

\section{OPERATING EQUIPMENT}

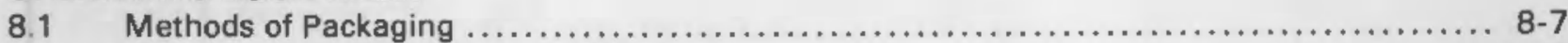

8.2 Comparison of Circuit Layout Methods ...................................... $8-10$

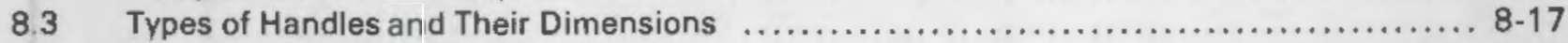

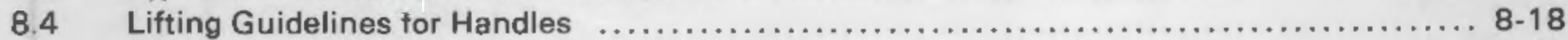

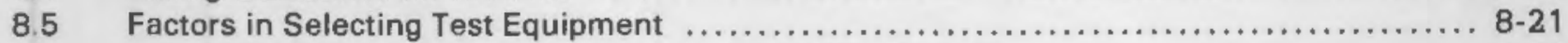

8.6 Advantages and Disadvantages of Built-In Test Equipment $\ldots \ldots \ldots \ldots \ldots \ldots \ldots \ldots \ldots \ldots, 822$

\section{Chapter 9}

\section{INFORMATION NEEDS}

9.1 Human Senses and the Energies that Stimulate Them $\ldots \ldots \ldots \ldots \ldots \ldots \ldots \ldots \ldots \ldots \ldots \ldots . .2$

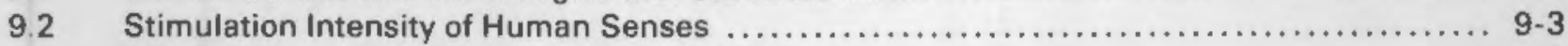

9.3 Height of Labels at Different Levels of Luminance $\ldots \ldots \ldots \ldots \ldots \ldots \ldots \ldots \ldots \ldots \ldots \ldots \ldots . \ldots \ldots$

9.4 Minimum Height of Characters at Specified Viewing Distances ..................... 9-5

9.5 Marking Processes and Recommended Gothic Type Styles ......................... 9-7

9.6 Color Combinations for Labels in Terms of Relative Legibility . . . . . . . . . . . . . . . .

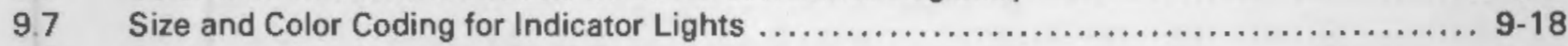

9.8 Choice of Visual Versus Auditory Presentations . . . . . . . . . . . . .

9.9 Functional Evaluation of Audio Signals ..................................... 9-22

9.10 Design Recommendations for Warning Devices ............................... 9-23

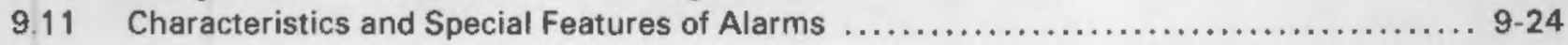




\section{List of Tables}

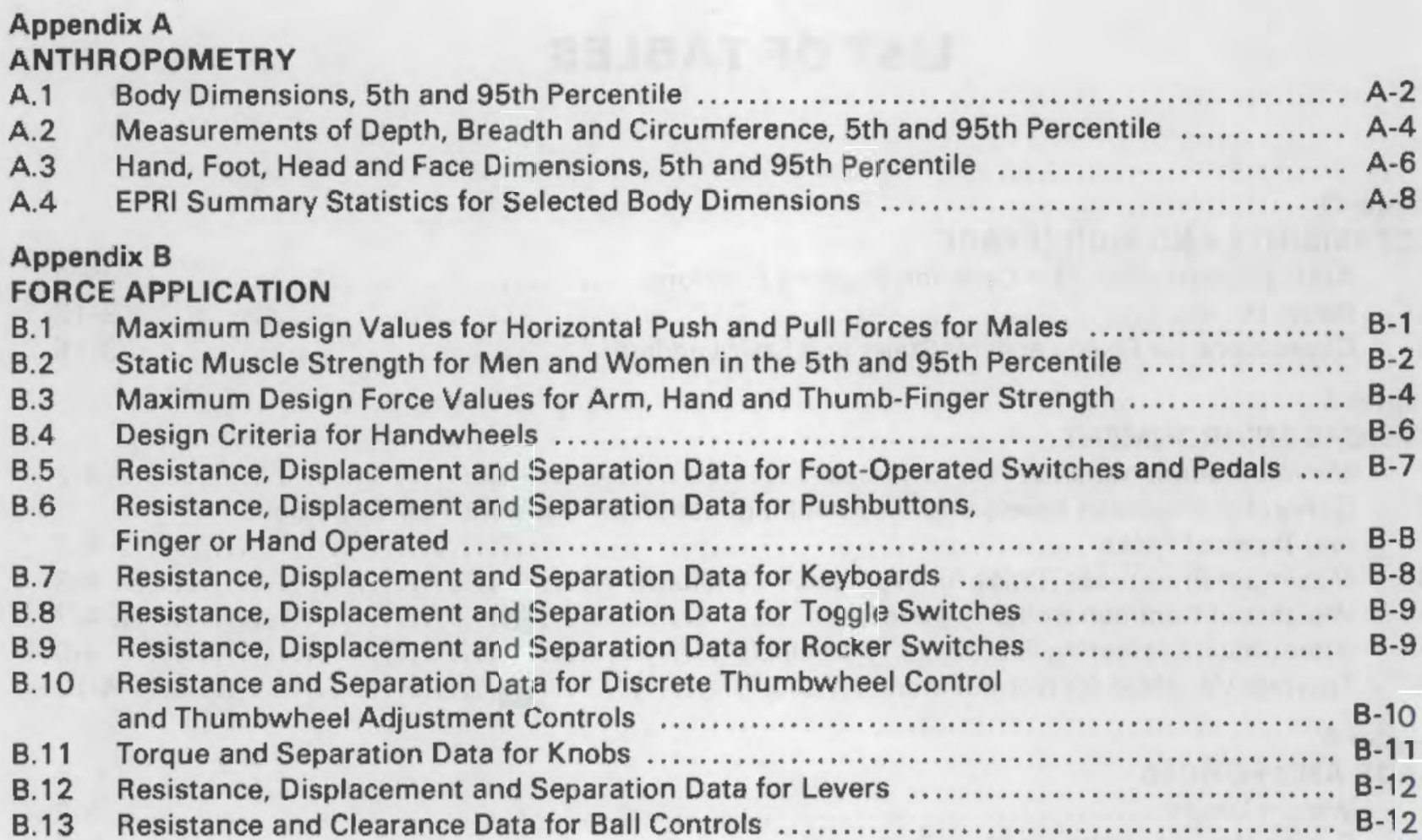




\section{LIST OF FIGURES}

\section{Chapter 3}

\section{ACCESSIBILITY AND WORKSPACE}

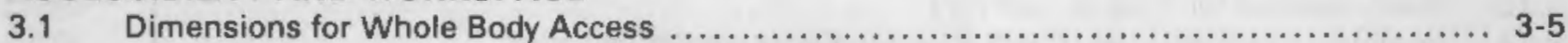

3.2 Use of Self-Supporting Hinges on Access Cover for a Large Heat Exchanger ............. 3-5

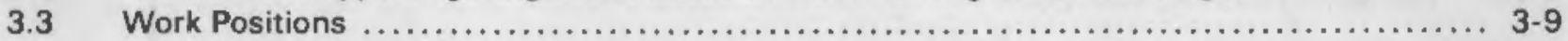

3.4 Preferred Angles of Inclinations for Ladders, Stair Ladders, Stairs, and Ramps .......... 3-12

3.5 Reference Numbers for Dimensions for Fixed Ladders, Stairs and Stair Ladders ......... 3-14

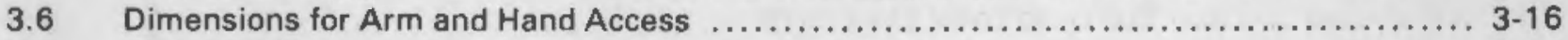

3.7 Clearance Between Terminals and Exposure of Wire End $\ldots \ldots \ldots \ldots \ldots \ldots \ldots \ldots \ldots \ldots, 3-18$

Chapter 4

PHYSICAL ENVIRONMENT

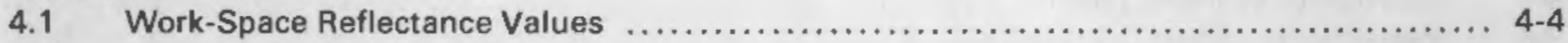

4.2 Permissible Noise Levels $\ldots \ldots \ldots \ldots \ldots \ldots \ldots \ldots \ldots \ldots \ldots \ldots \ldots \ldots \ldots \ldots \ldots \ldots \ldots \ldots \ldots \ldots \ldots \ldots \ldots \ldots, 4,5$

4.3 Permissible Distance Between a Speaker and Listeners for Specified Voice Levels

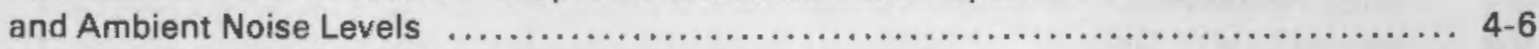

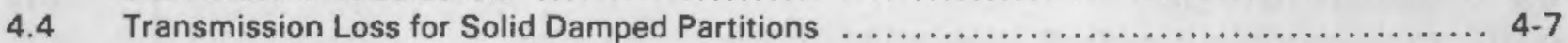

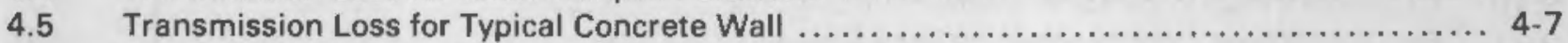

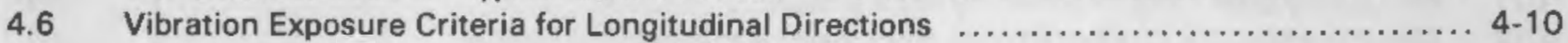

4.7 Environmental Requirements for Human Comfort .............................. 4 41

4.8 Human Heat Tolerances $\ldots \ldots \ldots \ldots \ldots \ldots \ldots \ldots \ldots \ldots \ldots \ldots \ldots \ldots \ldots \ldots, 4,12$

\section{Chapter 5}

\section{LOADS AND FORCES}

5.1 Endurance Time Expressed as a Function of Force Required $\ldots \ldots \ldots \ldots \ldots \ldots \ldots \ldots \ldots \ldots, 5-2$

Chapter 6

MAINTENANCE FACILITIES

6.1 Use Monorails to Move Heavy Equipment Within Workshops $\ldots \ldots \ldots \ldots \ldots \ldots \ldots \ldots \ldots, 6-3$

6.2 Provide Adequate Pull Space for Electrical or Mechanical Parts . . . . . . . . . . . . . . . . 6-4

Chapter 7

MAINTENANCE TOOLS AND EQUIPMENT

7.1 Extension Cables Allow Units to be Removed for Checking $\ldots \ldots \ldots \ldots \ldots \ldots \ldots \ldots \ldots \ldots, 7-4$

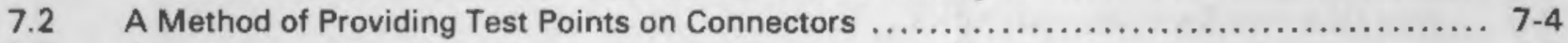

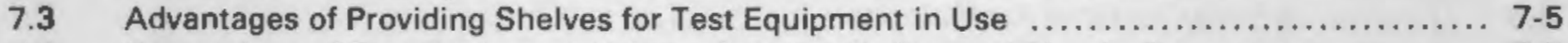

7.4 Comparison of Test Equipment Using a Selector Switch and Plug-In Connectors .......... 7-5

Chapter 8

OPERATING EQUIPMENT

8.1 Incorporate Fool-Proof Design Features to Prevent Maintenance Errors . . . . . . . .

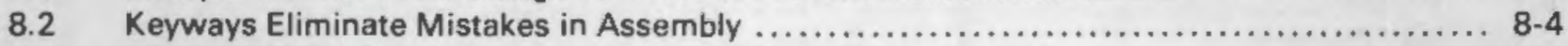

8.3 Off-Set Bolting Patterns Prevent Improper Assembly ............................... $8-4$

8.4 Asymmetrical Plugs Prevent Improper Connection ................................ 8

8.5 Provide Information at Test Point Location Whenever Possible ....................... 8-5

8.6 Avoid Placing Components so They are Blocked .................................. 8 


\section{List of Figures}

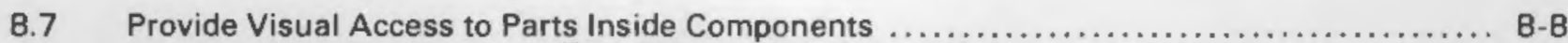

8.8 Modules Should Have Minimal Interactions Between Units $\ldots \ldots \ldots \ldots \ldots \ldots \ldots \ldots \ldots \ldots \ldots .6 .12$

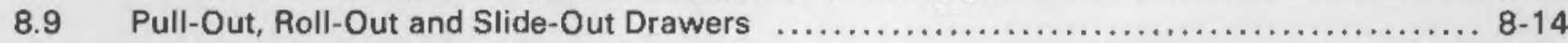

8.10 Alternate Methods for Providing Handles on Printed Circuit Boards . . . . . . . . . . . . . . . . . B -14

8.11 Additional Uses of Handles ................................................. 8 8

8.12 Place Handles to Facilitate Removal of Covers and Carrying of Units $\ldots \ldots \ldots \ldots \ldots \ldots \ldots, 8-15$

8.13 Place Handles for Ease in Carrying ........................................... 8

8.14 Common Orientation of Tube Sockets to Facilitate Replacement . . . . . . . . . . . . . . . . . 18

8.15 Test Points with Built-In Covers ............................................. B

Chapter 9

INFORMATION NEEDS

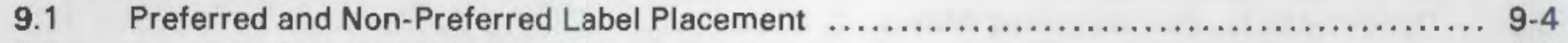

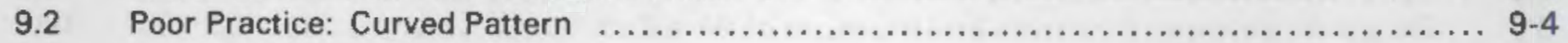

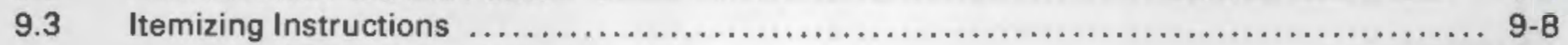

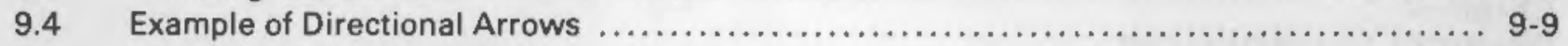

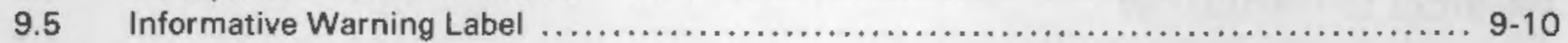

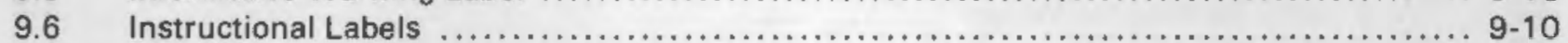

9.7 Code Component Installation Position ......................................... 9-11

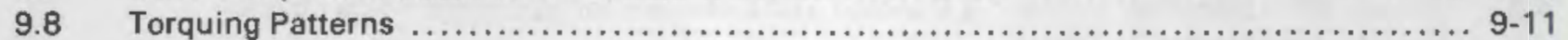

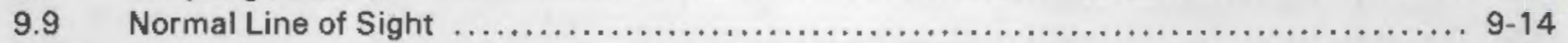

9.10 Optimum Visual Zone for Placement of Displays . . . . . . . . . . . . . . . .

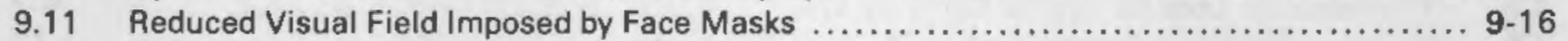

9.12 Manipulation of a Control Should Not Obscure the Related Display .................. 9-17

Appendix A

ANTHROPOMETRY

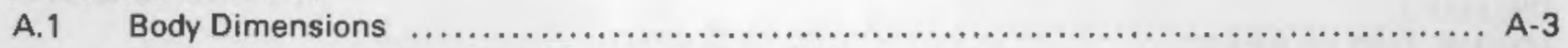

A.2 Depth, Breadth, Circumference and Surface Measurements $\ldots \ldots \ldots \ldots \ldots \ldots \ldots \ldots \ldots \ldots$. A-5

A.3 Measurements of Hand, Foot, Head and Face Dimensions $\ldots \ldots \ldots \ldots \ldots \ldots \ldots \ldots \ldots \ldots$ A-7

A.4 Definitions of Measurements for Selected Body Dimensions . . . . . . . . . . . . . . . . . . . . A

Appendix B

FORCE APPLICATION

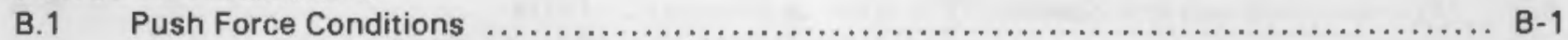

B.2 Body Conditions for Studies on Static Muscle Strength $\ldots \ldots \ldots \ldots \ldots \ldots \ldots \ldots \ldots \ldots \ldots \ldots \ldots$

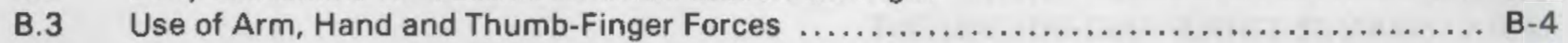

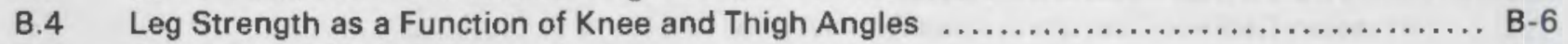

B.5 Foot Operated Switches and Pedals $\ldots \ldots \ldots \ldots \ldots \ldots \ldots \ldots \ldots \ldots \ldots \ldots \ldots \ldots \ldots \ldots \ldots \ldots \ldots \ldots \ldots \ldots, \mathbf{B}, 7$

B.6 Finger and Hand-Operated Pushbuttons $\ldots \ldots \ldots \ldots \ldots \ldots \ldots \ldots \ldots \ldots \ldots \ldots \ldots \ldots \ldots \ldots \ldots, \mathbf{B}-8$

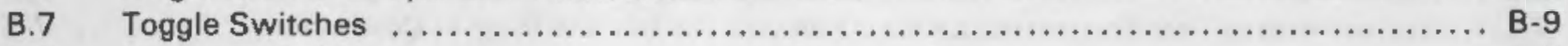

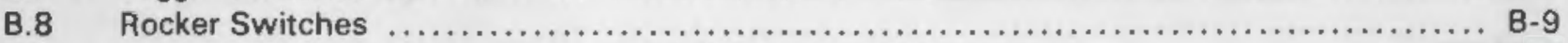

B.9 Discrete Thumbwheel and Thumbwheel Adjustment Controls $\ldots \ldots \ldots \ldots \ldots \ldots \ldots \ldots \ldots$ B-10

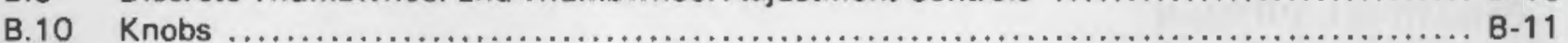

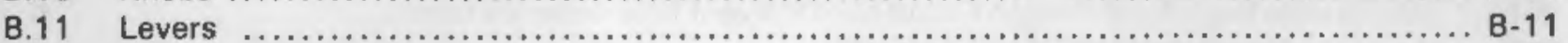

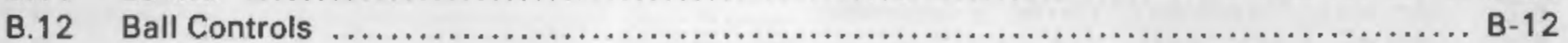




\section{Chapter 1 INTRODUCTION}

This document contains human engineering guidelines which can enhance the maintainability of nuclear power plants. The guidelines have been derived from general human engineering design principles, criteria, and data, and represent a distillation of guidelines contained in numerous sources across both the civilian and government sectors. NUREG-0700 already contains some human engineering guidelines which can increase nuclear power plant maintainability. For the most part guidelines in the current document provide a maintainability supplement to those in NUREG0700 . In areas of overlap (e.g., labeling), guidelines in the current document are consistent with those in NUREG-0700. They apply to nuclear power plant systems, equipment, and facilities, as well as to maintenance tools and equipment.

\subsection{PURPOSE}

The purpose of this document is to present selected human engineering guidelines which can reduce the incidence of design-induced maintenance errors and thereby increase the operational safety of nuclear power plants. Surveillance testing has been included within the scope of maintenance. Relatively economical maintainability enhancements are included in the document, as well as guidelines that may be most appropriate as specifications for the procurement of new/replacement equipment. The guidelines may assist (1) plant maintenance managers in evaluating plant/ equipment design and recommending maintainability improvements; (2) utility project managers in ensuring that maintainability considerations are incorporated in plant/equipment contract specifications and implemented in plant design and construction; (3) nuclear steam supply system (NSSS) and balance of plant (BOP) equipment vendors in designing equipment that is maintainable; (4) architect-engineers and facility designers in designing plants that incorporate equipment and workspace layouts, ambient environments and habitability provisions conducive to effective performance of maintenance personnel.
The guidelines might also assist NRC personnel in the performance of regular inspections and audits, and in responding to operating reactor events.

\subsection{BACKGROUND}

Maintainability refers to the ease of performing essential system maintenance. That "ease" is largely determined by a system's maintainermachine interface and is reflected in performance measures such as maintenance errors, or time to complete a repair. Maintainer-machine interfaces at nuclear power plants have been found to be poor in studies sponsored by the Electric Power Research Institute (EPRI) (Seminara and Parsons, 1981) and the Nuclear Regulatory Commission (NRC) (Badalamente et al., 1982). These findings have been underscored by recent events involving NPP maintenance where the potential for adverse effects on public health and safety was high. The studies sponsored by EPRI and NRC have recommended immediate development of nuclear power plant maintainability guidelines to resolve maintenance problems that may affect public health and safety. In addition, in its recommendations to the NRC on critical human factors issues, the Human Factors Society stressed the importance of design for maintainability and recommended that a guideline document, similar to NUREG-0700 on control room design, be published for maintainability. As a result, the NRC contracted with the Pacific Northwest Laboratory (PNL) to develop and recommend maintainability design guidelines for nuclear power plants.

\subsection{IMPACT OF MAINTENANCE ON SAFETY}

Maintenance deals with the failure, or potential failure of operating equipment. The extent of maintenance undertaken is based on the anticipated consequences of failure. The most important of these consequences is a threat to safety. This is true whether the system in question is an automobile, a fighter aircraft, or a reactor coolant pump. The impact of maintenance on the safe 
operation of a nuclear power plant is well established. In fact, the initiating event for the Three Mile Island (TMI) accident involved maintenance on the condensate polisher system (Rogovin and Frampton, 1979). A member of the President's commission on the accident at TMI stated that there were "...many examples of faulty maintenance that contributed to the accident at TMI," and concluded that "management of nuclear safety must include proper maintenance..." (Pigford, 1981).

NRC Task Force findings on the January 25, 1982 steam tube generator rupture at Ginna indicated that faulty maintenance was a direct contributor to the event. A TV-optics examination revealed the existence of five groups of foreign objects in the $B$ steam generator and three in the A steam generator. Included among the objects found in the B steam generator was a $4 \times 6 \times 0.5$-inch-thick piece of magnetic carbon steel plate left in the generator after modifications in 1975 (U.S. NRC, 1982).

More recently, the first Pressurized Water Reactor (PWR) Anticipated Transient Without Scram (ATWS) at Salem Nuclear Power Plant on February 22 and 25,1983 , were attributed in large part to inadequate maintenance. An NRC task force investigating the event stated that, "controls on the maintenance program at Salem were ineffective in providing adequate assurance that the reliability of the reactor trip system would be maintained" (U.S. NRC, 1983).

The integrity of nuclear power plant reactor protection and safety systems has been degraded on numerous occasions by improper maintenance. Maintenance errors obtained from Licensee Event Reports (LERs) and from the Nuclear Plant Reliability Data System (NPRDS) include: installing electrical connectors incorrectly; mounting equipment, such as checkvalves, backwards or out of alignment; using the wrong parts in equipment repair; deactuating and working on the wrong system or component; misaligning valves after maintenance; failing to remove lockwire from critical switches after service, and so on.
Thus, maintenance can impact the safe operation of a nuclear power plant when: (1) it is not accomplished, or is not accomplished in a timely manner; and $(2)$ when it is done improperly.

\subsubsection{MAINTAINABILITY}

One of the most important factors determining the efficiency and effectiveness of maintenance is maintainability. As stated previously, maintainability refers to the "ease" with which maintenance may be performed. It is an inherent characteristic of system or equipment design and is achieved through the proper application of human factors engineering principles.

It is generally agreed that maintainability is one of the prime factors in the process of optimizing system design and must be integrated with other design considerations if optimization is to occur. The most effective way of achieving maintainability in the design of power plants is to incorporate human engineering design principles for maintainability in the early phases of power plant concept definition-well before the construction phase begins. However, maintainability cannot be realized unless emphasis is placed on it throughout a system's life cycle, from inception to disposal/ decommissioning. The degree of maintainability achieved depends on the requirements imposed and the degree to which management emphasizes maintainability during the system/equipment life cycle (U.S. Department of Defense, 1981 b).

Even though optimal maintainability stems from emphasis on that characteristic from the concept definition phase onward, a well-thought-out maintainability enhancement program can often produce a significant increase in maintainability. Attention to the maintainability of NPPs, either from the concept definition phase onward or as an enhancement program, can increase operating safety and reduce maintenance costs.

\subsection{ORGANIZATION AND FORMAT}

The guidelines are presented in seven chapters. These chapters, which help to identify the scope of 
this document, are: accessibility and workspace, physical environment, loads and forces, maintenance facilities, maintenance tools and equipment, operating equipment design, and information needs. Each of these chapters contains general definitions, related NPP maintainability problems, discussions of potential safety impact to the public and to plant personnel resulting from maintainability problems, and human engineering guidelines selected to help resolve the problems. 



\section{Chapter 2 GENERAL PRINCIPLES}

Throughout this document the terms "design and design for maintainability" encompass efforts to improve both the initial design of plants and the design of existing plants. Some human engineering guidelines involve simple enhancements which can be applied regardless of a plant's age. Other guidelines can affect the basic design of the plant and its equipment and, as a result, may be difficult to apply to anything but an initial design. Users of the guidelines should carefully consider maintenance problems and their potential consequences before selecting corrective actions. Design improvements should provide the necessary correction without creating new problems. To this end maintenance personnel, engineering personnel, and human engineering specialists should all be involved in the process if possible.

A key objective in applying design for maintainability principles to nuclear power plants is to improve plant operational safety by minimizing maintenance errors that occur as a result of poor equipment design (i.e., are design-induced). In addition, design for maintainability reduces the time and effort required to perform maintenance. $A$ design for maintainability effort which results in an integrated, coherent, and consistent interface between the plant and its maintainers may mean not only increased plant safety but increased availability and personnel safety as well.

\subsection{MAINTAINABILITY ANALYSIS AND IMPROVEMENT}

Nuclear power plant staffs should have the capability to assess maintenance performance in order to improve maintainability. This capability results from: (1) accurate reporting of equipment failure modes and effects, maintenance corrective and preventive activities, material/equipment deficiencies, accidents/incidents, and violation of technical specifications; (2) systems to process, aggregate, summarize, and analyze the data; and (3) qualified personnel to interpret results and recommend corrective action.

\subsection{DESIGN TO AVOID CONDITIONS THAT INCREASE PROBABILITY OF HUMAN ERROR}

In designing systems for operation and maintenance, designers should consider human characteristics, tolerances, limitations, and needs, just as they would consider the attributes or physical properties of various inanimate system components. Unless they do so, conditions may be created where the probability of human error is increased; such conditions may even preclude the assignment of a human to certain system functions. Designers of nuclear power plants should avoid creating conditions where human reliability is degraded. In general terms, these conditions are (U.S. Air Force, 1980):

Sensory and/or perceptual requirements that are near or beyond physiological limits

Manual response requirements that are physically difficult, conflict with established habit patterns, or cannot be checked or monitored

Decisions that require reliance on detailed memory or which must be made in too short a time to determine, assemble, evaluate and integrate the major relevant considerations, or whose consequences cannot be foreseen quickly and confidently

Communications, information-gathering and information-processing requirements that interfere with each other, or with other activities

Operating conditions that can overload the sensory mechanisms, or be distracting, irritating, or even intolerable

Tasks that (1) involve excessive workload, (2) result in inadequate workload distribution, (3) do not permit adequate and timely monitoring of status, (4) are sequentially ordered, overlap, have time limitations or otherwise impose undue time and/or time-management stress, or (5) involve prolonged periods of inactivity with the resulting decrease in alertness and ability to react quickly and correctly. 


\subsection{FOOL-PROOF DESIGN}

The design of nuclear power plant safety/safetyrelated systems, equipment, and components should reflect, to the maximum extent possible, the use of design to preclude improper maintenance, i.e., fool-proof design. The following items should be checked (Topmiller, 1964):

Are assembly parts designed with orienting seats, pins, etc., to aid in getting parts in proper position for fasteners?

Is the proper orientation of units within their respective case made obvious, either through design of the cases or by means of appropriate labels?

Are components or access covers designed so they can be easily oriented for fastening by providing alignment pins or grooves?

Are all interchangeable units physically coded (keyed) so that it is impossible to insert a wrong unit?

Are units coded (labels, colors, etc.) to indicate the correct unit and its orientation for replacement?

Are guide pins or other means used on units and assemblies for alignment during mounting?

Is there some means of physical design to prevent mismating or interchanging connections (unique fastener or socket, routing of cables or lines so lengths vary, spreader blocks, etc.)?

Are connector plugs designed so that pins cannot be damaged (aligning pins extend beyond electrical pins)?

Is the design such that it is physically impossible to reverse connections or terminals in same, or adjacent, circuits?

Are plugs, connectors, and receptacles clearly marked to show proper position of keys for aligning pins for proper insertion position?

Are keyways for tubes and tube sockets suitably marked so that workers do not have to rely on "feel" to find the proper position?
Are control linkage attachments designed so that reversed assembly is not physically possible?

Do controls that are intended to have a limited degree of motion have adequate mechanical stops to prevent damage?

Are control knobs that only require occasional resetting provided with a cover seal or otherwise guarded against inadvertent actuation?

Are pointer knobs designed so there is no possibility of mistaking which end of the knob is the pointing end?

Do the controls that are multi-position selectors have detent positions to prevent leaving the switch between detent positions?

Are sensitive adjustments located or guarded to prevent workers from inadvertently bumping them out of adjustment?

Is adequate clearance provided between switches and knobs to prevent inadvertent actuation, and allow sufficient finger room for manipulation?

Are self-locking safety catches provided on connector plugs rather than safety wire?

Do access doors to high-voltage areas have provisions for automatically shutting off power (safety interlocks on door, etc.)?

Detailed guidelines on fool-proof design may be found in Chapter 8.

\subsection{LABELING}

An important means of reducing the probability of maintenance error is the proper labeling of equipment and components. All nuclear power plant safety/safety-related equipment/components should be labeled to the extent necessary to reduce the possibility of misidentification, misalignment or otherwise improper maintenance. The following items should be checked (Topmiller, 1964):

Do display labels appear on every item that workers must recognize, read, or manipulate?

Do display labels provide full identifying information? 
Are display labels imprinted, embossed, or attached so that they will not be lost, mutilated, or become otherwise unreadable?

Are displays and controls labeled to correspond to notations found in system diagrams, technical manuals, etc.?

Do labels identifying control handles appear on the handle as well as the panel, since the panel may be removed during maintenance?

Are the functions of each control clearly labeled?

Do display and control labels clearly indicate their functional relationship? Displays should be labeled by functional quantity rather than operational characteristics (i.e., gal., p.s.i., ohms, etc.).

When selector switches have to be used with a cover panel off, are there duplicate switchposition labels on the internal unit so you don't have to refer to the label on the case or cover panel?

Are displays and their associated controls clearly labeled to show their relationship?

Are color codes or other symbolic coding schemes used for identifying test points, tracing wire, or lines easily identifiable under all illumination conditions?

Are electrical terminals clearly marked " + " or "-"?

Do display labels for each termination have the same code symbol as the wire or line attached to them?
Are access points individually labeled?

Do accesses have labels specifying the frequency for maintenance either by calendar or operating time?

Do accesses have labels indicating what auxiliary equipment is needed for servicing, checking, etc., at this point?

Do accesses have labels that tell what can be reached through this point?

Are appropriate labels used for each test point?

Are parts that require access from two or more openings properly marked to indicate this requirement?

Do access covers have permanent part numbers marked on the cover?

On component covers, are there display labels that provide relevant information concerning electrical, pneumatic, or hydraulic characteristics of the part?

Are all potted parts labeled with current, voltage, impedance, terminal information, etc.?

Is piping labeled or coded to indicate contents, pressure, and direction of flow?

Are access points individually labeled?

Detailed guidelines on labeling may be found in Chapter 9. 



\section{Chapter 3 ACCESSIBILITY AND WORKSPACE}

In this document, accessibility is discussed in terms of the ease with which maintenance and test personnel can gain sufficient physical and/or visual contact with equipment to perform their tasks. The discussion is extended to include the ability to move plant equipment and tools when that is a requirement of the task. Perfect access for personnel would accommodate the full anthropometric range of the adult population. "Good" access for personnel is typically judged to be that which accommodates the anthropometric range from the 5 th percentile adult female to the 95 th percentile adult male.

\subsection{PROBLEMS}

Lack of accessibility to perform maintenance is the most universal complaint voiced by maintenance personnel at nuclear power plants (Seminara and Parsons, 1981; Badalamente et al., 1982). Several categories or classes of problems exist in this area, including: equipment location, component arrangement within an end item of equipment, access to equipment and/or equipment internals through manways or hatches, access for maintenance tools and equipment, and visual access for inspection, test, calibration, and/or repair. The following specific problems relative to accessibility for NPP maintenance have been identified (Badalamente et al., 1982; Looram et al., 1981; Seminara and Parsons, 1981; Murach, 1976):

placement of equipment (especially valves) in overhead locations, when no direct access (e.g., permanent platforms, ladders) is provided and the equipment is also difficult to reach using mobile equipment, (e.g., work stands)

unnecessary placement of equipment in overhead or out-of-reach locations, requiring special provisions for access (e.g., permanent or mobile work platforms, stands, ladders)

placement of equipment in locations that cannot be reached from a normal work position

placement of equipment in locations where equipment removal or replacement are rendered difficult placement of heavy equipment in locations where maintenance handling equipment (e.g., forklifts) cannot be used

inadequate clearance across access ways or hatches

restricted access to components resulting from arrangement/packaging of end item of equipment

inadequate attention to features of equipment design that would accommodate maintenance personnel wearing protective gear

lack of sufficient access to equipment for inspection/test, calibration, and servicing.

\subsection{SAFETY IMPACT}

Lack of appropriate physical and visual access for maintenance can result in improper or incomplete maintenance. The safe operation of a nuclear power plant is affected when required maintenance is not accomplished, or is not accomplished in a timely manner, and when maintenance is accomplished improperly.

Equipment components placed far out of normal reach with no provision for access (e.g., catwalks) invite neglect. Visual inspection on routine walkthrough is impossible and maintenance supervisors are hesitant to add special inspection requirements to an already crowded schedule. Servicing (e.g., lubrication) becomes difficult and time consuming and may be deferred beyond manufacturer's recommendations until an extended outage occurs. When attempts are made to reach the equipment, maintenance personnel may climb on other equipment to reach their destination, often damaging the equipment they climb on as well as putting themselves at risk. Once the technician reaches the equipment he is to repair or service, he may have to work in an awkward position under uncomfortable (e.g., hot, noisy, etc.), poorly lit conditions. Degraded performance is a well-established outcome of such stress-producing situations (see, for example, Swain and Guttman, 1980). 
Lack of proper access for tools and test equipment can cause makeshift attempts at repair or calibration, resulting in misalignment, miscalibration, or damage to equipment. Sometimes functioning equipment must be removed to reach components needing repair or servicing. This not only increases the time and effort necessary to do the job, it results in added and unnecessary wear and tear on equipment.

Where exposure to radiation is a consideration, lack of accessibility is of particular concern. Maintenance is already more time consuming and difficult when protective gear must be worn. The addition of accessiblity problems can extend the job to a point where radiation exposure limits require rotating shifts of workers. Pressure to hurry the job along and degraded continuity due to changing the task crew invite maintenance errors.

Over the long run, poor accessibility to equipment results in increased maintenance backlogs, degraded equipment performance, and, in turn, degraded plant safety.

\subsection{GENERAL CONSIDERATIONS}

Problems of accessibility in nuclear power plants (Section 3.1) can be avoided by constructing or modifying nuclear power plants in accordance with accepted human engineering guidelines for maintainability. Maintenance technicians should be able to gain access to the equipment they are to maintain.

An accessible design allows sufficient clearance to use the tools necessary for accomplishing a job. Adequate space permitting convenient removal and replacement of components must be available, as well as adequate visual access to the task area. If adequate access is not provided, attempts to accomplish maintenance often result in errors, equipment damage, skinned knuckles, and lost time. Moreover, simple tasks, such as routine inspections or other preventive maintenance, become tedious and time-consuming and may be neglected or done poorly. The system designer should give special attention to the location of the work place in relation to the task, postures dictated by the task, anthropometric dimensions and physi- cal capabilities of the technician, and environmental and clothing factors. In a few instances, relatively complete and specific data are available in the literature for use in determining minimum access size requirements (see Appendix A). When this is not the case, the designer may have to estimate space requirements on the basis of task analyses, dimensions and functional characteristics of tools and equipment components, and anthropometric data (Van Cott and Kinkade, 1972).

\subsubsection{DECISION FACTORS}

Access should be provided to all points, items, units, and components that require or may require testing, servicing, adjusting, removal, replacement, or repair. The type, size, shape and location of the access should be based upon a thorough understanding of the:

operational location, setting, and environment of the unit

frequency of entry into the access

maintenance functions that will be performed through the access

time required for performing maintenance functions

types of tools and accessories required by maintenance functions

work clearances required for performing maintenance functions

type of clothing likely to be worn by the technician

distance to which the technician must reach within the access

visual requirements of the technician in performing maintenance tasks

packaging or mounting of items and elements, etc., behind the access

hazards related to use of the access

size, shape, weight, and clearance requirements of human appendages, tools, units, or other items that must enter the access (Rigby, Cooper and Spickard, 1961). 


\subsubsection{TYPES OF ACCESS IIN ORDER OF PREFERENCE)}

Maintenance is facilitated by open unobstructed access to equipment. Types of access in order of preference are listed below.

FULLY EXPOSED. When structural, environmental, operational, and safety conditions permit, equipment should be left exposed for maintenance. This is particularly true of test and service points, maintenance displays and controls, and rack-mounted "black-boxes".

PARTIALLY EXPOSED. Partial exposure of equipment can be accomplished by means of:

pull-out racks or drawers

full-length doors on cabinets or equipment racks

quick-opening hoods or covers

dust covers and cases that can be removed quickly and easily (Rigby, Cooper and Spickard, 1961).

UNCOVERED OPENINGS. Openings should be uncovered only when environmental control is not required and when danger to equipment or personnel is minimal. Work clearances around mounts, components, etc., should be left as uncovered, limited access openings that are subject to the size requirements provided below in Section 3.4 (Ibid.).

COVERED OPENINGS. Covered openings that provide limited access should be evaluated in terms of the types of covers and fasteners employed (lbid.).

STRESS DOORS. These are usually required in high performance equipment, but should be avoided wherever possible. When required, access through stress doors can be improved by selection of fasteners (see Section 8.5.7) (Ibid.).

RIVETED PANELS OR DOORS. These should never be used as access points. Overall layout and design of equipment should not require removal of permanently attached structures, even for infrequent maintenance. (lbid.).

\subsubsection{GENERAL ACCESS PRINCIPLES}

The design of unit accessibility features should be correlated with the accessibility requirements of the overall system.

SPLIT LINE DESIGN. Where possible and feasible, design for accessibility should incorporate a hinged or removable chassis (i.e., "split line"). Major units and assemblies (particularly motors, turbines, etc.) should be designed so that housing can be removed and complete inspections are possible (Rigby, Cooper and Spickard, 1961).

COMPONENT ARRANGEMENT. Design, locate, cover, and fasten accesses so that personnel do not need to remove components, wires, or other materials before reaching the item requiring maintenance (see Section 8.5.2) (lbid.).

ACCESS TO REPLACEABLE UNITS. Removal of any replaceable unit should require the opening of only one access, unless the accesses are of the latched and hinged door type (lbid.).

VISUAL INSPECTION/CONTROL. Items within the access that require visual inspection (hydraulic reservoirs, gauges, etc.) should be placed so they can be observed without removing panels or other components. Provide visual access for all maintenance operations requiring visual control, particularly where hazards may be encountered within the access (lbid.).

SHARP EDGES. To prevent personnel injuries (which might affect job performance), line the edges of the access with internal fillets or other suitable protection wherever sharp edges might protrude (lbid.).

DANGEROUS COMPONENTS. Where accesses are located over unavoidable dangerous mechanical or electrical components, design the access door so that when opened, an internal light is activated. A warning label should be placed prominently on the door (Ibid.).

HIGH VOLTAGES. Safety interlocks should be provided on accesses leading to equipment with high voltages. If the equipment circuit must be "O $n$ " during maintenance, provide a bypass switch 
that automatically resets when the access is closed (Ibid.). (See Figure 8.1, Section 8.3.1)

\subsubsection{SHAPE OF ACCESSES}

Make accesses whatever shape is necessary to permit easy passage of the required items, body appendages, implements, etc. Accesses need not be of regular geometric shapes; if dictated by the access needs, the designer should consider irregular shapes that will best satisfy both structural and accessibility requirements. Considerations should be given to:

dimensions of the various units that must go through the access

protuberances, attachments, handles, etc., on these units

methods of grasping units during removal and the required clearances

clearance requirements for work within the compartment

requirements for visual control of functions performed within the compartment (Rigby, Cooper and Spickard, 1961).

\subsubsection{LOCATION OF ACCESSES}

EQUIPMENT ACCESSES. These should be located only on unit faces that will be accessible in normal installation and on the same face as related displays, controls, test points, cables, etc. (Rigby, Cooper and Spickard, 1961).

PASSAGES. Passages should permit direct access and maximum convenience for job tasks. They should be placed away from high voltages or dangerous moving parts; otherwise, adequate insulation, shielding, etc., should be provided to prevent injury to personnel (Ibid.).

LIMITED ACCESS. The bottom edge of a limited access should be no lower than $24 \mathrm{in}$. and the top edge no higher than 60 in. from the floor or work platform (Ibid.).

\subsubsection{SIZE OF ACCESSES}

Size of an access should be dictated by the same considerations as shape. In general, one large access is preferable to two or more small ones; but where structural or other considerations require, visual and physical access may be provided separately. Where stress doors are employed or access covers are otherwise difficult to remove, provide a smaller access to frequently used test or service points. Accesses should have dimensions that will accommodate work stands or carts that will be needed during maintenance tasks (Rigby, Cooper and Spickard, 1961). Specific data relative to access size are contained in Appendix A.

\subsection{GUIDELINES FOR DESIGNING HATCHES AND MANWAYS FOR WHOLE BODY ACCESS}

Hatches should be designed to accommodate personnel who are suitably equipped and clothed. Design criteria should take into account limiting dimensions for location and operability and clearance dimensions for size and passage factors (see Appendix A). Where personnel must carry equipment through the hatch, allowance should be made for clearance of suitably clothed 95th percentile hands or arms, as applicable (U.S. Department of Defense, 1981a).

\subsubsection{ESTABLISHING DIMENSIONS}

Dimensions for rectangular access openings should not be less than those shown in Figure 3.1. Minimum diameter for circular hatches should be 30 in. $(760 \mathrm{~mm})$. This should be increased where access requires the wearing of protective garments (Figure 3.1). Diameters of oval hatches should not be less than 17 and $28 \mathrm{in} .(430$ and $710 \mathrm{~mm})$. Where rescue of personnel may be required because of environmental hazards such as heat exhaustion, larger access openings that allow passage of more than one person may be necessary. Where "step down" through a top access exceeds 27 in. $(690 \mathrm{~mm})$, appropriate foot rests or steps should be provided (U.S. Department of Defense, 1981a). 


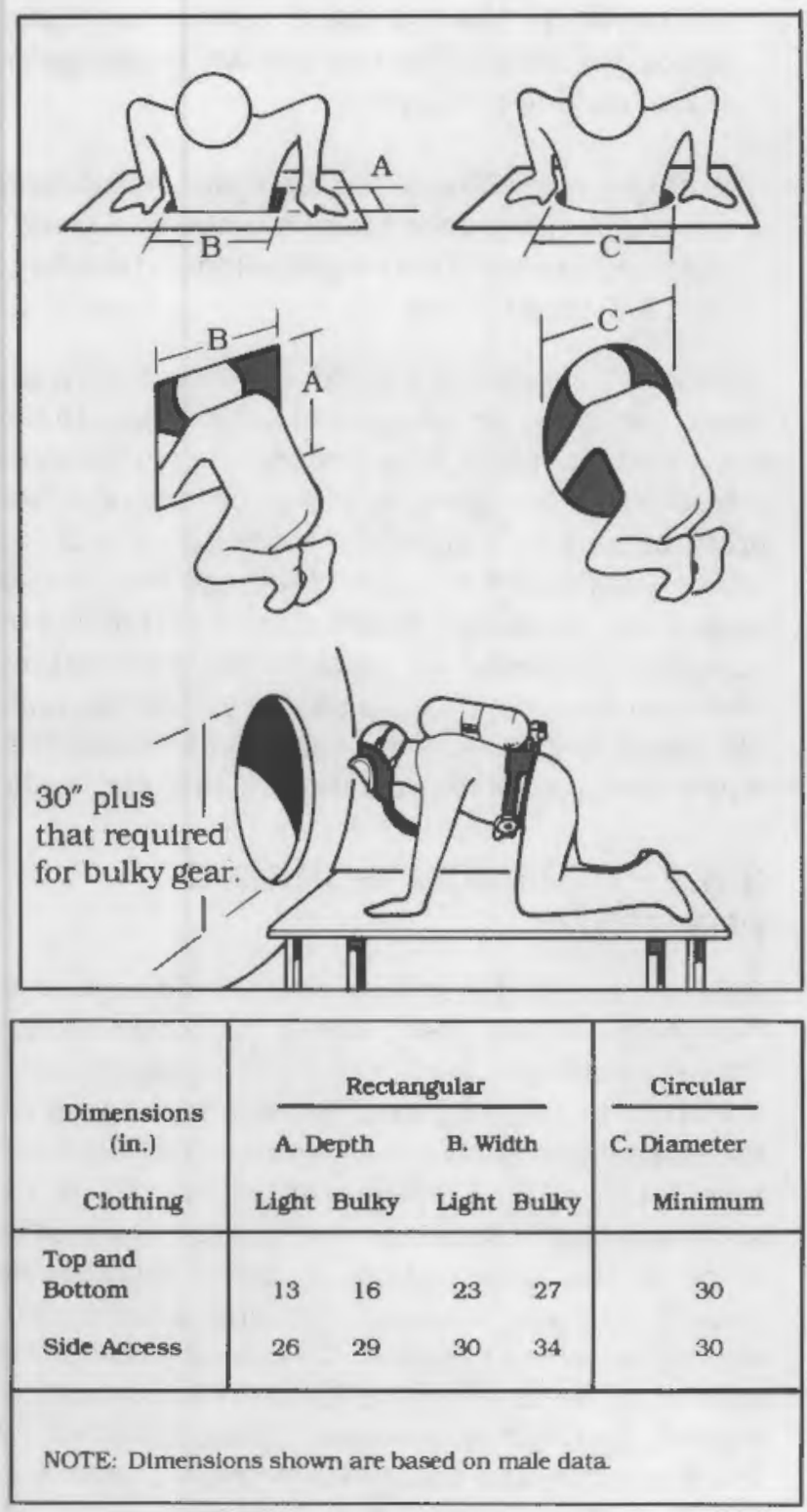

Figure 3.1. Dimensions for Whole Body Access

\subsubsection{WALL HATCHES}

Wall hatches should be flush with the floor where structural considerations will permit. Personnel should be able to open hatches with a single motion of the hand or foot (U. S. Department of Defense, 1981 a).

\subsubsection{SLIDING DOORS}

Sliding doors should never be installed as the only personnel exit from a compartment. When a sliding door is used, a separate hinged door in the sliding door should be provided for personnel. Fixed equipment should be at least 3 in. $(75 \mathrm{~mm})$ from the swept area of hinged doors (U.S. Department of Defense, 1981a).

\subsubsection{SELF-SUPPORTING COVERS}

Manways or access covers weighing more than 75 Ib should be designed with hinges that will support the cover in the open position (Figure 3.2).

\subsubsection{BULKHEADS AND BRACKETS}

Bulkheads, brackets, and other units should not interfere with removal or opening of covers on units within which work must be performed (U.S. Department of Defense, 1981 a).

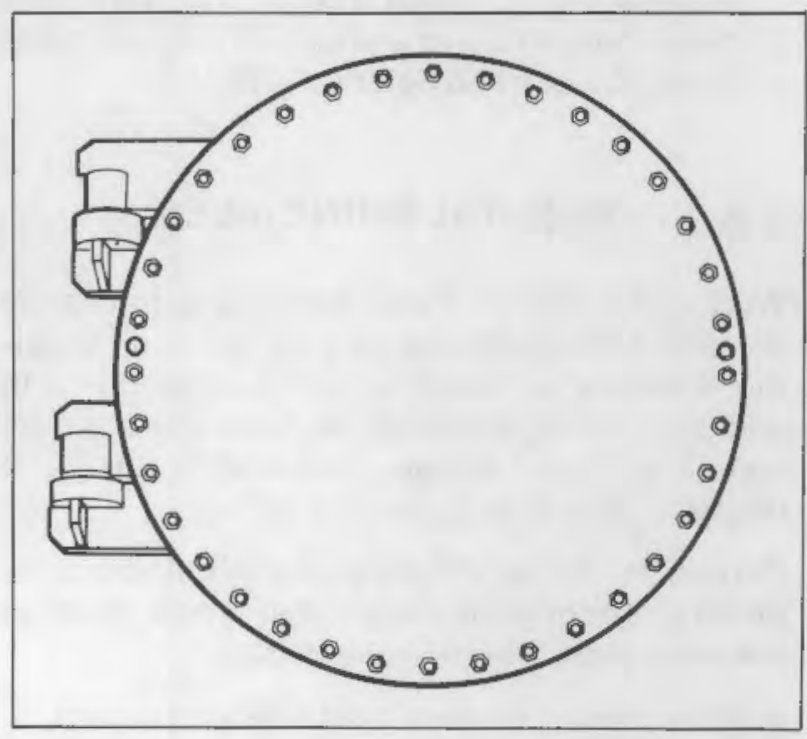

Figure 3.2. Use of Self-Supporting Hinges on Access Cover for a Large Heat Exchanger 


\subsection{GUIDELINES FOR DESIGN OF WORK SPACE}

Sufficient work space should be provided for technicians to perform maintenance functions. The layout and design of equipment should always be preceded by a task analysis of at least sufficient thoroughness to allow determination of:

points where maintenance is or may be required approximate body positions necessary to perform maintenance tasks

requirements for space and clearances that will accommodate body position and required movements

requirements for access or passage to the work point

the size and weight of tools, loads, etc. that must be carried to or from the work point

requirements for wrenching or grasping space about the items that must be manipulated

requirements for space and light that will enable the technician to see and control manipulations (Rigby, Cooper and Spickard, 1981).

\subsubsection{GENERAL PRINCIPLES}

Work space should allow technicians to change posture if the maintenance task requiring kneeling, crawling, or crouching is a prolonged one. In addition, provisions should be made to protect the technician from hazards considered in Chapter 4 (Rigby, Cooper and Spickard, 1961).

Certain items that will assist the technician in the performance of maintenance should be provided at the work place wherever practicable:

auxiliary hooks, holders, lights, service outlets, etc. (see Section 6.5.2)

Auxiliary stands or shelves that support test equipment, removable units, or items to be repaired. lattice work, low cabinets, mirrors, or open space, that allow visual contact with related displays, moving parts, etc.

features that allow or facilitate communication among maintenance team members, supervisors, or personnel in the control room (see Section 7.6) (lbid.).

Additional clearance should be provided when loads, vehicles, or equipment other than those described must also pass through the spaces described or when doors, shelves, covers or other proturbances must open into or occupy some of the space described. Additional clearance should also be provided to prevent technicians from coming in contact with electrical, mechanical, chemical, or radiation hazards. Designs should include enough clearance space to accommodate work stands, test equipment, tool cases, radiation shields, etc. (lbid.).

\subsubsection{COMMON WORKING POSITIONS}

Appropriate anthropometric data should be used in designing workspaces where personnel must stand, sit, stoop, kneel or assume a supine position. Data in Table 3.1 and Figure 3.3 are based on measurements of 300 Army women and 106 Army men, taken in 1977; differences between Table 3.1 and the tables in Appendix A should be resolved in favor of the latter tables. Suitable allowances should be made for heavy clothing or protective equipment when required. Clearance dimensions should not be less than the 95 th percentiles values for men, and limiting dimensions should not exceed the 5 th percentile values for women (Table 3.1; U.S. Department of Defense, 1981a).

\subsubsection{PROVIDING STANDING WORK SPACE}

Design should allow workers to perform brief and routine maintenance from a standing position (Rigby, Cooper and Spickard, 1961). Work surfaces to support job instruction manuals or worksheets 
should be approximately $36 \mathrm{in}$. $(915 \mathrm{~mm})$ above the floor (U.S. Department of Defense, 1981 a).

\subsubsection{PROVIDING KICK SPACE}

All cabinets, consoles, and work surfaces that require a technician to stand or sit close to the front surface should contain a kick space at the base. Dimensions of the space should be at least 4 in. $(100 \mathrm{~mm})$ in depth and height to allow for protective or specialized apparel (U.S. Department of Defense, 1981 a).

\subsubsection{RECESSING HANDLES}

Handies on cabinets and consoles should be recessed whenever practicable, so that projections on the surface will be eliminated. If handles cannot be recessed, they should be designed so that they neither injure personnel nor entangle clothing or equipment (U.S. Department of Defense, 1981 a).

\subsubsection{PROVIDING FREE FLOOR SPACE}

Enough space should be allowed so that personnel can perform all required tasks. The space should accommodate kneeling and bending, simultaneous work by more than one operator, and simultaneous performance of operational and maintenance tasks as may be required (U.S. Nuclear Regulatory Commission, 1981).

DEPTH OF WORK AREA. A minimum separation of 50 inches is recommended between a single row of equipment/panel and a wall or other opposing surface (lbid.).

SPACE BETWEEN CABINETS. A minimum separation of 50 inches is also recommended between two rows of facing equipment if both rows are worked by a single operator (Ibid.).

OPPOSING ROWS OF EQUIPMENT. A minimum of 8 feet is recommended between opposing rows of equipment where more than one person must work simultaneously on operational or maintenance tasks and kneeling, bending, or use of test equipment may be necessary (lbid.).

\subsection{GUIDELINES FOR DESIGN OF INSTALLED PLATFORMS, WORK STANDS, AND LADDERS}

Platforms, stands and ladders should be provided where they will facilitate required maintenance. Design of these structures should meet user specifications and requirements and take work space considerations (Section 3.5) and environmental considerations (Chapter 4.0) into account.

Platforms, stands and ladders should be designed and evaluated for the rapidity and ease which these items allow required maintenance functions to be performed and for their potential for reducing human error. Evaluation should focus specifically on:

the time and effort involved in installation

the safety of such items under possible extreme conditions such as earthquakes

requirements for servicing, resurfacing, etc.

Ideally, platforms, stands and ladders should be designed and fabricated so that they require no maintenance.

\subsubsection{GENERAL PRINCIPLES}

Platforms, stands and ladders should be provided with the following, where appropriate:

work space and clearances consistent with the task

non-skid surfacing where personnel must walk or stand

fasteners for removable or adjustable parts in accordance with the preferences and requirements discussed in Section 8.13.2.1 (see Rigby, Cooper and Spickard, 1961).

Ramps or elevators should be provided when equipment must be hand carried. Ladders are inappropriate in such cases, since both hands should be free to grasp the ladder. Stairs and steps should not be used where personnel must handcarry bulky loads or loads in excess of $29 \mathrm{lb}(13 \mathrm{~kg})$ (U.S. Department of Defense, 1981a). 


\section{Accessibility and Workspace}

Table 3.1. Anthropometric Data (in.) for Common Working Positions (from U.S. Department of Defense, 1981 a) (Refer to Figure 3.3)

\begin{tabular}{lrrrr}
\hline & \multicolumn{2}{c}{$\begin{array}{c}\text { MEN } \\
\text { Percentile }\end{array}$} & \multicolumn{2}{c}{ WOMEN } \\
& 5 Percentile \\
& 129.1 & 95 th & 5 th & 95 th \\
\hline A. Weight, clothed (Ib) & 66.4 & 198.8 & 107.6 & 164.5 \\
B. Stature, clothed & 28.6 & 74.4 & 61.8 & 70.3 \\
C. Functional reach & 33.2 & 39.0 & 25.2 & 31.1 \\
D. Functional reach, extended & 78.9 & 90.8 & 28.9 & 36.5 \\
E. Overhead reach height & 13.9 & 16.5 & 73.0 & 84.7 \\
F. Overhead reach breadth & 49.4 & 59.0 & 12.4 & 14.9 \\
G. Bent torso height & 16.1 & 19.0 & 44.4 & 54.6 \\
H. Bent torso breadth & 50.3 & 57.9 & 14.5 & 17.1 \\
I. Overhead reach, sitting & 43.5 & 50.3 & 46.2 & 54.9 \\
J. Functional leg length & 48.0 & 53.9 & 39.2 & 46.7 \\
K. Kneeling height & 25.2 & 29.7 & 45.1 & 51.3 \\
L. Kneeling leg length & 17.6 & 21.1 & 23.3 & 27.8 \\
M. Bent knee height, supine & 59.4 & 68.1 & 16.3 & 19.5 \\
N. Horizontal length, knees bent & & & 55.2 & 64.5 \\
& & & & \\
\hline
\end{tabular}

Requirements for platforms, stands and ladders include consideration of fixtures, labels and size and configuration, discussed below.

\subsubsection{FIXTURES}

Where practical and feasible, provide platforms, stands and ladders with built in features such as:

electrical outlets and fixtures for adequate lighting

shelves for resting test equipment, tools, or components at a convenient operating or working level

hooks, eyes, clip fasteners, and supports that facilitate the support and connection of associated wiring, hoses, and block-and-tackle arrangements

appropriate storage space, cable winders, supports or clamps for manuals, slings, special tools or extension cables (Rigby, Cooper and Spickard, 1961).

\subsubsection{LABELING PRINCIPLES}

Platforms and stands should be provided with high visibility labels that indicate the maximum capacity in pounds, provide necessary warnings and cautions, mark the center of gravity where applicable, and meet the requirements noted in Section 9.3 (Rigby, Cooper and Spickard, 1961).

\subsubsection{SIZE AND CONFIGURATION PRINCIPLES}

Size, shape, and configuration of platforms, stands and ladders should permit personnel to perform all intended maintenance operations. Adequate work space and clearances for the maximum number of personnel required in these operations should be provided, as described in Section 3.5 (Rigby, Cooper and Spickard, 1961).

ACCESSIBILITY. All equipment, mounts, and features internally related to the maintenance operations they support should be easily accessible (Rigby, Cooper and Spickard, 1961). For example, work platforms for a main steam isolation 

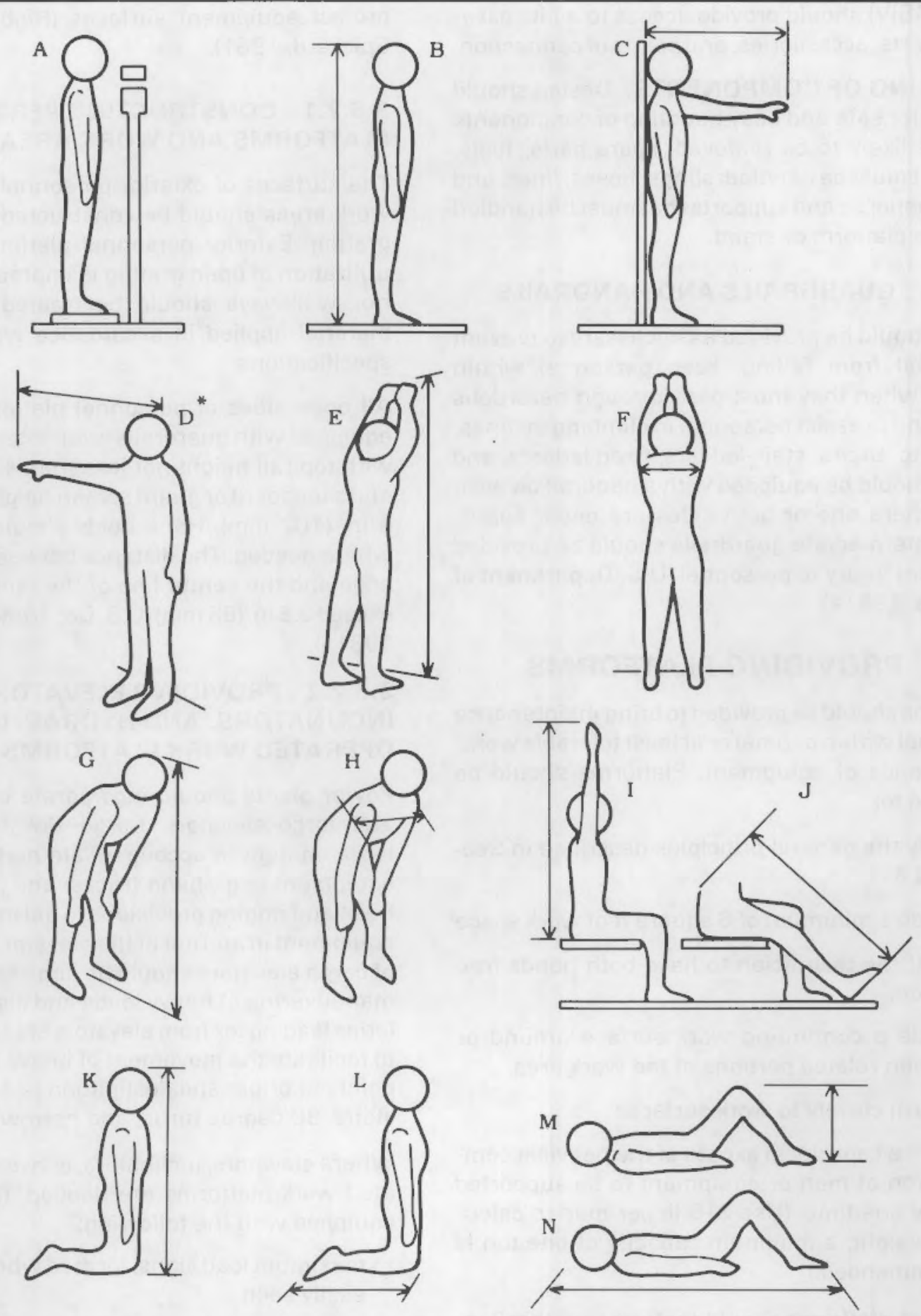

*Same as C, except right shoulder is extended as far foward as possible while keeping back of left shoulder firmly against back wall.

Figure 3.3. Work Positions (from U.S. Department of Defense, 1981a) 
valve (MSIV) should provide access to all its associated parts, accessories, and points of connection.

HANDLING OF COMPONENTS. Design should provide for safe and easy handling of components that are likely to be removed; spare parts, tools, etc., that must be handled; slings, hoses, lines, and other supports; and supports that must be handled from the platform or stand.

\subsubsection{GUARDRAILS AND HANDRAILS}

These should be provided as necessary to prevent personnel from falling, keep personnel within bounds when they must pass through hazardous areas, and to assist personnel in climbing inclines, stairs, etc. Stairs, stair-ladders, fixed ladders, and ramps should be equipped with a handrail on each side. Where one or both sides are open, appropriate intermediate guardrails should be provided to prevent injury to personnel (U.S. Department of Defense, 1981 a).

\subsubsection{PROVIDING PLATFORMS}

Platforms should be provided to bring maintenance personnel within optimal or at least tolerable working distance of equipment. Platforms should be designed to:

satisfy the general principles described in Section 3.6

provide a minimum of 6 square $f t$ of work space permit the technician to have both hands free for work

provide a continuing work surface around or between related portions of the work area.

conform closely to work surfaces

permit a capacity in excess of the heaviest combination of men or equipment to be supported at any one time. (Use $\mathbf{2 1 5} \mathrm{lb}$ per man to calculate weight; a minimum capacity of one ton is recommended.)

In general, platforms should conform to within 2 in. of the work surface. Gaps greater than 6 in. are normally objectionable and contact plates, cushions, bumpers, or pads should be provided to protect equipment surfaces (Rigby, Cooper and Spickard, 1961).

\subsubsection{CONSTRUCTING PERSONNEL PLATFORMS AND WORK AREAS}

The surfaces of exterior personnel platforms and work areas should be constructed of open metal grating. Exterior personnel platforms, for which utilization of open grating is impractical, and interior walkways should be treated with nonskid material applied in accordance with appropriate specifications.

All open sides of personnel platforms should be equipped with guardrails (with intermediate rails), with top rail height not less than $42 \mathrm{in} .(1.070 \mathrm{~m})$ and a toeboard or guard screen height not less than 4 in. $(102 \mathrm{~mm})$. Hand holds should be furnished where needed. The distance between the platform edge and the center line of the railing should not exceed 2.5 in. $(65 \mathrm{~mm})$ (U.S. Department of Defense, 1981a).

\subsubsection{PROVIDING ELEVATORS INCLINATORS, AND HYDRAULICALLY OPERATED WORK PLATFORMS}

Power plants should incorporate both personnel and cargo elevators. Cargo elevators should be large enough to accommodate material handling equipment (e.g., hand trucks) and should include hoist and rigging provisions to aid in moving heavy equipment in and out of the elevator. Space in front of cargo elevators should be large enough to allow maneuvering of heavy loads and aisleways or galleries leading to/from elevators should be designed to facilitate the movement of heavy loads between points of origin and destination (e.g., avoid steps/ stairs, 90 degree turns, and narrow aisleways).

Where elevators, inclinators, or hydraulically operated work platforms are needed, they should be equipped with the following:

maximum load signs, located where they can be easily seen

guards, to prevent accidental operation of the lift limit stops, to prevent injury to personnel and damage to equipment 
an automatic failsafe brake or other self-locking device in case of lift mechanism failure

provision for manually lowering platform or elevator when feasible

surface construction or treatment of open platforms, accomplished in accordance with Section 3.6.2.1 (U.S. Department of Defense, 1981 a).

\subsubsection{PROVIDING STANDS}

Stands and rests should be provided when surfaces to work on are needed, when personnel need elevation to reach an optimal working distance, or to provide support for major units during repair, handling or transport (Rigby, Cooper and Spickard, 1961).

Stands and rests should provide adequate support and protection for equipment and should facilitate maintenance operations. Stands should be slightly larger than the equipment they support so that damage to equipment from forklifts, handling vehicles, etc. will be prevented. Stands should be at equal height or higher than racks from which equipment must be removed, so that lifting or lowering of heavy components is minimized. Stands should be compatible in height with slide-out tracks or rails, or other handling features of the basic equipment (lbid.).

\subsubsection{PROVIDING STAIRS, LADDERS AND RAMPS}

Stairs, ladders and ramps should be provided when they will allow the most immediate and efficient access to and between work places and areas.

Stairs, ladders or ramps should be provided at all locations where equipment design or maintenance actions require personnel to change elevation abruptly by more than 12 in. Stairs (stiles) and ramps may also be used to provide safe and easy passage over low objects (pipes, lines, ridges, etc.) in corridors and passageways. The layout and design of stairs, ladders and ramps should consider:

limitations in the amount of space and clearance available anticipated environmental conditions, particularly for structures likely to become wet or covered with oil or grease

the type, direction and frequency of traffic over the structure

the relative efficiency of alternative traffic plans and patterns

loads or other encumberments to be carried by personnel in passage

the size and weight of other equipment that may have to be moved over the route (Rigby, Cooper and Spickard, 1961).

CONSTRUCTION. Stairs ladders and ramps should be constructed of materials that are lightweight, non-conductive, splinter-proof, waterproof, and resistant to humidity and chemical action. These structures should be strong enough to withstand the combined weights and strengths of the largest number of personnel likely to be on them at any one time, times a safety factor of five. Strength should never be less than that required to support a moving concentrated load of $1000 \mathrm{lb}$ ( 29 CFR 1910.24). (For calculating weight, use $215 \mathrm{lb}$ per man.)

SAFETY. To provide for safety, all areas where personnel are expected to step, walk or stand should have nonskid surfaces. Obstructions, edges, notches, or burrs that could injure personnel or damage hoses and cables should be removed. Adequate lighting and warnings against dangers such as unavoidable low overheads should be provided (see Section 4.3 and Section 9.3.12).

RISER HEIGHT. The distance between steps or stairs (riser height) should be uniform, and the distance between steps and landings should not be less than 6 in. or more than the uniform riser height (Rigby, Cooper, and Spickard, 1961).

DECONTAMINATION. Stairs, ladders and ramps should be designed so they may be decontaminated when necessary. 


\subsubsection{ANGLE OF INCLINATION}

The primary basis for deciding among stairs, ladders, and ramps is the angle of inclination of the structure as a function of the available space and structural constraints. Figure 3.4 shows the preferred angles of incline suitable for these structures (Rigby, Cooper and Spickard, 1961; U.S. Department of Defense, 1981a).

\subsubsection{TYPES OF STRUCTURES, IN OROER OF PREFERENCE}

STAIRS. Stairs allow the fastest, safest, and easiest passage, particularly when personnel are required to carry loads (such as tools, parts, and test equipment). Stair ladders are preferred to ladders; they provide better footing and faster, safe passage. But both hands are required on the handrails for sure balance and fast movement, and it is hazardous for personnel to carry loads up stairladders (Rigby, Cooper and Spickard, 1961).

LADDERS. Ladders are not desirable for frequent passage. They are comparatively unsafe, difficult

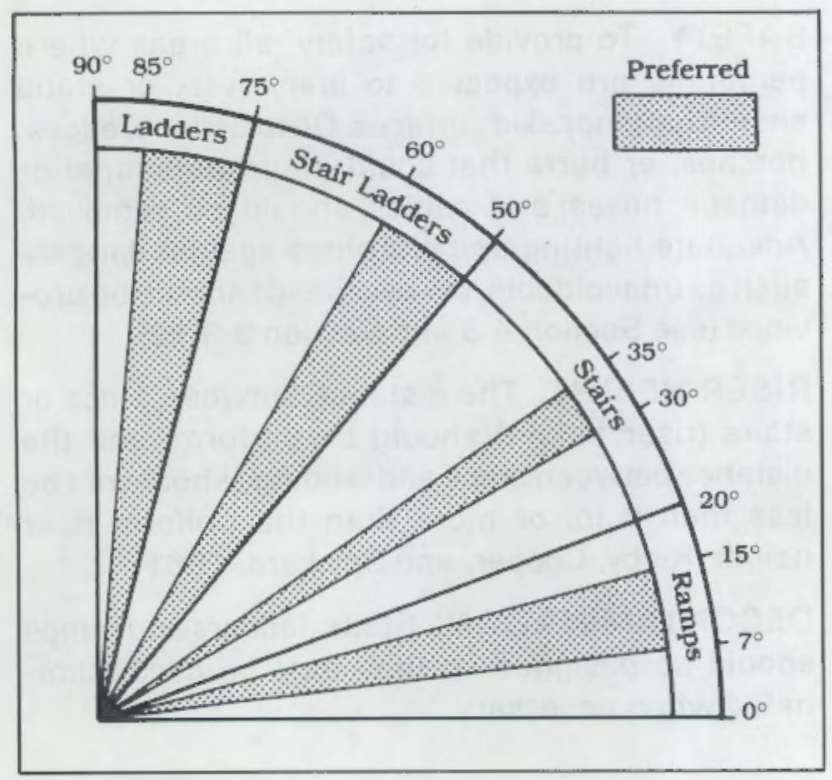

Figure 3.4. Preferred Angles of Inclinations for Ladders, Stair Ladders, Stairs and Ramps to climb, and difficult to work from. Only loads that are strapped to personnel can be carried up ladders. Fixed ladders are preferable to semi-permanent or movable ladders; fixed ladders are more stable, less subject to clearance problems, and can be affixed with guardrails and other safety features. Portable ladders should be needed and provided only for emergency functions or for use during infrequent maintenance tasks. Permanent ladders or maintenance stands are preferable (lbid.). Metal ladders should not be used for working on electrical circuits or equipment.

RAMPS. In general, ramps are of value only when rolling stock must be moved between different levels and this same space can be used for pedestrian traffic. Long ramps are undesirable except for selfpropelled vehicles. Tasks where personnel push or pull rolling stock up ramps should be carefully evaluated in terms of safety and human strength (Ibid.).

\subsubsection{RAMPS}

Ramp dimensions should conform to the values indicated in Table 3.2. Width dimensions should be determined by the function or use of the ramp, particularly by the size of rolling stock and loads.

Table 3.2. Ramp Dimensions (in.)'

\begin{tabular}{|c|c|c|c|}
\hline Dimension & Min & $\operatorname{Max}$ & Best \\
\hline Angle of rise & - & $20^{\circ}$ & $7-15^{\circ}$ \\
\hline $\begin{array}{l}\text { Distance between } \\
\text { cleats }\end{array}$ & 9 & 16 & 14 \\
\hline Height of handrails & 38 & 44 & 42 \\
\hline Diameter of handrail & $1.5^{1}$ & 3 & 1.5 \\
\hline $\begin{array}{l}\text { Clearance around } \\
\text { handrail }\end{array}$ & 31 & - & 3 \\
\hline Width & $30^{1}$ & - & - \\
\hline \multicolumn{4}{|c|}{$\begin{array}{l}\text { 'Indicates values from } 29 \text { CFR 1910; all others from } \\
\text { U.S. Department of Defense, } 1981 \text { a. }\end{array}$} \\
\hline
\end{tabular}


CLEATS. Where cleating of pedestrian ramps is necessary, the cleats should be spaced 14 in. $(360 \mathrm{~mm})$ apart; they should extend from handrail to handrail at right angles to the line of traffic (Rigby, Cooper and Spickard, 1961).

PEDESTRIAN/VEHICLE TRAFFIC. When a ramp is required for both pedestrian and vehicle traffic, the vehicle bearing surface should be located in the center of the ramp, with the pedestrian surface next to the handrails. A vehicle ramp with an adjacent pedestrian stairway is preferred for this situation (lbid.).

\subsubsection{STAIRS AND STAIR LADDERS}

Stair/stair ladder dimensions should conform to recommended values and should be within the minimum and maximum limits indicated in Figure 3.5 and Table 3.3.

TREAD RISE. The tread rise should be open at the rear, and landings should be provided every tenth or twelfth tread.

TREAD SURFACES. The surface of treads on exterior stair ladders should be constructed of open grating material or should be treated with nonskid material.

STAIR LADDERS. Stair ladders should be constructed from metal, and provided with handrails that have nonslip surfaces (U.S. Department of Defense, 1981 a).

\subsubsection{FIXED LADDERS}

Fixed ladder dimensions should conform to recommended values and should be within the specified minimum and maximum limits shown in Figure 3.5 and Table 3.3. Fixed ladders that are used to provide access to multiple levels should be offset at each successive level.

Guardrails should be provided around the opening at the top of each fixed ladder. All fixed ladders more than $20 \mathrm{ft}(6 \mathrm{~m})$ high should be equipped with provisions for positive protection from falls (see 29 CFR 1910.27).

\subsection{GUIDELINES FOR DESIGN OF ARM AND HAND ACCESS}

Access openings provided for adjusting and handling interior items should be large enough to permit the required operations and, where possible, provide an adequate view of the item being manipulated. Access covers should be equipped with grasp areas or features for opening. The dimensions of access openings for arms, hands and fingers should be no less than those shown in Figure 3.6, and allowance should be made for clearance of gloved or mittened hands, as appropriate. If a hazardous condition exists behind the access, the physical barrier over the access should be equipped with an interlock that will de-energize the hazardous equipment when the barrier is opened or removed. Where physical access is necessary, the following features should be provided in order of preference:

an opening with no cover, unless this is likely to degrade system performance or safety

A sliding or hinged cap or door, where dirt, moisture, or other foreign materials might otherwise create a problem

A quick-opening cover plate, if a cap will not meet stress requirements (U.S. Department of Defense, 1981).

\subsubsection{ACCESS TO CONNECTORS}

When possible, designers should consider the final installed position for a component or unit of equipment and locate connectors so that they will be accessible both visually and physically.

REACH. Reference should be made to anthropometric dimensions in determining whether connectors are within the functional arm reach of maintenance personnel (Van Cott and Kinkade, 1972).

CLEARANCE. Connections should be spaced so that sufficient clearance is allowed for operation, whether by bare hand, gloved hand, or with tools. For example, terminals for soldered connections should be spaced far enough apart to permit proper 


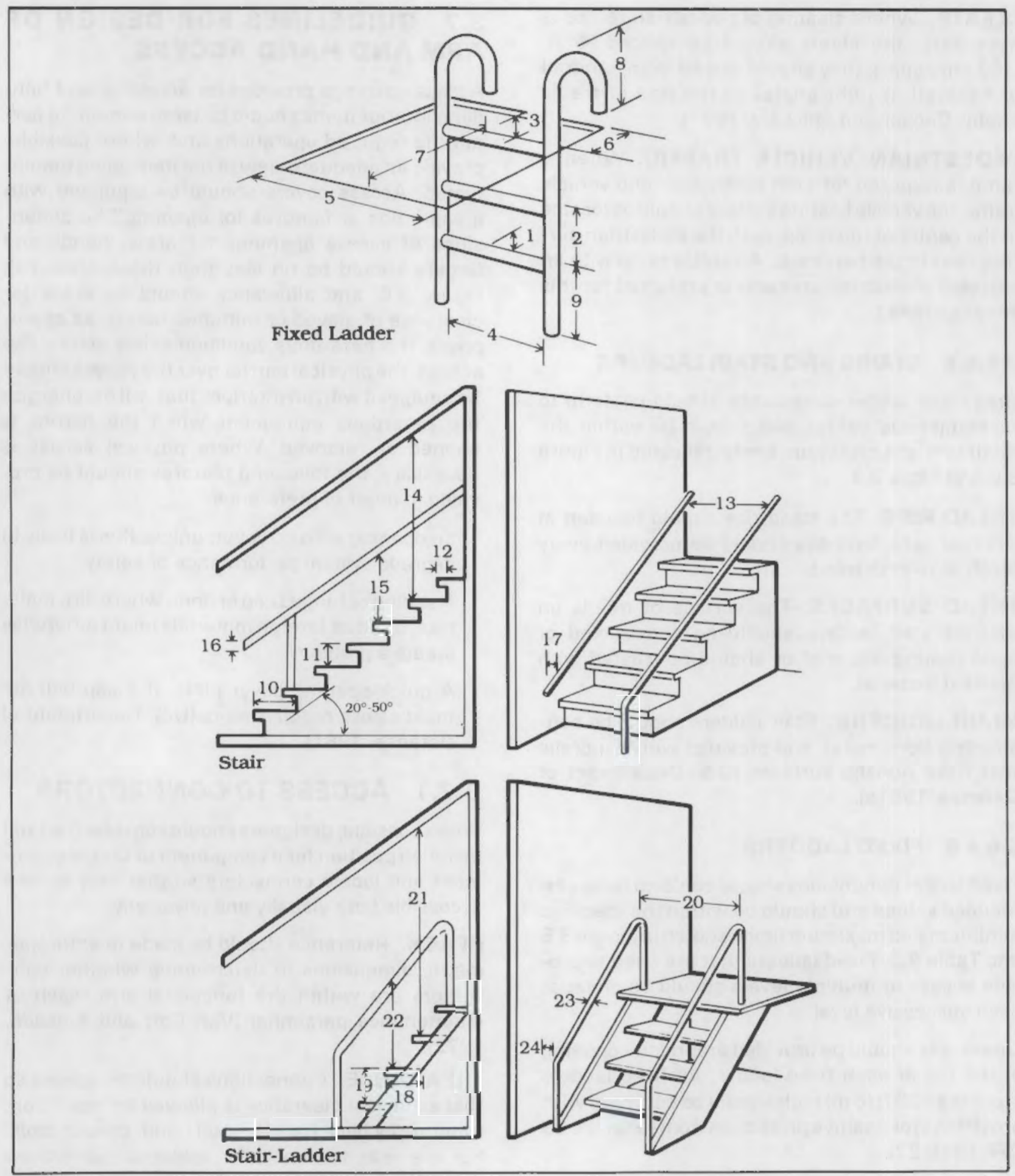

Figure 3.5. Reference Numbers for Dimensions for Fixed Ladders, Stairs and Stair Ladders (from U.S. Department of Defense, 1981a) (Refer to Table 3.3) 
Table 3.3. Dimensions (in.) for Fixed Ladders, Stairs and Stair Ladders (from U.S. Department of Defense, 1981a) (refer to Figure 3.5)

\begin{tabular}{|c|c|c|c|c|c|}
\hline & \multirow{2}{*}{$\begin{array}{l}\text { Fig. } 3.5 \\
\text { reference } \\
\text { number }\end{array}$} & & \multirow[b]{2}{*}{ Minimum } & \multirow[b]{2}{*}{ Maximum } & \multirow[b]{2}{*}{ Recommended } \\
\hline & & & & & \\
\hline \multirow{11}{*}{$\begin{array}{r}\text { Fixed } \\
\text { Ladder }\end{array}$} & 1 & Rung thickness: & & & \\
\hline & & $\begin{array}{l}\text { Wood } \\
\text { Protected metal }\end{array}$ & $\begin{array}{c}1-1 / 8 \\
3 / 4\end{array}$ & $\begin{array}{l}1-1 / 2 \\
1-1 / 2\end{array}$ & $\begin{array}{l}1-3 / 8 \\
1-3 / 8\end{array}$ \\
\hline & & $\begin{array}{l}\text { Protected metal } \\
\text { Corrosive metal }\end{array}$ & 1 & $1-1 / 2$ & $1-3 / 8$ \\
\hline & 2 & Rung spacing & 9 & 15 & 12 \\
\hline & 3 & Height, rung to landing & 6 & 15 & 15 \\
\hline & 4 & Width between stringers & 12 & - & $18-21$ \\
\hline & 5 & Climbing clearance width & 24 & - & 30 \\
\hline & 6 & Clearance depth in back of ladder & 6 & - & 8 \\
\hline & 7 & Clearance depth on climbing side & \multicolumn{3}{|c|}{ Range of 36 for $75^{\circ}$ to 30 for $90^{\circ}$} \\
\hline & 8 & Height of stringer above landing & 33 & - & 36 \\
\hline & 9 & Height from lower elevation to bottom rung & - & 15 & - \\
\hline \multirow[t]{8}{*}{ Stair } & 10 & Tread depth (including nosing & $9-1 / 2$ & 12 & $11-12$ \\
\hline & 11 & Riser height & 5 & 8 & $6-1 / 2-7$ \\
\hline & 12 & Depth of nosing (where applicable) & $3 / 4$ & $1-1 / 2$ & 1 \\
\hline & 13 & $\begin{array}{l}\text { Width (handrail to handrail): } \\
\text { One-way stairs } \\
\text { Two-way stairs }\end{array}$ & $\begin{array}{l}30 \\
48\end{array}$ & $\overline{-}$ & $\begin{array}{l}36 \\
51\end{array}$ \\
\hline & 14 & Overhead clearance & 76 & - & 78 \\
\hline & 16 & $\begin{array}{l}\text { Height of handrail (from leading edge } \\
\text { of } \\
\text { tread) }\end{array}$ & 30 & 36 & 33 \\
\hline & 16 & Handrail diameter & $1-1 / 4$ & 3 & $1-1 / 2$ \\
\hline & 17 & Rail clearance from wall & $1-3 / 4$ & - & 3 \\
\hline \multirow[t]{7}{*}{$\begin{array}{l}\text { Stair- } \\
\text { Ladder }\end{array}$} & 18 & $\begin{array}{l}\text { Tread depth range: } \\
\text { For } 50^{\circ} \text { rise } \\
\text { For } 75^{\circ} \text { rise (open ladders only) }\end{array}$ & $\begin{array}{l}6 \\
3\end{array}$ & $\begin{array}{c}10 \\
5-/ 12\end{array}$ & $\begin{array}{c}8-1 / 2 \\
4\end{array}$ \\
\hline & 19 & Riser height & 7 & 12 & 9 \\
\hline & 20 & Width (handrail to handrail) & 21 & 24 & 22 \\
\hline & 21 & Overhead clearance & 68 & - & 78 \\
\hline & 22 & $\begin{array}{l}\text { Height of handrail (from leading edge } \\
\text { of } \\
\text { tread) }\end{array}$ & 34 & 37 & 35 \\
\hline & 23 & Handrail diameter & $1-1 / 4$ & 3 & $1-1 / 2$ \\
\hline & 24 & Rail clearance from wall & 2 & - & 3 \\
\hline
\end{tabular}




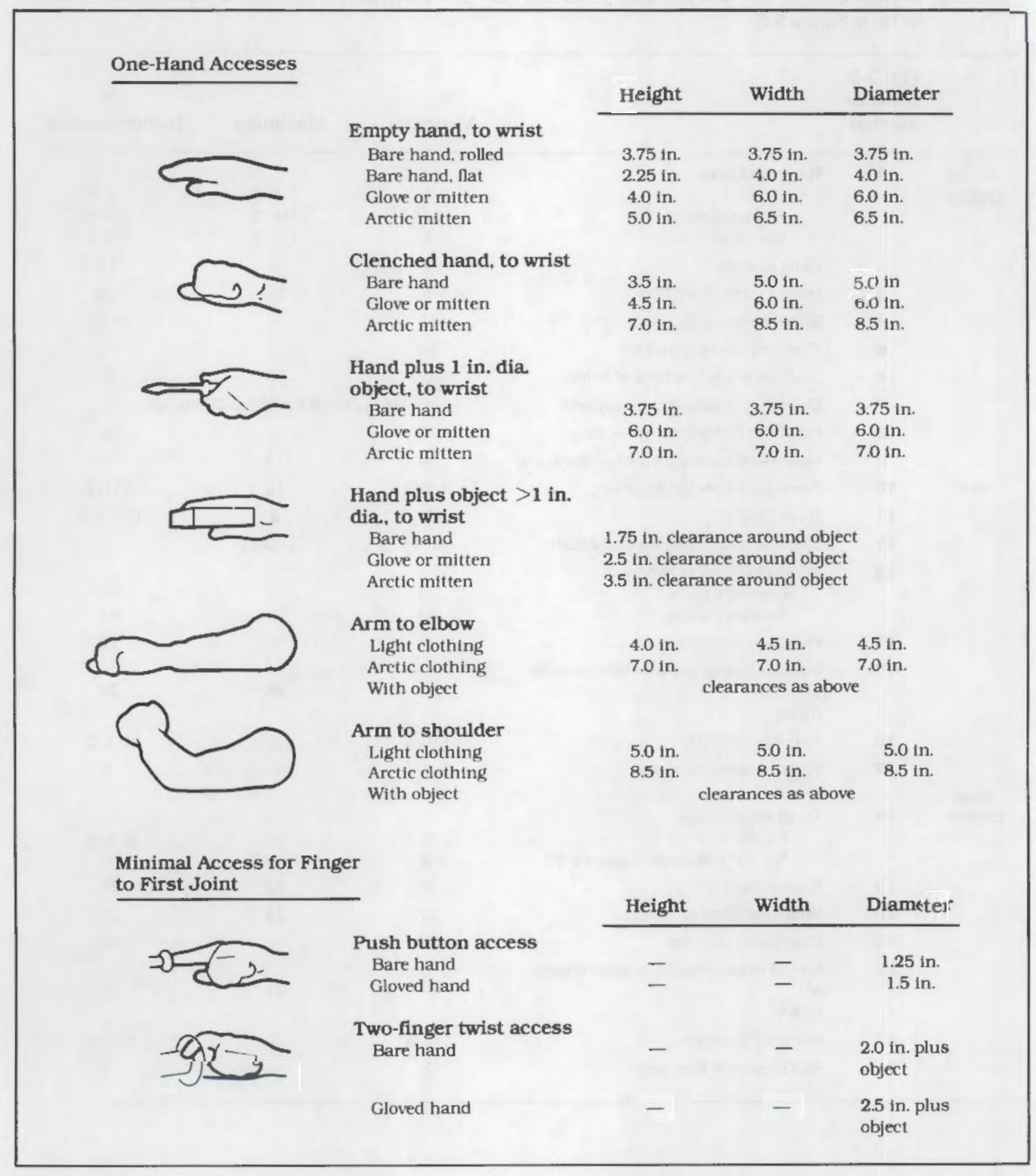

Figure 3.6. Dimensions for Arm and Hand Access 


\section{Two-Hand Accesses}
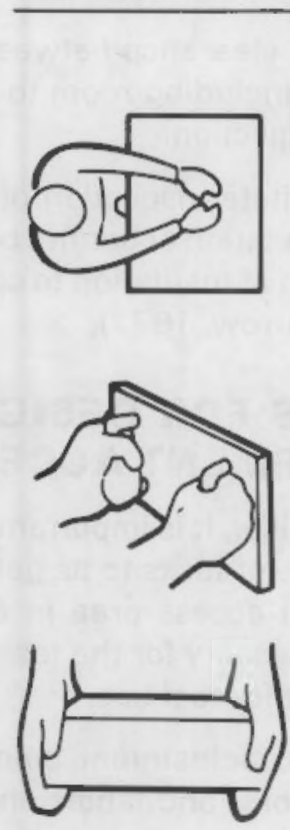

\section{Reaching with both}

hands, 6 in. -19.25 in.

Light clothing

Arctic clothing

\section{Reaching full arm's length to shoulders with both arms}

\section{Inserting box grasped} by handle on the front

Inserting box with hands on the sides Light clothing

Arctic clothing

\begin{tabular}{ll} 
Height & \multicolumn{1}{c}{ Width } \\
\hline & \\
5 in. & $\begin{array}{l}8 \text { in. or depth of reach } \\
7 \text { in. } \\
\text { of reach } 3 / 4 \text { depth }\end{array}$
\end{tabular}

5 in.

$19.5 \mathrm{in}$.

$1 / 2$ in. clearance around box, assuming adequate clearance around handles.

\section{5 in. or $0.5 \mathrm{in}$.} around box ${ }^{1.2}$

Box plus 4.5 in.

8.5 in. or 0.5 in. around box ${ }^{1.2}$
Box plus 7 in.

'Whichever is larger.

${ }^{2}$ If hands curt around bottom. allow an extra $1.5 \mathrm{in}$. for light clothing. 3 in. for artic clothing.

Figure 3.6. (Continued) 
clearance for a soldering iron. The end of the wire should be left exposed to facilitate removal as shown in Figure 3.7 (lbid.).

CONNECTING AND DISCONNECTING. Connectors should be spaced far enough apart so that they can be grasped firmly for connecting and disconnecting. Space between adjacent connectors or between a connector and any adjacent obstructions should be compatible with the size and shape of electrical plugs. Space should not be less than 1 in., except where connectors are to be removed sequentially and replaced and $1 \mathrm{in}$. clearance is provided in a swept area of at least $\mathbf{2 7 0}$ degrees around each connector at the start of its removal/ replacement sequence. Spacing should be measured from the outermost portion of the connector (from the backshell), strain relief clamp, dust cover or shield (U.S. Department of Defense, 1981a).

HIGH TORQUE. Where high torque is needed to tighten or loosen the connector, space should be provided for use of a connector wrench (lbid.).

\subsubsection{DESIGNING PIPING}

Because pipe is more rigid than tubing or cables and is difficult to remove, space allowed for tool operation during the connecting and disconnecting of unions is often critical to efficient maintenance.

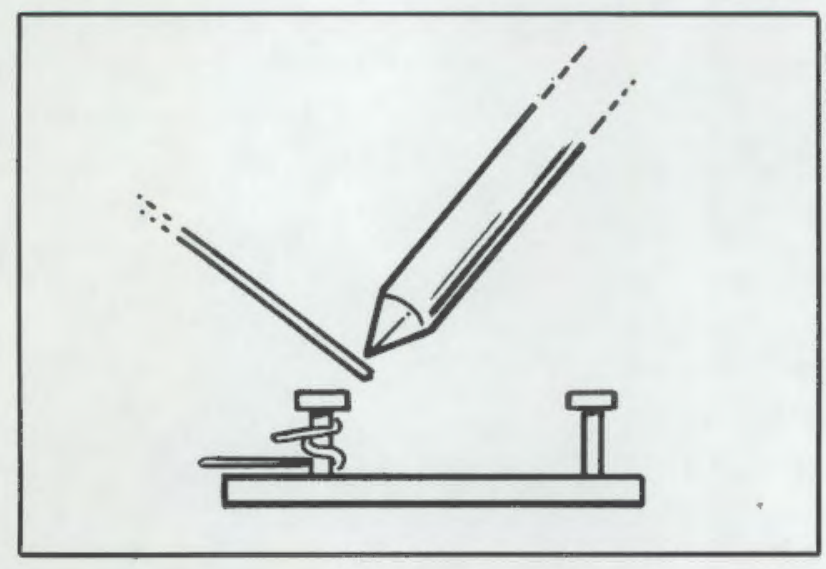

Figure 3.7. Clearance Between Terminals and Exposure of Wire End (Van Cott and Kinkade, 1972)
FLANGES. Provide space between pipes and/or pipe supports to allow proper alignment and bolt tightening/untightening of flanges.

VALVES. Allow ample clearance between pipes for rising-stem valves, including room to remove stem and bonnet for inspection.

INSULATION. To facilitate inspection of valves, end permanent pipe insulation at bonnet bolts and use a removable section of insulation to cover the bonnet (Higgins and Morrow, 1977).

\subsection{GUIDELINES FOR DESIGN OF TOOL AND EQUIPMENT ACCESS}

In planning for accessibility, it is important to consider the specific nature of tasks to be performed through or within each access area in order to determine the tools necessary for the task and, in turn, the space required for tool use.

LABELS. Check points, adjustment points, test points, cables, connectors, and labels should be accessible and visible during maintenance.

TOOL SPACE. Sufficient space should be provided so that test equipment and other required tools can be used without difficulty or hazard (Van Cott and Kinkade, 1972; U.S. Department of Defense, 1981 a).

Detailed equipment design principles may be found in Chapter 8.

\subsection{GUIDELINES FOR DESIGN TO FACILITATE INSPECTION, TEST AND SERVICING}

Equipment should be designed to facilitate preventive maintenance, including lubrication, surveillance testing, calibration, and periodic replacement. System design should permit periodic on-line test of safety-related features, such as reactor trip breakers.

FUNCTIONAL MODULES. Modules should be designed so that each unit can be checked and adjusted independently, with minimal requirements for additional adjustment when the modules are assembled to form the system or subsystem. 
LUBRICATED MECHANICAL ASSEMBLIES. Units that include lubricated mechanical assemblies should be equipped with external fittings so that disassembly will not be necessary when lubrication is required.

REGULAR INSPECTION. Similarly, units that require regular inspection for signs of excessive wear can sometimes be designed with cover plates or openings, rendering a complete disassembly unnecessary (Van Cott and Kinkade, 1972).

ROUTING CABLES. Cables should be routed so that they are readily accessible for inspection and repair (U.S. Department of Defense, 1981a).

See Section $\mathbf{8 . 4}$ for additional guidelines on design to facilitate inspection.

\subsection{GUIDELINES FOR DESIGN OF VISUAL ACCESS}

Minimum access sizes often reflect the amount of space required for physical access or manual manipulation only. Provision should also be made for visual access so that the technician will not have to work "blind." Special lighting should be considered for critical tasks likely to be obscured from standard facility lighting (see Section 4.3). The need for ready access for inspection purposes should also be considered. Transparent viewing ports may meet such needs; however, sometimes it is also necessary to touch or handle components in order to detect temperature discrepancies, breaks, corrosion, wear, etc. (Van Cott and Kinkade, 1972). Where visual access only is required, the following features should be provided, given in order of preference:

an opening with no cover, except where this might degrade system performance

a transparent window if dirt, moisture, or other foreign materials might otherwise create a problem

a break-resistant glass window if physical wear, heat, or contact with solvents would otherwise cause optical deterioration

a quick-opening metal cover if glass will not meet stress or other requirements (U.S. Department of Defense, 1981a).

See Chapter 9 for additional guidelines for mounting displays and controls for seated and standing operation. 



\section{Chapter 4 PHYSICAL ENVIRONMENT}

This section deals with environmental factors that can affect the maintainability of a nuclear plant. These include illumination, noise, vibration, temperature, and radiation, all of which can have decided effects on maintenance personnel who must perform within the plant's environment.

\subsection{PROBLEMS}

Considerable background on the physical environment of nuclear power plants is available. In this document, our concerns focus on maintenance as it relates to physical environment. Designers are encouraged to consult other resources as well (ASHRAE, 1977 and IES, 1981; also see the reference list at the end of this guide).

Environmental factors contribute to poor maintainability within the nuclear plant in specific ways (Badalamente et al., 1982; Seminara and Parsons, 1981). These include:

insufficient lighting

exposure to radiation hazards

excessive noise

excessive heat or inadequate temperatureventilation control

excessive vibrations

lack of sufficient attention to shielding, remote handling, and other means of reducing exposure during maintenance.

\subsection{SAFETY IMPACT}

Maintenance performance can be both directly and indirectly affected by environmental factors. Conditions such as inadequate lighting or excess noise may directly contribute to maintenance errors. The same conditions and others, such as radiation and excess heat, can also contribute to psychological and physiological stress. Both high psychological and physiological stress can degrade human performance, and, under extreme conditions, high physiological stress can result in injury or death.
Organizational responses to environmental conditions can have other indirect effects on maintenance. For example, radiation or excess heat can cause needed maintenance work to be postponed, hastily completed, performed in cumbersome garments, or accomplished by multiple shifts. Such responses increase the probability of equipment breakdown and maintenance error.

Guidelines in this chapter are aimed primarily at avoiding environmental conditions that could lead to degraded human performance in maintenance and, in turn, to degraded plant safety. The health and welfare of maintenance personnel is also an issue, both by itself, and as it effects maintenance. Occupational Health and Safety Administration (OSHA) regulations provide guidelines designed to ensure a safe working environment.

\subsection{GUIDELINES FOR ILLUMINATION}

Because most maintenance tasks depend on adequate vision, illumination plays an important part in performing accurate and safe maintenance. Minimum illumination levels for specific areas are provided in Table 4.1 (ANSI, 1979). Minimum illumination levels as specified in Table 4.1 do not necessarily imply sufficient lighting for performing given maintenance tasks. Guidelines suggesting illumination levels and types of illumination for various tasks and task conditions are presented in Table 4.2 (Van Cott and Kincade, 1963). An examination of the illumination levels found in these two tables suggests that in many areas, supplemental lighting may be needed to complete maintenance tasks with accuracy and safety. Although illumination levels should ideally be equal over the entire working area, this is often impossible. The following guidelines are recommended to approximate the ideal.

\subsubsection{PLANNING BRIGHTNESS RATIOS}

Guidelines for maximum allowable brightness ratios are given in Table 4.3 (Rigby, Cooper and Spickard, 1961). 


\section{Physical Environment}

Table 4.1. Minimum Illumination Levels for Areas (from ANSI, 1979)

\begin{tabular}{|c|c|c|c|}
\hline Task & $\begin{array}{l}\text { Minimum } \\
\text { Level of } \\
\text { Illumination } \\
\text { ft-C }\end{array}$ & Task & $\begin{array}{l}\text { Minimum } \\
\text { Level of } \\
\text { Illumination } \\
\mathrm{ft}-\mathrm{C}\end{array}$ \\
\hline $\begin{array}{l}\text { Air-conditioning equipment, air } \\
\text { preheater and fan floor, ash sluicing }\end{array}$ & 10 & $\begin{array}{l}\text { Fuel handling building } \\
\text { Operating floor }\end{array}$ & $\begin{array}{l}20 \\
30\end{array}$ \\
\hline $\begin{array}{l}\text { Auxiliaries, battery rooms, boiler feed } \\
\text { pumps, tanks, compressors, } \\
\text { gauge eres }\end{array}$ & 20 & $\begin{array}{l}\text { Intake structures } \\
\text { Deck and laydown area }\end{array}$ & 5 \\
\hline Auxiliary building & 20 & Valve pits & 2 \\
\hline Cable room, circulator or pump bay & 10 & Inlet water area & 0.2 \\
\hline Chemical laboratory & 50 & Intermediate building & 20 \\
\hline $\begin{array}{l}\text { Condensers, deaerator floor, } \\
\text { evaporator floor, heater floors }\end{array}$ & 10 & Off gas building & 20 \\
\hline $\begin{array}{l}\text { Control rooms } \\
\text { Vertical face of switchboards } \\
\text { simplex or section of duplex operator: } \\
\text { Type A-large, centralized control }\end{array}$ & & $\begin{array}{l}\text { Parking areas } \\
\text { Main plant parking } \\
\text { Secondary parking }\end{array}$ & $\begin{array}{l}2 \\
1\end{array}$ \\
\hline room 65 in. above floor & 50 & $\begin{array}{l}\text { Radwaste building } \\
\text { Reactor building }\end{array}$ & $\begin{array}{l}20 \\
20\end{array}$ \\
\hline $\begin{array}{l}\text { Type 8-ordinary control room } \\
66 \text { in. above floor }\end{array}$ & 30 & $\begin{array}{l}\text { Reactor building } \\
\text { Steam headers and throttles }\end{array}$ & $\begin{array}{l}20 \\
10\end{array}$ \\
\hline $\begin{array}{l}\text { Section of duplex facing away } \\
\text { from operator }\end{array}$ & 30 & $\begin{array}{l}\text { Substation } \\
\text { Horizontal general area }\end{array}$ & 2 \\
\hline Bench boards (horizontal level) & 50 & Vertical tasks & 5 \\
\hline Area inside duplex switchboards & 10 & & \\
\hline $\begin{array}{l}\text { Rear of all switchboard panels } \\
\text { (vertical) }\end{array}$ & 10 & $\begin{array}{l}\text { Switchgear, power } \\
\text { Telephone equipment room }\end{array}$ & $\begin{array}{l}20 \\
20\end{array}$ \\
\hline Emergency lighting, all areas & 3 & Transformer yards & \\
\hline Controlled access area & & Horizontal genera! area & 2 \\
\hline $\begin{array}{l}\text { Count Room } \\
\text { Laboratory }\end{array}$ & $\begin{array}{r}70 \\
100\end{array}$ & Vertical tasks & 5 \\
\hline Radiation protection service room & 70 & Tunnels or galleries, piping & 10 \\
\hline Health physics office & 100 & & \\
\hline Medical aid room & 100 & Turbine areas & \\
\hline Hot laundry & 30 & building surrounds & 2 \\
\hline Storage room & 20 & Turbine and heater decks, unloading & \\
\hline $\begin{array}{l}\text { Cooling towers } \\
\text { Fan deck, platforms, stairs, }\end{array}$ & & bays, entrances, stairs and platforms & 5 \\
\hline Valve areas & 5 & Turbine room & 30 \\
\hline Pump areas & 2 & Visitor's gallery & 20 \\
\hline Diesel generator building & 30 & Water treating area & 20 \\
\hline $\begin{array}{l}\text { Dispatch boards } \\
\text { Horizontal plane (desk level) }\end{array}$ & 50 & Water treating building & 20 \\
\hline $\begin{array}{l}\text { Vertical face of board ( } 48 \text { in. above } \\
\text { floor, facing operator) }\end{array}$ & - & & \\
\hline $\begin{array}{l}\text { System load dispatch room } \\
\text { Secondary dispatch room }\end{array}$ & $\begin{array}{l}50 \\
80\end{array}$ & & \\
\hline
\end{tabular}


Table 4.2. General Illumination Levels and Types of Illumination for Different Task Conditions and Types of Tasks (Van Cott and Kinkade, 1963)

\begin{tabular}{|c|c|c|c|}
\hline Task Condition & Type of Task or Area & $\begin{array}{l}\text { Illuminance } \\
\text { Level } \\
\text { (ft.-c) }\end{array}$ & Type of Illumination \\
\hline $\begin{array}{l}\text { Small detail, low contrast, } \\
\text { prolonged periods, high } \\
\text { speed, extreme accuracy }\end{array}$ & $\begin{array}{l}\text { Sewing, inspecting dark } \\
\text { materials, etc. }\end{array}$ & 100 & $\begin{array}{l}\text { General plus supplementary, } \\
\text { e.g., desk lamp }\end{array}$ \\
\hline $\begin{array}{l}\text { Small detail, fair contrast, } \\
\text { speed not essential }\end{array}$ & $\begin{array}{l}\text { Machining, detail drafting, } \\
\text { watch repairing, inspecting } \\
\text { medium materials, etc. }\end{array}$ & $50-100$ & General plus supplementary \\
\hline $\begin{array}{l}\text { Normal detail, prolonged } \\
\text { periods }\end{array}$ & $\begin{array}{l}\text { Reading, parts assembly; } \\
\text { general office and laboratory } \\
\text { work }\end{array}$ & $20-50$ & $\begin{array}{l}\text { General, e.g., overhead } \\
\text { ceiling fixture }\end{array}$ \\
\hline $\begin{array}{l}\text { Normal detail, no prolonged } \\
\text { periods }\end{array}$ & $\begin{array}{l}\text { Washrooms, power plants, } \\
\text { waiting rooms, kitchens }\end{array}$ & $10-20$ & $\begin{array}{l}\text { General e.g., random natural } \\
\text { or artificial light }\end{array}$ \\
\hline $\begin{array}{l}\text { Good contrast, fairly large } \\
\text { objects }\end{array}$ & Recreational facilities & $5-10$ & General \\
\hline Large objects & $\begin{array}{l}\text { Restaurants, stairways, } \\
\text { bulk-supply warehouses }\end{array}$ & $2-5$ & General \\
\hline
\end{tabular}

Table 4.3. Maximum Brightness Ratios for Workplace Conditions (Rigby, Cooper and Spickard, 1961)

Ratio Condition

5:1 Between task and adjacent surroundings

20:1 Between task and remote surfaces

40:1 Between light source (or sky) and surfaces adjacent to it

80:1 Between the immediate work area and remainder of the environment

\subsubsection{AVOIDING GLARE}

Glare is an illumination problem created when relatively bright light shines into the observer's oyes as the observer tries to observe a relatively dim visual field (U.S. Department of Defense, 1981b). To avoid glare which slows work, increases the probability of error and produces fatigue:

Use surfaces and paints that diffuse rather than reflect light.

Place lights high and directly above the work area.

Use indirect lighting wherever possible.

Use diffused lighting where possible, with lights spaced high and close together. 
Arrange light sources to avoid equal lighting and viewing angles.

Provide shields, hoods and visors to reduce or prevent glare.

Use many light sources of low intensity.

Avoid placing bright surfaces within the working visual field and placing bright light sources within 60 degrees of the central visual field (Rigby, Cooper and Spickard, 1961).

DIRECT GLARE. Direct glare arises from a light source within the visual work field. To control it:

Avoid bright light sources within 60 degrees of the center of the visual field. Since most visual work is at or below the eye's horizontal position, placing luminaires high above the work area minimizes direct glare.

Use indirect lighting.

Use more, relatively dim light sources, rather than a few very bright ones.

Use polarized light, shields, hoods, or visors to block the glare in confined areas (U.S. Department of Defense, $1981 \mathrm{~b}$ ).

REFLeCTED GLARE. Reflected glare refers to reflection from shiny surfaces in the visual field. It should be controlled by:

Using surfaces that diffuse incident light, rather than reflecting light specularly.

Arranging direct-light sources so their angle of incidence to the visual work area is not the same as the operator's viewing angle (Ibid.).

Use surface reflectance values for control rooms, offices and maintenance areas as recommended in Figure 4.1 (lbid.)

\subsubsection{LIGHTING DISPLAYS AND CONTROLS}

ILLUMINATED CONTROLS. When the quality or intensity of light would otherwise hinder color discrimination, self-illuminated indicators of back

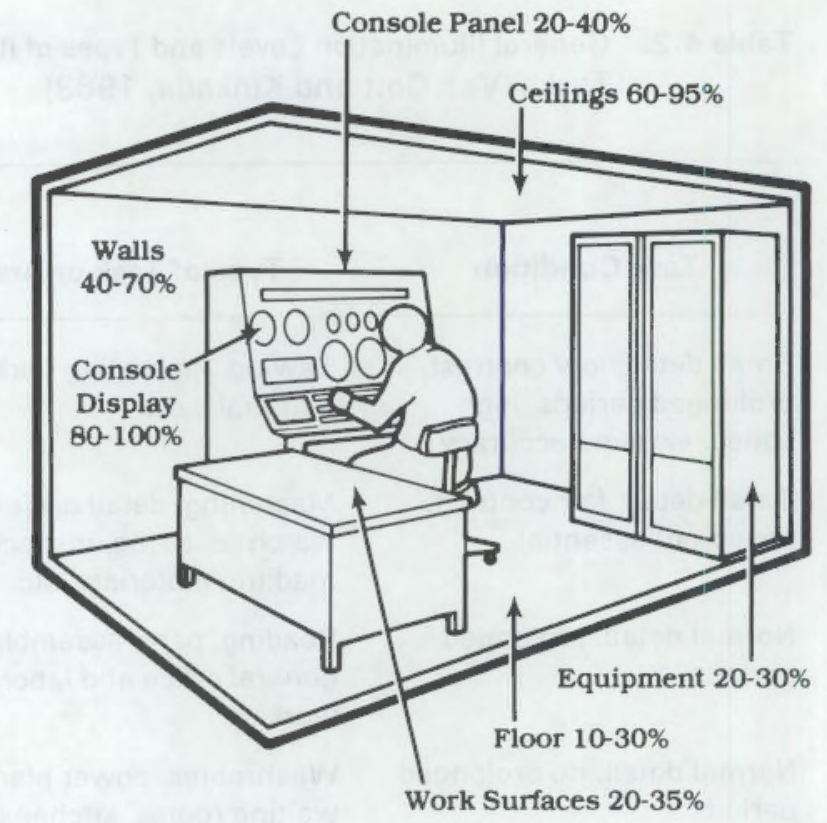

Figure 4.1. Work-Space Reflectance Values (U.S. Department of Defense, 1981 b)

lighting should be used. (See U.S. Nuclear Regulatory Commission, 1981 for additional guidance on visual alarms and displays.)

ALTER NATIVES. Under poor lighting conditions, auditory signals should be used where perception of visual displays is difficult. Controls should be coded by shape and spacing when they cannot be seen clearly.

\subsubsection{SUPPLEMENTAL LIGHTING}

General and supplementary lighting should be used as appropriate to insure that illumination is compatible with each task situation, and portable lights should be provided for personnel performing visual tasks in areas lacking fixed illumination.

It should be noted that portable lighting has the following advantages:

reduces total quantity of supplementary lighting fixtures

reduces maintenance time required 
reduces fixture deterioration when stored in controlled environment

often provides better lighting for specific tasks.

\subsubsection{EMERGENCY LIGHTING}

Emergency lighting should be provided for potential power failures in critical maintenance areas (Rigby, Cooper and Spickard, 1961).

\subsection{GUIDELINES FOR NOISE}

Noise can be defined as an auditory stimulus that does not provide information for the task at hand. In the industrial environment, noise can affect maintenance performance directly by making communication difficult and by covering up sounds that may be useful for trouble-shooting (McCormick and Sanders, 1982).

\subsubsection{GENERAL PRINCIPLES}

While noise cannot be completely avoided, high noise levels may impair hearing, hinder voice communication and interrupt the transmission of audio signals. Therefore, as a general rule, engineering control measures should be instituted wherever practical in design so that noise levels never exceed the limits recommended in Section 4.4.2. Where cumulative noise level approaches these limits, noise reduction can be achieved through equipment design (e.g., vibration mounts), enclosures for noise producing sources, sound absorbing materiais between the noise source and personnel, and sound attenuating devices (e.g., mufflers on engine exhausts, ear plugs for personnel) (Rigby, Cooper and Spickard, 1961).

\subsubsection{MAXIMUM RECOMMENDED EXPOSURES}

STEADY-STATE NOISE LIMITS. Maximum recommended exposures in personnel-occupied areas when hearing protection is not available are presented in Figure 4.2 (U.S. Department of Defense, 1981 a). Ear protection is recommended for 100 percent exposure when sound pressure levels exceed the 8 hour unprotected exposure time. Additional information regarding noise limits

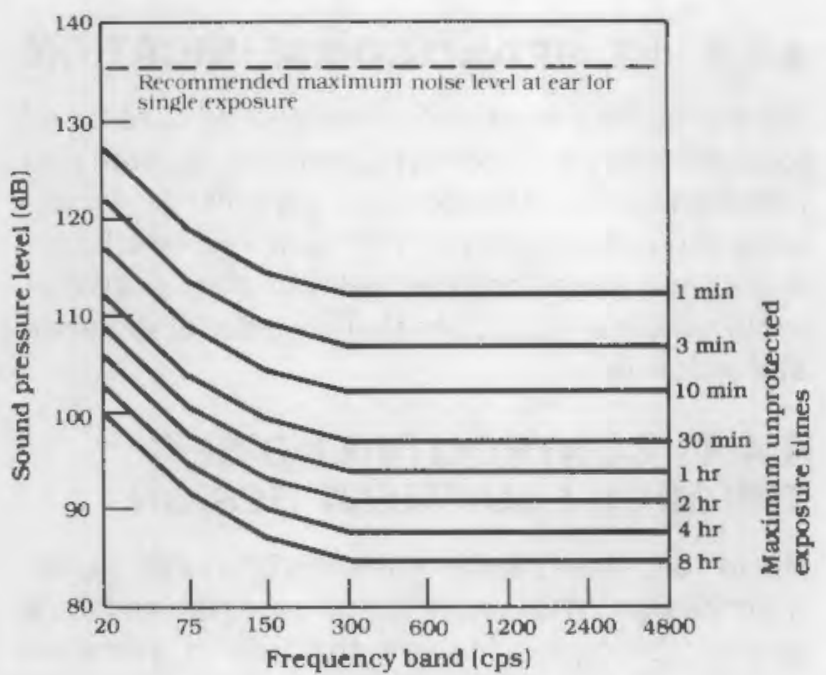

Figure 4.2. Permissible Noise Levels (from Rigby, Cooper and Spickard, 1961)

for categories of personnel occupied areas is available (U.S. Department of Defense, 1979).

IMPULSE NOISE LIMITS. The recommended maximum noise level at the ear for a single exposure is given in Figure 4.2. A single exposure consists of either a single pulse for non-repetitive systems (not more than one impulse per second) or a burst for repetitive systems (more than one impulse per second). For pressure levels above these limits hearing protection is strongly suggested based upon peak pressure levels, noise durations and expected number of exposures per day. Further information is available from U.S. Department of Defense (1979).

IOENTIFYING NOISE HAZARD AREAS. When steady-state equipment noise levels exceed 85 $\mathrm{dB}(\mathrm{A})$ or impulse noise exceeds $140 \mathrm{~dB}$ peak pressure level, noise hazard caution signs should be permanently posted on or near the equipment (see Section 9.3 on labelling). In addition, operation and maintenance manuals should discuss hearing protection requirements, type of protection necessary, noise levels and the distance at which $85 \mathrm{~dB}(\mathrm{~A})$ and $140 \mathrm{~dB}$ pressure levels will be encountered (U.S. Department of Defense, 1979). 


\subsubsection{NOISE AND COMMUNICATION}

Where feasible, workplace noise should be reduced to levels that permit direct (person-to-person) and telephone communication, and establish an acceptable acoustical work environment. Figure 4.3 provides guidance on the relationship between required vocal-effort, speaker-to-listener distance and noise level.

\subsubsection{CONTROLLING NOISE THROUGH EQUIPMENT DESIGN}

Noise reduction can be enhanced through equipment design. In this case the noise is reduced at its source. Examples include the use of vibration mounts, gaskets, proper balancing of equipment, mufflers or baffles on such parts as engine exhausts, and vents in high pressure systems.

\subsubsection{CONTROLLING NOISE THROUGH STRUCTURAL DESIGN}

Sources of noise may be separated from personnel by structures that reduce the transmission of noise. For example, absorbing materials on the walls of workspaces act as acoustical structures. Maintainability designs should ensure that such structures provide maximum noise reduction by reducing the amount of noise transmitted, by absorbing the noise, or both (see OSHA, 1980).

TRANSMISSION REDUCTION. The amount of noise transmitted depends primarily on the mass of the structures between the noise source and receiver (Figure 4.4 and Table 4.4). An example of transmission reduction is illustrated in Figure 4.5, where reduction is expected to be $70 \mathrm{~dB}$ from $6 \mathrm{in}$.

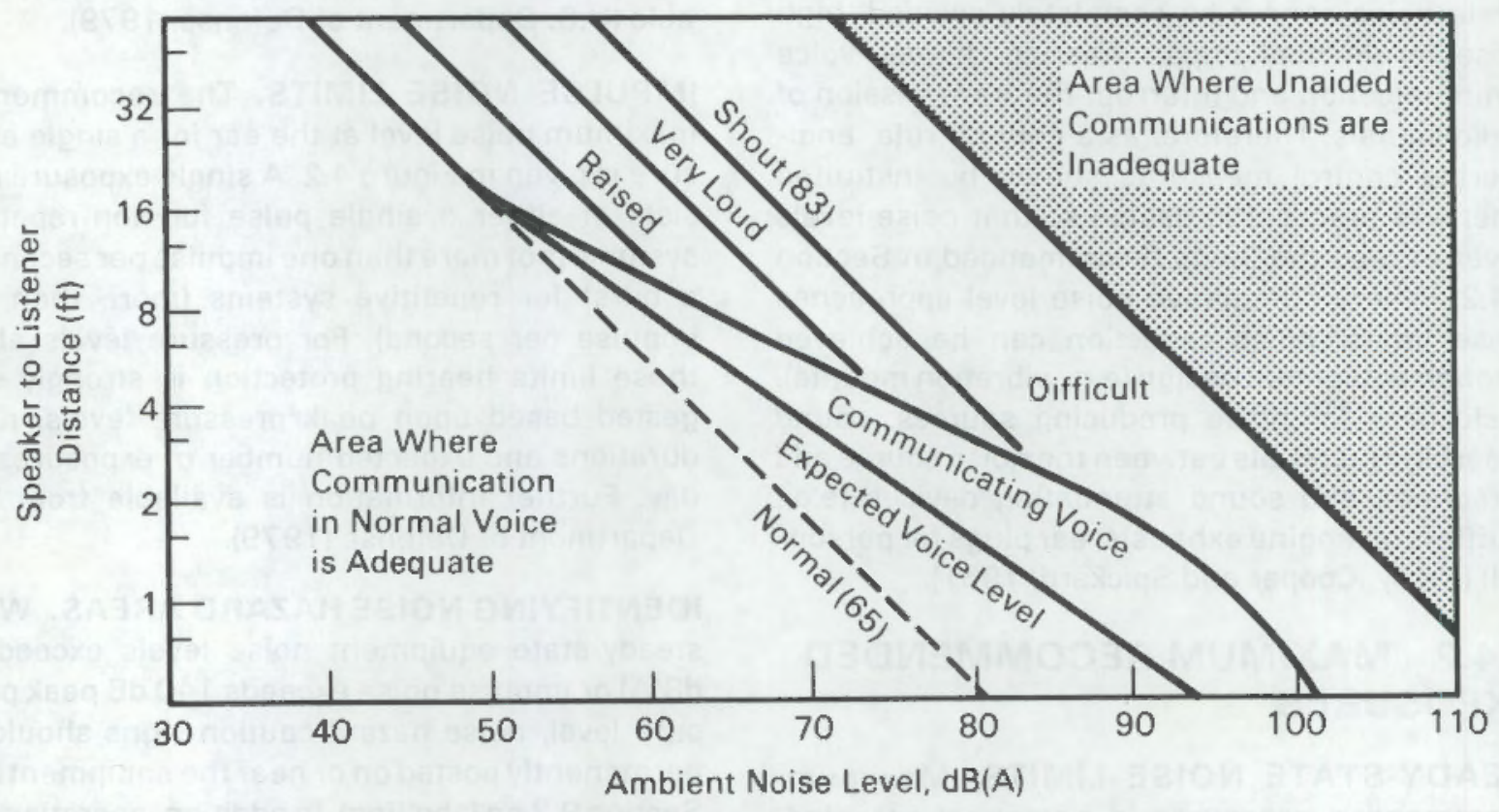

Figure 4.3. Permissible Distance Between a Speaker and Listeners for Specified Voice Levels and Ambient Noise Levels. (The levels in parentheses refer to voice levels measured one meter from the mouth.) (from U.S. Department of Defense, 1981 a) 


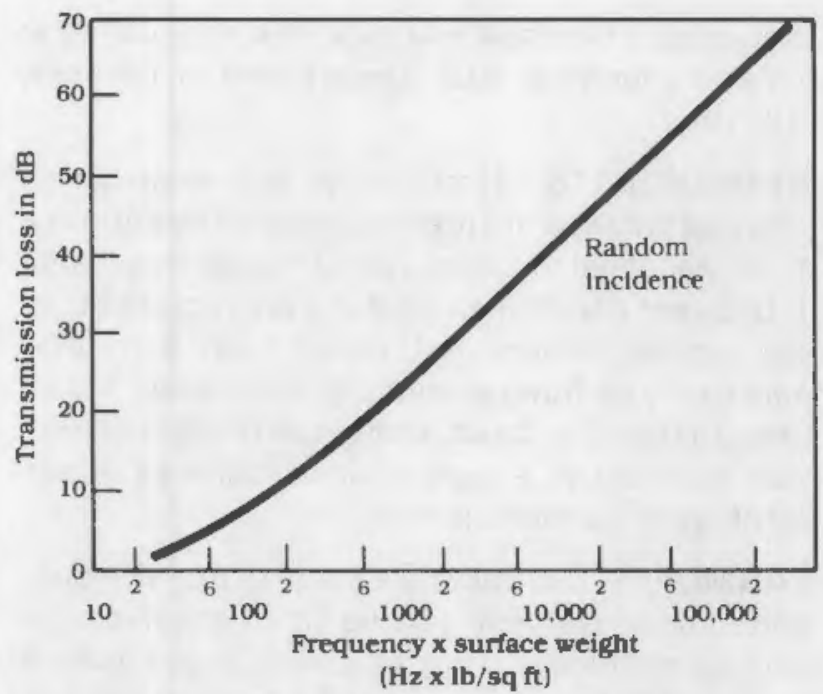

Figure 4.4 Transmission Loss for Solid Damped Partitions (see Table 4.4 for surface weight values) (from U.S. Air Force, 1980)

Table 4.4. Weights of Common Building Materials ${ }^{1}$

\begin{tabular}{l}
\hline \multicolumn{1}{c}{$\begin{array}{c}\text { Murface Weight, } \\
\text { lb/sq ft/(inch thickneas) }\end{array}$} \\
\hline Brick
\end{tabular}

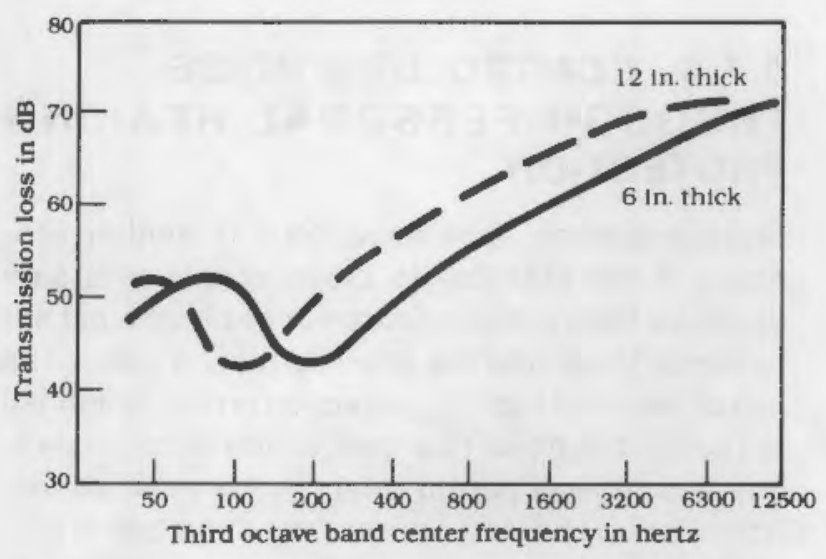

Figure 4.5. Transmission Loss for Typical Concrete Wali

concrete walls. Door and window seals, ventilating ducts, electrical conduits, and plumbing are the limiting components in structures designed for high transmission loss. In addition, resonances reduce the transmission loss at particular frequencies. Particular attention should be made to these acoustical leaks to obtain a reasonable noise reduction from the structure (U.S. Air Force, 1980).

SOUND ABSORBERS. While sound-absorbing treatments can improve noise levels, the capabilities of such treatments are often overestimated. Characteristics include:

Sound absorbers absorb sound only in the room or compartment in which they are located and will not reduce the sound transmitted.

They are generally made of lightweight materials, and are most effective in hard-surfaced rooms.

Clothing will absorb sound, so consideration should be given to whether a large number of people will occupy the room.

Sound-absorbing treatment on the walls will be most effective in rooms with high surface-tovolume ratio. 


\subsubsection{CONTROLLING NOISE THROUGH PERSONAL HEARING PROTECTION}

Situations often arise in which it is neither economical nor practical to move people to a safe distance from a noise source or to place a barrier between them and the source. In such cases, the use of personal hearing protection is recommended to reduce the noise to a level which is not hazardous and/or will permit effective communication. Attenuation characteristics of various types of personal hearing protections (Army) are shown in Table 4.5 (U.S. Department of Defense, $1981 \mathrm{~b}$ ).

COMMUNICATION IMPROVEMENT. Hearing protectors will often improve person-to-person and loudspeaker-to-person communication in noise. The same speech signal-to-noise ratio reaches the ear with and without protection in such cases, but the use of protection may cause the speech signal to reach the ear at a level in the optimum range for speech intelligibility (i.e., overall RMS level of about $70 \mathrm{~dB}$ ). This effect may, therefore, influence the selection of hearing protection for use in a given situation. It would be undesirable to recommend a highly effective hearing protector for use in a relatively low noise level, for example, since this might reduce the speech signal to below the optimum speech level (Ibid.).

EARPLUGS. Earplug inserts are available in two forms: (1) preformed rubber or plastic plugs supplied in up to seven sizes, and (2) disposable plugs, such as wax-impregnated cotton, or "glass down" (a very fine, non-irritating glass wool). To be most effective, earplugs should be:

properly fitted for size,

properly inserted each time they are used,

tight, and

kept clean to minimize the possibility of ear infections (Ibid.).

If it is necessary to protect hearing from an intense pure tone, earplugs can be designed that are effective against the offending frequency only. These devices may provide up to $25 \mathrm{~dB}$ attenuation at the frequency of interest and very little attenuation at other frequencies (U.S. Department of Defense, 1981 b).

SEMI-INSERTS. Semi-inserts are available in one size only and are pressed against the entrance to the ear canal by a light, spring-loaded headband. If frequent donning and doffing are required they are very convenient and, unlike bulky earmuffs, may easily be hung around the neck when not in use. On the other hand, semi-inserts may not provide as effective a seal against sound as either earplugs or earmuffs (lbid.).

EARMUFFS. Earmuffs are made in one size only and almost everyone can be fitted satisfactorily with little difficulty. They attenuate sound as well as, or better than, earplugs at high frequencies, but are slightly poorer than plugs below $1 \mathrm{kHz}$. The primary disadvantages of earmuffs are their bulk and relative expense. They do not, however, entail the fitting and insertion problems of earplugs. Another advantage, in certain situations, is that a supervisor can readily determine from a distance that all of his personnel are wearing their hearing protectors (Webster and Rubin, 1962).

HELMETS. Helmets can provide more attenuation than the aforementioned devices if they cover the greater portion of the head. The acoustical importance of such a helmet increases when the sound-pressure level reaches a point where boneconducted sound transmission through the skull becomes a controlling factor. The maximum attenuation which can be provided by a plug, muff or semi-insert is about $35 \mathrm{~dB}$ at $250 \mathrm{~Hz}$ and is greater at higher frequencies. After reductions of this magnitude, the remaining sound is conducted through the bones of the skull directly to the inner ear (U.S. Department of Defense, 1981b)

AMPLITUDE-SENSITIVE (NON-LINEAR) EARPLUGS. These experimental plugs have been designed to provide high attenuation against high impulse noise level and low attenuation at lower energy levels, hence the term "non-linear." Lower level sounds are allowed to pass into the ear since they do not create as much turbulence (Ibid.). 
Table 4.5. Attenuation' of Hearing Protectors, in Decibels (from U.S. Department of Defense, 1981b)

\begin{tabular}{|c|c|c|c|c|c|c|c|c|c|}
\hline \multirow[b]{2}{*}{ Name } & \multicolumn{9}{|c|}{ Frequency (Hz) } \\
\hline & 125 & 250 & 500 & 1000 & 2000 & 3000 & 4000 & 6000 & 8000 \\
\hline \multicolumn{10}{|c|}{ Insert (e.g., ear plugs) } \\
\hline E-A-R & 31 & 32 & 33 & 33 & 37 & 42 & 44 & 44 & 42 \\
\hline Fingers $^{2}$ & 32 & 29 & 27 & 29 & 31 & 26 & 32 & 33 & 35 \\
\hline Wax Cotton & 24 & 23 & 24 & 27 & 39 & 41 & 42 & 36 & 33 \\
\hline V51R & 23 & 21 & 23 & 25 & 33 & 34 & 31 & 28 & 30 \\
\hline Silaflex & 22 & 18 & 20 & 21 & 29 & 43 & 43 & 41 & 34 \\
\hline Triple Flange & 22 & 18 & 20 & 21 & 29 & 34 & 34 & 37 & 35 \\
\hline \multicolumn{10}{|l|}{ Sound Sentry } \\
\hline $5000-B$ & 23 & 19 & 17 & 18 & 32 & 35 & 32 & 30 & 26 \\
\hline $5000-W$ & 20 & 16 & 16 & 16 & 28 & 30 & 28 & 30 & 25 \\
\hline \multicolumn{10}{|c|}{ Circumaural (e.g., helmets) } \\
\hline \multicolumn{10}{|c|}{$\mathrm{DH}-132 \mathrm{Std}^{3}$} \\
\hline Gentex & 15 & 14 & 24 & 28 & 30 & 35 & 35 & 35 & 30 \\
\hline $\mathrm{SPH}-4 \mathrm{Std}^{3}$ & 16 & 14 & 25 & 24 & 30 & 40 & 43 & 44 & 36 \\
\hline \multicolumn{10}{|l|}{ Wilson $365^{4}$} \\
\hline $\mathrm{OTH}^{5}$ & 17 & 24 & 33 & 44 & 4 & 37 & 46 & 39 & 35 \\
\hline \multicolumn{10}{|l|}{ Sound } \\
\hline \multicolumn{10}{|l|}{ Stifler } \\
\hline Bilsom OTH & 12 & 15 & 24 & 37 & 35 & 39 & 41 & 34 & 27 \\
\hline \multirow{2}{*}{$\begin{array}{ll}\text { UF1 } & \begin{array}{l}\text { UTC }^{6} \\
\text { BTH }^{7}\end{array}\end{array}$} & 10 & 11 & 20 & 33 & 32 & 37 & 33 & 31 & 26 \\
\hline & 8 & 7 & 18 & 30 & 37 & 40 & 42 & 34 & 29 \\
\hline David Clark OTH & 16 & 20 & 30 & 42 & 36 & 38 & 42 & 37 & 34 \\
\hline \multirow{2}{*}{$\begin{array}{l}\text { E-310 BTH } \\
\text { UTC }\end{array}$} & 6 & 6 & 18 & 26 & 31 & 32 & 39 & 34 & 30 \\
\hline & 6 & 2 & 12 & 24 & 28 & 32 & 39 & 35 & 26 \\
\hline American OTH & 12 & 18 & 26 & 38 & 38 & 34 & 38 & 34 & 36 \\
\hline Optical BTH & 7 & 9 & 19 & 30 & 37 & 33 & 34 & 32 & 27 \\
\hline 1720 UTC & 10 & 11 & 21 & 32 & 34 & 32 & 32 & 32 & $2 B$ \\
\hline \multicolumn{10}{|c|}{$\begin{array}{l}\text { 1. Mean real-ear attenuation data provided by USAHEL (ASA standard Z24.22-1957) unless otherwise noted. } \\
2 \text { Attenuation data from HEL, Technical Mermorandum 2-68, dated January } 1968 \text {. } \\
3 \text { Minimum acceptance values per purchasing contract. These are not mean real-ear attenuation values. } \\
\text { 4 Wright-Patterson Air Force mean real-ear attenuation data. }\end{array}$} \\
\hline
\end{tabular}




\section{Physical Environment}

FINGERS. Fingers, when used to depress the tragi over the ear canal entrance, provide better attenuation (especially at low frequencies) than the V51-R earplug. Therefore, if both hands are free during a period of intense, short-duration noise, the fingers or palms should not be overlooked as a means of protecting hearing. It should be emphasized, however, that the fingers are not considered adequate as personal hearing protection in normally high noise environments (lbid.).

\subsubsection{USE OF MULTIPLE HEARING PROTECTION DEVICES}

Where very intense noise levels exist, it may be desirable to wear both earplugs and earmuffs. The total sound attenuation does not, of course, equal the sum of the individual protector attenuations, but this combination will ordinarily provide increased attenuation at most frequencies, with particular benefit being derived at the low frequencies (Webster and Rubin, 1962).

\subsection{GUIDELINES FOR VIBRATION}

Increased levels of vibration affect maintenance in that equipment subjected to vibration will likely require more frequent maintenance and the maintainer exposed to vibration will likely experience degradation in task performance. Performance of the maintainer is adversely affected to the degree that vibration:

can at high levels cause critical bodily damage

makes dials and lettering difficult to read

makes tools, controls and other objects difficult to manipulate

contributes to increased fatigue, nervousness and irritability, and, thus, to maintenance errors or oversights (Rigby, Cooper and Spickard, 1961).
Personnel are most affected by vibrations transmitted through the longitudinal axis of the body, head to toe, regardless of body position. Vibration can be reduced and controlled by:

isolating equipment from vibration sources with shock mountings, fluid couplings, etc.

providing proper balance of rotating elements of equipment

providing damping materials or cushioned seats for standing or seated personnel (Rigby, Cooper and Spickard, 1961).

MANIPULATING CONTROLS. Where whole body vibrations of the human operator or parts of the body are not a factor, equipment should be designed so that oscillations will not impair human performance with respect to control manipulations or the readability of numerals or letters. Equipment should be designed to prevent vibrations in the shaded area of the upper curve of Figure 4.6 (Ibid.).

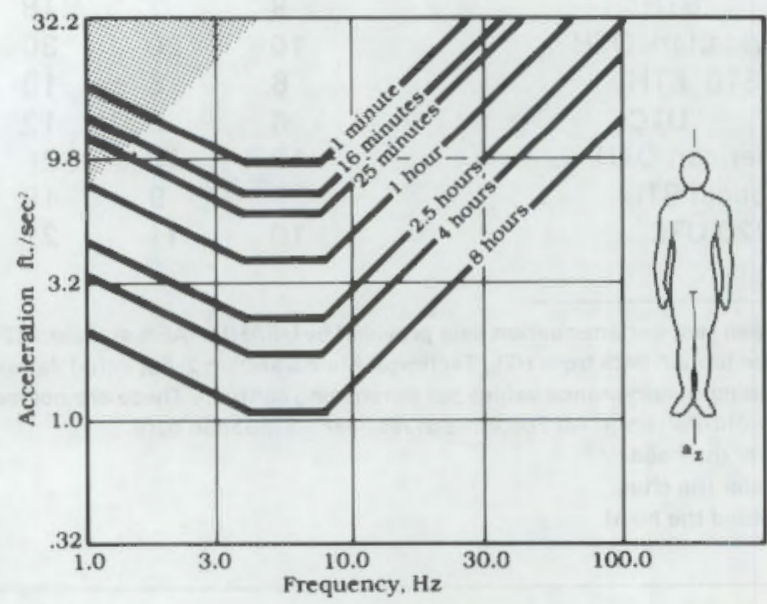

Figure 4.6. Vibration Exposure Criteria for Longitudinal Directions (from U.S. Department of Defense, 1981 a) 


\subsection{GUIDELINES FOR TEMPERATURE AND HUMIDITY}

The human body continually generates heat as a consequence of metabolic activity. Since the metabolic process is continuous, the body is continually in the process of trying to maintain thermal equilibrium with its environment through the heat exchange process. Factors that affect this process include air temperature, air humidity, air movement, and radiant temperature. Where possible, these factors should be controlled with heating, ventilation and air conditioning, so that the comfort and efficiency of maintenance personnel will be maximized.

\subsubsection{GENERAL PRINCIPLES}

Temperature and humidity affect both the need for maintenance and the ability to perform maintenance. The plant design engineer should ensure that:

the environmental conditions in which the maintenance technician must work are within tolerable limits, as defined in the next section

the effects of temperature on maintenance are taken into consideration (Rigby, Cooper and Spickard, 1961).

\subsubsection{TEMPERATURE EXTREMES}

In environments outside the comfort zone, body heat content changes and thermoregulatory mechanisms come into play. If an environment is such that these cannot completely compensate, the body is in a transient thermal state, and after a time will reach a core temperature at which it will no longer function usefully. The time required for a thermally comfortable man to reach a state of dysfunction is the tolerance time for that particular environment. Potential dynfunction occurs at a core temperature about 4 degrees $\mathrm{F}$ above or below the normal 98.6 degrees F (U.S. Air Force, 1980).

TOLERANCE. Tolerance can be determined in terms of core temperature rise, body heat storage (BHS) or time to tolerance with respect to an environmental index (Ibid.; AFSC 1-3 DN 3C2, Par 2 and 3). Although a rough estimate of BHS rate can be made from heat transfer equations given in U.S. Air Force, 1980 (AFSC 1-3 DN 3C1, Par 1), an easier method is to use tolerance time graphs with respect to an appropriate environmental index (see Figures 4.7, 4.8, and Table 4.6. If a significant radiative or wind factor exists, the best index to use is the wet bulb globe temperature (Figure 4.8 ). If temperature and humidity are the significant factors, the wet/dry index is a good predictor. In the cold, dry bulb temperature must be used.

TOLERANCE LIMITS. Tolerance limits are usually defined in two ways: maximum allowable internal temperature and tolerance times with respect to various environmental indices.

Typically, core temperatures of 102 degrees $F$ for resting individuals and 104 degrees $F$ for individuals at hard labor should not be exceeded. The comfort zone chart shown in Figure 4.7 is one example

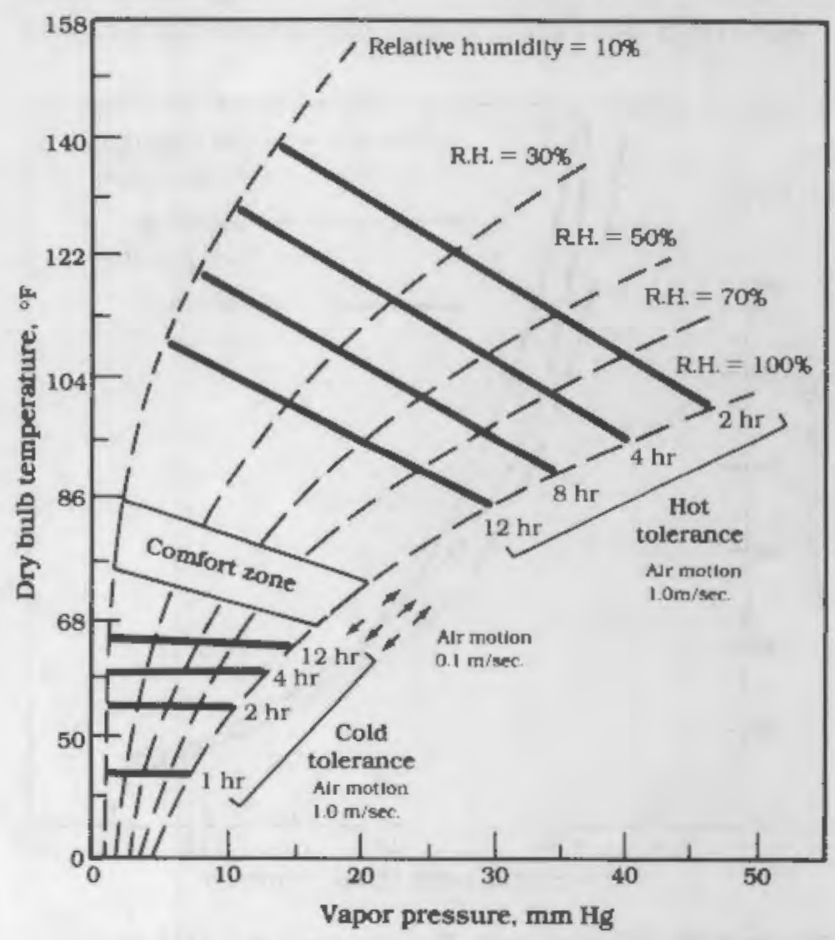

Figure 4.7. Environmental Requirements for Human Comfort (from U.S. Air Force, 1980) 
of a tolerance time graph. Tolerance time decreases rapidly between 100 degrees $F$ and 104 degrees $F$ stress index temperature (Figure 4.8). Tolerance times are discussed in U.S. Air Force (1980).

ACCLIMATIZATION. Acclimatization has an important effect on tolerance time. An environment that is intolerable for an unacclimatized working man may be tolerable for increased time periods to an acclimatized one (Ibid., 1980). Acclimatization can be used effectively to increase maintenance time in hot or cold environments. It takes approximately 1 to 3 weeks in a progressive exposure program to acclimate to a hot environment.

COLD ENVIRONMENTS. In cold weather (e.g., at intake water source, outside turbine decks), especially where moderate to heavy winds can be expected, the overriding concern is that only short periods of work can be accomplished before workers need to warm themselves. This is a serious factor in considering whether or not to supply movable shelters with heaters for performing critical field work (U.S. Air Force, 1980). Within permanent and

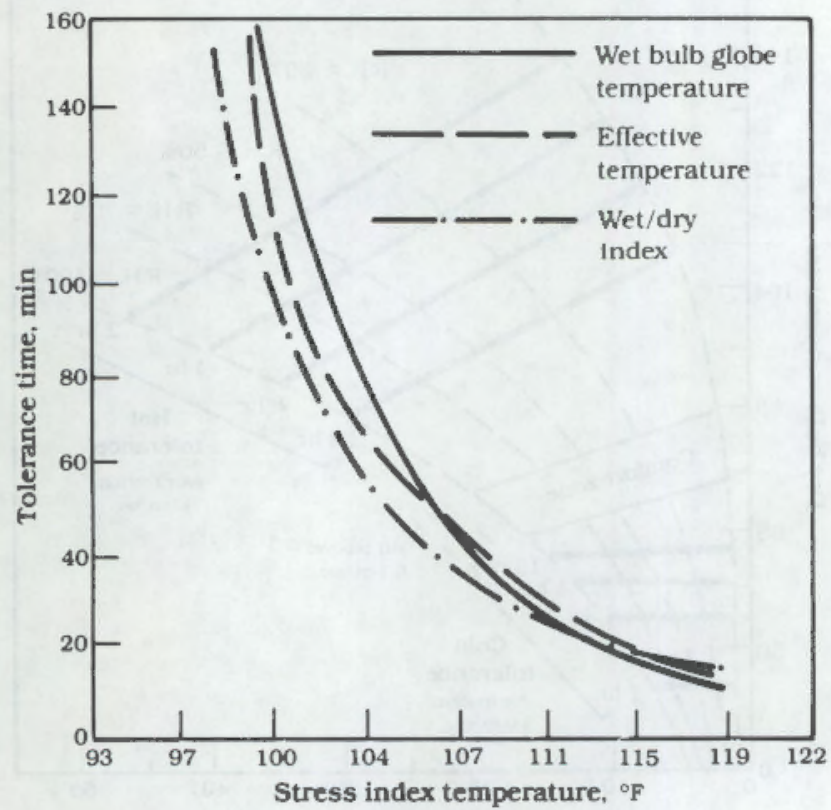

Figure 4.8. Human Heat Tolerances (from U.S. Air Force, 1980)
Table 4.6. Thermal Variables for Normal Men (from U.S. Air Force, 1980)

\begin{tabular}{|c|c|c|c|}
\hline Variable & $\begin{array}{l}\text { Normal } \\
\text { Value }\end{array}$ & $\begin{array}{c}\text { Normal } \\
\text { Range }\end{array}$ & Condition \\
\hline Weight, kg & $70-80$ & $55-110$ & \\
\hline $\begin{array}{l}\text { Surface area } \\
\text { (BSA), } \mathrm{m}^{2}\end{array}$ & $1.7-1.8$ & $1.5-2.2$ & \\
\hline $\begin{array}{l}\text { Core temp. } \\
\left(T_{c}\right),{ }^{\circ} \mathrm{C}\end{array}$ & 37 & $\begin{array}{l}36.5-37.5 \\
35 \cdot 39\end{array}$ & $\begin{array}{l}\text { Normal } \\
\text { Tolerance }\end{array}$ \\
\hline $\begin{array}{l}\text { Skin temp. } \\
\left(T_{s}\right),{ }^{\circ} \mathrm{C}\end{array}$ & $32-33$ & $\begin{array}{l}31-34 \\
0-47\end{array}$ & $\begin{array}{l}\text { Normal } \\
\text { Tolerance }\end{array}$ \\
\hline $\begin{array}{l}\text { Skin insula- } \\
\text { tion, clo }\end{array}$ & $0.3-0.6$ & $0.2-1.0$ & $\begin{array}{l}\text { Depending on body fat } \\
\text { and blood circulation }\end{array}$ \\
\hline $\begin{array}{l}\text { Sweat } \\
\text { production, } \\
\mathrm{g} / \mathrm{hr}\end{array}$ & Negligible & $\begin{array}{l}0 \\
1000 \\
2000\end{array}$ & $\begin{array}{l}\text { Comfort } \\
\text { Maximum for resting } \\
\text { man } \\
\text { Maximum for acclima- } \\
\text { tized man working } \\
\text { maximally } \\
\text { (Evaporation can be } \\
20 \%-80 \% \text { of production, } \\
\text { depending on humidity } \\
\text { and air movement) }\end{array}$ \\
\hline $\begin{array}{l}\text { Metabolic } \\
\text { heat produc- } \\
\text { tion (MR). } \\
\mathrm{kcal} / \mathrm{hr}\end{array}$ & $100-150$ & $\begin{array}{l}75 \\
100-200 \\
200-400 \\
400-550 \\
550-600\end{array}$ & $\begin{array}{l}\text { Sleep } \\
\text { Light work } \\
\text { Moderate work } \\
\text { Heavy work } \\
\text { Highest possible } \\
\text { continuous workload } \\
\text { for normal men }\end{array}$ \\
\hline $\begin{array}{l}\text { Skin } \\
\text { emissivity (E) }\end{array}$ & & 1.0 & Infrared \\
\hline $\begin{array}{l}\text { Skin } \\
\text { reflectivity } \\
\text { infrared } \\
\quad \text { solar }\end{array}$ & & $\begin{array}{l}0 \\
35 \% \\
20 \%\end{array}$ & $\begin{array}{l}\text { White skin } \\
\text { Black Skin }\end{array}$ \\
\hline
\end{tabular}


semi-permanent facilities, provisions should be made to maintain an effective temperature (ET) not less than 64 degrees $F(18$ degrees $C$ ) unless workload or extremely heavy clothing dictate otherwise. The ET is a calculated value which equals the temperature of still, saturated air which would induce the same sensation as the conditions under examination. Heating systems should be designed so that hot air discharge is not directed on personnel (U.S. Department of Defense, 1981a).

HOT ENVIRONMENTS. Under high-temperature working conditions, performance degradation can be controlled through rotating personnel, decreasing workloads, providing protective equipment or microclimatic adjustments and acclimatization. Adequate water should be available for personnel and individuals should be alerted to problems of dehydration, fatigue, muscle cramps, and symptoms of heat stroke, etc.

\subsubsection{VENTILATION}

Adequate ventilation should be assured by introducing a minimum of 30 cubic $\mathrm{ft}$ per minute per person into any personnel enclosure; approximately two thirds should be outside air.

AIR VELOCITY. Air should move past personnel at a velocity not more than $100 \mathrm{ft}$ per minute $-65 \mathrm{ft}$ per minute if possible.

SPECIAL CONDITIONS. Under conditions where chemicals or radioactivity are present, ventilation requirements should be modified as required (see Section 4.7). Ventilation or other protective measures should be provided to keep gases, vapors, dust, and fumes within the limits specified in the American Conference of Governmental Industrial Hygienists Threshold Limit Values, (U.S. Department of Defense, 1981a).

INTAKE. Intakes for ventilation systems should be placed so that the introduction of contaminated air from such sources as exhaust pipes, etc. will be minimized (Ibid.). See also ACGIH, 1983; Clayton and Clayton, 1978 and Mackison et al., 1981 for additional information.

\subsubsection{ENVIRONMENTAL CONTROL WHERE PROTECTIVE CLOTHING IS WORN}

In areas where special protective clothing or personal equipment are required and worn, a comfort microclimate between 68 degrees $F, 7.5$ in, water ambient water vapor pressure and 95 degrees $F$, 1.6 in. ambient water vapor pressure is desirable. Where possible, these conditions should be maintained by the HVAC system (U.S. Department of Defense, 1981a).

\subsection{GUIDELINES FOR RADIATION}

The radiation environment within a nuclear power plant probably impacts maintenance more than any other environmental concern. Special protection requirements for maintenance personnel can impact the efficiency of maintenance within radiation zones. Therefore, the designer can influence how well a plant is maintained by following sound design practices for the facility, equipment, shielding, and tools where radiation is present.

\subsubsection{FACILITY AND EQUIPMENT CONSIDERATIONS}

Changes made in shielding or facility layout after construction has begun are often difficult to accomplish and cannot limit dose equivalent rates to the desired level without prohibitive cost and loss of usable work space. Thus, shielding, containment, confinement and work-space should be designed conservatively and should take possible future increases in workload into account (Pacific Northwest Laboratory, 1970).

COMMUNICATION. When designing or modifying a facility to improve maintenance capabilities, designers should consider ways of facilitating communication while minimizing exposure to radiation. Alarm and warning systems should be carefully evaluated.

REMOTE COMMUNICATION. Adequate remote communication, including closed circuit TV, should be incorporated so that the need for direct supervision of the maintenance personnel will be reduced. 


\section{Physical Environment}

This will reduce the exposure time of supervisors, operators, and quality control inspectors (Seminara, 1982).

WORKSPACE. Designers should take care to provide adequate room for workshops, storage and traffic routes in areas where exposure to contamination or radiation is a possibility (Seminara, 1982).

SERVICING AREAS. Equipment and components requiring frequent servicing should be placed in areas that are either free of radiation or in the lowest practicable radiation field(U.S. Department of Energy, 1981a). Waste storage areas should include step-off pads and contaminated garment collection barrels.

EQUIPMENT ACCESS. Permanent or fixed access should be provided to equipment located in radioactive work sites to eliminate radiation exposure incurred in erecting temporary access provisions such as ladders and scaffolding (Seminara, 1982).

COMPATIBILITY WITH PROTECTIVE GEAR. Equipment in radiation zones should be designed to be serviceable by maintenance personnel that are encumbered by protective garments and associated gear. In addition, openings in equipment should be provided for convenient ingress/egress by personnel who are encumbered by protective gear (lbid.).

LOCATIONS. In designing equipment to aid maintenance, plan to place equipment so that personnel can perform maintenance easily and quickly in radiation zones. For example, design for quick disconnect fasteners (Seminara, 1982).

\subsubsection{TOOL AND SHIELDING CONSIDERATIONS}

Special tools and shielding, both permanent and portable, can be very effective in reducing exposure to radiation.
DESIGN. When designing for maintainability, provide special tools, remotely controlled handles, and similar devices that will separate maintenance personnel from sources of radiation as much as possible (Seminara, 1982).

STORAGE. Adequate storage for tools and spare parts should be conveniently located within the zones to ease personnel requirements and reduce clutter in the work area (lbid.).

ACCESS. Where possible, shielding should be designed so that the repairman's ability to reach components or work effectively is minimally affected and the repairman's exposure time is reduced (Ibid.).

\subsubsection{PROTECTIVE GARMENTS}

Protective garments are necessary for maintenance personnel working in a contaminated environment. Specifically, protective garments should provide for multistress environments, e.g., heat and radiation. Laundering facilities or disposable clothing should also be provided, so that an adequate supply of clean, decontaminated protective garments is available, especially during peak work periods (Seminara, 1982).

MARKING. Protective clothing sizes should be clearly identifiable (U.S. Nuclear Regulatory Commission; 1981).

TRAINING. Operators should be well practiced in donning protective equipment (Ibid.).

PROCEDURES. Instructions for donning, doffing, and controlling personal protective equipment should be provided (Ibid.).

REPAIR. When applicable, equipment should be designed so that it can be removed, replaced, and repaired by personnel wearing personal and special purpose clothing and equipment (U.S. Department of Defense, 1981 a). 


\section{Chapter 5 LOADS AND FORCES}

This chapter addresses muscle strength needed to perform tasks, isolating the special cases of lifting and force application involved in maintenance tasks.

Muscle strength is defined as a single maximum voluntary effort by an isolated muscle group under given conditions. The extent of the force produced by this muscle group depends on such direct factors as muscle cross section, cardiovascular response, muscle fiber tension during the contractile phase and the mechanical advantage within the system. With the exception of muscle cross section, all factors can be altered with a change in joint position (Van Cott and Kinkade, 1972). In addition, biological, environmental and occupational factors affect muscle strength and physical work capacity (Section 5.3). Consideration of muscle strength needed to perform a task can enhance maintainability.

\subsection{PROBLemS}

Problems of maintainability at nuclear power plants with respect to human strength include location of equipment and provisions for handling equipment (Badalamente et al., 1982; Looram et al., 1981 and Seminara and Parsons, 1981). Specific concerns include the need to perform maintenance tasks which involve lifting excessive weights or applying excessive forces.

When equipment is placed in areas that are inaccessible from normal work positions or where equipment handling aids are not available, personnel may be exposed to situations that require excessive force or lifting to complete simple maintenance tasks.

Detailed guidelines have been developed for maximum forces which should be needed to push, pull, turn and lift a variety of controls and loads (Sandia Labs, 1978). These guidelines are included here with the reminder that individuals differ substantially with respect to physical strength. Unless personnel are specially selected, equipment design should allow weaker individuals of the population to perform maintenance tasks effectively (Murrell, 1969).
In addition to force capacities, other factors should be recognized. As an example, the appropriate resistance for controls may depend primarily upon whether the operator is sitting or standing, or on the position of the control relative to the operator. In addition, resistance for controls may be affected by the presence and type of gloves worn by the operator and by bracing or restraining features that restrict or assist operator movement (Sandia Labs, 1978).

\subsection{SAFETY IMPACT}

If nuclear power plants are to be operated safely, demands imposed by tasks should not exceed the physical capability of personnel.

Whenever physical limitations are ignored, adverse effects may be witnessed in the integrity of equipment, timely completion of tasks and in the safety of personnel.

To meet industrial needs of equipment maintenance, timeliness and safety, access to appropriate tools should be provided. In addition, plans should call for a sufficient number of maintenance personnel to execute tasks during emergencies. Equipment failures often result when personnel attempt to improvise force applications for turning valves or torquing bolts; such failures and safety hazards may be eliminated by appropriate planning.

Incapacity of personnel arises from two fundamental causes relating to forceful exertions: 1) sudden exercise of force and 2) continuous exercise of some muscles over long periods of time (Murrell, 1969). Because resistance levels for operating or maintaining equipment can affect comfort and efficiency, resistance levels should be set with regard to the capabilities of the weakest personnel. Performance requirements should be set below the upper limits of physical ability in order to eliminate fatigue and a lower level of performance (Van Cott and Kinkade, 1972). Tasks that require heavy physical activity may require rest pauses at appropriate intervals, both for the sake of safety and efficiency. 


\subsection{GENERAL CONSIDERATIONS FOR ESTABLISHING GUIDELINES}

Data included in this section indicate trends and orders of magnitude of human force output only. Muscle strength capability is situation-specific and varies even within the same individual. Because muscle strength is influenced by sex, age, body size, physical condition, occupational constraints, motivation and other factors, general data cannot be considered as universally valid (Van Cott and Kinkade, 1972).

BIOLOGICAL FACTORS. Biological factors affecting muscle strength and endurance that should be taken into consideration when designing work tasks include age, sex, physical condition and body stature. Typical examples of biological factors affecting work performance are as follows:

Table 5.1 provides suggested weight limits as a function of age and sex. This suggests that, on the average, a woman's strength is about twothirds that of a man and that both men and women reach a maximum strength in the twenty to thirty-five year range.

An endurance curve illustrating the relationship between percent of maximum strength and time is given in Figure 5.1. This suggests that tasks requiring sustained muscular efforts should be designed to an exertion level of under $25 \%$ of an individual's maximum strength (Kroemer, 1970).

Table 5.1. Weight Limits (lb) (McCormick and Sanders, 1982)

\begin{tabular}{ccc}
\hline Age & Male & Female \\
\hline $14-16$ & 33 & 22 \\
$16-18$ & 42 & 26 \\
$18-20$ & 52 & 32 \\
$20-35$ & 55 & 33 \\
$35-50$ & 45 & 29 \\
Over 50 & 36 & 22 \\
\hline
\end{tabular}

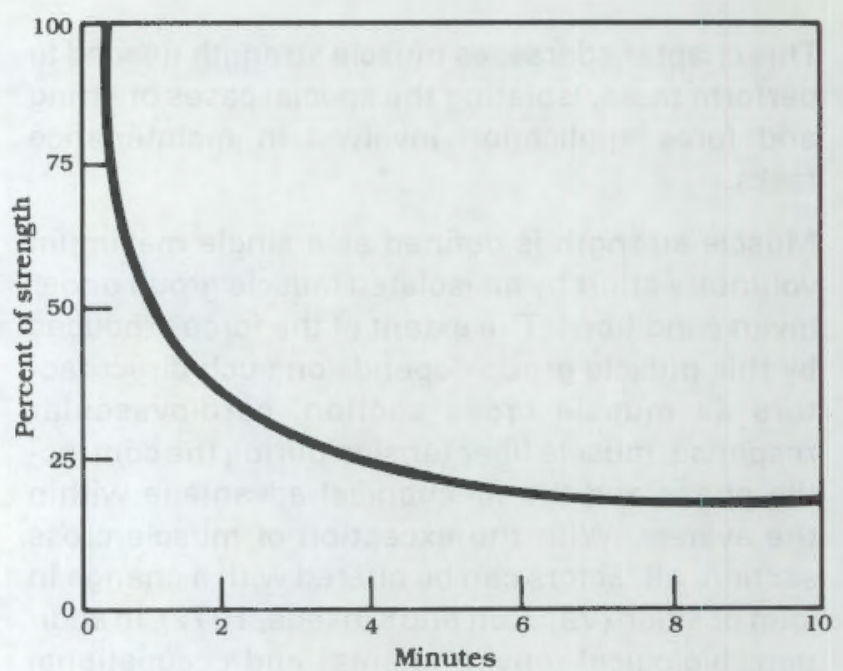

Figure 5.1. Endurance Time Expressed as a Function of Force Required (From Kroemer, 1970)

ENVIRONMENTAL FACTORS. The following environmental factors should be taken into consideration when establishing specific tasks in and around nuclear power plants:

High ambient temperatures which reduce endurance for muscular work can be countered through use of protective clothing with capabilities for cooling maintenance personnel.

High humidity can limit evaporative heat loss and may also adversely affect endurance for muscular work. Personnel will experience more difficulty working at high temperatures if the humidity is high.

The effects of low ambient temperatures experienced during exterior plant maintenance (e.g., intake fouling at water sources, maintenance at turbine decks under temporary covers) can be countered with protective clothing to prevent heat loss.

Protective clothing used for both high and low ambient temperature conditions can severely impair task performance. Tasks, equipment and clothing should be designed to produce compatibility. 
Comfort zones and tolerance limits have been established for combined temperature and humidity conditions (see Figure 4.6) and can be used as guidelines.

OCCUPATIONAL FACTORS. Occupational factors affecting muscle strength and endurance include psychological stress as well as physical constraints. Examples of factors which should be accommodated by the task and equipment include:

information overload, vigilance, danger or confinement. These sources of psychological stress can result in decreased output (McCormick and Sanders, 1982).

Body positions or constraints imposed on personnel by working conditions, equipment design or equipment locations can limit the range of motion or reduce dynamic balance, and thus can reduce potential strength output (Ibid.).

OTHER CONSIDERATIONS. Tasks and equipment which assume the application of human muscular force should also take the following factors into consideration:

the number of persons involved in a given task the parts of the body that actually apply forcee.g., back, arms, etc.

the nature of the task required-e.g., lifting, carrying, etc.

the frequency with which the task must be accomplished

the distance over which force must be exerted

equipment features that are available or must be supplied to complete the task-e.g., handles, carts, dollies, lifts, etc. (Rigby, Cooper and Spickard, 1961).

REDUCING RECOMMENDEDVALUES. Recommended values should be reduced if:

the object is very difficult to handle (e.g. bulky, slippery, etc.).

access and work space are less than optimum the required force must be applied continuously for more than one minute

the object must be finely positioned or delicately handled

the task must be repeated frequently (e.g., many times on a given day) (lbid.).

INCREASING RECOMMENDED VALUES. Recommended values may be slightly increased if:

lifting yoke or other special harness will be used the object is unusually easy to handle

the required force must be applied infrequently or for a few seconds only

suitable support is provided for the working body parts (Rigby, Cooper and Spickard, 1961).

\subsection{GUIDELINES FOR LIFTING LOADS}

General Guidelines for lifting loads should include the following:

Objects lifted infrequently and through a small range of motion by one person should not exceed $75 \mathrm{lb}$.

Objects lifted frequently or over moderate distances by one person should not exceed $40 \mathrm{lb}$.

Portable equipment should not exceed $14 \mathrm{lb}$. (Rigby, Cooper and Spikard, 1961).

In general, weight limits specified for men should be reduced by one-third for females (U.S. Department of Defense, 1981a).

Modules or other removable assemblies should be designed so that rapid and easy removal and replacement can be accomplished by one person, two persons, or handling equipment, in that order of preference (Rigby, Cooper and Spickard, 1961).

\subsubsection{ONE-PERSON LIFTS}

WEIGHT LIMITS. The weight limits in Table $\mathbf{5 . 2}$ should be used as the maximum values for determining the design weight of items requiring one 
Table 5.2. Design Weight Limits for Male Personnel (from U.S. Department of Defense, 1981)

\begin{tabular}{cc}
\hline $\begin{array}{c}\text { Height of Lift } \\
\text { from Ground }\end{array}$ & $\begin{array}{c}\text { Maximum } \\
\text { Weight } \\
\text { of Item }\end{array}$ \\
\hline $6 \mathrm{ft}$ & $29 \mathrm{lb}$ \\
$5 \mathrm{ft}$ & $35 \mathrm{lb}$ \\
$4 \mathrm{ft}$ & $50 \mathrm{lb}$ \\
$3 \mathrm{ft}$ & $65 \mathrm{lb}$ \\
$2 \mathrm{ft}$ & $80 \mathrm{lb}$ \\
$1 \mathrm{ft}$ & $85 \mathrm{lb}$ \\
\hline
\end{tabular}

person to lift with both hands, providing the item to be lifted is of convenient configuration, not more than $15 \mathrm{in.}(380 \mathrm{~mm})$ long, or $12 \mathrm{in.}(300 \mathrm{~mm})$ high, and handles or grasp areas conform to appropriate specifications (see Section 8.5.4) (U.S. Department of Defense, 1981a).

WEIGHT LIMIT MODIFICATIONS. The limits indicated in Table $\mathbf{5 . 2}$ do not apply to repetitive lifting. Values apply to males only and should be modified for females by reducing each value by one-third (lbid.).

\subsubsection{TWO-PERSON LIFTS}

WEIGHT LIMITS. Weight limits requiring a lift by two persons should be no more than double those indicated for a lift by one person (Table 5.2). The item to be lifted should be a convenient configuration, with handles and grasp areas that conform to appropriate specifications (see Section 8.5.4), and the one-man limit, as stated above, should not be exceeded for either man (U.S. Department of Defense, 1981 a).

WEIGHT LIMIT MOOIFICATIONS. The values shown in Table 5.2 apply to males only and should be modified for females by reducing each value by one-third (lbid.).

\subsubsection{PROVIDING LIFTING AIDS AND LABELS}

LIFTING AIDS. When necessary, lifting aids should be provided to permit a second person to assist personnel in placing the load on the body (U.S. Department of Defense, 1981a). (Also see Section 7.5.2 on hoists and cranes.)

LABELS. Items exceeding weight limits indicated in Table 5.2 should be prominently labeled with weight indication and lift limitation, i.e., mechanical or two-person lift. Where mechanical or power lift is needed, hoist and lift points should be provided and clearly labeled (Ibid.).

\subsection{GUIDELINES FOR CARRYING LOADS}

Individual portions of equipment should be designed so that when carried, the weight of the load will be distributed through as many muscle groups as possible. Pressure should be avoided or minimized on sensitive areas, such as large blood vessels. Maximum use should be made of standard load carrying systems or components (U.S. Department of Defense, 1981a).

\subsubsection{LOAD CONFIGURATION}

Loads should be designed to permit freedom of movement. Any carrying method that requires an alteration of the erect posture or normal gait will be inefficient and physiologically costly.

LOAD SHAPE. The load should be free of sharp edges or projections that might harm personnel or snag on other equipment. The shape and weight of the load should not interfere with:

length of step

movements of the head 
movement of the load

visibility of feet, when walking

vertical body movement (squatting)

regulation of body temperature

maintenance of normal posture (U.S. Department of Defense, 1981a).

BULKY EQUIPMENT. For bulky equipment, the center of gravity should not be more than 20 in. $(508 \mathrm{~mm}$ ) from the carrier's body (U.S. Air Force, 1980).

COMPACT EQUIPMENT. The more compact the container, the more easily it can be carried.

\subsubsection{LOAD CARRYING CAPACITY}

In general, a "heavy" weight is one that reaches or exceeds $35 \%$ of an individual's body weight (U.S. Air Force, 1980). The following are guidelines for carrying loads where the individual does not have to maintain a rapid pace (U.S. Department of Defense, 1981a).

INDIVIDUAL LOADS WITH HAND GRIPS. Recommended weight limits for individual loads that are carried in either hand by means of hand grips are:

about $60 \mathrm{lb}(27.22 \mathrm{~kg}$ ) for short distances (5 steps)

$35 \mathrm{lb}(15.88 \mathrm{~kg})$ for longer distances (U.S. Air Force, 1980).

BULKY LOADS. The weight of bulky articles (around $30 \mathrm{in}$. or $762 \mathrm{~mm}$, to a side) should not exceed $20 \mathrm{lb}(9.07 \mathrm{~kg}$ ) (lbid.).

PORTIONS OF EQUIPMENT. Individual portions of equipment may weigh up to $35 \mathrm{lb}(16 \mathrm{~kg})$ if the load is balanced and is distributed over many muscle groups (U.S. Department of Defense, 1981a).

MODULES. Modules or other removable assemblies should be designed so that handling and carrying are possible by one man. In particular,

loads should be less than $45 \mathrm{lb}$ loads that are difficult to reach should weigh less than $25 \mathrm{Ib}$

loads over $45 \mathrm{lb}$ should be designed for twoperson handling

hoist lugs should be provided for units over $80 \mathrm{lb}$ (Rigby, Cooper and Spickard, 1961).

\subsubsection{CARRYING AIDS}

When a load is designed to be carried by two persons, a combination of stretcher handles and shoulder support should be used, if feasible. For additional information, see Section 8.5.4 on handles (U.S. Department of Defense, 1981 a).

\subsection{GUIDELINES FOR APPLYING FORCES}

In general, controls involving the application of force should not:

exceed the strength limits of the expected user population

involve exertion of high forces without proper body or limb support (e.g., seat backrest, foot support

involve high, sustained forceful exertions (i.e., greater than 3 seconds) (U.S. Department of Defense, 1981a).

\subsubsection{HORIZONTAL PULL-PUSH FORCES}

Manual horizontal push and pull forces needed to set an object in motion or to sustain motion over a short period of time should not exceed values presented in Appendix B.

FORCE APPLICATION SURFACE. Surfaces for the application of horizontal force should be verti$\mathrm{cal}$ and rough; they should be approximately $16 \mathrm{in}$. $(400 \mathrm{~mm})$ wide and 20 to $50 \mathrm{in}$. $(0.510$ to $1.270 \mathrm{~m})$ above the floor, so that personnel can apply force with the hands, the shoulder or the back (for force values refer to Figure 8.1 and Table B.1). 
MULTIPLE OPERATORS. Values in Appendix B may be doubled for two and tripled for three operators pushing simultaneously. No more than $75 \%$ push capacity should be added for the fourth and each additional operator.

\subsubsection{VERTICAL PULL-PUSH FORCES}

Manual push and pull forces needed for vertical movement should not exceed values given for the fifth percentile peak (Appendix B, Table B.2 and Figure B.2).

\subsubsection{ARM, HAND, THUMB-FINGER CONTROL FORCES}

Where arm, hand and thumb-finger controls requiring high control forces are to be used, the maximum force needed should not exceed those illustrated in Appendix B, Figure B.3.

\subsubsection{FOOT CONTROL FORCES}

Where foot controls needing high control forces are to be used, the push force exerted by the leg depends on the thigh angle and the knee angle. The maximum push occurs when the knee is bent at an angle of about 160 degrees; this angle is referred to as the limiting angle (see Appendix B) (U.S. Department of Defense, 1981 a).

\subsubsection{FORCE APPLICATION AIDS}

PEDALS. Force application aids should be provided to assist the operator in applying maximum forces (U.S. Department of Defense, 1981a). These include:

seat backrest

double-width pedal so that both feet can be used optimized seat height-to-pedal and normal reach distance (i.e., seat reference point (SRP) and pedal are at the same vertical height and reach distance is configured so the upper thigh and lower leg create an angle of approximately 160 degrees or 2790 mrad; see Figure B.4).

TURNING AIDS. Turning aids, either singly or in combination, include knurls, indentations, or highfriction coverings. These should be built into the handwheel to facilitate operator grasp for applying maximum torque and to reduce the possibility of the wheels being jerked from the operator's hands (Ibid.).

MANIPULATORS. Manipulators should be provided for tasks that require dexterity and load capacities of less than $22 \mathrm{lb}(10 \mathrm{~kg})$. The following features should be provided:

position control (i.e., zero-order control, in which the operator's control output directly determines the machine output)

mutual force reflection between control and effector

seven degrees of freedom in motion and force control (i.e., three for translation, three for rotation, and one for gripping).

electrically or hydraulically powered manipulators with rate control for loads heavier than $22 \mathrm{lb}$ $(10 \mathrm{~kg})$ [ [n this case, the operator's control output directly determines the rate of change of the machine output (U.S. Department of Defense, 1981a)].

\subsubsection{RESISTANCES FOR SPECIFIC CONTROLS}

Recommended resistances are given in Appendix $B$ for the specific controls. Additional information on general design guidelines for controls can be obtained from U.S. Army (1972) and U.S. Department of Defense (1981a). 


\section{Chapter 6}

\section{MAINTENANCE FACILITIES}

This chapter is concerned with the facilities needed to support maintenance at nuclear power plants. Proper maintenance facilities help create a working environment that is conducive to a conscientious, safety-oriented, and productive maintenance staff.

Maintenance facilities typically include mechanical, electrical and instrument and control workshops, warehouse, tool cribs, storage provisions, on-site work provisions (including service outlets), technical documentation centers/libraries, maintenance control rooms, and administrative offices.

\subsection{PROBLEMS}

Many existing nuclear power plants have maintenance facilities that were designed for much smaller maintenance staffs and fewer maintenance activities than are currently needed. The result is overcrowded workshops and severely restricted office space.

Specific problems identified by Badalamente et al. (1982) and Seminara and Parsons (1981) include:

overcrowded workshops

overcrowded warehouses/tool cribs

inadequate space for storage of contaminated tools

inadequate space for maintenance on and/or storage of large, contaminated items

inadequate facilities for decontamination of tools and equipment

inconvenient placement of warehouses

overuse of temporary structures

inadequate facilities to accommodate expanded outage work force and maintenance requirements such as decontamination

inadequate laydown areas for maintenance.

All of these deficiencies are magnified many times over during refueling outages, when as many as a thousand additional personnel may be on site.

\subsection{SAFETY IMPACT}

Adequate facilities for maintenance are a prerequisite to maintaining safe operating conditions at nuclear plants. Crowded workshops result in injuries to personnel; uncleanliness; skipped work steps; interference in work between shifts; lost parts, drawings, and manuals; parts left out during equipment reassembly; damaged components; and worker frustration.

Overcrowded warehouses and tool cribs also contribute to work delays and frustration. Inadequate facilities to decontaminate, work on, and store contaminated items results in increased exposure to radiation.

Poorly located workshops and warehouses result in work delays and detrimental short cuts. Temporary structures for maintenance leave less space for other maintenance and operations, demand time to put up and take down, and often end up becoming permanent space obstacles and safety hazards.

Lack of adequate laydown space around equipment can result in the same incidents already mentioned for overcrowded workshops. Lack of adequate site service outlets for air or electricity add to the delay of work, cause accidents, cause detrimental short cuts and unsafe work conditions.

\subsection{GUIDELINES FOR WORKSHOPS}

The quality of maintenance can be affected by the size and arrangement of the workshop, the location of the workshop and features within the workshop.

\subsubsection{SIZING AND ARRANGEMENT}

Workshops should be large enough to accommodate the peak manpower levels that will be assigned to the shops. 
INGRESS-EGRESS. Ingress-egress routes through workshops should be kept free of impediments. Plant layout should discourage use of the maintenance shops as a thoroughfare (Seminara, 1982).

ARRANGEMENT. The workshop should be arranged to promote efficient and safe maintenance activities. For example, convenient meeting places should be available to maintenance personnel so they can gather periodically and discuss work-related matters (Ibid.).

NOISE. Extremely noisy equipment should be properly isolated and enclosed, avoiding the necessity for ear plugs or the use of Hear-Here booths in the shops (Ibid.).

SMOKE, HEAT, SPARKS. Maintenance activities that generate smoke, heat, sparks, or noxious odors should be conducted in separated, screenedin, and well-ventilated areas (lbid.).

\subsubsection{LOCATION AND INTEGRATION}

Maintenance workshops should be located and integrated into the overall plant layout in a manner that minimizes the time required for personnel movement between shops and work sites. In multiunit plants where the units contain different major systems, separate maintenance organizations and workshops should be considered for each unit (Seminara, 1982).

TOOL ROOM. The main tool room should be integrated within the maintenance shop area or in the immediate proximity of the shops (lbid.).

INSTRUMENTATION AND CONTROL. Instrumentation and control facilities should be located near the control room (Ibid.).

TECHNICAL LIBRARY. Maintenance personnel should have easy access to a well-organized and controlled technical library that includes procedures, vendor manuals, plant schematics, etc. (Ibid.).

HEALTH PHYSICS. Health physics facilities should be close to workshops, so that maintenance personnel can avoid delays in making the transition from "clean" to "hot" areas and vice versa (lbid.).

INTEGRATION. The workshop should be well integrated into the overall plant design and should allow for comfort as well as safety. Workshops should be properly shielded from plant noises. Workshops should be designed to be free of drafts. Besides serving as a source of discomfort, drafts may affect the ability of maintenance personnel to maintain close tolerances while operating shop machinery (lbid.).

\subsubsection{FEATURES}

The specific features included in workshops depend on the category or type of maintenance to be accomplished. However, in general, the features listed below should be considered.

WORKBENCHES. Sufficient workbenches should be provided for repairmen and technicians assigned to the various maintenance shops. Workbenches should offer: adequate laydown space; illumination aids; space and supports for accommodating procedures, prints, or manuals; access to power sources; magnifiers if needed; built-in test equipment as needed; and other work aids (Seminara, 1982).

MOVEMENT AIDS. Appropriate cranes, monorails, forklifts, and other movement aids should be available within the workshops to permit movement of heavy hardware items within the shops (Figure 6.1) (Ibid.).

STORAGE SPACE. Storage space for tools, materials, and personal effects should be available in the workshops. Maintenance personnel should be assigned personal storage lockers in clothing change areas that are adequately secure from thefts of personal effects. Sufficient lockers or cabinets should be available for personal storage space so that workbenches and seats remain free of clutter (lbid.). 


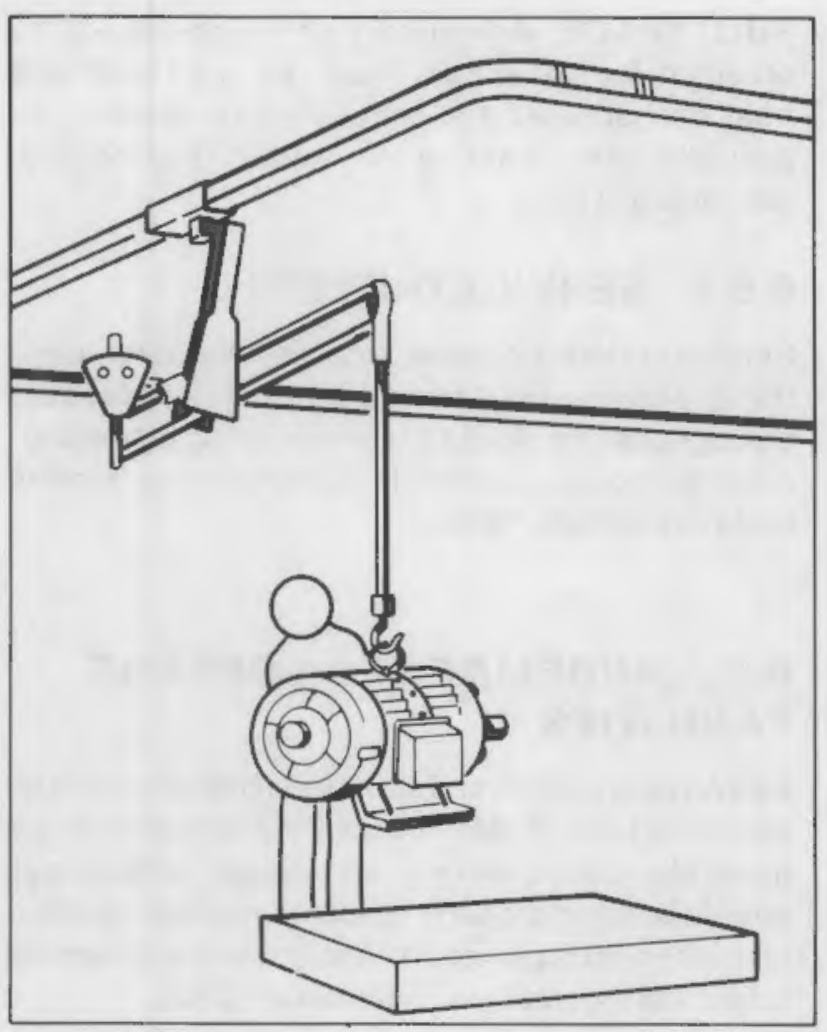

Figure 6.1. Use Monorails to Move Heavy Equipment Within Workshops

HOT SHOPS. Special facilities should be available for performing maintenance work on equipment that is contaminated with radioactivity (e.g., "hot" machine shops). These "hot" shops should be fully enclosed to avoid spreading contaminated particles. Separate "hot" shops should be available in normally contaminated areas to prevent the necessity for working on contaminated hardware in normally "clean" shops using tents. Pressure within "hot" shops should be maintained negative with respect to surrounding spaces, and exhaust air should be filtered through dual HEPA filters (lbid.).

\subsection{GUIDELINES FOR WAREHOUSES AND TOOL CRIBS}

Guidelines for warehouses and tool cribs include considerations for sizing and arrangement, location and integration, and features such as storage for contaminated items.

\subsubsection{SIZING AND ARRANGEMENT}

Storage facilities should be accessible and well organized. Facilities should be available for seasonal items such as fans and heaters.

ARRANGEMENT. The warehouse should be organized so that the potential for damage to parts, materials, test equipment, etc. is minimal. Designs should discourage haphazard or indiscriminate stacking of parts and materials that might lead to equipment damage or delayed retrieval of necessary items (Seminara, 1982).

VEHICULAR AIDS. Personnel should have easy access to wheeled carts and vehicular aids for handling heavy parts and supplies (lbid.).

TOOL ROOM. The tool room should be large, arranged to permit orderly storage of tools, and a minimum of delays in obtaining needed items. The tool room should be properly stocked with conventional and special tools (lbid.).

\subsubsection{LOCATION ANDINTEGRATION}

ACCESS TO WAREHOUSE. The warehouse should be located within easy reach from the maintenance workshops; personnel should have immediate access within. For example, designs shouldn't call for placement of the warehouse outside locked gates or security check points (Seminara, 1982).

ACCESS TO PARTS. Access to parts and supplies in the warehouse should be sufficiently convenient and reliable to discourage the development of "miniwarehouses" or private hoards and special inventory systems by maintenance organizations (lbid.). 
SEASONAL ITEMS. Seasonally or periodically used items should be stored in a manner that does not infringe on normal ingress-egress pathways, vehicular traffic paths, or emergency escape routes (Ibid.).

\subsubsection{FEATURES}

HOT TOOL CRIB. A "hot" tool crib should be provided in nuclear plants to allow orderly storage and easy retrieval of potentially contaminated tools (Seminara, 1982).

CONTROL. The control and storage of contaminated debris, work aids, equipment, spare components, etc. should be adequate to prevent these items from becoming an impediment to the movement of personnel and vehicles (lbid.).

FACILITIES FOR DECONTAMINATING. Maintenance personnel should be provided convenient access to facilities for decontaminating tools when this function is not the sole responsibility of the health physics organization (lbid.).

\subsection{GUIDELINES FOR IN-PLANT MAINTENANCE WORK SPACE}

Consideration of maintenance work space should include design for laydown areas, pull space, and service outlets.

\subsubsection{LAYDOWN AREAS AND PULL SPACE}

LAYDOWN AREAS. Adequate laydown areas for temporary placement of tools and equipment components should be provided in the vicinity of major equipment systems such as the turbine. These spaces should contain sufficient space to accommodate tools, equipment components, test equipment, procedures, temporary lighting devices, and other job aids.

EGRESS ROUTES. Equipment units that may have to be removed from an installation should be placed so that they pass through egress routes in a straight, or moderately curved line.
PULL SPACE. Adequate pull space should be provided for equipment (such as shell and tube heat exchangers) that requires dissassembly for periodic maintenance or repair (Figure 6.2) (Seminara, 1982).

\subsubsection{SERVICE OUTLETS}

Service outlets for power sources (air, water, electrical, and welding) should be readily accessible throughout the plant to operate tools, test equipment and to set up portable illumination or heating units (Seminara, 1982).

\subsection{GUIDELINES FOR OUTAGE FACILITIES}

Convenient spaces and support facilities should be available for outside contractor personnel that are generally added during an outage. Workshops should be sized properly to accommodate the regular personnel organization and any extra personnel added during outages (Seminara, 1982).

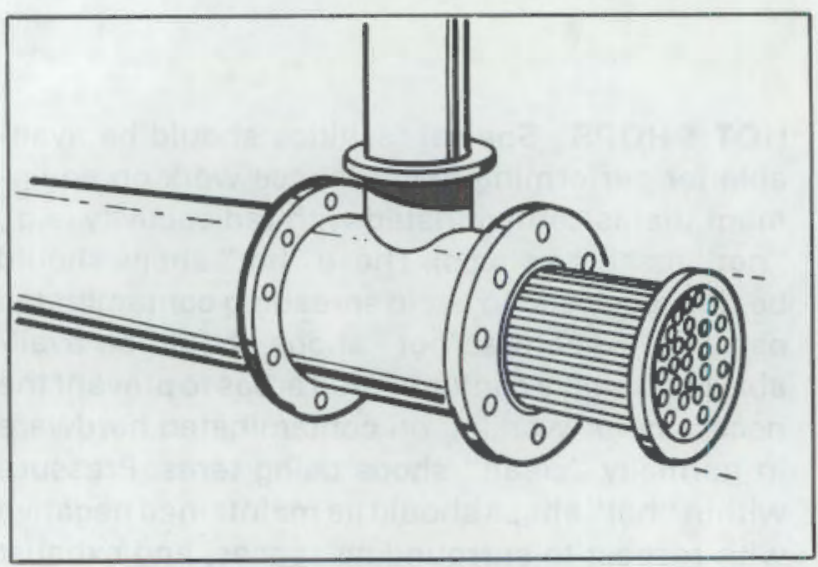

Figure 6.2. Provide Adequate Pull Space for Electrical or Mechanical Parts 
PRIVATE CHANGE, TOILET, AND SHOWER FACILITIES. Private change, toilet, and shower facilities should be made available. Dressing rooms, bathing rooms, and toilets should be placed so as to minimize the time required for preparing for work in radioactive environments. Separate dressing, bathing, and toilet facilities should be available for male and female employees engaged in radioactive work (lbid.).

SPECIAL PROVISIONS. Special provisions should be made for storing and protecting equipment used primarily during outages. Such provisions should include storage for tools and special equipment used during overhauls or contaminated equipment that is used during outages (Ibid.).

LAUNDRY. Health physics laundry provisions should be adequate to ensure the immediate availability of clean, properly-sized, and decontaminated protective clothing, gloves, boots, etc., especially during outage periods (Ibid.).

\subsection{GUIDELINES FOR USE OF TEMPORARY STRUCTURES}

When equipment has been placed beyond normal standing reach of maintenance personnel, permanent access provisions, such as work platforms with access ladders, should be provided where recurrent or emergency maintenance may be needed. (See Section 3.6.) Wooden scaffolding should be used only as a last resort and should be removed when the work is completed.

RADIOACTIVE WORK SITES. Permanent or fixed access provisions should be available for equipment located in radioactive work sites so that personnel will not incur radiation exposure in erecting temporary scaffolds or other access structures (Seminara, 1982).

MOVABLE WORK PLATFORMS. Where it is not possible to erect permanent access provisions to otherwise inaccessible components, movable work platforms, ladders, or scaffolding should be available so that personnel do not have to assume unsafe work postures (lbid.). 


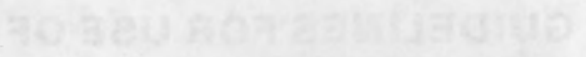

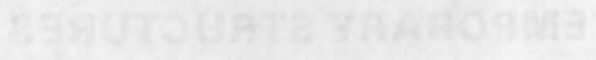

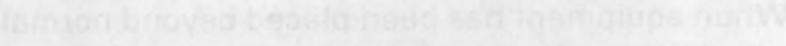

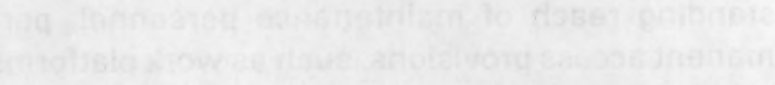

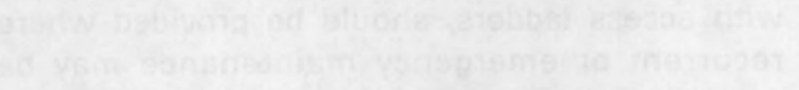

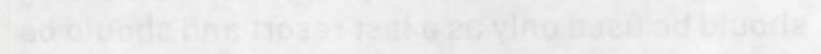

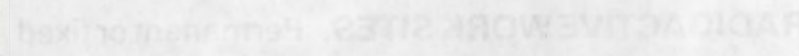

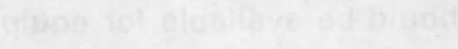

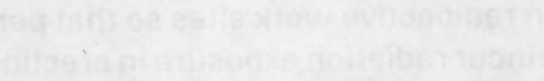

-

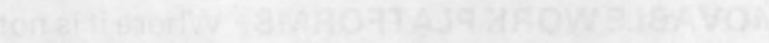

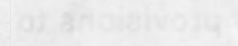

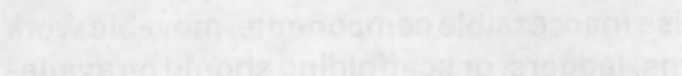




\section{Chapter 7 \\ MAINTENANCE TOOLS AND EQUIPMENT}

Maintenance tools used in nuclear power plants consist of common hand tools and special purpose tools. Maintenance equipment includes support equipment, such as fork lifts, dollies, and work stands; test equipment, ranging from simple volt meters to complex non-destructive testing systems; and communications equipment such as phones or walkie-talkies.

\subsection{PROBLEMS}

Providing appropriate, well-designed tools and equipment for maintenance at nuclear power plants can be complicated by the need to decontaminate equipment after use in radioactive environments, special needs of personnel wearing protective gear, and the need for special purpose, nuclear steam supply system (NSSS) equipment. Several studies have pointed out deficiencies in maintenance tools and equipment at nuclear power plants (Badalamente et al., 1982; Looram et al., 1981; Seminara and Parsons, 1981). These deficiencies include:

inadequate provisions for aided equipment handling such as overhead cranes or hoists

failure to design maintenance tools or equipment to accommodate personnel wearing protective gear

inadequate test equipment

inadequate function monitoring of operating equipment

inadequate communication equipment (e.g., inplant phones, sound suppression booths, two-way radios, etc.)

failure to design maintenance tools and test equipment for ease of decontamination.

\subsection{SAFETY IMPACT}

Use of poorly designed or inappropriate tools and equipment can result in a degradation of maintenance performance and, in turn, plant operating safety. In addition, such tools may pose a hazard to maintenance personnel. For example, removal and replacement of an $800 \mathrm{lb}$. manway cover for a steam generator requires special handling provisions, special torquing tools (bolting is covered by the American Society of Mechanical Engineers in its Boiler and Pressure Vessel Code), and protective apparel or special shielding and ventilation control equipment. A dropped manway cover can cause equipment damage or personal injury; improper torquing can result in leaks, damaged gaskets, or damaged studs or bolts; and the lack of appropriate tools can increase exposure time in a high radiation field. In the instrument and control area, test equipment with poorly designed controls and displays can result in erroneous readings and improper set-point adjustments. Finally, inadequate provisions for decontaminating tools can result in a lack of the proper toois necessary to do the job. This means the job doesn't get done or is accomplished under less than optimum circumstances. Either way, plant operating safety can be compromised.

\subsection{GUIDELINES FOR TOOLS}

Weli-designed tools and support equipment are an essential element of effective and efficient maintenance. Properly designed maintenance tools and equipment extend the maintenance technician's motor, sensory, and perceptual capabilities. Hand tools such as pliers provide more grip strength, while wrenches provide torque. Work stands extend the technician's reach; test equipment enhances the technician's capability to detect faults. The Occupational Safety and Health Administration has established general industry standards for tools and equipment aimed at safeguarding the personnel who use them (see 29 CFR 1910); guidelines contained here address maintainability.

NUMBER OF TOOLS. The occurrence of problems related to the number of tools needed to perform maintenance can be reduced. For example, the number of different tools needed can be reduced if the same tools can be used in maintaining a number of equipment items. Equipment not requiring tools or requiring only standard tools could also be used. 
SPECIAL FEATURES. Special features, such as tool guides or safety guards, will facilitate proper tool positioning and mating with controls or fasteners when hazardous or difficult operations may be involved (Van Cott and Kinkade, 1972).

SPECIAL TOOLS. Special tools should be used only because of reasons peculiar to the equipment or situation. Some security situations, for example, might warrant the controlled access to equipment so that tampering or maintenance by other than selected specialists can be prevented (Ibid.).

STANDARD TOOL KITS. Standard tool kits should be used as guides in determining tool needs. Additional tools should be provided only if needed (lbid.).

\subsubsection{TOOL HANDLES}

Tool handles should provide adequate gripping surfaces. Knurled or grooved surfaces are appropriate if edges are not too sharp, unless tools are intended for use in radioactive environments (see Section 7.3.3).

HANDLE SIZE. Handle size should be based on encumbering effects of protective clothing as well as on anthropometric dimensions of the nude subject. For example, tool handles with diameters of 1.5 in. have been used effectively in conjunction with pressurized gloves (Seeman et al., 1966).

REMOTE-HANDLING. Rather extensive tool modification is usually necessary to achieve an effective interface with remote-handling devices, such as those used for handling radioactive materials (Van Cott and Kinkade, 1972).

\subsubsection{TORQUE REQUIREMENTS}

When tools are being selected, torque requirements should be considered carefully. If factory assembly is done with torque wrenches, for example, torque wrenches may also be necessary for maintenance.
PRECISION TOROUING. If precision torquing is necessary, wrenches should have variable torque settings. If torque values are high, power tools or wrenches with lever-type handles are preferred (Van Cott and Kinkade, 1972).

RATCHET SCREW DRIVERS. Ratchet screw drivers, which can be operated with one hand, are suitable when torque requirements are low and space is limited. Offset screw drivers should be avoided. Controlling the direction of forces applied by these screwdrivers is difficult; screw head damage frequently results (lbid.).

\subsubsection{TOOLS FOR USE IN SPECIAL ENVIRONMENTS}

Tools intended for use in dangerous areas should reflect user needs.

RADIOACTIVE ENVIRONMENTS. Tools intended for use in radioactive environments should be designed so that they may be decontaminated easily. For example, knurled handles should be avoided. Tools should be designed so that maintenance personnel are kept as far away as possible from the source of radiation.

DANGEROUS AREAS. Tools that will be used in high voltage areas should have insulated handles and tools used in high temperature areas should be made of materials that won't be degraded by heat. Tools intended for use adjacent to flammable sources should be made of non-sparking materials.

\subsection{GUIDELINES FOR TEST EQUIPMENT}

Like any other equipment, test equipment and bench mockups must be checked, calibrated, and maintained. For this reason, recommendations about the design of units, covers and cases, cables and connectors, test points, displays, and controls apply just as much to test equipment and bench mockups as to prime equipment. Readers should consult Chapters 8 and 9 for appropriate guidelines. 


\subsubsection{TYPES OF TEST EQUIPMENT}

Test equipment used in maintenance work may be divided into four categories:

built-in test equipment (BITE), which is an integral part of the prime equipment, and can be a complex automatic checker or a simple voltmeter with external leads;

go-no-go equipment, which allows workers to determine if a signal is in or out of tolerance range;

automatic test equipment, which checks two or more signals in sequence without help from the technician (with automatic test equipment, the test usually stops when the first out-of-tolerance signal is detected); and

collating test equipment, which presents the results of two or more checks as a single display. With collating test equipment, a light might come on only if a number of different signals are within tolerance range (Van Cott and Kinkade, 1972).

These four types of test equipment are not mutually exclusive; a given test unit might possess all or some combination of the features mentioned above. The relative advantages and disadvantages of each feature must be judged in terms of the demands that will be placed on the equipment and on maintenance technicians in the field (Table 7.1). (Fac-

Table 7.1. Advantages and Distadvantages of Test Equipment (Van Cott and Kinkade, 1972)

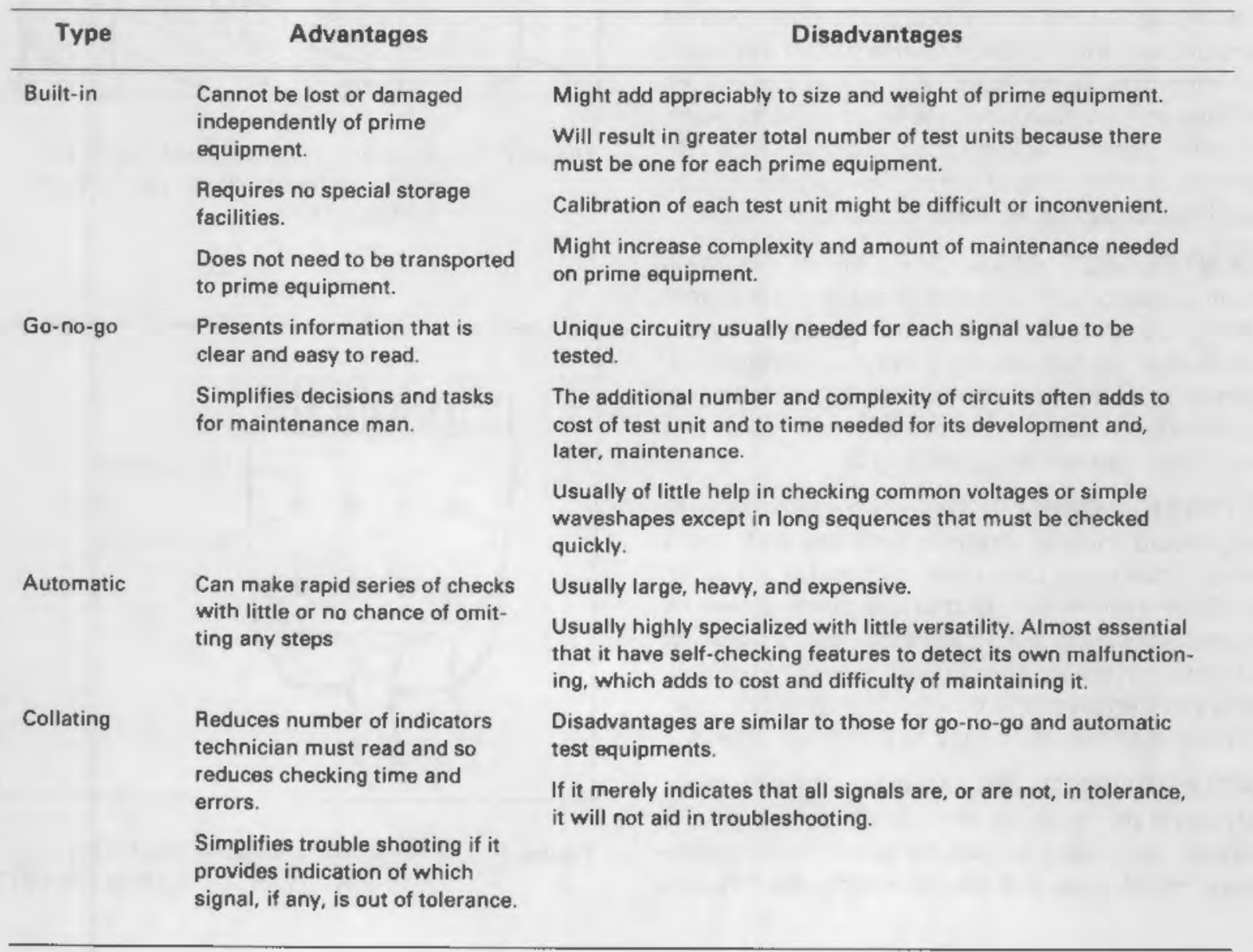


tors in test equipment selection are covered in Chapter 8, Table 8.5. See Table 8.6 for a summary of the advantages and disadvantages of BITE.) Very elaborate test equipment can simplify the job of the technician and reduce preparation or down time for systems, but may not necessarily reduce the total maintenance load. In fact, complex test equipment sometimes needs so much maintenance that the total amount of maintenance required increases. Above all, test equipment should be designed so that it is easy, fast, safe to use, and as light as possible, since heavier equipment is more likely to receive rough treatment in handling (lbid.).

\subsubsection{BENCH MOCKUPS}

The term "bench mockup" refers to prime equipment units that are set up in a maintenance shop for the purpose of checking or locating faults in units brought in from the plant. Such mockups may consist of an entire system or only part of a system, and they may be provided with signal generators and dummy loads to simulate inputs and outputs. Although bench mockups are usually put together from production units of the prime equipment, they should be designed as items of test equipment.

MAINTENANCE AIDS. Often bench mockups require additional maintenance aids such as signal generators, dummy loads, extra junction boxes, terminal strips, test points, controls, and displays. Operating instructions for the mockup should give correct signal values and tolerances for each test point (Van Cott and Kinkade, 1972).

EXTENSION CABLES. Designs for bench mockups should include extension cables with extra heavy coverings. Extension cables for all units should be removable, so that the mockup may be checked (see Figure 7.1). An extra heavy covering such as vinyl tubing should be provided on mockup cables so that wear and tear from frequent connection and disconnection may be prevented (lbid.).

CABLE CONNECTORS. Mockup cables need not withstand strong vibration or shock, but because of the way mockups are used, cables will require frequent connecting and disconnecting. As a result, end connectors on all mockup cables should require only a strong push or pull for connecting or disconnecting. In addition, mockup cables, including extension cables for units, should be provided with test points to check the signal flow through each wire. One satisfactory design is to provide test points at the connector (Figure 7.2) (Ibid.).

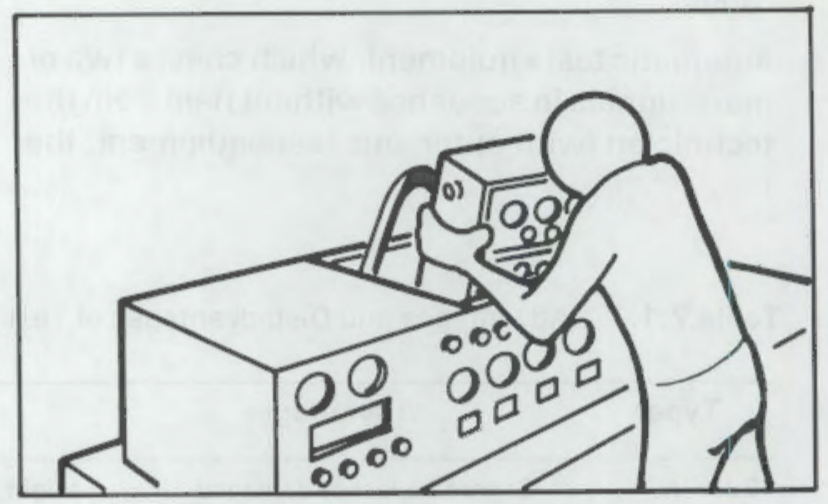

Figure 7.1. Extension Cables Allow Units to be Removed for Checking (Van Cott and Kinkade, 1972)

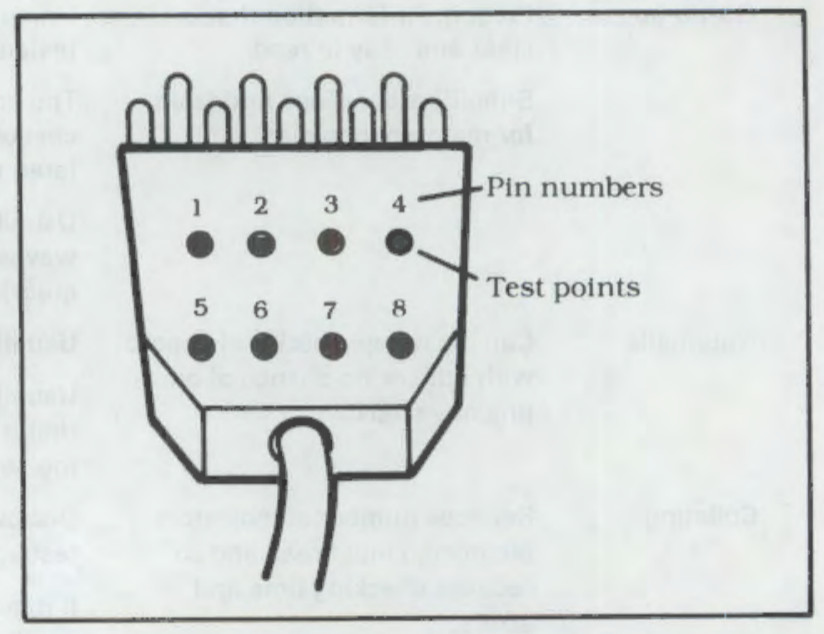

Figure 7.2. A Method of Providing Test Points on Connectors (Van Cott and Kinkade, 1972) 
ACCESSIBILITY. A good mockup design will provide enough space so that technicians can get at all the units. Moreover, each unit should be accessible without the need to remove other units. Transparent plastic covers should be used on mockup units that can be checked visually, except when a metal cover is needed for electrical shielding (lbid.).

PULLOUT SHELVES. pullout shelves or other methods of supporting the test equipment during use should be provided as shown in Figure 7.3 (lbid.).

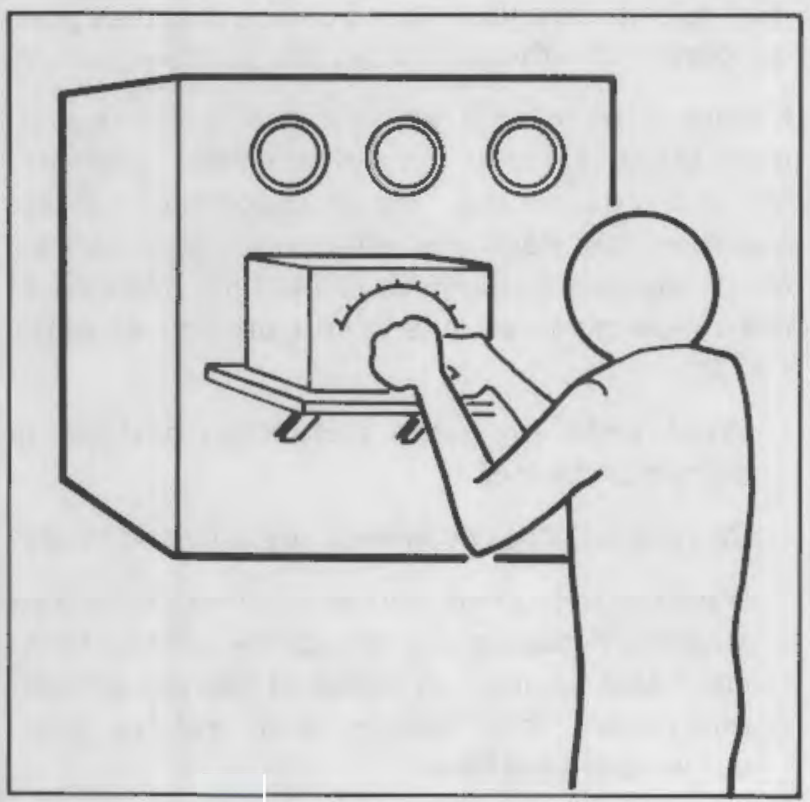

Figure 7.3. Advantages of Providing Shelves for Test Equipment in Use (Van Cott and Kinkade, 1972)

\subsubsection{CONTROLS AND DISPLAYS}

Test equipment should have the minimum necessary number of controls and displays. The number and complexity of the steps required to operate the equipment should be reduced by "ganging" certain controls or by making certain operations automatic.

CIRCUIT PROTECTION. Circuit protection devices such as circuit breakers and fuses should be provided to protect equipment from use of a wrong switch or jack position. In addition, a simple check should be provided to show when equipment is out of calibration or not working properly.

TEST LEADS. Test leads should need no more than a fraction of a turn for attachment to the prime equipment.

SELECTOR SWITCHES. Selector switches should be used rather than plug-in connections on test equipment (Figure 7.4). Selector switches are quicker to use and reduce the likelihood of faulty connections (Van Cott and Kinkade, 1972; U.S. Department of Defense, 1981a).

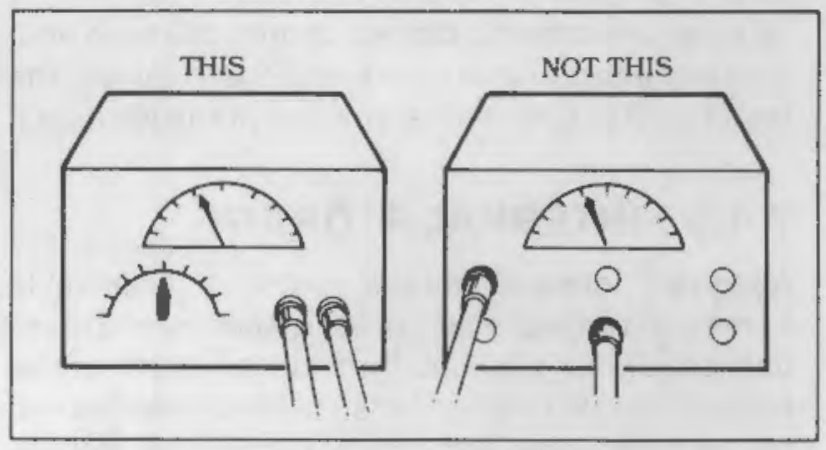

Figure 7.4. Comparison of Test Equipment Using a Selector Switch and Plug-In Connectors (Van Cott and Kinkade, 1972) 


\subsubsection{LABELS AND INSTRUCTIONS}

Items that the technician must recognize, read or use should be labeled. That includes the outer case and all removable parts of a piece of equipment; information should include purpose of the equipment and the precautions that should be observed during use. Full instructions for using the equipment should be stored inside the cover; in addition, a checklist for equipment operation should be on a metal plate attached to the equipment. Labels should indicate where and how equipment will be stored (Van Cott and Kinkade, 1972; U.S. Department of Defense, 1981a).

INSTRUCTIONS. Labels should provide clear operating and maintenance instructions. Instruction for operation should be placed on the face of the equipment, in a lid, or in a special compartment. Either a signal to show when the test equipment is ready to use or a label near the warmup switch indicating the needed warmup time should be provided (lbid.).

CALIBRATE. Where applicable, a reminder to calibrate the equipment before use should be provided (Ibid.).

REVERSE INTERLOCKS. Test equipment should be provided with "reverse interlocks" that turn it off when the cover is closed, or provided with both warning lights and written warnings to remind the technician to turn it off at the end of the job (lbid.).

\subsubsection{INTEGRAL STORAGE}

Adequate integral storage space for removable items such as test leads, probes, spares, and manuals should be provided. In addition, fasteners or holders should be provided so that accessories will be held securely and safely within the storage compartment. Portable test equipment should be rectangular in shape and have recessed or hinged handles on the cover; these measure should make storage more convenient (Van Cott and Kinkade, 1972; U.S. Department of Defense, 1981a).

\subsection{GUIDELINES FOR SUPPORT EQUIPMENT}

Vehicles, stands or dollies are used to support many maintenance operations; the way these and other pieces of support equipment are designed can impact the efficiency and safety of maintenance operations substantially. Support equipment that is difficult to use, poses personnel hazards, or fails to provide features necessary to fulfill an intended purpose will severely detract from the maintainability of the prime equipment. For example, if a maintenance stand proves to be difficult to position, provides no space for auxiliary tools or equipment, or poses other problems to the technician, it may not be used. In its place, technicians may substitute a jury-rigged device that may pose dangers both to the technician and plant equipment.

Failure to insure that maintenance support equipment is both reliable and conveniently maintainable will add to the overall burden of system maintenance. Particular attention should be paid to the support equipment related implications of the following questions (Van Cott and Kinkade, 1972):

What tasks must the technician perform in using the device?

Can the tasks be accomplished easily and safely?

Does the item of support equipment under consideration adequately provide for safe and efficient task support in terms of the equipmentequipment interface as well as the manequipment interface?

What effect will the expected physical and climatic environments have on the utility of the device

What design characteristics must be employed to insure that the utility of the equipment item is not adversely affected by environmental conditions?

Considerations related to the design of some types of support equipment are discussed in the next three sections. 


\subsubsection{MAINTENANCE STANDS}

Effective maintenance stands are essential to technicians in most maintenance applications. Adherence to the following guidelines should contribute to ease of operation and general utility of maintenance stands.

HEIGHT. Stands should correspond to or adjust to the height of the pullout racks they are to accommodate (Van Cott and Kinkade, 1972).

BUILT-IN SHELVES. Wherever space permits, built-in shelves and stands should be provided on prime equipment. Such shelves or stands are particularly useful if prime equipment requires frequent maintenance that involves removal of components or if test equipment must be used (Ibid.).

HINGED ACCESS COVERS. Hinged access covers should serve as maintenance stands when open. At the same time, however, access covers must be easy to open and close (lbid.).

TABLES AND STANDS. Tables and stands should be capable of use without tipping on a 15 degree incline, even if the weight is applied to the lower edge of the stand. "Drop leaf" tables or stands should be stable, especially when loads are applied to the outer edge of the extended leaf. Capacity of the stand or table, in pounds, should be clearly stated in a prominent label (see Section 9.3) (lbid.).

PLATFORMS, STANDS AND SHELTERS. Platforms, stands and shelters should be permanently installed or built-in wherever possible (see Section 3.6). Where they must be used at a number of locations, they should be:

light-weight and capable of being handled, erected or installed by no more than two men

collapsible or adjustable as necessary to facilitate handling, transporting or moving

provided with fool-proof, self-locking devices for all attachments, adjustments and collapsible supports

provided with wheels as necessary to facilitate moving (Rigby, Cooper and Spickard, 1961).
WHEELS. Wheels should have wheel-locks or brakes to ensure stability during use. In addition, they should be large enough to allow easy passage over ridges at least $.75 \mathrm{in}$. high, and should provide firm grip and adequate support on slippery surfaces (lbid.).

(NOTE: Temporary scaffolding is never desirable when frequent access is required.

\subsubsection{HOISTS, RIGGING, AND OTHER EQUIPMENT}

Provisions for handling nuclear power plant equipment and components that are too heavy to lift or move manually should be made (see Chapter 5).

PAD EYES, BEAMS. Pad eyes, beams, or other appropriate lift points should be provided directly over units that are too heavy for manual lifting. Heavy components that must be lifted and moved for repair or servicing should be designed to facilitate safe lifting by eye bolts; eye bolts should be located over the unit's center of gravity (Seminara, 1982).

LIFTING CAPACITIES. The lifting capacities of hoists, cranes, and other lifting devices should be clearly marked on the devices, as should the weight of heavy components that must be moved (Ibid.).

HOISTING EQUIPMENT. Hoisting equipment should be provided for all removable components that cannot be readily handled by one person (see Section 5.4.1) (lbid.).

HOISTING LUGS OR HAND POINTS. Motors, gearboxes, and similar units exceeding $45 \mathrm{lb}$ should have hoisting lugs or hand points to assist handling when they are removed or replaced (U.S. Army, 1972). Slings, hoists, and other lifting devices should be stored in a central place that allows adequate control and easy retrieval (lbid.).

\subsubsection{CRANES}

Cranes assume key importance in handling large equipment components typically found in nuclear 
power plants. Thus, crane availability and design is an important factor in maintainability.

CRANE CAPACITY AND COVERAGE. Crane capacity and coverage should be sufficient to avoid a negative impact on critical path scheduling during outages. Where major crane coverage is insufficient, add supplementary smaller cranes to avoid tying up major cranes with relatively small items. Similiarly, in multiunit plants, avoid multiple use of major cranes across both units so that delays may be prevented. Crane coverage should be adequate to avoid the necessity for time-consuming rigging operations or the need for intermediate vehicular lifting devices to move heavy objects from a major crane drop-off point to a truck bed (Seminara, 1982).

ACCESS PROVISIONS. Cranes should be designed to include convenient and safe access provisions. For example, personnel should be able to reach cranes for operation inspection, servicing, and corrective maintenance (lbid.).

EMERGENCY ESCAPE. Emergency escape provisions should be made for cranes that are operated from an integral control station, in the event that the crane becomes disabled in mid-traverse (lbid.).

SHIELDING MEASURES. Appropriate shielding measures should be applied to the crane cab to protect the operator when a manned crane must travel over highly radioactive areas (lbid.).

COMMUNICATION. Crane cab operators should always be provided with a reliable communication system (lbid.).

ACCESS OPENINGS BETWEEN PLANT LEVELS. Access openings between plant levels should be appropriately sized to provide adequate clearance when equipment is raised or lowered through such openings by means of a crane (lbid.).

\subsection{GUIDELINES FOR COMMUNICATIONS EQUIPMENT}

Adequate provisions should be made for maintenance personnel to communicate with others during the course of their work. This is especially important where radiation hazards may limit the number of people sent in to do a job and technical or supervisory guidance needs to be provided from outside the work area. It is also important when the job depends on teamwork.

\subsubsection{GENERAL PRINCIPLES}

The communication system should be large enough to provide sufficient capacity during peak manpower conditions, such as major outages.

COVERAGE. Communications coverage should extend to all areas of the plant where men will be working. Where necessary, portable communications devices should be available to supplement the fixed communication system when coverage is inadequate or communications are not reliable (Seminara, 1982).

NOISE ABATEMENT. Noise abatement or noise insulation measures should be considered to minimize noise interference with communications (see Section 4.4). Similar sound insulation devices should be distributed in high noise areas where communications would not otherwise be possible or reliable (lbid.).

\subsubsection{WALKIE-TALKIE RADIO TRANSCEIVERS}

Walkie-talkies are used in both emergency and normal operations for two-way communications beyond the range of installed telephone connections or as a convenient alternative to the soundpowered phone. However, users should determine the extent to which radio interference could adversely affect other operations.

SOUND QUALITY. Within the engineering constraints imposed by radio frequency spectrum availability and by design for easy portability, walkie-talkies should realize the same quality desired throughout all of the communications systems, namely:

good frequency response, preferably to telephone standards of 200 to $3300 \mathrm{~Hz}$.

sufficient dynamic range and gain to handle instantaneous pressures found in speech and 
develop necessary signal level at the headphone or loudspeaker (U.S. Nuclear Regulatory Commission, 1981).

MODULATION AND RADIO FREQUENCY. Modulation and radio frequency should be chosen, as FCC regulations permit, to provide broad-area walkie-talkie communication within the plant and its environs and to and from the control room. One consideration for frequency selection should be radio-wave penetration of metal or reinforced concrete barriers, which at certain frequencies would tend to attenuate or bounce the signal (lbid.).

LOW-LEVEL ANALOG OR DIGITAL EQUIPMENT. Use of walkie-talkies should be prohibited in areas close to low-level analog or digital equipment unless EMI noise susceptibility tests have been conducted that demonstrate that equipment is not affected by the frequency bands used (Ibid.).

PACKAGING Walkie-talkies should be small, light, and easy to carry. Their use should leave one hand, and preferably both, available most of the time for other tasks. The microphone should be integrated into the transceiver package (lbid.).

PARTYIDENTIFICATION. When there are more than two parties on a channel operating at separate locations, procedures should provide for unambiguous identification of the speaker (lbid.).
BATTERY REPLENISHMENT. A supply of fresh replacement batteries should be stowed in an accessible, well-marked space. The stock should be kept large enough to support long periods of continuous operation in case of emergency (lbid.).

\subsubsection{EMERGENCY COMMUNICATIONS}

Provisions should be made to assure complete internal and external communications capabilities during emergencies.

EQUIPMENT USABILITY. Communications equipment should be usable by personnel wearing protective gear without impeding tasks.

VOICE COMMUNICATIONS WITH MASKS. Emergency face masks should be equipped with diaphragms that are specially designed to transmit speech. The diaphragms should be able to separate voice from exhaust valve action. If not equipped with diaphragms, masks should be equipped with electronic speech systems which pick up the voice with an internal microphone and transmit it to a loudspeaker attached outside the mask (U.S. Nuclear Regulatory Commission, 1981). 



\section{Chapter 8 OPERATING EQUIPMENT}

This chapter addresses those features of operating equipment that facilitate reliable, safe, and efficient conduct of maintenance tasks. Operating equipment is defined as all equipment that carries out the functions of the plant. It therefore includes all pumps, valves, breakers, controls, displays, instrumentation, and other system-related electronic, hydraulic, pneumatic, or mechanical components. Operating equipment as defined in this document does not include support equipment such as test apparatus, workstands, or forklifts.

\subsection{PROBLEMS}

Failure to provide features associated with good maintainability has been identified as a major problem of nuclear power plant operating equipment maintenance (Seminara and Parsons, 1981; Badalamente et al., 1982). This chapter addresses five specific areas of concern that were identified as a result of detailed studies of maintenance practices in nuclear power plants (Badalamente et al., 1982; Looram, et al, 1981; Seminara and Parsons, 1981; Murach, 1976). The five operating equipment design problems are:

Equipment components are often arranged so that functioning components must be removed to reach malfunctioning components.

Much operating equipment lacks provision for easy removal and replacement of built-in components.

Provisions for built-in test, inspection, and service are often inadequate.

Equipment lacks "fool-proof design" features that reduce human error in maintenance tasks.

Ease of decontamination is seldom a consideration.

\subsection{SAFETY IMPACT}

Features associated with ease of maintenance of operating equipment at nuclear power plants affect the safety of the public and maintenance personnel. Moreover, equipment which is easy to maintain results in quicker, higher quality repairs.
Equipment that is maintainable typically incorporates several important features. First, it does not require employees to remove working components in order to repair non-working components. Removal of working components always increases the risk of creating new malfunctions. High maintainability allows defective components to be isolated from the system, removed, and replaced without disturbing any other part of the system.

A second feature inherent in highly maintainable equipment is the capability for built-in testing and service. This capability allows maintenance personnel to test equipment easily and frequently, but does not impose costs associated with removal of components for evaluation. Equipment with a built-in test feature can also permit easy adjustment if provisions for appropriate feedback through built-in or easily connected test instrumentation are included. Such adjustments can frequently eliminate or delay the need for repair and replacements of components.

Other maintainability features allow for safe and speedy repairs, thereby reducing exposure of staff to hazardous radiation. Features that can reduce repair time include modular design, use of a minimum number of standardized fasteners, use of quick disconnect plugs and fittings, and logical layout of components. Built-in test and service features can also reduce worker radiation exposure by speeding diagnosis and eliminating unnecessary removal of components located in radiation zones. Finally, equipment that is easy to decontaminate allows safer repair if it has to be removed from radiation zones.

\subsection{GUIDELINES FOR REDUCING IMPROPER MAINTENANCE}

Human error occurs when any element in the input-output sequence of the man-machine system is broken. This may include the failure to perceive a stimulus, the inability to discriminate among stimuli, misinterpretation of stimuli, not knowing what response to make to a particular stimulus, physical inability to make a required 
response and responding out of sequence (McCormick and Sanders, 1982). Two methods exist by which the probability of improper maintenance can be reduced. The first method incorporates equipment features that preclude improper maintenance (i.e., fool-proof design) and may include such features as alignment pins, keyways and interlocks. The second method reduces the probability of improper maintenance through the use of features which provide necessary information to the maintainer. Examples of such features include color coding, labeling, and the functional grouping of test points.

\subsubsection{PHYSICAL FEATURES TO PRECLUDE IMPROPER MAINTENANCE}

Fool-proof design is a general concept applicable to any type of operating equipment. With regard to maintenance, the idea is to design or modify the equipment in such a way that necessary maintenance cannot be accomplished improperly, e.g., checkvalves cannot be installed backwards, cables cannot be erroneously interchanged, gaskets cannot be improperly mounted, $\mathrm{O}$-rings cannot be left out in assembly, switches cannot be left in the wrong position, etc. This concept has been referred to as "engineering out the problem," "because equipment features that accomplish fool-proof design are "engineered" into the equipment.

The concept of fool-proof design should be used wherever the consequences of improper maintenance could threaten the safe operation of the plant or personnel safety. Aspects of fool-proof design are included below and may be found in sections of this chapter. Figure 8.1 summarizes the concept. Additional details are covered below.

KEYWAYS AND CONNECTORS. The major factors to be considered in selecting connectors for maintainability, regardless of the types of systems being joined, are size, space available, method of insertion and removal, and method of securing the connector. Specific systems should provide: keyways on all connectors that can be misassembled (Figure 8.2) so that coupling misalignment and inadvertent interchange are avoided.

different sizes and shapes of keyways on adjacent connectors that may be confused with one another.

keyways on connectors having fragile pins to ensure that parts are lined up before the pins contact the sockets (U.S. Air Force, 1978).

ASYMMETRIC BOLTING PATTERNS. Equipment can have bolting patterns that are not symmetrical so that parts can only be assembled one way (Figure 8.3). Use of these asymmetric bolting patterns are of particular value when proper alignment is not already discernible.

GUIDE PINS. Guide pins or an equivalent should be provided to assist in alignment during mounting and to preclude improper insertion, particularly on modules that are themselves connectors. Aligning pins should extend beyond the plug's electrical pins to ensure that alignment is obtained before the electrical pins engage. (See Figure 8.4) (U.S. Department of Defense, 1981a).

INTERLOCKS. Where applicable, interlocks should be provided to ensure disconnection of drawer- or rack-mounted equipment that could otherwise be damaged or that could pose a hazard to personal safety (lbid.).

GUIDES AND STOPS. Guides, tracks, and stops should be provided as necessary to facilitate handling and to prevent damage to equipment or injury to personnel (Ibid.).

GUARDS AND SHIELDS. Guards and shields should be provided to prevent damage to fragile or sensitive parts during movement of the assembly. Some features that can prevent damage are:

stops, to prevent the assembly from being dropped

guards or retaining devices, to prevent heavy assemblies from tipping the equipment 
Use physical features to preclude improper assembly
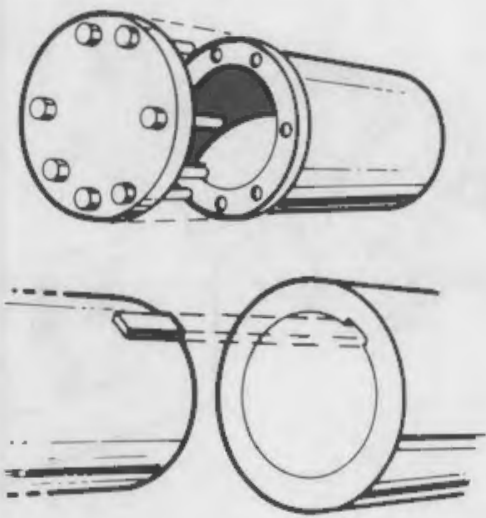

Physically key interchangeable units so that it is impossible to insert a wrong unit

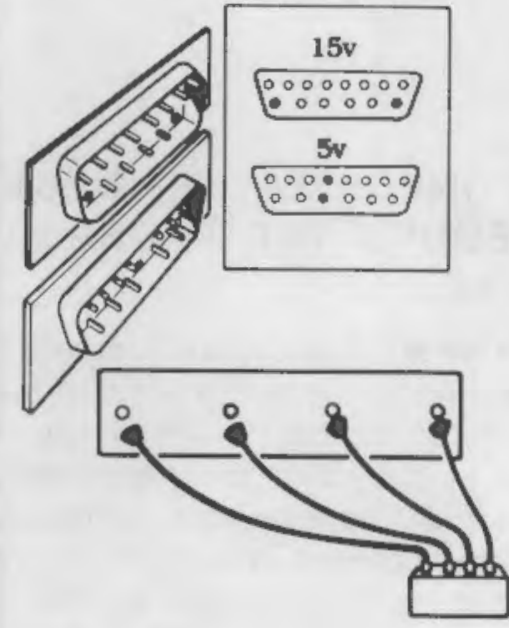

Use alignment pins to preclude improper connections
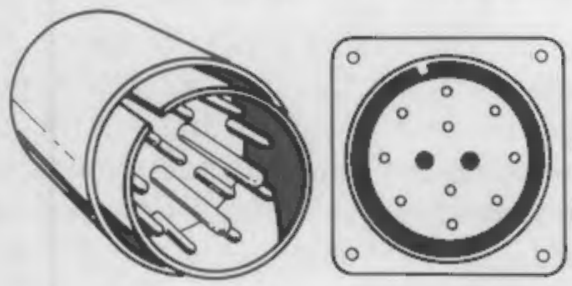

Guard or isolate critical controls or sensitive parts to avoid inadvertent activation or damage during maintenance
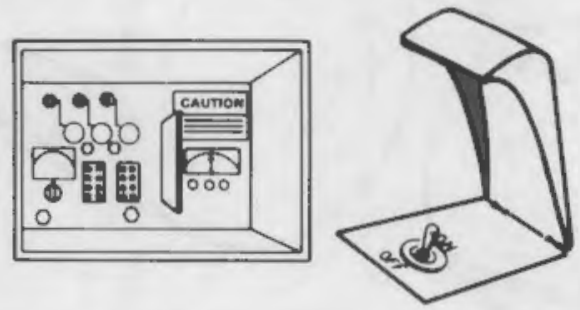

Use interlocks to preclude improper sequence of maintenance tasks

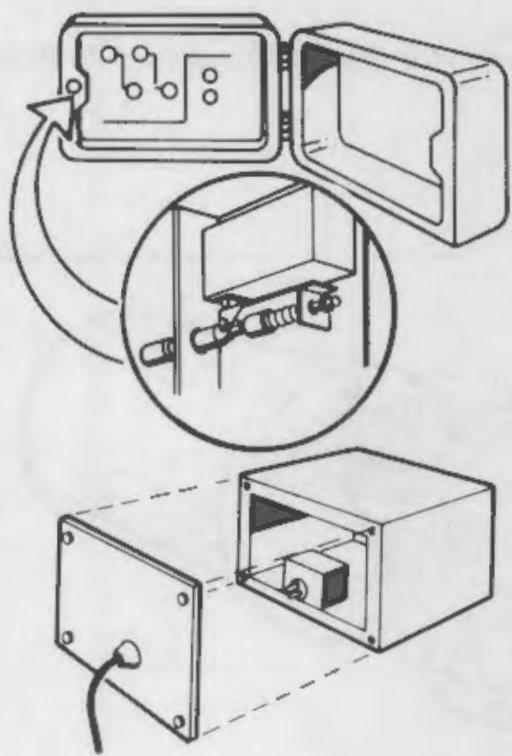

Use physical features to preclude damage to equipment through improper malntenance

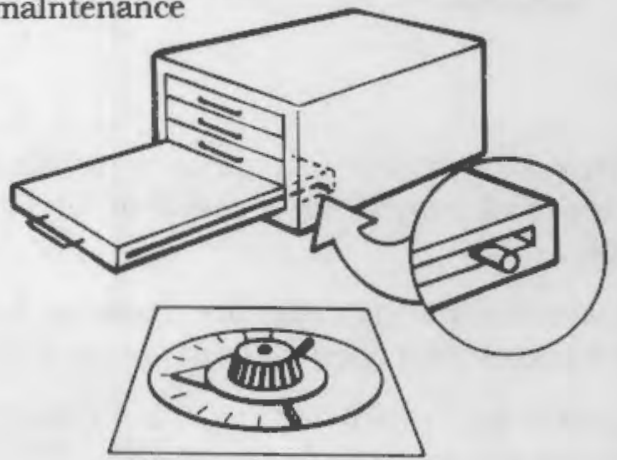

Figure 8.1. Incorporate Fool-Proof Design Features to Prevent Maintenance Errors 


\section{Operating Equipment}

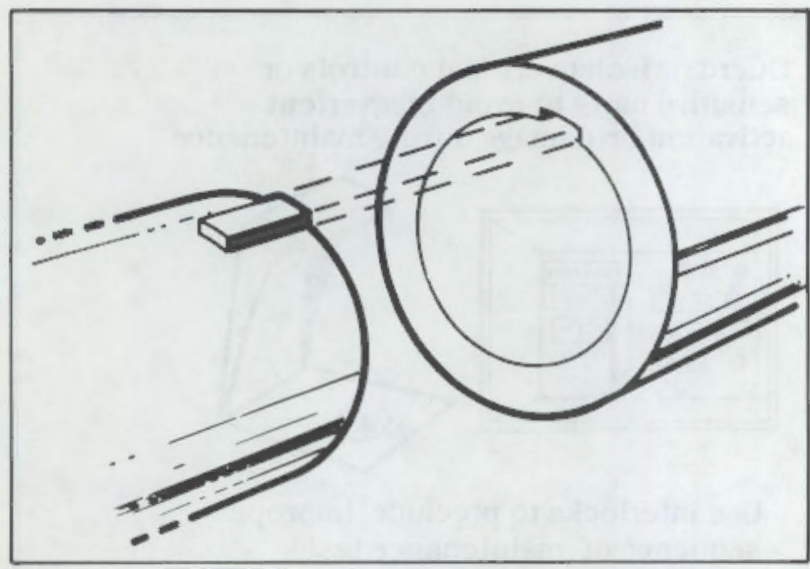

Figure 8.2. Keyways Eliminate Mistakes in Assembly

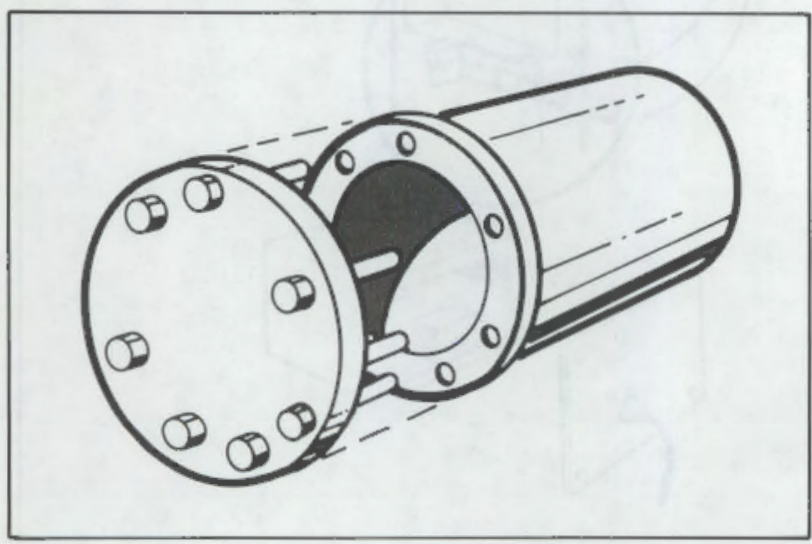

Figure 8.3. Off-Set Bolting Patterns Prevent Improper Assembly

limit stops with release mechanisms, to allow complete and convenient removal of the assembly

stops that will allow the assembly to open its full distance and remain open without being held

guide pins or equivalent devices to aid in alignment of connectors (U.S. Army, 1972).

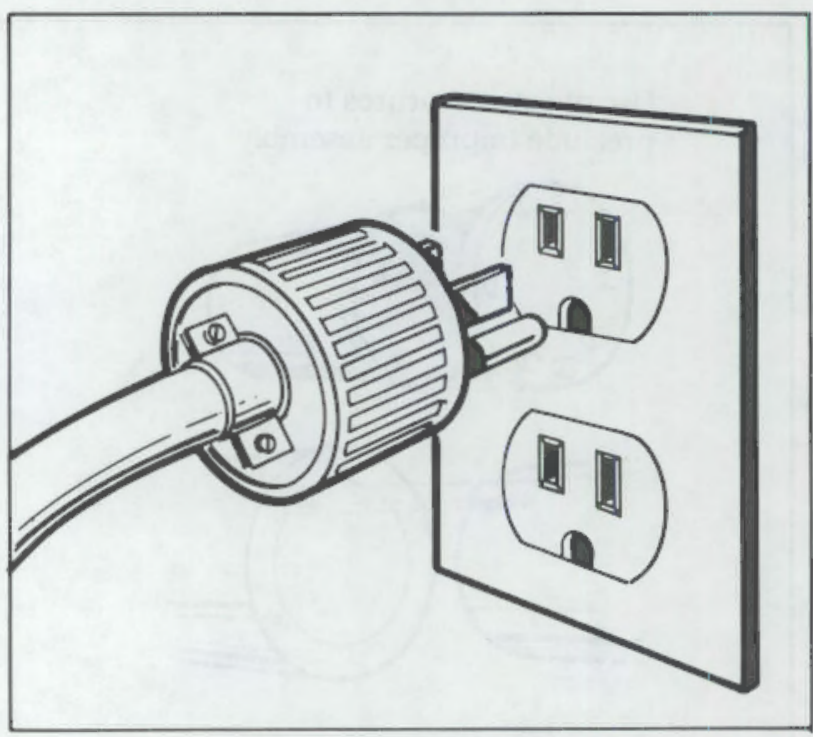

Figure 8.4. Asymmetrical Plugs Prevent Improper Connection

\subsubsection{INFORMATION NECESSARY TO REDUCE THE PROBABILITY OF ERRORS}

Where it is not feasible to preclude improper maintenance through the use of physical features, the probability of improper maintenance can still be reduced by providing the maintainer with the necessary and appropriate information for completing specific tasks. This information assists the maintainer in making positive identification of equipment, avoiding hazards and reducing the probability of error that could occur while conducting maintenance.

In large part, providing this information involves equipment labeling. Considerations include deciding label content, insuring that instructions are brief but complete, insuring that nomenclature on labels and written procedures are consistent, using standard and familiar symbols and abbreviations and insuring that labels are durable in the given environment. These areas and others dealing with 
labeling and visual displays are covered in more detail in Chapter 9. Areas for consideration with reference to specific detail in Chapter 9 are covered below.

\subsubsection{LABELING AND INSTRUCTIONS}

\section{DIFFERENTIATING SYSTEMS AND UNITS.}

Equipment and equipment components should be labeled or othwerwise coded to allow the maintainer to make positive identification of equipment on which maintenance is to be performed. Refer to Section 9.3.9.

WARNING LABELS. Caution and warning labels should be provided as necessary to warn personnel of hazardous conditions and of precautions necessary to ensure safety (U.S. Army, 1972). Refer to Section 9.3.10.

INSTRUCTIONS. Maintenance instructions should include general information on the type of equipment, equipment function, capabilities, capacities, and operating and maintenance instructions. In addition, calibration requirements, lubrication requirements, equipment access points and test points should be labeled. Further information can be obtained from Sections 9.3.5, 9.3.11, 9.3.13.

\subsubsection{TESTS POINTS, FAULTINDICATORS AND OTHER EQUIPMENT DISPLAYS}

TEST POINTS. The location of test points and the information provided in connection with essential tests are critical to the reduction of potential errors and time needed to complete tasks. The following guidelines specifically address requirements for test points:

Test points should be suitably labeled or should be physically located close to the replaceable items being tested, so that failure indications at the test points can be directly associated with the specific unit to be replaced (U.S. Air Force, 1978).

Each test point should be labeled with a symbol to designate the function measured and painted with an outstanding, preferably luminescent color (U.S. Army Missile Command, 1965).
Realistic voltages and wave shapes for test patterns, including ranges for satisfactory operations, should be determined. This information should be provided at the test point location whenever practicable (Figure 8.5) (Ibid.).

Terminal boards should be mounted in accessible positions; connections used as test points should be identified (lbid.).

FAULT INDICATORS. Fault indicators should be provided in built-in test equipment. They should allow accurate and easy determination of equipment performance. Go-no-go indicators should be used wherever possible. Auditory signals should be used to supplement fault indicators (U.S. Army Missile Command, 1965).

DISPLAYS. Personnel may be required to consult displays in order to gain sufficient information to perform a maintenance task. The following should be considered in an attempt to reduce maintenance errors:

label displays to indicate functional quantity measured

instrument scales should provide the minimum amount of information needed for a maintenance technician to make a decision

insert test data through switching

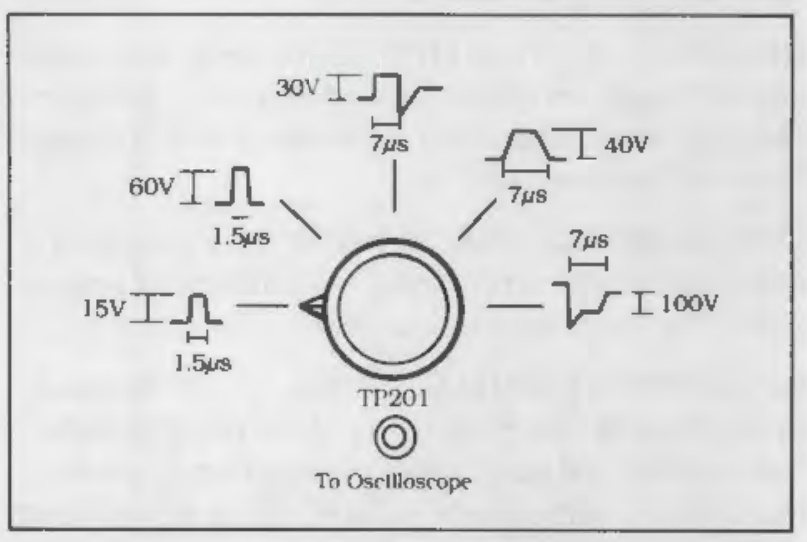

Figure 8.5. Provide Information at Test Point Location Whenever Possible (U.S. Air Force, 1978) 


\section{Operating Equipment}

locate maintenance displays so they can be observed from one position

locate all displays so they can be observed without disassembly or removal of equipment

use all-or-none displays where these items will convey sufficient information (lbid.).

\subsection{GUIDELINES FOR ACCESSIBILITY TO EQUIPMENT AND COMPONENTS}

This section addresses equipment features that enhance accessibility for equipment/component removal, inspection, and testing. Proper accessibility reduces the time and effort required for maintenance, decreases personnel radiation exposure, reduces equipment wear and tear and limits the chance of improper maintenance. Accessibility can be achieved by prioritizing the location of equipment, providing appropriate clearance for maintenance tasks and tools, packaging equipment end items for accessibility, orienting equipment components for ease of inspection/testing, and considering fault location needs.

\subsubsection{LOCATION OF EQUIPMENT}

Accessibility for maintenance can be enhanced by prioritizing the location of equipment based on the considerations discussed below.

RELATIVE CRITICALITY. Items that are most critical to system operation and require rapid maintenance should be most accessible (U.S. Department of Defense, 1981a).

FREQUENT ACCESS. When relative criticality is not a factor, items requiring most frequent access should be most accessible (Ibid.).

SPECIALIZED SKILLS. Access to items maintained by one technician should not require disturbance of critical equipment maintained by another technician, particularly where highly specialized skills are involved in maintenance (lbid.).
SERVICING AND REPLACEMENT. Assemblies, parts, or units to be serviced or replaced (e.g., fuses and filters) should be accessible without need for removal of other components. For example, personnel should be able to remove pumps, filters, valves and similar equipment from a tank without having to remove the tank from its mountings (U.S. Army, 1972).

PUMPS AND VALVES. Pumps should be easily and rapidly removed and replaced by manipulating a minimum number of fasteners and pipes. Personnel should not need to remove or replace other components when installing pumps. Valves should permit rapid and easy replacement of all internal seats, seals, and packings without removal of the valve body or piping from the system (Ibid.).

\subsubsection{CLEARANCE FOR MAINTENANCE TASKS}

Sufficient space/clearance should be provided so that maintenance personnel can perform tasks using the necessary tools and test equipment and wearing whatever protective gear may be necessary or appropriate. General work space considerations have been covered in Section 3.5. Other considerations include those discussed below.

STRUCTURAL IMPEDEMENTS. Frames and structural members should be placed so that they do not interfere with maintenance, inspection, or operation (Figure 8.6) (U.S. Army, 1972).

PROTECTIVE CLOTHING. Parts should be spaced so that access around inspection areas is adequate to permit easy use of transducers or probes by personnel wearing protective clothing (U.S. Air Force, 1978).

ACCESS COVERS. Removal of any replaceable item should involve opening or removing a minimum number of covers or panels. Covers should be sufficiently larger than the items they cover to mimimize the possibility of damaging wires or other parts when the cases are installed or removed and should be large enough to allow mounting screw clearance without perfect case alignment. 


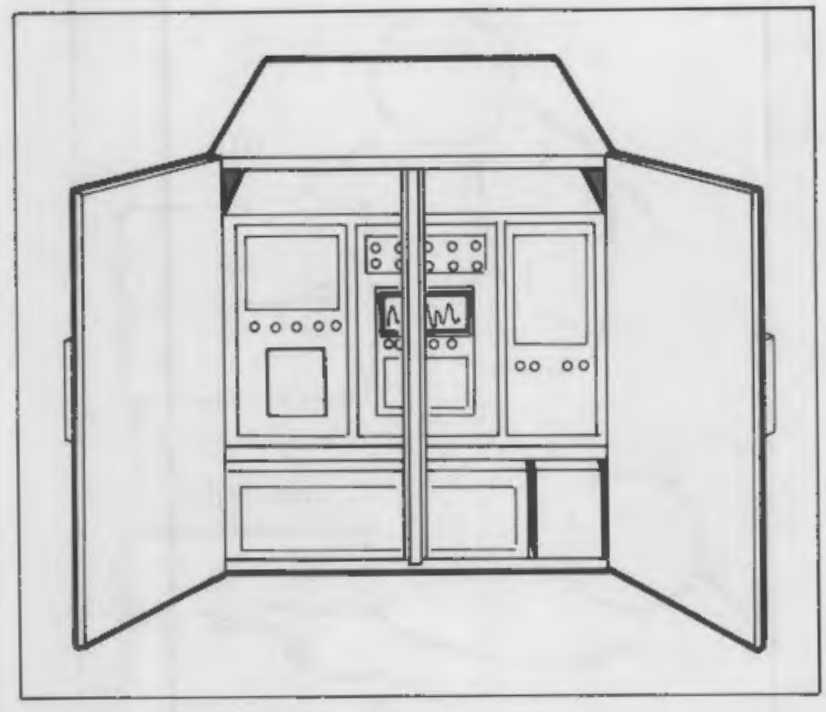

Figure 8.6. Avoid Placing Components so They are Blocked

Brackets, bulkheads, and other units should not interfere with removal or opening of covers on units that personnel will be examining (U.S. Department of Defense, 1981a).

REAR ACCESS. Sliding, rotating, or hinged equipment that personnel must be able to reach from the rear should be free to open or rotate enough to allow access (lbid.).

Table 8.1. Methods of Packaging
TOOL CLEARANCE. Sufficient space should be provided within equipment cases and between components to permit use of tools and test equipment without hazard to the technician or damage to adjacent components (Ibid.).

VISUAL ACCESS. Check points, adjustment points, test points, cables, connectors, guages, and labels should be accessible and visible during maintenance. (lbid.).

\subsubsection{PACKAGING}

Packaging, in the context of hardware design, encompasses the physical features used to assemble the electronic, hydraulic, pneumatic, and mechanical components into separate, serviceable units. Packaging affects maintainability down to the level of the throwaway item only; the methods of packaging within throwaway items can be ignored. The most desirable packaging methods require component items to be plugged into sockets on a supporting member (Table 8.1). The word "item" in Table 8.1 represents a throwaway item or an assembly of such items (such as a repairable module). When packaging equipment components, consider the areas listed below.

MODULAR DESIGN. Modular designs allow for the prioritizaton of equipment location, taking the frequency of failure and ease of accessibility into consideration. For more detail refer to Section 8.5.2.

\section{Mounting}

Interconnection

Most Desirable:

Items plugged into socket on supporting member (chassis, circuit board, etc.) and clamped down

Desirable:

Items fastened (screws, etc.) to supporting member; contacts completed by attaching a connector or connectors

Leat Desirable:

Same as above, except that contacts are completed by attaching individual lead to each contact
Printed circuits point-to-point wiring, cabling, etc. soldered (or equivalent) to socket

Same as above, except soldered to connector(s) instead of socket

Same as first method, except soldered to item contacts instead of socket 
PACKAGING DENSITY. Motors, valves, sensors, etc., should not be placed in densely packaged arrangements that offer insufficient clearances for maintenance.

REPLACEABLE PARTS. An overall packaging concept that will allow the removal of a replaceable assembly or part without removing any other should be developed (U.S. Army Missile Command, 1965).

INTERNAL ACCESS. Internal access that does not require mechanical disassembly should be provided for components and parts. In packaging the equipment, sufficient room should be provided for maintenance (lbid.).

SMALL VS. LARGE PARTS. Small parts should be placed so that large or heavy parts do not prevent access to them; moreover, parts should not be stacked (Ibid.).

\subsubsection{NON-DESTRUCTIVE EXAMINATION}

The orientation of a structural part relative to the access provided for it directly affects the type of inspection that can be performed. The orientation of structural parts becomes critical when nondestructive examination (NDE) techniques are necessary to the inspection procedure. The following provides general information and guidelines specific to various selected techniques.

\subsubsection{GENERAL NDE GUIDELINES}

PROXIMITY. The accuracy and reliability of inspection depends directly on how close to the part the inspector can get. Deeper parts are more difficult to inspect unless special provision is made for visual access (Figure 8.7). In addition, the proximity of one part or area to another not only constrains the type of nondestructive inspection that may be used, but also inhibits visibility of the part for interpretation of results.

ORIENTATION OF INSPECTED SURFACES. Parts that are to be inspected by penetrant, ultrasonics, magnetic particle, and eddy current should have the inspected face oriented toward the access point.

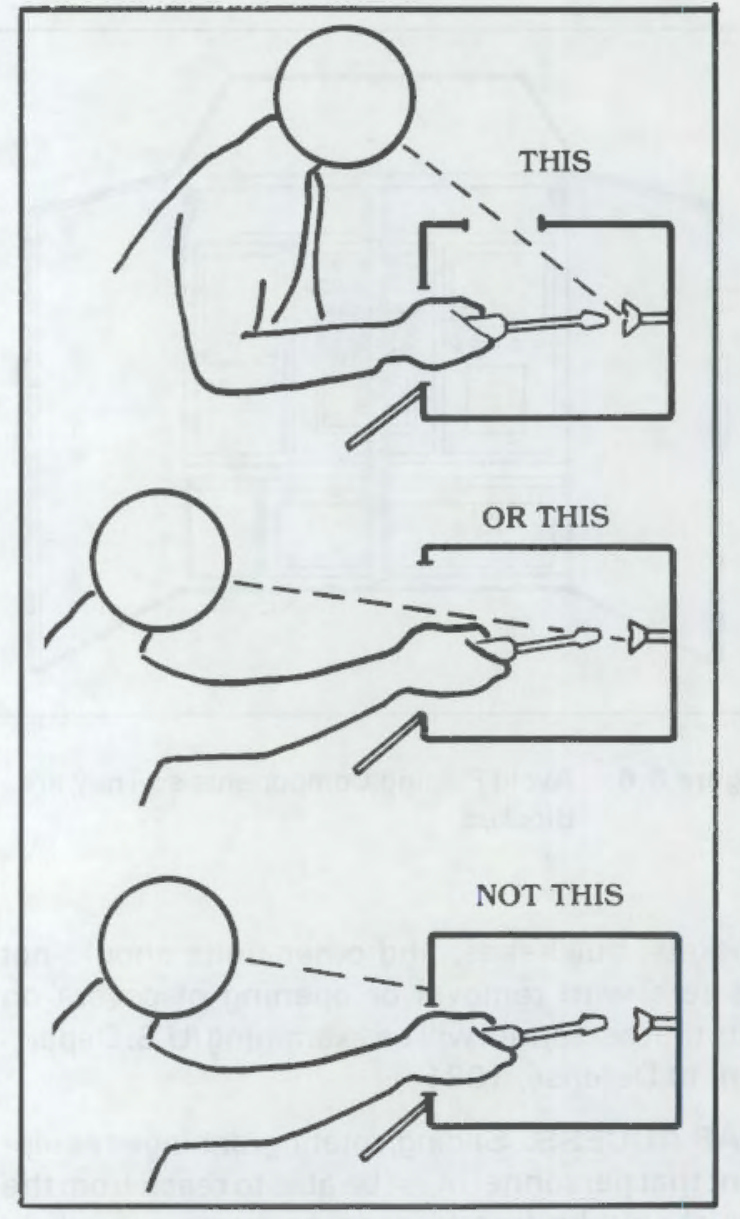

Figure 8.7. Provide Visual Access to Parts Inside Components (U.S. Army, 1972)

ORIENTATION OF STRUCTURAL PARTS. When the dynamic environment of the part is determined, defect location and direction can be predicted. Structural parts should be oriented so that the defect to be detected faces in a direction suitable for the inspection technique to be used. This orientation may vary according to the type of defect as well as the method selected to detect it.

DISTANCE FROM MOLD LINE. Parts that require inspection should be placed so that there is a minimum distance from the mold line to the area for inspection. This will allow maximum visibility during inspection using penetrant, eddy current, ultrasonics, or magnetic particle methods. 
FREQUENT INSPECTION. Items that must be inspected frequently should be installed closer to the mold line than items in the same area requiring fewer inspections (U.S. Air Force, 1978).

\subsubsection{GUIDELINES FOR SPECIFIC NDE TECHNIQUES}

RADIOGRAPHY. Parts to be inspected using radiography should have sufficient distance around them to allow adequate film and X-ray tube head placement. This also means that the part should not be so close to adjacent members that proper $X$-ray beam angle cannot be achieved (U.S. Air Force, 1978).

ULTRASONICS OR EDDY CURRENT. If the use of ultrasonics or eddy current is necessary and access is limited to one arm only, parts should be less than $20 \mathrm{in}$. from the mold line, since accurate placement of probe or transducer is not possible beyond this distance. For fatigue cracks, for example, parts to be inspected with eddy current should be oriented so that scanning across the crack plane can be accomplished (lbid.).

MAGNETIC PARTICLE. When a structural part is deep inside the component, the use of fluorescent penetrant and magnetic particle methods will become difficult. Structures should allow removal of excess inspection materials after inspection. This may be accomplished by providing sufficient access to allow complete cleanup. The wet bath magnetic particle method is not recommended for areas that face downward. For magnetic particle inspections, the part needs to be oriented so that a contour probe can be placed across the plane of suspected cracks (lbid.).

FIBER OPTICS. White paint or primer should be used on closed-out areas and interior compartments to allow maximum illumination when using borescopes or fiber optic inspection. For corrosion detection, the area to be inspected should be oriented so that film placement can be readily accomplished. If borescopes or fiber optics are used to detect corrosion, provide direct paths through adjacent structures (Ibid.).

\subsubsection{ACCESSING TEST POINTS}

Fault location needs are dictated to some extent by the test approach selected for the equipment or system. However, in any fault location scheme. access points for determining the adequacy of circuit operations should be provided. In setting up a fault location scheme, the electronic and physical locations and the number of these access or test points are the primary factors to be considered. The number of test points should be related to the number of replaceable units.

TEST POINTS. Necessary test points should be considered for each level of maintenance to establish the total number of test points required. A test point is generally needed for each output or input, although when a test point at an output from one unit also serves as the input to another unit, only one test point may suffice. Test points may be either the signal sensing type or the signal injection type (U.S. Air Force, 1978).

TEST POINT ARRANGEMENT. The physical location of test points depends on the testing method selected and on whether built-in test equipment is to be used. When external test equipment is to be used, accessibility and convenience are major considerations. Other considerations include the following:

Test points should be located on units with adjustment facilities so that direct observation of adjustment can be made during testing (U.S. Air Force, 1978).

Maximum accessibility is achieved when all test points are brought to the outside of the item being tested (lbid.).

Components of a system should be arranged so that sufficient space is available for testing probes, soldering irons, or other tools. Enough space to minimize the potential for damaging adjacent components should be allowed (Seminara, 1982). 


\section{Operating Equipment}

\subsubsection{CIRCUIT LAYOUT}

Circuit layout refers to the physical location of components in electronic equipment. Within throwaway items, circuit layout does not affect maintainability, though at higher levels of complexity, layout can seriously affect fault location time, test and alignment time, and repair time.

METHODS. Empirical evaluations of the effects on fault location time are available for several methods of electronic circuit layout (Table 8.2). Layout methods and features that apply to electronic circuits apply equally well to pneumatic and hydraulic circuits. (U.S. Air Force, 1978).

OTHER FACTORS. Other circuit layout factors to be considered include ease of making adjustments and the location of test points (lbid.).

\subsection{SIMPLIFYING EQUIPMENT DESIGN}

The ease and accuracy of maintenance can be facilitated by keeping equipment simple. In general, equipment should be as simple as possible consistent with its functional and reliability requirements, service life, and expected service conditions. In addition, equipment should incorporate safety features, such as those to preclude inadvertent activation or personnel exposure to hazards (e.g., electric shock).

\subsubsection{GENERAL GUIDELINES FOR SIMPLIFYING THE MAINTENANCE TASK}

Equipment should be kept simple. The maintainer's task along with his skills, knowledge, equipment and tools should be considered in the effort to

Table 8.2. Comparison of Circuit Layout Methods (U.S. Air Force, 1978)

\begin{tabular}{|c|c|c|}
\hline Layout Method & Description & $\begin{array}{l}\text { Aelative Fault } \\
\text {-ocation Time } \\
\text { (sec) }\end{array}$ \\
\hline Component Grouping & $\begin{array}{l}\text { All components of a similar nature are grouped together in one } \\
\text { location. Within each group, all items performing a similar } \\
\text { function are subgrouped. }\end{array}$ & 0.74 \\
\hline Circuit Grouping & $\begin{array}{l}\text { All similar or identical circuits are grouped together in one } \\
\text { location. }\end{array}$ & 0.71 \\
\hline Logical-Flow Grouping & $\begin{array}{l}\text { Layout follows block diagram of electronic circuits, with } \\
\text { components within each block grouped together. }\end{array}$ & 0.50 \\
\hline Frequency Grouping & $\begin{array}{l}\text { All circuits functioning in a particular frequency range are } \\
\text { grouped together. }\end{array}$ & * \\
\hline Standard Construction & $\begin{array}{l}\text { Satisfactory circuit operation is the only criterion used for layout } \\
\text { of components. }\end{array}$ & 1.00 \\
\hline
\end{tabular}


simplify equipment. For example, information processing requirements necessary for fault diagnosis should be considered. In addition to mental reasoning, the general layout of parts, strategy for replaceable items, and ease of decontamination should be assessed.

\subsubsection{MENTAL REASONING}

To decrease the amount of mental reasoning necessary to determine the origin of a malfunction:

Units should be designed so they can be checked independently

Circuits should be grouped so that a minimum of criss-crossing of signals between units is required

Modules should have as few input and output signals as possible

Trick or extremely sensitive circuitry should be avoided through use of standard circuits

Operational circuitry should be separate from maintenance circuitry

Maximum use should be made of maintenance aids such as troubleshooting procedures, maintenance diagrams, and circuit data

Maintenance procedures should be designed at the same time as the equipment. (U.S. Army Missile Command, 1965)

\subsubsection{GENERAL LAYOUT}

The following general guidelines should be used with laying out parts within components:

anticipate the environmental and space conditions likely to be present around the equipment after it is installed

use standard parts and fasteners whenever possible

use as few different parts and fasteners as possible use coding techniques (e.g., shape, color, location, labels) where feasible to enhance discriminability among controls, displays, components, and parts

Place adjusting units close to the controls and displays that are used in the adjustment (U.S. Department of Defense, 1981a).

standardize the orientation of connectors and plug-in parts (U.S. Army Missile Command, 1964).

\subsubsection{REPLACEABLE ITEMS}

To simplify removal and replacement of items, consider the areas listed below.

HAND TOOLS. Operators should be able to replace mechanical items with common hand tools and simple handling equipment (U.S. Department of Defense, 1981a).

FILTERS. Filters should be designed so that personnel do not have to disconnect pipe fittings in order to drain or replace the filter element. Personnel should be able to withdraw the filter housing easily, without interfering with or removing other components (U.S. Army, 1972).

DISPOSABLE ITEMS. Inexpensive components should be placed on separate plug-in type boards that are mounted beneath the chassis to facilitate disposal at failure (lbid.).

SIMILAR PARTS. Similar parts (tubes, etc.) that are likely to require replacement at the same time should be grouped together (lbid.).

IN-PLACE TESTING. Equipment should be designed so that parts can be tested without removal; or, if this is not possible, make parts requiring testing easily removable (U.S. Army Missile Command, 1965). 


\subsubsection{GUIDELINES FOR MODULAR DESIGN}

Major subsystems and components of highly maintainable equipment reflect modular concepts. This means that major subsystems will be replaceable as a unit and capable of being repaired and tested outside the machine or parent item. Maintenance considerations for modules include ease of removal and repair, cost, and accessibility of components.

MODULAR UNITS. Equipment should be divided into as many modular units as are electrically and mechanically practicable, making efficient use of space and considering the reliability of equipment. This can be achieved by following the concepts below:

Systems should allow for modular replacement where it is not safe or cost-effective to have plant personnel troubleshoot and make repairs to the systems element level (Seminara, 1982).

Modules and their component parts should be of uniform shape and size, and should be designed so that they can function independently (U.S. Army, 1972).

Assemblies made up of two or more subassemblies should allow subassemblies to be removed independently. This type of placement is especially valuable when life expectancies of the subassemblies vary widely (Ibid.).

Units should contain components that are optimized for a given function, rather than capable of multiple, divergent functions (lbid.).

To make removal and replacement easier, control levers, linkages, and fittings should be attached so that they can be easily disconnected from components (lbid.).

Sensitive adjustment points should be located or guarded so that adjustments will not be disturbed inadvertently. Suitable hand or arm support should be provided to make the adjustment easier in all cases where the maintainer is subjected to disturbing vibration or motion during the adjustment (U.S. Department of Defense, 1981).
PLACEMENT. Equipment placement should consider frequency of inspection, reliability of individual items, and functional grouping. More specifically:

Placement of equipment should maximize functional independence of units, while minimizing interaction between units, as shown in Figure 8.8 (U.S. Army, 1972).

If all except one or two components of a module are reliable, consider arranging the module so that unreliable components may be removed from the exterior of the package (Ibid.).

Components that require frequent visual inspection should be installed in positions where they can be seen easily without removing panels, covers, or other units (lbid.).

Components that are maintained by the same technician should be grouped together and arranged so that system checking can be accomplished with a minimum of movement from position to position (lbid.).

REQUIRED MANPOWER. Only one technician should be required for repair tasks whenever possible (U.S. Army, 1972). This dictates access to and weights limits of equipment as follows:

Access to modules maintained by one technician should not require removal of critical

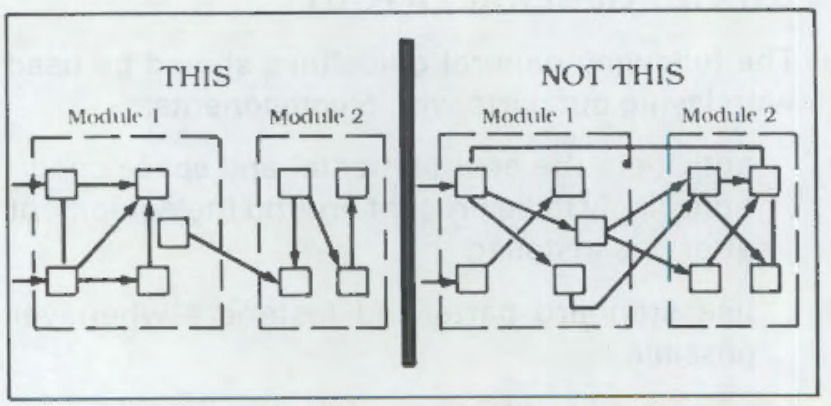

Figure 8.8. Modules should have Minimal Interactions Between Units (U.S. Army, 1972) 
equipment maintained by another technician, particularly where repair requirements involve highly specialized skills (U.S. Department of Defense, 1981a).

Equipment should be easy to remove and replace by only one person wherever structural and functionai limitations permit. Modular equipment should fall within the weight limitations contained in Section 5.4.1 of this document (lbid.).

OPERATIONAL TESTING. Modular units and subunits should permit operational testing when the units are removed from equipment and should need little or no calibration following replacement. Independent checks of each module should be possible. It should be possible to make any necessary adjustments to an individual unit, separate from other units (U.S. Army, 1972).

EXPENDABLE ITEMS. Expendable items such as fuses should be readily accessible for removal and replacement. They should not require removal of other components for access. No special tools should be needed for fuse placement unless required by safety considerations (Ibid.).

LUBRICATION. Automatic lubricators should be used where lubrication points are out of normal reach or are easily overlooked (Seminara, 1982).

DISPDSABLE MODULES. Other than maintenance time, the only factors to be considered in deciding not to test are cost and logistics. A decision not to test may be made, for example, if the system or equipment is inexpensive enough to be discarded upon failure. Tests might also be avoided if the supply situation will allow for replacement systems in the event of equipment failure iU.S. Air Force, 1978). Guidelines for disposable modules are:

isolate expensive and long-lived parts from inexpensive parts.

make inexpensive and noncritical items disposable

encapsulate throw-away modules wherever practical make all encapsulated modules disposable

encapsulate modules to meet performance and reliability requirements

specify the maintenance level of "throwaway" items

specify test procedures to be applied before disposal and be sure that those procedures provide clean and unequivocal results

include a label that reads: "DISPOSE AT FAILURE" (U.S. Army, 1972).

\subsubsection{GUIDELINES FOR DRAWERS, RACKS AND SLIDES}

Drawers and racks that pull out, roll out or slide out should be used whenever practical (Figure 8.9). Shelves, racks or other hinged or sliding assemblies should be provided to: optimize work space, tool clearance, and accessibility; reduce the need for the technician to handle fragile or sensitive items; facilitate handling or positioning of heavy or awkward items; and facilitate maintenance of items that must be frequently moved from the installed position for checking, servicing or repair (U.S. Army, 1972). Other features should include the following:

limit stops on racks and drawers that must be pulled out of their installed positions for checking or maintenance. The limit stop should permit convenient overriding of stops for unit removal (U.S. Department of Defense, 1981a).

drawers with a smooth operating bearing assembly, and automatic locking in both the servicing and operating positions (U.S. Army, 1972).

handles to ease drawer operation (lbid.).

extension cables or hoses to allow assemblies that are completely removable to be checked in a convenient location (Ibid.).

provision for opening assemblies without breaking internal connections that are necessary for the required maintenance (Ibid.). 


\section{Operating Equipment}

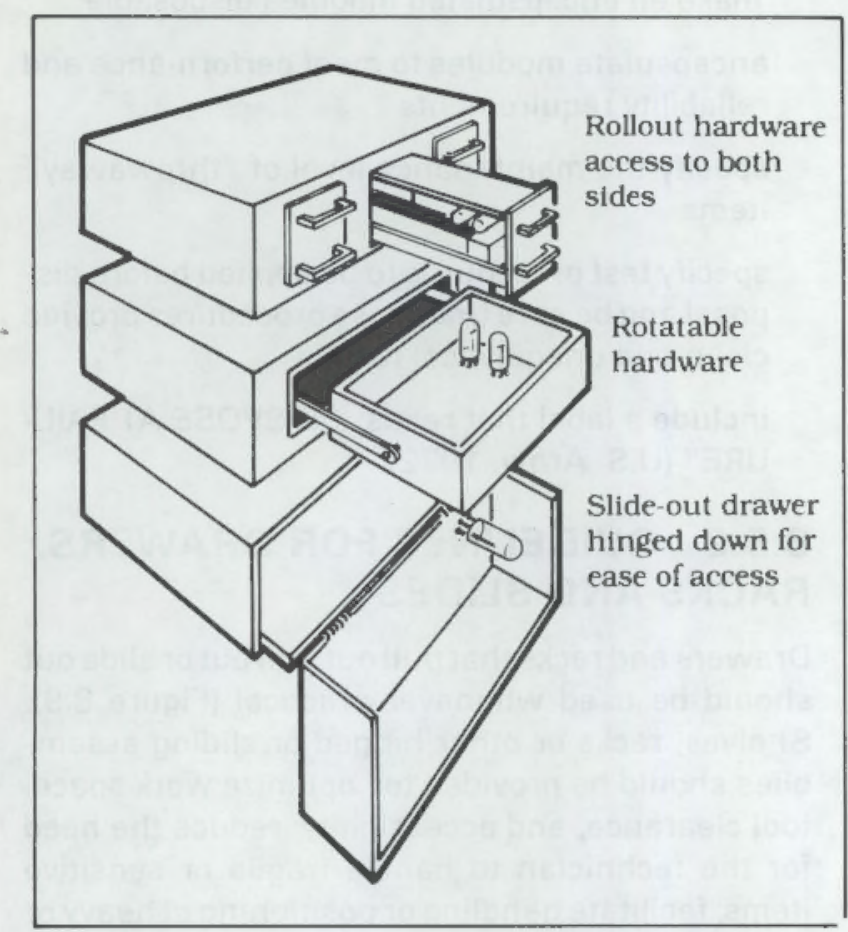

Figure 8.9. Pull-Out, Roll-Out and Slide-Out Drawers (U.S. Army, 1972)

\subsubsection{GUIDELINES FOR HANDLES}

Consideration should be given to providing handles for all units which are intended be removed and replaced or to be carried.

TYPES OF HANDLES. Some commonly used handles are the finger recess, hand recess, bar, T-bar, and J-bar (see Table 8.3). When units are to be carried frequently or for long periods, a molded handle to prevent slide pressure on the fingers should be used. Recessed grips should be provided near the back of heavy units. Recessed, concealed, or folding handles can be used to conserve space, but they should be accessible without tools and should remain securely folded when not in use.

USES. Besides serving as a means for carrying components, handles can also be used for: withdrawing and handling printed circuit boards (Figure 8.10).

supports, protection, or security (Figure 8.11), and

removal of covers on units (Figure 8.12).

\subsubsection{WHEN TO PROVIDE HANDLES}

Handles should be provided on all packages, units, components, and covers whenever these items are frequently handled or are difficult to carry. Handles should also be provided on packages that incorporate fragile components or weigh over $10 \mathrm{lb}$. Handles should take into account the:

weight and center of gravity of the item or unit number of people or hands required to lift or carry the item

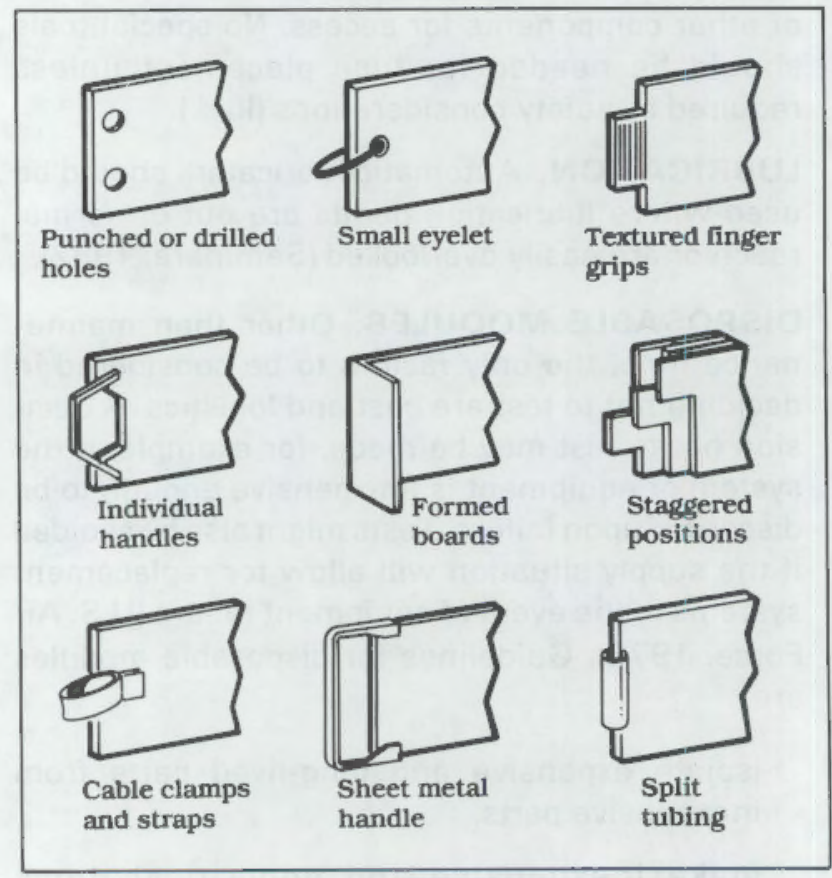

Figure 8.10. Alternate Methods for Providing Handles on Printed Circuit Boards (U.S. Army, 1972) 


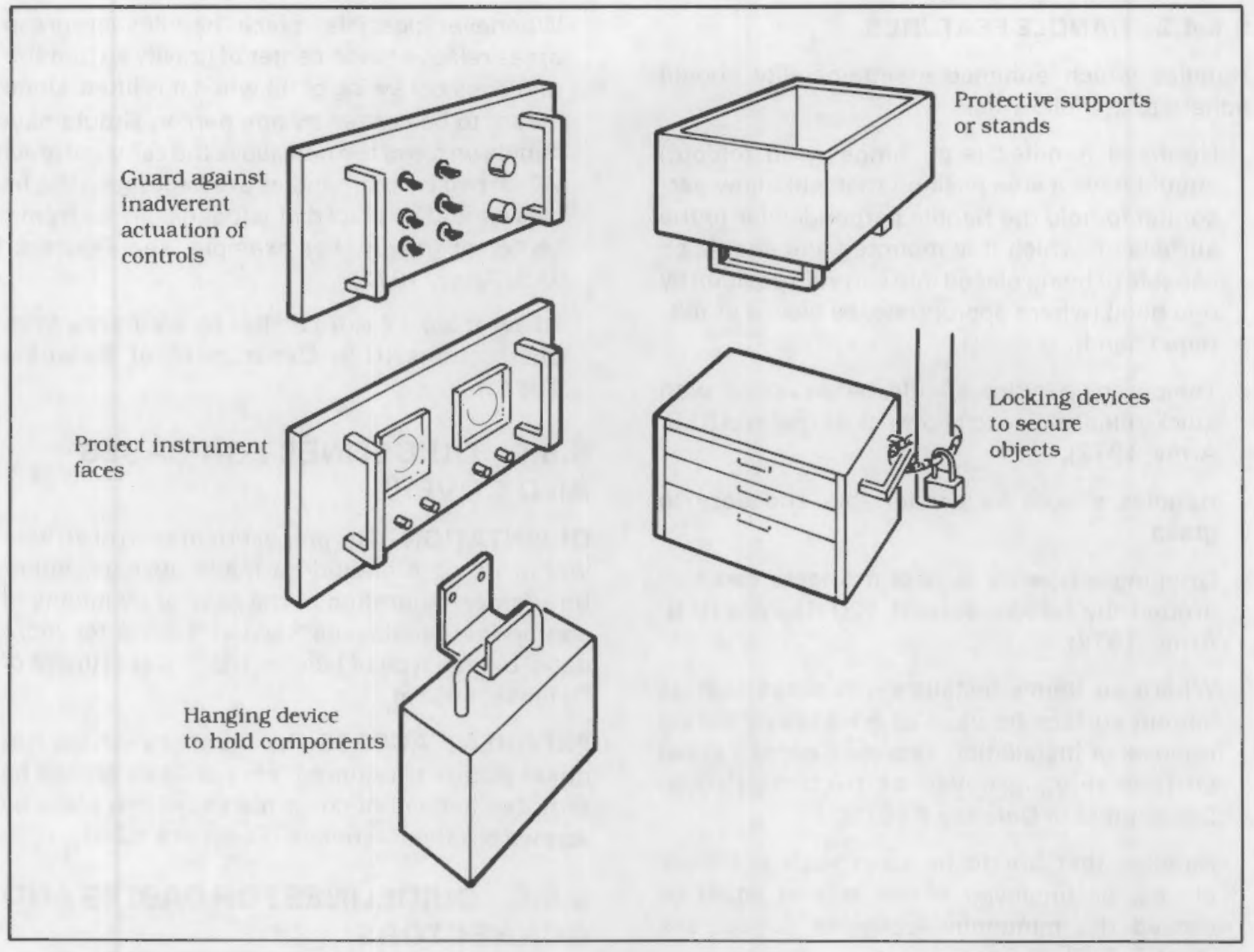

Figure 8.11. Additional Uses of Handles (U.S. Army, 1972)

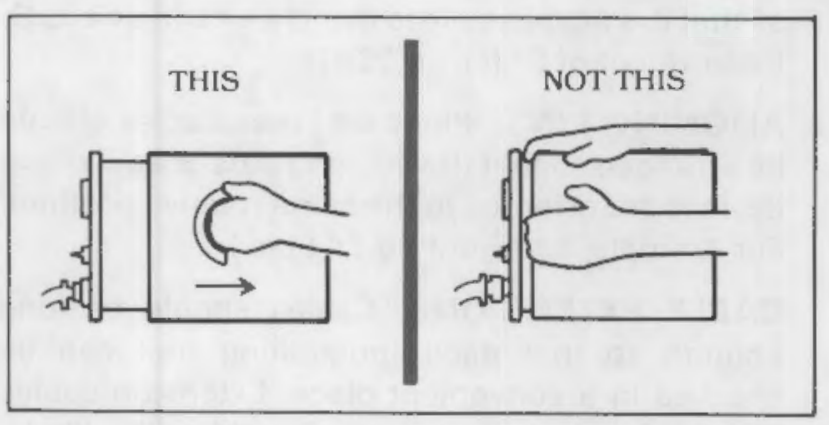

Figure 8.12. Place Handles to Facilitate Removal of Covers and Carrying of Units (U.S.

Army, 1972) type of clothing and gloves worn by personnel handling the equipment

operational position of the item relative to other items

manner in which the item is to be handled or positioned

distance over which the item must be carried.

frequency with which the item must be handled or carried

additional uses the handles could serve (U.S. Army, 1972). 


\subsubsection{HANDLE FEATURES}

Handles which enhance maintainability should adhere to the following:

Nonfixed handles (e.g., hinges and foldout) should have a stop position that will allow personnel to hold the handle perpendicular to the surface on which it is mounted and should be capable of being placed into carrying position by one hand (where appropriate, by gloved or mittened hand).

Temporary handles should be equipped with quick-release pins to allow easier removal (U.S. Army, 1972).

Handles should be comfortable and easy to grasp.

Gripping efficiency is best if fingers can curl around the handle at least 120 degrees (U.S. Army, 1972).

Where an item's installation requires that its bottom surface be used as a handhold during removal or installation, provide a nonslip grasp surface (e.g., grooved or frictional) (U.S. Department of Defense, 1981a).

Handles that are to be used with mittened, gloved, or ungloved hands should equal or exceed the minimum applicable dimensions given in Table 8.3.

Handles should meet the guidelines shown in Table $\mathbf{8 . 4}$ for protective clothing and for weight of objects to be lifted (U.S. Army, 1972).

Handles should also meet the lifting guidelines given in Section 5.4 of this document.

Items requiring handling should be provided with a minimum of two handles, or one handle and one grasp area. Items weighing less than $10 \mathrm{lb}$ that can be handled easily do not need handles (U.S. Department of Defense, 1981a).

For units weighing more than 100 to $150 \mathrm{lb}$, suitably labeled lifting eyes should be provided.
Whenever possible, place handles or grasp areas relative to the center of gravity so that the unit does not swing or tilt when it is lifted. Units meant to be carried by one person should have a handle on top of the unit above the center of gravity. When two or four handles are necessary, the handles should be placed at equal distances from the center of gravity. For example, see Figure 8.13 (U.S. Army, 1972).

Allow at least 2 extra inches for clearance from obstructions (U.S. Department of Defense, 1981 a).

\subsubsection{GUIDELINES FOR CASES AND COVERS}

ORIENTATION. The proper orientation of an item within its case should be made obvious, either through configuration of the case or by means of appropriate labels (see Section 9.3.1.4 for more detail on this type of labeling) (U.S. Department of Defense, 1981a).

FREQUENT ACCESS. In situations where frequent access is required, hinged doors should be provided instead of cover plates held in place by screws or other fasteners (Seminara, 1982).

\subsubsection{GUIDELINES FOR CABLES AND CONNECTORS}

IDENTIFICATION. All connectors should contain permanent mating identification and appropriate coding on both halves, or on their cable or mating chassis. Interchangeable units that are functionally dissimilar should be physically coded or keyed so that it is not possible to insert a wrong unit (U.S. Department of Defense, 1981a).

ALIGNING PINS. Plugs and receptacles should be arranged so that the aligning pins or equivalent devices are oriented in the same relative position. For example, see Figure 8.14 (lbid.).

CABLE EXTENSIONS. Cables should be long enough so that each functioning unit can be checked in a convenient place. Extension cables should be provided where this is not feasible (Ibid.). 
Table 8.3. Types of Handles and Their Dimensions (U.S. Department of Defense, 1981 a)

\begin{tabular}{|c|c|c|c|c|c|c|c|c|c|c|}
\hline \multirow{3}{*}{ Illustration } & \multirow{3}{*}{$\begin{array}{l}\text { Type of } \\
\text { Handle }\end{array}$} & \multicolumn{9}{|c|}{ Dimensions in inches } \\
\hline & & \multicolumn{3}{|c|}{ (Bare Hand) } & \multicolumn{3}{|c|}{ (Gloved Hand) } & \multicolumn{3}{|c|}{ (Mittened Hand) } \\
\hline & & $\mathbf{x}$ & $\mathbf{Y}$ & $z$ & $\mathbf{x}$ & $\mathbf{Y}$ & $z$ & $x$ & $\mathbf{Y}$ & $z$ \\
\hline & Two-finger bar & $1-1 / 4$ & $2-1 / 2$ & 3 & $1-1 / 2$ & 3 & 3 & \multicolumn{3}{|c|}{ Not Applicable } \\
\hline & One-hand bar & $1-7 / 8$ & $4-3 / 8$ & 3 & 2 & 5 & 4 & 3 & $6-1 / 4$ & 6 \\
\hline & Two-hand bar & $1-7 / 8$ & $8-1 / 2$ & 3 & 2 & $10-1 / 2$ & 4 & 3 & 11 & 6 \\
\hline & T-bar & $1-1 / 2$ & 4 & 3 & 2 & $4-1 / 2$ & 4 & \multicolumn{3}{|c|}{ Not Applicable } \\
\hline & J-bar & 2 & 4 & 3 & 2 & 4-1/2 & 4 & 3 & 5 & 6 \\
\hline & Two-finger recess & $1 \cdot 1 / 4$ & $2-1 / 2$ & 2 & $1-1 / 2$ & 3 & 2 & \multicolumn{3}{|c|}{ Not Applicable } \\
\hline & One-hand recess & 2 & $4-1 / 4$ & $3-1 / 2$ & $3-1 / 2$ & $5-1 / 4$ & 4 & $3-1 / 2$ & $5-1 / 4$ & 5 \\
\hline & Finger-tip recess & $3 / 4$ & & $1 / 2$ & 1 & & $3 / 4$ & \multicolumn{3}{|c|}{ Not Applicable } \\
\hline & One-fmger recess & $1-1 / 4$ & & 2 & $1-1 / 2$ & & 2 & \multicolumn{3}{|c|}{ Not Applicable } \\
\hline
\end{tabular}


Table 8.4. Lifting Guidelines for Handles ${ }^{1}$ (From U.S. Air Force, 1978

\begin{tabular}{lccc}
\hline $\begin{array}{l}\text { Weight } \\
\text { To Be } \\
\text { Lifted }\end{array}$ & $\begin{array}{c}\text { Handle } \\
\text { Diameter }\end{array}$ & $\begin{array}{c}\text { Finger } \\
\text { Clearances }\end{array}$ & $\begin{array}{c}\text { Handle } \\
\text { Width }\end{array}$ \\
\hline Under $25 \mathrm{lb}$ & $0.25-0.5$ & 2 & 4.5 \\
Over $25 \mathrm{lb}$ & $0.5 \cdot 0.75$ & 2 & 4.5 \\
$\begin{array}{l}\text { Lifted by } \\
\text { gloved hand }\end{array}$ & & 2.5 & 5 \\
\hline
\end{tabular}

${ }^{1}$ Dimensions given in inches.

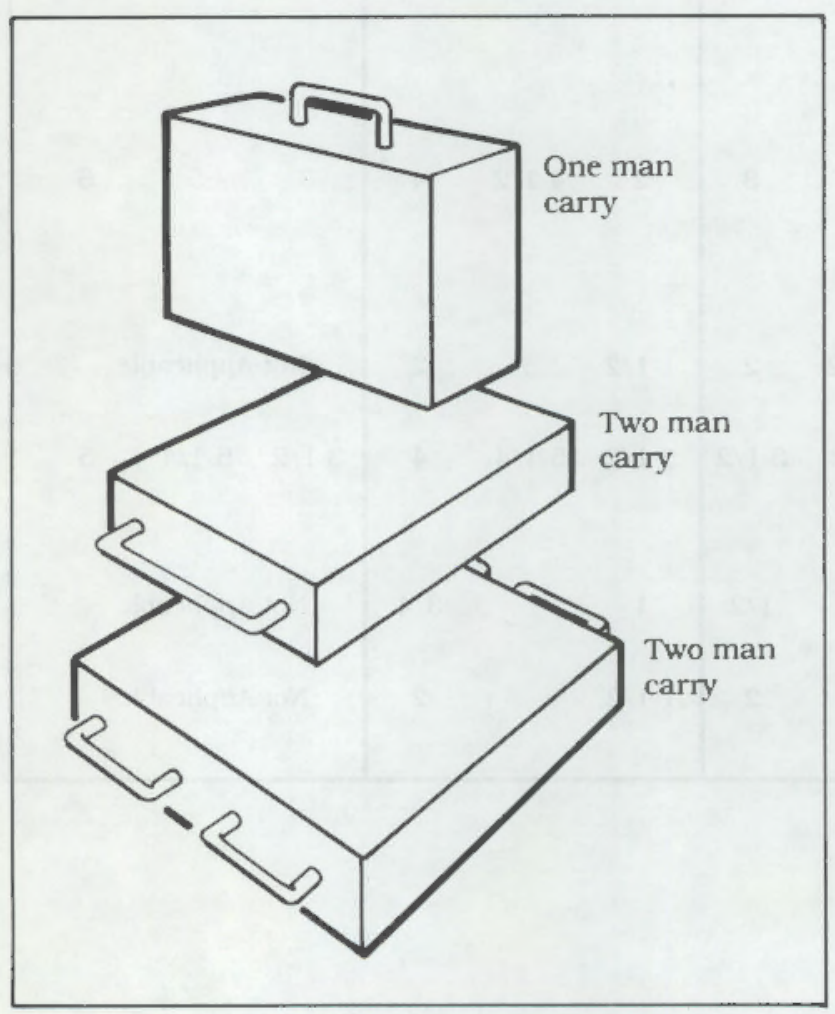

Figure 8.13. Place Handles for Ease in Carrying (U.S. Army, 1972)

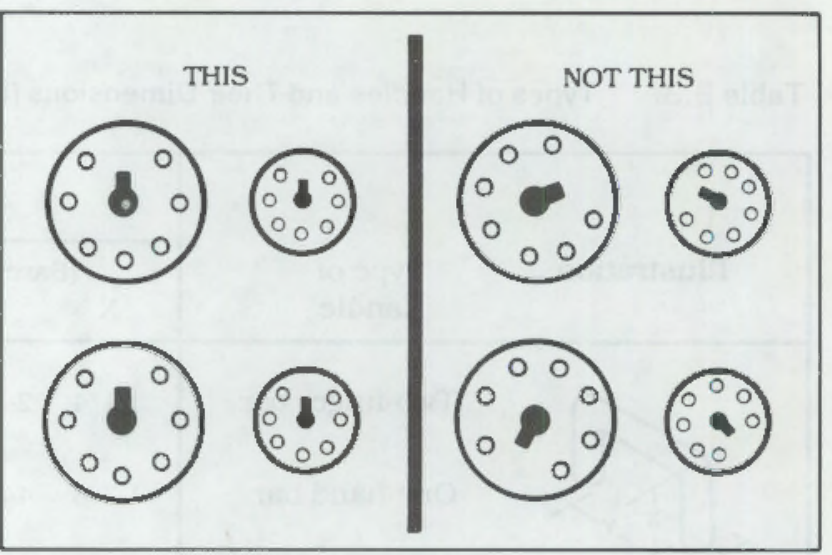

Figure 8.14. Common Orientation of Tube Sockets to Facilitate Replacement (U.S. Department of Defense, 1981 a)

SELF-LOCKING CONNECTORS. Where internal connection is not needed during maintenance, connectors to the drawer or shelf may be attached to the assembly itself so that connection takes place when the assembly is closed. Equipment that uses this type of connection requires that connector parts be mounted on the assembly and wall. Locks should be used to ensure that connectors remain engaged, while guides ensure proper orientation of the assembly prior to pin engagement. Insulation should be provided to ensure safety (U.S. Army, 1972).

ROUTING CABLES. Cables or lines should be routed through walls so that they can be easily installed or removed. Cutting and splicing of lines should be avoided (Seminara, 1982).

\subsubsection{GUIDELINES FOR FASTENERS}

The use of common fasteners and the appropriate number of fasteners, simplified clips and brackets can greatly simplify a maintenance task. Included here are specific guidelines for fastener design.

GEOMETRY. Use the simplest geometry possible, so that fastening and securing adjacent parts is made easy (U.S. Army Missile Command, 1965). 
ATTACHMENT POINTS. Use common attachment points for securing adjacent clips and brackets with the minimum number of fastener holes that are consistent with strength requirements (Ibid.).

CAPTIVE LATCHES. Latches and fasteners should be captive whenever possible and should not require special tools (lbid.).

RELEASE. Fasteners should require only a fraction of a turn to release, or if bolts are used, the number of turns required should be kept to a minimum (lbid.).

TYPES AND SIZES. A minimum number of types and sizes of hand-operated fasteners should be used (Ibid.).

BOLTS. If bolts are used on internal latches or fasteners, the heads should be hexagonal, with deep internal slots (lbid.).

SETSCREWS. All setscrews should have the same type and size head (Ibid.).

COVER. Personnel should be able to tell when a cover is not secured, even though the cover may be in place (U.S. Department of Defense, 1981 a).

\subsubsection{GUIDELINES FOR INTEGRATING TESTING NEEDS WITH EQUIPMENT}

The use of various categories of test equipment can simplify maintenance tasks. However, means to satisfy testing needs should be carefully integrated into the equipment. Poorly conceived testing features can complicate maintenance and increase the probability of error.

\subsubsection{USE OF AUTOMATIC AND SEMI- AUTOMATIC TESTING METHODS}

Automatic and semiautomatic testing should be considered only when one or more of the following conditions exist:

turnaround time or downtime must be held to an absolute minimum

many repetitive measurements must be made maintenance loads are heavy.
LOCATION OF TEST POINTS. When automatic and semiautomatic testing methods are used, the test points should interface with the tester through a minimum number of multiple-contact connectors located on the face of the item, rather than through large numbers of individual test points. Less preferable is the internal location of individual test points (for manual testing) close to the circuit elements for which they serve as input or output points (Figure 8.15 ). These locations should be easily accessible; system operation should not be interrupted to engage the test point (U.S. Air Force, 1978).

LOCATION OF CONNECTORS. Connectors to be used with automatic and semiautomatic testers can be located inside the item, as long as they are logically grouped and clearly marked (lbid.).

USE OF BUILT-IN TEST EQUIPMENT (BITE). Internal test equipment, usually referred to as Built-In Test Equipment (BITE), performs specific test functions of a component or system. By contrast, external test equipment can serve either general purposes, such as general tests on generators, meters, and scopes, or special purposes (lbid.).

CONSIDERATIONS FOR SELECTION. In Selecting the type of test equipment to be used, designers should consider the qualifications of the maintenance technician, physical factors involved

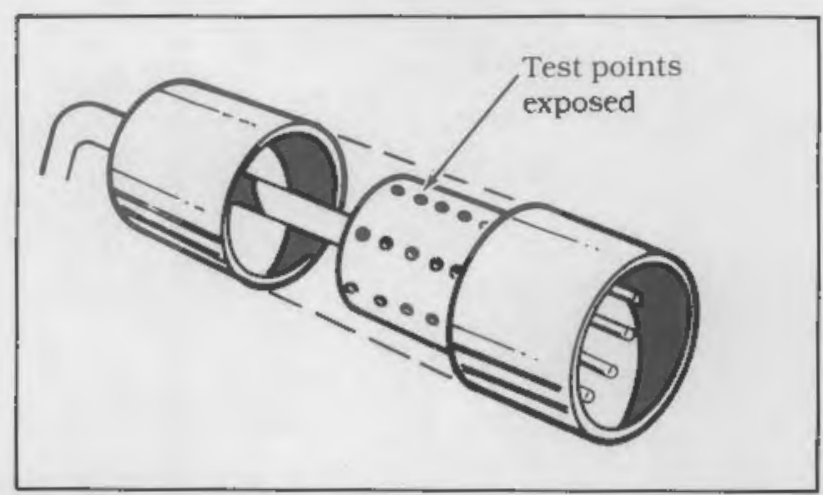

Figure 8.15. Test Points with Built-In Covers (U.S. Air Force, 1978) 
in accomplishing the test, the maintainability of the test equipment, and the logistics of conducting tests (Table 8.5). Some advantages and disadvantages of using BITE are detailed in Table 8.6 (Ibid.).

\subsubsection{GUIDELINES FOR DESIGN OF EQUIPMENT TESTING FEATURES}

SENSORS. Wherever possible, sensors used for testing should be passive. Passive sensors perform their functions with unpowered circuits, e.g., voltage-divider networks and integrating circuits. By contrast, active sensors use powered circuits such as amplifiers and flip-flops. Sensors are best specified by identifying the characteristics desired, such as the function to be performed, the input range, the output characteristics, and the time constant (U.S. Air Force, 1978).
SWITCHES. As the amount of testing increases, switching functions become more complex. It is often convenient to arrange the switches in matrices as the number of switching devices increases, so that control becomes simpler (lbid.).

SIGNALTYPE. As a general guide, digital signals should be converted to analog (if conversion is required) as near to the test point as possible and arrange test points so that a minimum number of converters is required (Ibid.).

TEST POINTS. Where manual testing methods are to be employed, test points should be arranged to be compatible with the sequence of testing (lbid.). 
Table 8.5. Factors in Selecting Test Equipment (U.S. Air Force, 1978)

\begin{tabular}{|c|c|c|c|c|}
\hline \multirow[b]{2}{*}{ Factor } & \multirow[b]{2}{*}{ Consideration } & \multicolumn{3}{|c|}{ Rating } \\
\hline & & Built-In & $\begin{array}{l}\text { Special } \\
\text { Purpose }\end{array}$ & $\begin{array}{l}\text { General } \\
\text { Purpose }\end{array}$ \\
\hline \multirow{6}{*}{$\begin{array}{l}\text { Maintenance } \\
\text { Technician }\end{array}$} & Personnel acceptance & High & Medium & Low \\
\hline & Personnel safety & High & High-Medium & Medium-Low \\
\hline & Complexity of test equipment operation & Low & Medium & High \\
\hline & Time to complete tests & Least & Medium & Most \\
\hline & Personnel training time & Least & Medium & Most \\
\hline & Tendency to over-depend on test equipment & High & High & Low \\
\hline \multirow[t]{7}{*}{ Physical Factors } & Limits on size of test equipment & \multicolumn{2}{|c|}{$\begin{array}{l}\text { Minimum limits; depends on } \\
\text { prime equipment and } \\
\text { application }\end{array}$} & $\begin{array}{l}\text { Maximum limits; } \\
\text { limited by portability }\end{array}$ \\
\hline & Limits on weight of test equipment & \multicolumn{2}{|c|}{$\begin{array}{l}\text { Minimum limits, depends on } \\
\text { prime equipment application }\end{array}$} & $\begin{array}{l}\text { Maximum limits; } \\
\text { limited portability }\end{array}$ \\
\hline & Complexity of "wiring in" test equipment & High & High & Low \\
\hline & $\begin{array}{l}\text { Need for additional test points in prime } \\
\text { equipment }\end{array}$ & None & None & Many \\
\hline & Space in work areas & Least & Some & Most \\
\hline & Storage problems & None & Medium & Many \\
\hline & Need for traffic considerations & Low & Medium & High \\
\hline \multirow{3}{*}{$\begin{array}{l}\text { Maintainability } \\
\text { and } \\
\text { Reliability }\end{array}$} & Probability of damage to test equipment & Low & Low & High \\
\hline & $\begin{array}{l}\text { Probebility of damage to prime equipment } \\
\text { caused by testing }\end{array}$ & Low & Low & High \\
\hline & $\begin{array}{l}\text { Effect on prime equipment operation of repairing } \\
\text { test equipment failures }\end{array}$ & Some & Slight & None \\
\hline \multirow[t]{4}{*}{ Logistics } & Cost to incorporate test equipment & High & Medium-High & None \\
\hline & Time to procure test equipment & High & Medium & Low \\
\hline & Design-engineering effort & High-Medium & High-Medium & Low \\
\hline & $\begin{array}{l}\text { Compliance of test equipment to same } \\
\text { specifications as prime equipment }\end{array}$ & Must & May & May \\
\hline \multirow[t]{4}{*}{ Application } & $\begin{array}{l}\text { Advantage of long duration and high-frequency } \\
\text { usage in given location }\end{array}$ & High & High-Medium & Low \\
\hline & Versatility of application & Low & Low & High \\
\hline & Opportunity for incorrect usage & Low & Low & High \\
\hline & System adaptability to new test equipment & Low & Medium & High \\
\hline
\end{tabular}




\section{Operating Equipment}

Table 8.6. Advantages and Disadvantages of Built-In Test Equipment (U.S. Air Force, 1978)

\begin{tabular}{|c|c|}
\hline Advantages & Disadvantages \\
\hline Minimizes requirements for external support equipment. & $\begin{array}{l}\text { Resulting hardware is heavier, larger, and requires more } \\
\text { power. Requires compromise on part of designer on } \\
\text { minimum number and types of tests that could be } \\
\text { performed on equipment without exceeding weight and } \\
\text { size limitations. }\end{array}$ \\
\hline $\begin{array}{l}\text { Minimizes downtime required to troubleshoot equipment. } \\
\text { Also decreases service-induced failures and possible } \\
\text { injury to repairman by allowing fault isolation to be } \\
\text { performed without needless probing into interior of } \\
\text { equipment. }\end{array}$ & $\begin{array}{l}\text { Increases complexity of prime equipment, thus increasing } \\
\text { development effort, cost, and time. Also increases } \\
\text { maintenance to be performed on prime equipment and } \\
\text { system. }\end{array}$ \\
\hline $\begin{array}{l}\text { Identifies performance degradation by operating personnel } \\
\text { in sufficient time to avoid serious breakdowns. }\end{array}$ & $\begin{array}{l}\text { Difficult to calibrate test facilities because of inability to } \\
\text { separate these facilities from prime equipment. }\end{array}$ \\
\hline $\begin{array}{l}\text { Increases system confidence through availability of } \\
\text { monitoring facilities. }\end{array}$ & $\begin{array}{l}\text { Requires additional self-checking features to ensure that } \\
\text { degradation of test facilities does not go unnoticed. }\end{array}$ \\
\hline $\begin{array}{l}\text { Assures that modifications of prime equipment are made } \\
\text { concurrently with integral test facilities. }\end{array}$ & $\begin{array}{l}\text { Requires extreme caution in selection of test to be } \\
\text { performed. Changes in procedures require equipment } \\
\text { redesign. Inflexibility in this area is limiting factor. }\end{array}$ \\
\hline
\end{tabular}




\section{Chapter 9 INFORMATION NEEDS}

The human sensory system consists of receptors that are responsive to specific types and ranges of stimuli. Physical stimuli produce sensations in sense organs, or receptors. The physical effect on these receptors is usually measurable and therefore predictable, just as it would be for a machine. In humans it is possible to estimate an output for a known input; however, the accuracy of this prediction is much lower than the same predictions made for a machine. This degree of uncertainty is accounted for in the perceptual processes that occur between the input stimuli and resulting outputs such as motor functions (Murrell, 1969).

The human sensory organs respond to a variety of sensations (Table 9.1). Moreover, the threshold for detection of stimuli to the largest tolerable intensity may cover a wide range (Table 9.2). From Tables 9.1 and 9.2 and a superficial understanding of perceptual processes, it should be obvious that controlling the responses of personnel not only depends upon the appropriate stimulus range, but also upon relevant stimuli that can be accurately recognized and understood.

\subsection{PROBLEMS}

Human characteristics, tolerances, limitations, and needs should be considered in the operation and maintenance of systems just as the attributes/ physical properties of various inanimate system components are considered. Without such considerations, work conditions may foster an increase in the probability of human error and may even preclude the completion of certain system tasks (Badalamente et al., 1982). The U.S. Air Force (1980) lists conditions that may result in human unreliability: (1) sensory or perceptual demands that are near or beyond physiological limits; (2) demands for manual response that are physically difficult, conflict with established habit patterns, or cannot be checked or monitored; (3) decision-making that relies on detailed memory or overly quick or uncertain determinations; (4) communications, information-gathering and information-processing demands that interfere with each other, or with other activities; and (5) operating conditions that can overload the sen- sory mechanisms or distract, irritate, or even harm personnel (U.S. Air Force, 1980). All of these conditions point to the need for providing relevant visual, tactile and auditory stimuli for maintenance personnel.

The extreme environments in which maintenance personnel operate are demanding. Protective clothing required in these environments mask visual, tactual and auditory signals that are important for maintenance task completion and occupational safety. Moreover, personnel often perform maintenance tasks on equipment that lacks identification or instructional labels, easily viewed display gauges, or accurately identified lines, valves or controls. They sometimes cannot distinguish between reactor units and often perform tasks that are not outlined. Such deficiencies cause delays in task completion, increase downtime, costs and maintenance time, and sometimes cause increases in radiation exposures. Specific problems identified by Badalamente et al. (1982) include:

maintenance equipment displays or indicators that are placed in locations beyond normal reading range

placards/tags for identifying equipment that are illegible

visual fields that are restricted by protective gear tactile sensation that is masked by protective gear equipment that is insufficiently identified or coded

insufficient warnings, load limits, torque requirements and contamination levels on equipment placards or labels

symbolic displays that are not standardized.

\subsection{SAFETY IMPACT}

Public and occupational safety are affected when maintenance tasks are not accomplished, not done in a timely manner, or when done improperly. For instance, the tendency for personnel to improvise increases when labeling is not provided. Labels must be accurate and complete to prevent injury to 
Information Needs

Table 9.1. Human Senses and the Energies that Stimulate Them (From Van Cott and Kinkade, 1972)

\begin{tabular}{|c|c|c|c|}
\hline Sensation & Sense Organ & Stimulation & Origin \\
\hline Sight & Eye & Some electromagnetic waves & External \\
\hline Hearing & Ear & $\begin{array}{l}\text { Some amplitude and frequency } \\
\text { variations of pressure in surround- } \\
\text { ing media }\end{array}$ & External \\
\hline \multirow[t]{2}{*}{ Rotation } & Semicircular canals & $\begin{array}{l}\text { Change of fluid pressures in inner } \\
\text { ear }\end{array}$ & Internal \\
\hline & Muscle receptors & Muscle stretching & Internal \\
\hline $\begin{array}{l}\text { Falling and rectilinear } \\
\text { movement }\end{array}$ & Otoliths & $\begin{array}{l}\text { Position changes of small, bony } \\
\text { bodies in inner ear }\end{array}$ & Internal \\
\hline Taste & $\begin{array}{l}\text { Specialized cells in tongue and } \\
\text { mouth }\end{array}$ & Chemical substances & $\begin{array}{l}\text { External on } \\
\text { contact }\end{array}$ \\
\hline Smell & $\begin{array}{l}\text { Specialized cells in mucous mem- } \\
\text { brane at top of nasal cavity }\end{array}$ & Vaporized chemical substances & External \\
\hline Touch & Skin & Surface deformation & On contact \\
\hline Pressure & Skin and underlying tissue & Surface deformation & On contact \\
\hline Temperature & Skin and underlying tissue & $\begin{array}{l}\text { Temperature changes of surround- } \\
\text { ing media or objects, friction, and } \\
\text { some chemicals. }\end{array}$ & $\begin{array}{l}\text { External on } \\
\text { contact }\end{array}$ \\
\hline Pain & $\begin{array}{l}\text { Unknown, but thought to be free } \\
\text { nerve endings }\end{array}$ & $\begin{array}{l}\text { Intense pressure, heat, cold, shock, } \\
\text { and some chemicals }\end{array}$ & $\begin{array}{l}\text { External on } \\
\text { contact }\end{array}$ \\
\hline \multirow{3}{*}{$\begin{array}{l}\text { Position and movement } \\
\text { (kinesthesis) }\end{array}$} & Muscle nerve endings & Muscle stretching & Internal \\
\hline & Tendon nerve endings & Muscle contraction & Internal \\
\hline & Joints & Unknow்n & Internal \\
\hline Mechanical vibration. & No specific organ & $\begin{array}{l}\text { Amplitude and frequency variations } \\
\text { of pressure }\end{array}$ & $\begin{array}{l}\text { External on } \\
\text { contact }\end{array}$ \\
\hline
\end{tabular}

personnel or damage to equipment (Badalamente et al., 1982). In extreme cases, misinformation could result in improperly maintained equipment, thus increasing public risk associated with the failure of that equipment or system.

Of the sensory organs functioning to detect stimuli, the visual channel is the most important to maintenance personnel. The efficiency with which this channel operates depends both upon the nature of the visual information and the manner in which it is displayed (Murrell, 1969). The guidelines presented in this chapter concentrate on these areas, with emphasis on labels (Section 9.3) and displays (Section 9.4). Additional areas on tactual feedback and auditory signals have been addressed because of tactual masking problems introduced by protective gear and because of auditory signals masked by high noise maintenance environments. 
Table 9.2. Stimulation Intensity of Human Senses (From Van Cott and Kinkade, 1972)

\begin{tabular}{|c|c|c|}
\hline Sensation & Smallest Detectable (threshold) & Largest Tolerable or Practical \\
\hline Sight & $10^{-6} \mathrm{~mL}$ & $10^{4} \mathrm{~mL}$ \\
\hline Hearing & $2 \times 10^{-4}$ dynes $/ \mathrm{cm}^{2}$ & $<10^{3}$ dynes $/ \mathrm{cm}^{2}$ \\
\hline Mechanical vibration & $\begin{array}{l}25 \times 10^{-5} \mathrm{~mm} \text { average amplitude at the } \\
\text { fingertip (maximum sensitivity } 200 \mathrm{~Hz} \text { ) }\end{array}$ & $\begin{array}{l}\text { Varies with size and location of stimulator. } \\
\text { Pain likely } 40 \mathrm{~dB} \text { above threshold. }\end{array}$ \\
\hline Touch (pressure) & $\begin{array}{l}\text { Fingertips, } 0.04 \text { to } 1.1 \text { erg (One erg approx. } \\
\text { kinetic energy of } 1 \mathrm{mg} \text { dropped } 1 \mathrm{~cm} \text {.) } \\
\text { "Pressure," } 3 \mathrm{~g} / \mathrm{mm}^{2} \text {. }\end{array}$ & Unknown. \\
\hline Smell & $\begin{array}{l}\text { Very sensitive for some substances, e.g., } 2 \times \\
10^{-7} \mathrm{mg} / \mathrm{m}^{3} \text { of vanillin. }\end{array}$ & Unknown. \\
\hline Taste & $\begin{array}{l}\text { Very sensitive for some substances, e.g., } 4 \mathrm{x} \\
10^{-7} \text { molar concentration of quinine sulfate }\end{array}$ & Unknown. \\
\hline Temperature & $\begin{array}{l}15 \times 10^{-5} \mathrm{~g}-\mathrm{cal} / \mathrm{cm}^{2} / \mathrm{sec} \text {. for } 3 \text { sec. exposure } \\
\text { of } 200 \mathrm{~cm}^{2} \text { skin. }\end{array}$ & $\begin{array}{l}22 \times 10^{2} \mathrm{~g}-\mathrm{cal} / \mathrm{cm}^{2} / \mathrm{sec} \text {. for } 3 \mathrm{sec} \text {. exposure } \\
\text { of } 200 \mathrm{~cm}^{2} \mathrm{skin} .\end{array}$ \\
\hline Position and movement & $\begin{array}{l}0.2-0.7 \mathrm{deg} . \text { at } 10 \mathrm{deg} . / \mathrm{min} \text { for joint } \\
\text { movement }\end{array}$ & Unknown. \\
\hline Acceleration & $\begin{array}{l}0.02 \mathrm{~g} \text { for linear acceleration } \\
0.08 \mathrm{~g} \text { for linear deceleration } \\
0.12 \mathrm{deg} . / \mathrm{sec}^{2} \text { rotational acceleration for } \\
\text { oculogyral illusion (apparent motion or } \\
\text { displacement of viewed object). }\end{array}$ & $\begin{array}{l}5 \text { to } 8 \mathrm{~g} \text { positive: } \\
3 \text { to } 4 \mathrm{~g} \text { negative. } \\
\text { Disorientation, confusion, vertigo, blackout, } \\
\text { or redout. }\end{array}$ \\
\hline
\end{tabular}

\subsection{GUIDELINES FOR LABELS}

Labels, legends, placards, signs, and markings, or a combination of these should be provided whenever it is necessary for personnel to identify, interpret, follow procedures or avoid hazards. Labels should be consistent with:

accuracy of identification required

time that is available for recognition or other responses

appropriate distance for reading the label

illuminant level and color

critical nature of the function labeled

consistency of label design within and between systems (U.S. Department of Defense, 1981a)

\subsubsection{LOCATING LABELS}

Labels should be placed close to the items they identify to eliminate confusion with other items and labels (U.S. Department of Defense, 1981a).

CONTROLS. Labels should not appear on the control itself when an adjustment or manipulation is required that causes the operator's hand to obscure the label for an extended time period (lbid.).

SEPARATION. Adjacent labels should be separated by sufficient space so that they are not read as one continuous label (Figure 9.1) (lbid.).

IDENTIFYING MAJOR ASSEMBLIES. GrosS identifying labels on a unit, assembly or major assembly should be located externally, in such a 


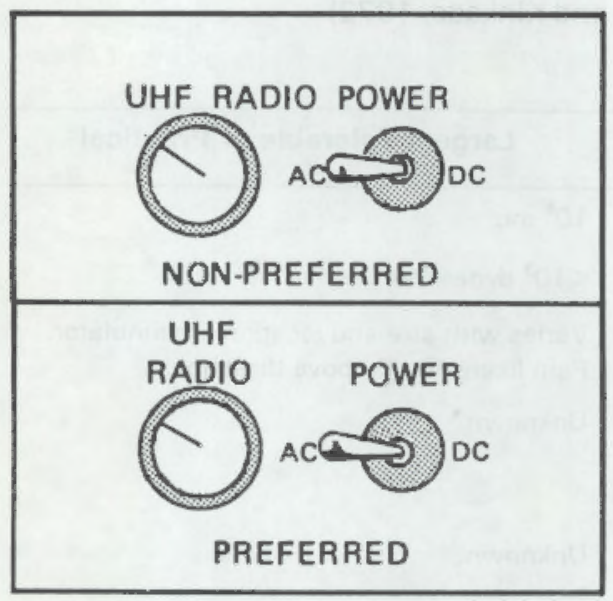

Figure 9.1. Preferred and Non-Preferred Label Placement (U.S. NRC, 1981)

position so that the label is not obscured by adjacent items (lbid.).

PROMINENCE. Labels should be placed on the flattest, most uncluttered surface available, on the main chassis of the equipment (lbid.).

PREVENTING OBSTRUCTION OR DAMAGE. Labels should be designed so that wear and obscurement by grease, grime or dirt are minimized and accidental removal, obstruction or damage from handling is precluded (Ibid.).

EASE OF OPERATION. Control and display labels should be placed so that ease of control operation has priority over visibility of control position labels (lbid.)

LABEL POSITION. Normally, labels should be placed above the controls and displays they describe. When the panel is above eye level, labels should be positioned to ensure label visibility (U.S. Department of Defense, 1981a). For additional information applicable to label panels, see U.S. Nuclear Regulatory Commission, 1981.

\subsubsection{LABEL ORIENTATION}

Labels and information should be oriented horizontally so that they may be read quickly and easily from left to right (U.S. Department of Defense, 1981a).

VERTICAL ORIENTATION. Although not normally recommended, vertical orientation may be used where space is limited and when labels are not critical for personnel safety or performance. When used, vertical labels should be read from top to bottom (lbid.).

CURVED PATTERNS. Curved patterns of labeling should be avoided (Figure 9.2) (lbid.).

NORMAL POSITION. Markings should be made so that information can be read when the unit is in the normal installed position (U.S. Army, 1972).

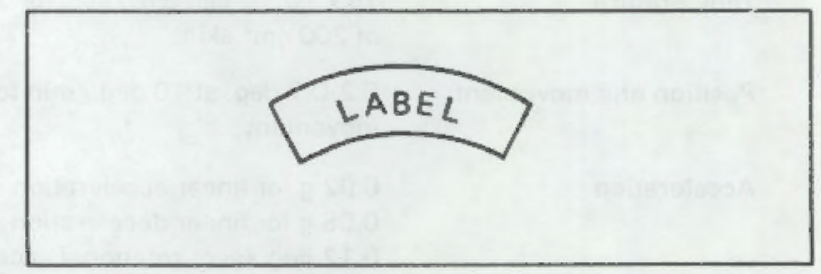

Figure 9.2. Poor Practice: Curved Pattern (U.S. NRC, 1981)

\subsubsection{LABEL VISIBILITY}

Legibility of instruction decals, checklists, and labels become critical during emergencies and when the operator is pressed for time. To insure visibility, placards and labels should be:

read easily under given maintenance conditions openly visible, not obscured by other units in the equipment assembly

visible to the operator during control actuation painted with a color that contrasts with the equipment background

subject to administrative procedures for periodic cleaning (U.S. Department of Defense, 1981 a). 
LIGHT ADAPTATION. When lighting conditions are such that ambient illuminance will be above $0.9 \mathrm{ft}$-c (10-lux.), black characters should be used against a light background (Ibid.).

DARK ADAPTATION. Where adaptation to dark is necessary, letters or numerals should be visible without interfering with night vision. In this case, markings should be white on a dark background (lbid.).

DANGER AND CAUTION SIGNS. Letters may be 0.5 in. on DANGER and CAUTION signs (U.S. Army, 1972).

GRADUATED LETTER SIZE. To reduce operator search time, labels should be graduated in letter size such that: system/work station labels are about $25 \%$ larger than subsystem/functional group labels, which are about $25 \%$ larger than component labels, which are about $25 \%$ larger than control position identifiers (U.S. Department of Defense, 1981a).

\subsubsection{LABEL READABILITY}

The speed and accuracy of human performance in identifying controls/displays and equipment is influenced by the style and size of characters used for label lettering.

LETTER WIDTH. Letter width should be $3 / 5$ of the letter height, except for " $M$ " and " $W$ " which should be 4/5 of the letter height, and "I," which should be one stroke wide (U.S. Department of Defense, 1981 a).

NUMERAL WIDTH. Numeral width should be $3 / 5$ as wide as high, except for the " 4 ," which should be one stroke width wider, and the "1," which should be one stroke wide (lbid.).

CHARACTER HEIGHT. With a $28 \mathrm{in} .(710 \mathrm{~mm})$ viewing distance, the height of numerals and letters should be within the range of values indicated in Table 9.3 for "low" and "high" control-display luminance conditions. For general dial and panel design with the luminance normally about $1 \mathrm{ft}-\mathrm{c}$ $(3.5 \mathrm{~cd} / \mathrm{m})$, character height should conform to the values given in Table 9.4 (lbid.).
Table 9.3. Height of Labels at Different Levels of Luminance (from U.S. Department of Defense, 1981 a)

\begin{tabular}{|c|c|c|}
\hline \multirow[b]{2}{*}{ Marking } & \multicolumn{2}{|c|}{ Luminance } \\
\hline & $\leq 1 \mathrm{ft}-\mathrm{L}$ & $>1 \mathrm{ft}-\mathrm{L}$ \\
\hline $\begin{array}{l}\text { Critical markings, } \\
\text { position variable } \\
\text { (e.g., numerals on } \\
\text { counters and } \\
\text { settable or moving } \\
\text { scales) }\end{array}$ & $0.20-0.31 \mathrm{in.}$ & $0.12 \cdot 0.20 \mathrm{in}$ \\
\hline $\begin{array}{l}\text { Critical markings, } \\
\text { position fixed /e.g.. } \\
\text { numerals on fixed } \\
\text { scales, controls and } \\
\text { switch markings or } \\
\text { emergency } \\
\text { instructions }\end{array}$ & $0.16-0.31 \mathrm{in.}$ & $0.10-0.20$ in. \\
\hline $\begin{array}{l}\text { Non-critical mark- } \\
\text { ings (e.g., identifica- } \\
\text { tion labels, routine } \\
\text { instructions or mark- } \\
\text { ings required for } \\
\text { femiliarization only) }\end{array}$ & $0.05-0.20 \mathrm{in}$ & $0.05-0.20$ in. \\
\hline \multicolumn{3}{|c|}{$\begin{array}{l}{ }^{1} \text { Values for height assume a viewing distance of } 28 \text { in. For a } \\
\text { distance (D) other than } 28 \text { in., multiply the above values by } \\
\text { D/28. }\end{array}$} \\
\hline
\end{tabular}

Table 9.4. Minimum Height of Characters at Specified Viewing Distances (From U.S. Department of Defense, 1981 a)

\begin{tabular}{cc}
\hline Viewing Distance (in.) & $\begin{array}{c}\text { Minimum } \\
\text { Height (in.) }\end{array}$ \\
\hline$<19.7$ & 0.09 \\
$19.7-39.4$ & 0.18 \\
$39.4-78.7$ & 0.37 \\
$78.7-157.5$ & 0.75 \\
$157.5-315.5$ & 1.50 \\
\hline
\end{tabular}


CURVED SURFACES. Where conditions such as curved surfaces on equipment indicate the use of wider characters, the basic height-to-width ratio may be increased to $1: 1$ (lbid.).

STROKE WIDTH-TO-HEIGHT RATIOS. In general, stroke width-to-height ratio of characters should be between 1:6 and 1:8 (McCormick and Sanders, 1982). The stroke width should be the same for all letters and numerals of equal height (lbid.).

BLACK ON WHITE BACKGROUND. For black characters on a whjte or light background, stroke width should be $1 / 6$ to $1 / 7$ of the height (U.S. Department of Defense, 1981 a; U.S. Air Force, 1980).

WHITE ON BLACK BACKGROUND. Where dark adaptation is necessary, or legibility at night is a critical factor and white characters are specified on a black background, the stroke width of the characters should be from $1 / 7$ to $1 / 8$ of the height, which is narrower than specified for normal daytime vision (U.S. Department of Defense, 1981a).

SPACE BETWEEN LINES. The minimum space between lines should be one-half of the character height (Ibid.).

SPACE BETWEEN CHARACTERS. The minimum space between characters should be one stroke width (Ibid.).

SPACE BETWEEN WORDS. The minimum space between words should be one character width (Ibid.).

CHARACTER SELECTION. Labels should be prepared in capital letters when the information contained in the label is short (Ibid.).

LENGTHY TEXT. Instructional placards may employ capitals and lower case when the amount of material consists of several lines (Ibid.).

GOTHIC TYPE. The preferred style of gothic characters for various marking processes is given in Table 9.5.

\subsubsection{LABEL CONTENT}

PRIMARY INFORMATION. Equipment name plates should be permanently and legibly marked with:

\author{
item name (noun first) \\ specification no. \\ manufacturer's part no. (or government stand- \\ ard part no.) \\ serial no. (when available) \\ stock no. (when available) \\ manufacturer's name and address.
}

SECONDARYINFORMATION. Secondary information should include pertinent data on the equipment's function, capacity, capabilities, limits, ranges, frequency and current requirements. Weight, rpm and horsepower should also be included (U.S. Army, 1972).

OPERATING INSTRUCTIONS. Instruction plates should describe or illustrate basic operating instructions. They should contain:
calibration data and adjustment instructions
simple wiring or fluid flow diagrams
warning and safety precautions
location of test points
transistors and other pertinent electronic equipment
valve or ignition settings
types of fuels, oils or greases applicable
other data required for performing routine maintenance.

CALIBRATION. Include a reminder that the devices must be calibrated, especially if calibration is required before each usage or change in usage (Rigby, Cooper and Spickard, 1961).

PROXIMITY OF INFORMATION. When necessary, a permanent pocket or similar holding device 
Table 9.5. Marking Processes and Recommended Gothic Type Styles (From U.S. Army, 1972)

\begin{tabular}{|c|c|c|}
\hline Marking Method & Preferred Gothic Type Style (Capitals) & $\begin{array}{l}\text { Alternate Gothic Type Style } \\
\text { (Cepitals)(Specify Only if a } \\
\text { Design Requirement) }\end{array}$ \\
\hline Engraving & Gorton Condensed & Gorton Normal or Extra Condensed \\
\hline $\begin{array}{l}\text { Steel stamping: } \\
\text { Hand (Part identification) }\end{array}$ & Gorton Condensed & Groton Extra Condensed \\
\hline $\begin{array}{l}\text { Etching: } \\
\text { Electrical }\end{array}$ & Gorton Condensed & Gorton Extra Condensed \\
\hline $\begin{array}{l}\text { Chemical or photo (Metal } \\
\text { nameplates, designation } \\
\text { plates, information plates, } \\
\text { etc.) }\end{array}$ & Futura Medium Condensed & Futura Demi-Bold \\
\hline Sand casting & Gorton Normal & Gorton Condensed \\
\hline Rubber stamping & American Type Founders (ATF) & American Type Founders (ATF) \\
\hline Stenciling & News Gothic Condensed & News Gothic Extra Condensed \\
\hline Printing & $\begin{array}{l}\text { American Type Founders (ATF) } \\
\text { News Gothic Condensed (plus lower case) }\end{array}$ & $\begin{array}{l}\text { American Type Founders (ATF) } \\
\text { New Gothic Extra (plus lower case) }\end{array}$ \\
\hline Screen printing & $\begin{array}{l}\text { 1. Futura Medium Condensed (for } \\
\text { characters above } 0.125 \text { in.) } \\
\text { 2. Futura Demi-Bold (for Caution and } \\
\text { Warning Signs and for Characters } \\
0.125 \text { in. and less }\end{array}$ & \\
\hline $\begin{array}{l}\text { Decalcomania transfers } \\
\text { Aluminum foil labels }\end{array}$ & Futura Medium Condensed & Futura Demi-Bold \\
\hline
\end{tabular}

should be attached. Maintenance aids such as signal flow diagrams, diagnostic procedures, pictorial presentations and maintenance records can be placed inside the pocket.

MULTI-UNIT PLANTS. Labels and placards used in multi-unit plants should be sufficiently distinctive to prevent confusion of one unit for another. Label and tag notations should correspond to sys- tem diagrams, schematics and procedures (Seminara, 1982).

INSTRUCTIONS. When labels contain a number of steps to be performed sequentially, steps should be itemized rather than presented in paragraph form (Figure 9.3; U.S. Army, 1972). 


\section{Information Needs}

\begin{tabular}{|c|c|c|}
\hline & USE THIS & NOT THIS \\
\hline & Assembling Injector Tapping Tool & Assembling Injector Tapping Tool \\
\hline 1. & $\begin{array}{l}\text { Replace defective part } \\
\text { Install nut and washer on hand-tap shank }\end{array}$ & $\begin{array}{l}\text { First replace the defective part from supply. } \\
\text { Install nut and washer on hand-tap shank. }\end{array}$ \\
\hline 4. & $\begin{array}{l}\text { Install Rollpin in nut } \\
\text { Check tapping tool for proper operation }\end{array}$ & $\begin{array}{l}\text { Next, place the Rollpin in the nut. Upon } \\
\text { completion check the tapping tool for proper } \\
\text { performance. }\end{array}$ \\
\hline
\end{tabular}

Figure 9.3. Itemizing Instructions (From U.S. Army, 1972)

\subsubsection{LABEL BREVITY}

Words on labels should be concise and still convey the intended meaning. Redundancy should be minimized. Where the general function is obvious, only the specific function should be identified (U.S. Department of Defense, 1981 a).

\subsubsection{LABEL STANDARDIZATION}

CONTINUITY. A list of standard names, acronyms, abbreviations, and part/system numbers should be in place and administratively controlled (U.S. Nuclear Regulatory Commission, 1981).

CONSISTENCY. Labels should be consistent within and across pieces of equipment in their use of words, acronyms, abbreviations, and part/system numbers (Ibid.).

NOMENCLATURE. There should be no mismatch between nomenclature used in procedures and that printed on the labels (lbid.).

\subsubsection{LABEL SYMBOLS AND ABBREVIATIONS}

Symbols and abbreviations should be familiar to the user and follow accepted standards.
FAMILIARITY. Abstract symbols should be used only if they have a commonly accepted meaning for all intended users (e.g., \%) (U.S. Department of Defense, 1981 a).

UNIQUENESS. Symbols should be unique and distinguishable from each other (U.S. Nuclear Regulatory Commission, 1981).

STANDARD CONFIGURATION. A commonly accepted standard configuration should be used (U.S. Department of Defense, 1981 a).

CAPITALIZATION AND PUNCTUATION. The use of Roman numerals should be avoided. Capital letters should be used in abbreviations; periods should be omitted except when needed to prevent misinterpretation. The same abbreviation should be used for all tenses and both singular and plural forms of a word (lbid.).

ARROWS. Arrows, such as those indicating direction of flow in piping, should be clearly recognizable from a distance. Personnel are less likely to misinterpret the direction indicated by arrows with sharp angles and clean lines than arrows with wider angles and broader overall width-to-length ratios (Figure 9.4; U.S. Army, 1972). 


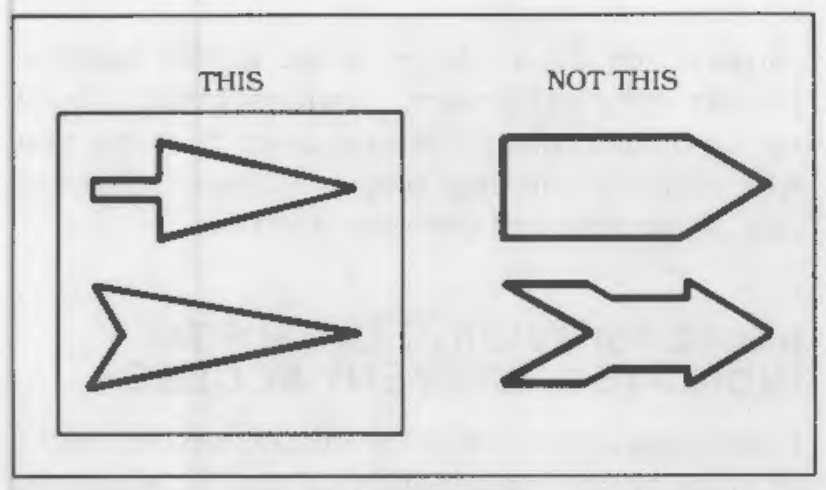

Figure 9.4. Example of Directional Arrows (From U.S. Army, 1972)

\subsubsection{COLOR CODING LABELS}

A permanent color coding scheme should be used for labeling systems and units.

DIFFERENTIATING SYSTEMS. A color coding system should be developed and applied consistently to differentiate system elements, e.g., fire protection, oil, water, hydrogen, etc.

DIFFERENTIATING UNITS. Color coding approaches should be considered to help differentiate between units in multi-unit plants. For example, coded color strips could be used on valve handles or to differentiate color schemes for walls and walking surfaces (Seminara, 1982).

PERMANENCE. Colors should be permanent; they should not wear off or fade (U.S. Department of Defense, $1981 \mathrm{a}$ ).

LEGIBILITY. Color combinations of printing and background on labels and signs should maximize legibility. Table 9.6 rates various color combinations in terms of relative legibility under normal luminance conditions (i.e., approximately $1 \mathrm{ft}$-c).

CONSISTENCY. The goal is a single, simple color code if color coding is used at all.

\subsubsection{PROVIDING WARNING LABELS}

CAUTION and WARNING markings should be provided as necessary to warn personnel of hazardous conditions and of precautions that need to be taken to ensure safety (U.S. Army, 1972).
Table 9.6. Color Combinations for Labels in Terms of Relative Legibility (From U.S. Nuclear Regulatory Commission, 1981)

\begin{tabular}{ll}
\hline \multicolumn{1}{c}{$\begin{array}{c}\text { Legibility } \\
\text { Rating }\end{array}$} & \multicolumn{1}{c}{ Color Combination } \\
\hline Very good & Black letters on white background \\
\hline Good & $\begin{array}{l}\text { Black on yellow } \\
\text { Dark blue on white } \\
\text { Grass green on white }\end{array}$ \\
\hline Fair & $\begin{array}{l}\text { Red on white } \\
\text { Red on yellow } \\
\text { White on black }\end{array}$ \\
\hline Poor & $\begin{array}{l}\text { Green on red } \\
\text { Red on Green } \\
\text { Orange on black } \\
\text { Orange on white }\end{array}$ \\
\hline
\end{tabular}

REFERENCE TO TECHNICAL MANUALS. Appropriate warning labels should be installed whenever the technician or mechanic needs to consult a technical manual before working on a component.

LABEL CONTENT. Warning labels should be as informative as possible and consistent with the space available (Figure 9.5). The content of the information will vary, but should inform maintenance personnel:

why a dangerous condition exists

places to avoid

behavior to avoid

sequence to follow to obviate the danger

where to refer for more information (U.S. Army, 1972)

HAZARDOUS CONDITIONS. Labels instructing the technician in hazardous situations should be prominently displayed. For example, instructions for opening and closing valves should be clear (Figure 9.6). High visibility warnings should be 


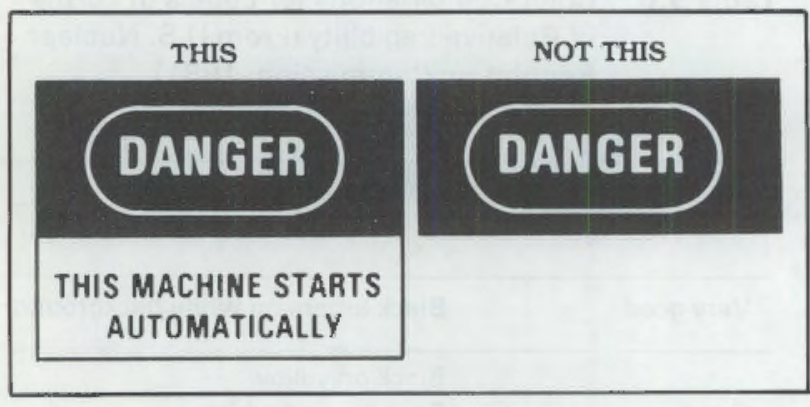

Figure 9.5. Informative Warning Label (From U.S. Army, 1972)

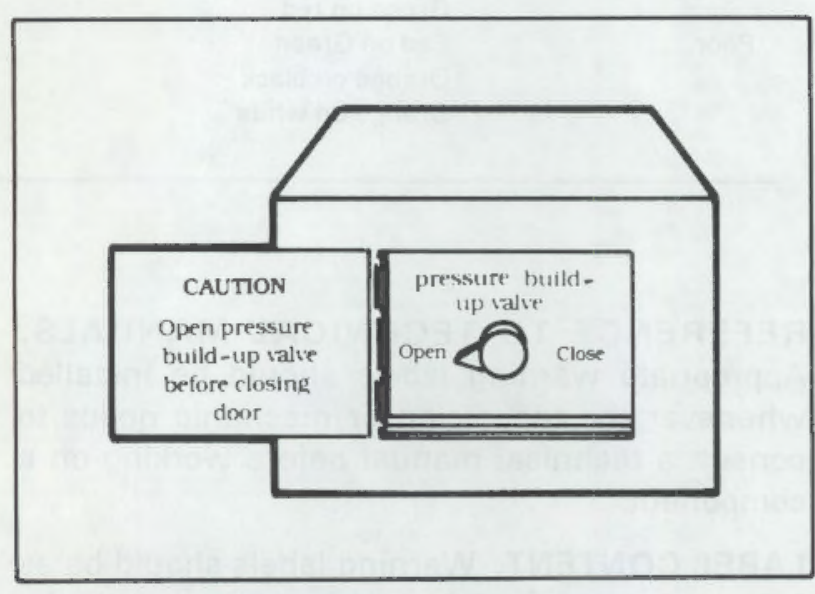

Figure 9.6. Instructional Labels (From U.S. Army, 1972)

erected where personnel may be subjected to harmful noises or sudden increases or decreases in pressure. Tolerance or safety load limits for apparatus should be displayed (lbid.).

\subsubsection{INDICATING LUBRICATION NEEDS}

Where lubrication is necessary, the type of lubricant to be used and the frequency of lubrication should be specified by a label mounted at or near the lube port. A lubrication chart of permanent construction should be mounted at the operator station of the equipment; individual labels should not be needed when the equipment has only one type of fitting and uses only one type of lubricant (U.S. Department of Defense, 1981a).

\subsubsection{PROVIDING LABELS TO INDICATE EQUIPMENT ACCESS}

Each access should have a unique number, letter or other symbol designation so specific accesses can be clearly identified in job instructions and maintenance manuals (U.S. Army, 1972).

COVERS. If the method of opening an access cover is not obvious from the construction of the cover itself, instructions should be permanently displayed on the outside of the cover (U.S. Department of Defense, 1981 a).

INTERIOR COMPONENTS. Accesses should have labels indicating the items that are accessible inside as well as the auxiliary equipment to be used.

INSERTION THROUGH ACCESSES. An indication of the position for insertion of components and connectors through small accesses should be provided. Use of matching stripes, dots or arrows on the cabinet and on the component to be inserted is recommended. Where space permits, a drawing of the pin position may be used (Figure 9.7; U.S. Army 1972).

LETTERING ON DOORS. If instructions applying to a covered item are lettered on a hinged door, the lettering should be oriented so that it can be read when the door is open (U.S. Department of Defense, 1981 a).

DANGEROUS COMPONENTS. Where accesses are located over dangerous mechanical components that can cause serious injury, an internal light should be lit automatically when the access is opened. A highly visible warning label on the access door should also be provided, and torquing patterns should be indicated (Figure 9.8; U. S. Army, 1972). 


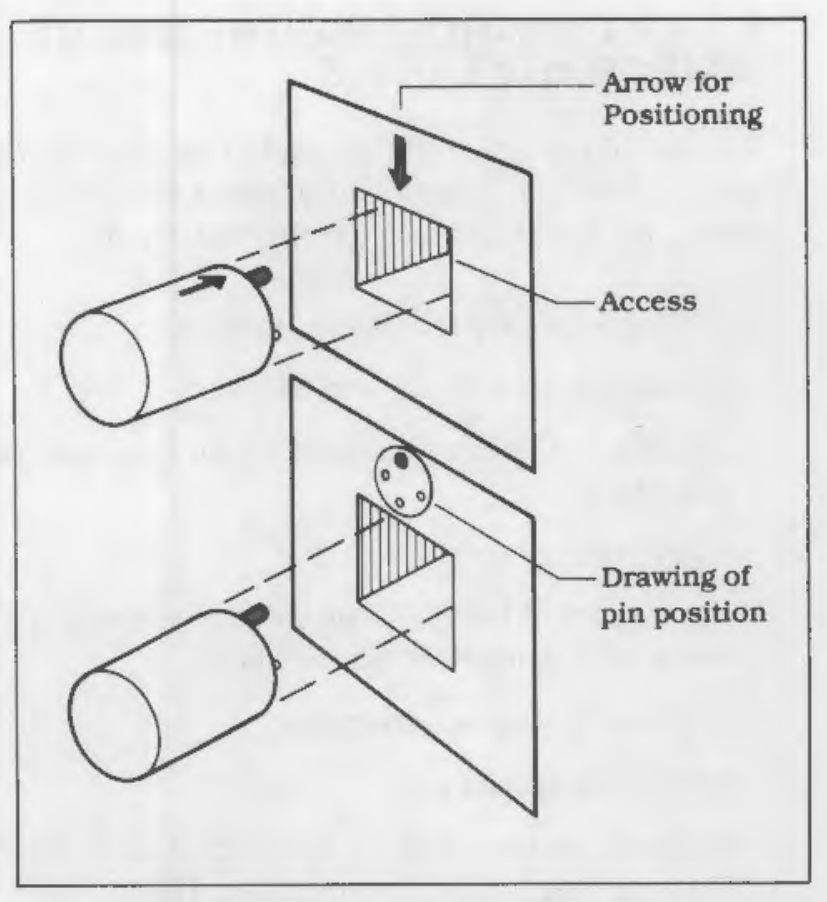

Figure 9.7. Code Component Installation Position (U.S. Army, 1972)

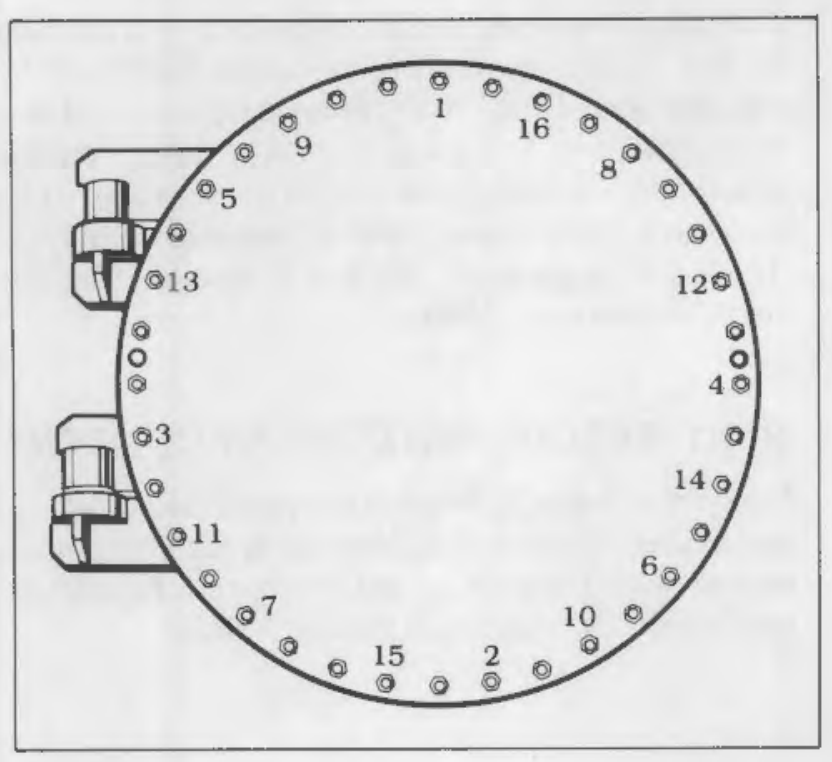

Figure 9.8. Torquing Patterns (Pattern should be continued until all bolts are torqued.)

\subsubsection{LABELING TEST POINTS}

When labeling test points, the following should be included:

a number, letter or other symbol that identifies the test point in the maintenance instructions

the in-tolerance signal and the tolerance limits of the signal that should be measured.

the name of the unit in the label, if possible color coding for easy identification (U.S. Army, 1972).

\subsubsection{LABELING ELECTRICAL EQUIPMENT}

Detailed information on marking electrical equipment can be found in MIL-STD-454 (see U.S. Department of Defense 1981 a).

CONNECTORS. Stripes or arrows should be painted on plugs and receptacles to show proper position of keys or how pins should be aligned for proper insertion. Each pin on each plug should be clearly identified. In addition, plugs should be coded to the receptacle to which they will be attached (lbid.).

CABLES. Long run cables, plumbing lines and conduits should be clearly identified or coded, not only at their terminal ends, but also at periodic distances between ends to facilitate accurate tracings of lines (Seminara, 1982). Cables should be labeled to indicate the equipment to which they belong and the connectors with which they mate (Ibid.).

WIRES. All replaceable wires and cables should be uniquely identified with distinct color or number codes. Suggested procedures may be found in MILSTD-681 (lbid.).

FUSES. The area of equipment served by the fuse or circuit breaker should be identified. The current rating of fuses should be permanently marked on the fuse holder, "SPARE" should be marked adjacent to each spare fuse holder (lbid.). 
FUSE RATINGS. Fuse ratings should be indicated either in whole numbers, common fractions (such as $1 / 4$ ), or whole numbers and common fractions (such as $2-1 / 4$ ) (Ibid.).

\subsubsection{LABELING DISPOSABLE MODULES}

For disposable modules, labels should indicate when the items should be thrown away; test procedures to be applied before disposal; and the notice, "DISPOSE AT FAILURE" (U.S. Army, 1972).

\subsubsection{USING TEMPORARY LABELS}

Temporary labels can be used when necessary to identify out-of-service equipment, to accommodate unique, one-time plant activities, and to improve maintenance personnel understanding and efficiency.

UTILIZATION. The following guidelines are suggested when the use of temporary labels is considered:

Temporary labels should be used only when necessary.

Temporary labels should conform to good human engineering principles.

Temporary labels should not obscure prior permanent labels unless the old label is to be replaced.

Tag-out labels should clearly identify out-ofservice components and equipment.

Tag-out labels should be securely affixed.

Tag-out labels should not obscure the label associated with the non-operable device.

Tag-out labels should be designed to physically prevent actuation of a control.

Tag-out labels should not obscure any adjacent devices or their associated labels.

\subsubsection{CONTROLLING THE USE OF TEMPORARY LABELS}

The use of temporary labels should be administratively controlled. A review procedure should be in place that will result in a determination of:

when temporary labels are needed,

how temporary labels will be used,

content of the label (given human engineering guidelines),

label installation.

the impact of label use on other system equipment (e.g., annunciators, mimics);

documentation requirements,

retraining needs, and

periodic review and removal of labels (U.S. Nuclear Regulatory Commission, 1981).

\subsection{GUIDELINES FOR VISUAL DISPLAYS}

The guidelines included in this section are specific to the visual display problems encountered by nuclear power plant maintenance personnel. For a more complete list of visual display design guidelines, additional sources should be reviewed (U.S. Department of Defense, 1981 a; Meister and Sullivan, 1969; Seminara et al., 1979; U.S. Nuclear Regulatory Commission, 1981).

\subsubsection{SPECIFYING DISPLAY CONTENT}

Analysis of tasks in relation to system engineering and system functional objectives is recommended as the surest means of establishing information needs (McCormick and Sanders, 1982). 
COMPLETENESS OF INFORMATION. VisUaI displays provided should give personnel all the information about system status and parameter values that is needed to accomplish the task in normal, abnormal, and emergency situations (Woodson and Conover, 1964; McCormick and Sanders, 1982).

UNNECESSARYINFORMATION. Efficient performance demands not only display of all needed information, but also avoiding the display of extraneous information in the prime operating area (Woodson and Conover, 1964; McCormick and Sanders, 1982).

REDUNDANCY. Redundancy in the presentation of information items should be limited to cases where needed for backup or to avoid excessive movement (Woodson and Conover, 1964; McCormick and Sanders, 1982).

DEMANDINFORMATION. Demand information shows that equipment has been commanded (by control settings or otherwise) to a particular state or level. It shows only what is demanded-not what is actually being realized. Status information shows the state or level actually in effect. To prevent confusion, it is essential that displays be identified as to whether they reflect demand or actual status (Woodson and Conover, 1964; McCormick and Sanders, 1982).

ACTUAL STATUS DISPLAY. Visual display of actual system/equipment status should be displayed for all important parameters (Woodson and Conover, 1964; McCormick and Sanders, 1982).

INSTRUMENT FAILURE. When panel instruments such as meters fail or become inoperative, the failure should be apparent (e.g., through offscale indication) (Woodson and Conover, 1964; McCormick and Sanders, 1981).

\subsubsection{SELECTING DISPLAYS}

Displays should be selected only after considering conditions to be monitored, frequency of information required and the environmental conditions under which the information is to be obtained.

READING QUANTITATIVE INFORMATION. Direct-reading counters should be used for rapid and accurate reading of stationary or slowly changing quantitative information. They should also be used to indicate revolutions in multi-revolution indicators and when economy of panel space is important (U.S. Army, 1972).

CONTINUOUS MONITORING. Scopes such as cathode-ray tubes should be used for continuous monitoring activity and to monitor or check read frequency or amplitude waves (Ibid.).

PERIODIC MONITORING. Dials, scales, gauges, or meters should be used to:

indicate direction of movement or orientation in space

distinguish increasing or decreasing trends in the values measured by the instrument

obtain approximate readings

check-read rather than to monitor continuously (lbid.).

LIGHTS. Lights should be used as qualitative go/no-go indicators, on-off indicators, malfunction indicators, emergency warning lights (use flashing signals), inoperative equipment indicators, caution indicators, and as indicators for operability of separate components.

LEGEND LIGHTS. When the panel contains sufficient space, legend lights, or words or numbers that are lighted from behind should be used. Lights should also be used as warm-up indicators (Ibid.).

WARNING DISPLAYS. Auditory displays such as buzzers or bells should be used to signal the end of an operating cycle. They should also be used as an emergency or warning device and when immediate action is important (lbid.).

AUDITORY DISPLAYS. Auditory displays can sometimes be used with, or as alternatives to lights. For example, auditory displays can be used when environmental lighting conditions are such that lights might not be detected easily. They might be used when the maintenance personnel will be occupied monitoring lights, dials, counters, and scopes, or when multiple signals (warning, emergency, malfunction) are needed. 
REDUNDANCY. When extreme redundancy is necessary, both types of auditory and visual signals as described above should be used. For further information on auditory displays, see Section 9.6.

\subsubsection{LOCATING AND ARRANGING DISPLAYS}

Displays should be located so that they can be read to the necessary degree of accuracy from normal viewing positions. The following guidelines provide information for optimum location and design.

POSITION OF PERSONNEL. The personnel should not have to assume an uncomfortable, awkward or unsafe position. Neither should personnel have to use ladders, flashlights or other special equipment to see displays (U.S. Department of Defense, 1981 a).

\section{LOCATION FOR STANDING OPERATIONS.} Location of visual displays with respect to the standing surface should conform to the following guidelines:

Visual displays mounted on vertical panels and used in normal equipment operation should be placed between $42 \mathrm{in}$. and $70 \mathrm{in}$. $(1.040 \mathrm{~m}$ to $1.780 \mathrm{~m}$ ) above the standing surface.

Displays which need precise and frequent reading should be placed between 50 in. and 65 in. $(1.270 \mathrm{~m}$ and $1.650 \mathrm{~m})$ above the standing surface.

All controls mounted on a vertical surface and used in normal equipment operation should be located between $34 \mathrm{in}$. and $70 \mathrm{in}$. $(860 \mathrm{~mm}$ and $1.780 \mathrm{~m}$ ) above the standing surface.

Controls which need precise or frequent operation and emergency controls should be mounted between $34 \mathrm{in}$. and $53 \mathrm{in}$. (860 $\mathrm{mm}$ and 1.350 $\mathrm{mm}$ ) above the standing surface and no farther than 21 in. $(530 \mathrm{~mm})$ laterally from the centerline (Ibid.).

DISPLAY FACES. Display faces should be perpendicular to the normal line of sight whenever feasible and should not be less than 45 degrees from the normal line of sight (Figure 9.9). Parallax should be minimized (lbid.).

REFLECTION. Displays should be constructed, arranged, and mounted to prevent reduction of information transfer due to the reflection of the ambient illumination from the display cover. Reflection of instruments and consoles in windshields and other enclosures should be avoided. If necessary, shields and filters should be employed to insure that system performance will not be degraded (lbid.).

SEOUENCE OF USE. Displays should be arranged according to their sequence of use. They should be arranged in sequence within functional groups, whenever possible, to provide a viewing flow from left to right or top to bottom. More frequently used displays should be grouped together and placed in the optimum visual zone (Figure 9.10; Ibid.).

CRITICAL DISPLAYS. Important or critical displays should be located in a privileged position in the optimum projected visual zone or otherwise highlighted (U.S. Department of Defense, 1981a; U.S. Army 1972).

CONSISTENCY. The arrangement of displays within a system should be consistent in principle from application to application.

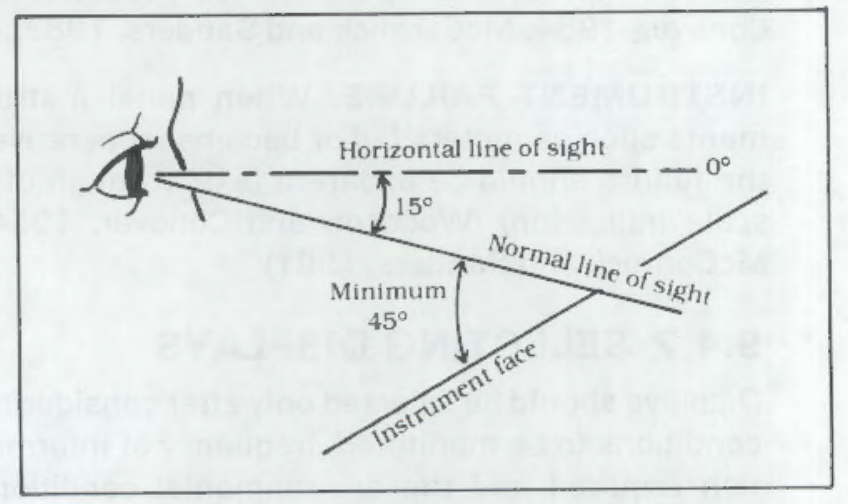

Figure 9.9. Normal Line of Sight (From U.S. Department of Defense, 1981 a) 


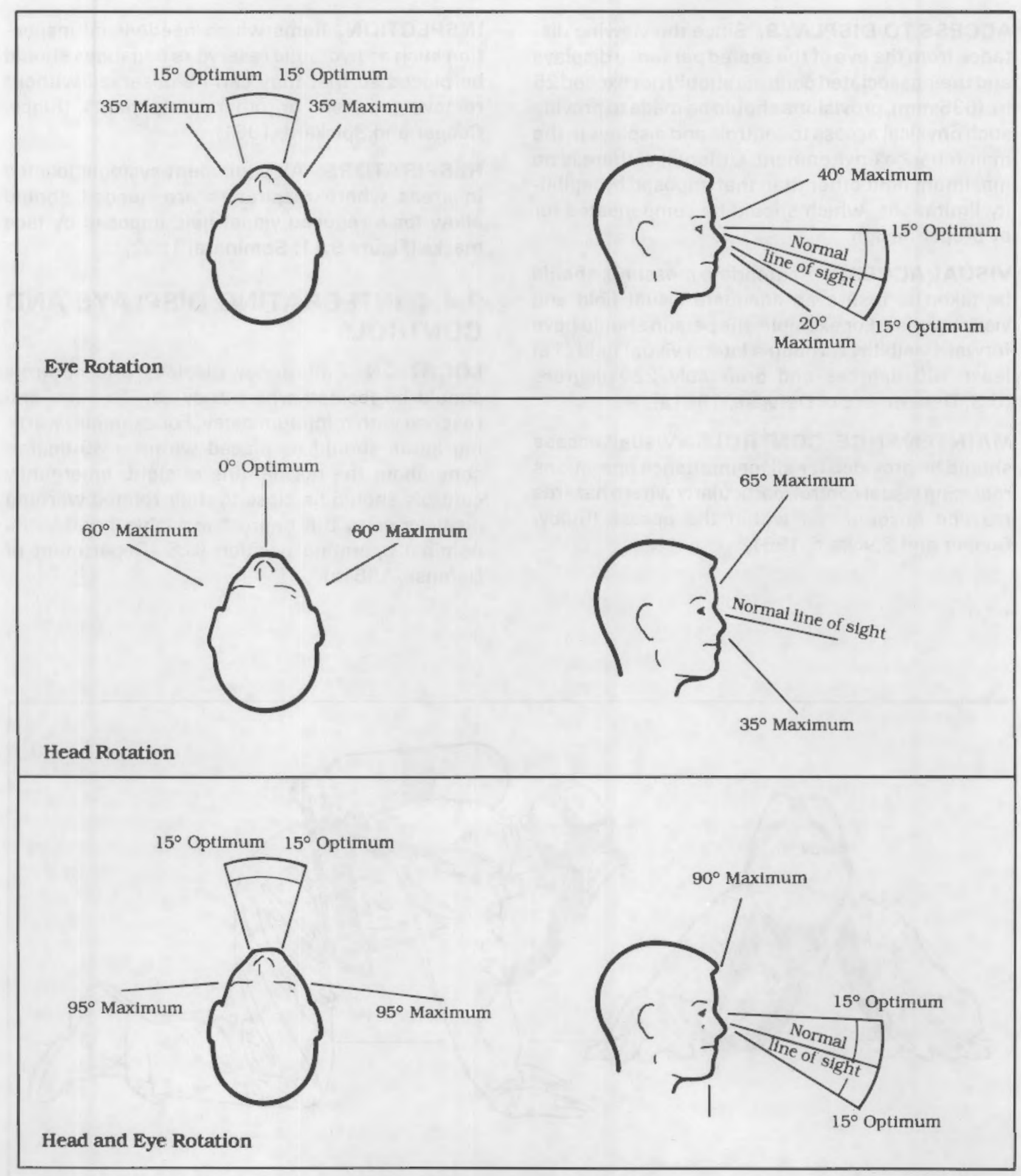

Figure 9.10. Optimum Visual Zone for Placement of Displays (From U.S. Department of Defense, 1981a) 


\section{Information Needs}

ACCESS TO DISPLAYS. Since the viewing distance from the eye of the seated person to displays and their associated controls should not exceed 25 in. $(635 \mathrm{~mm})$, provisions should be made to provide such physical access to controls and displays in the maintenance environment. Otherwise, there is no maximum limit other than that imposed by legibility limitations, which should be compensated for by proper design.

VISUAL ACCESS. Appropriate measures should be taken to insure an adequate visual field and visual access. For example, the person should have forward visibility through a lateral visual field of at least 180 degrees and preferably 220 degrees (U.S. Department of Defense, 1981a).

MAINTENANCE CONTROLS. Visual access should be provided for all maintenance operations requiring visual control, particularly where hazards may be encountered within the access (Rigby, Cooper and Spickard, 1961).
INSPECTION. Items which need visual inspection such as hydraulic reservoirs or gauges should be placed so that they can be observed without removing panels or other components (Rigby, Cooper and Spickard, 1961).

RESPIRATORS. All equipment systems located in areas where respirators are needed should allow for a reduced visual field imposed by face masks (Figure 9.11; Seminara, 1982).

\subsubsection{INTEGRATING DISPLAYS AND CONTROLS}

LOCATION. Emergency displays and controls should be located where they can be seen and reached with minimum delay. For example, warning lights should be placed within a 30-degree cone about the normal line of sight; emergency controls should be close to their related warning displays or to the nearest available hand in its nominal operating position (U.S. Department of Defense, 1981a).

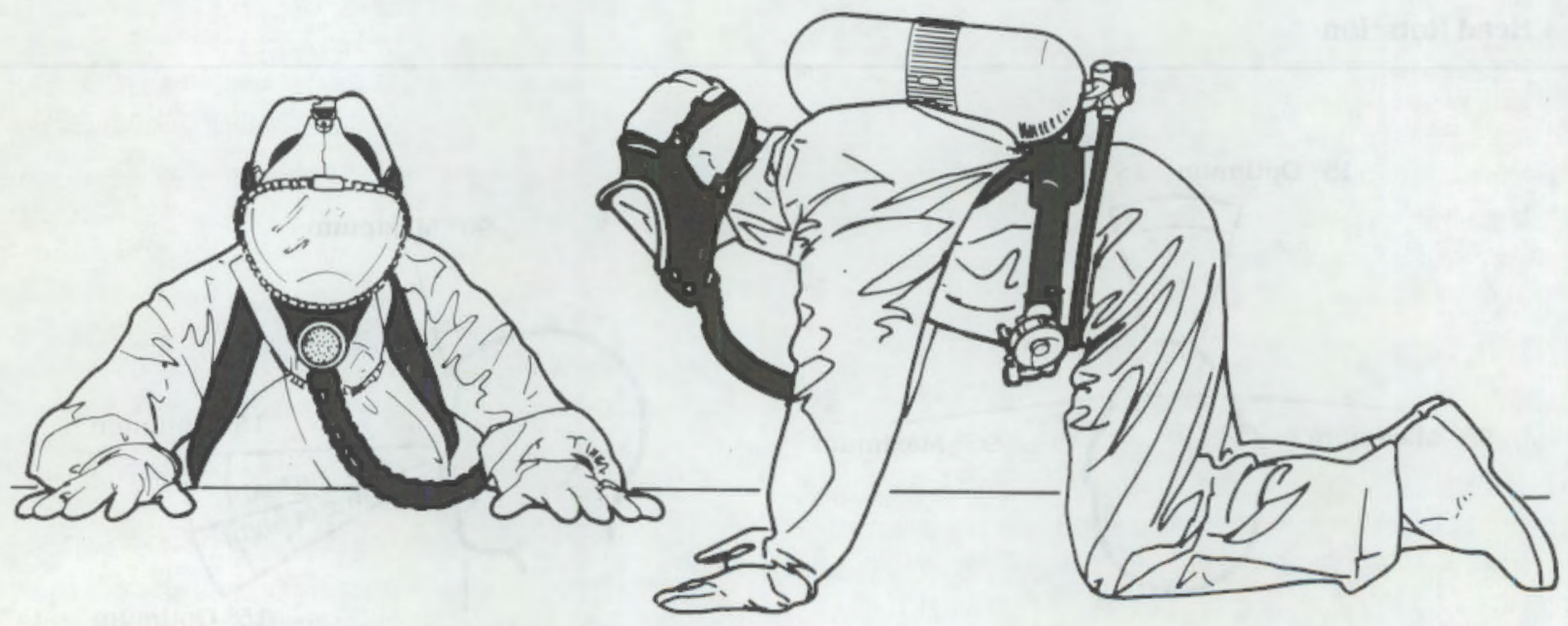

Figure 9.11. Reduced Visual Field Imposed by Face Masks 
EFFECTIVE PANEL LAYOUT. The location of controls and displays within a single panel should make the most effective use of the viewing and manual manipulative areas. The allocation of panel positions should first ensure the integrity of arrangement or grouping by system function and task sequence. Within those constraints, consideration should be given to the following factors:

the frequency with which controls and displays are used;

the significance of controls and displays in terms of their possible use during an emergency;

the importance of controls and displays to overall system performance; and

special needs in using a control device or display instrument, such as the need for accuracy, speed, application of force, or a particular type of movement (U.S. Nuclear Regulatory Commission, 1981).

AVOIDING PARALLAX. A visual display that must be monitored concurrently with manipulation of a related control should be located so that it is not necessary to observe the display from an extreme visual angle and thus introduce the possibility of parallax error (U.S. Department of Defense, 1981 a).

PLACEMENT OF SEVERAL DISPLAYS. When the manipulation of one control demands the reading of several displays, the control should be placed as near as possible to the related displays and preferably beneath the middle of the displays, but not so as to obscure displays when manipulating the control (lbid.).

COMBINED CONTROLS. When separate displays are affected by a combined control (e.g., concentrically ganged knobs), the display should be arranged from left to right with the combined control underneath the center of the displays, but not so as to obscure displays when manipulating controls. (Figure 9.12; Ibid.).

ASSOCIATION OF RELATED CONTROLS. Related controls and displays should be easily identified as being associated. This association can be established (or enhanced) by (1) location,

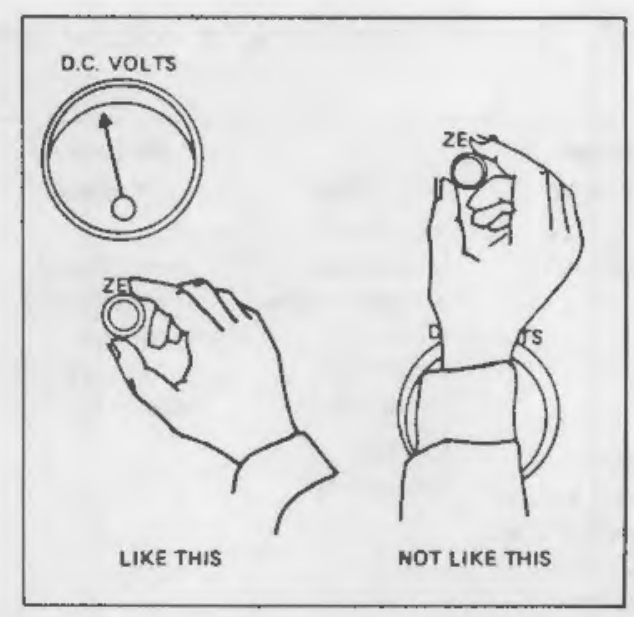

Figure 9.12. Manipulation of a Control Should Not Obscure the Related Display (U.S. NRC, 1981)

(2) labeling, (3) coding, (4) demarcation, and (5) consistency with expectations. The following relationships should be immediately apparent to the operator:

association of displays with controls

the direction of movement of control and display

the rate and limits of movement of the control and display (U.S. Nuclear Regulatory

Commission, 1981)

RELATED DISPLAYS ON SEPARATE PANELS. When related controls and displays are located on separate panels and both panels are mounted at approximately the same angle relative to the maintainer, the control positions on one panel should correspond to the associated display positions on the other panel. The two panels should not be mounted facing each other (U.S. Department of Defense, 1981 a).

\subsubsection{MAINTENANCE DISPLAYS}

INDICATOR LIGHTS. Indicator lights used solely for maintenance and adjustment should be covered during normal equipment operation, but should be readily accessible when required.Indicator lights should be color coded (Table 9.7; U.S. Department of Defense, 1981 a; U.S. Army, 1972). 
Information Needs

Table 9.7. Size and Color Coding for Indicator Lights (From U.S. Army, 1972)

\begin{tabular}{|c|c|c|c|c|c|}
\hline $\begin{array}{l}\text { Size of } \\
\text { Indicator }\end{array}$ & Red & $\begin{array}{l}\text { Amber or } \\
\text { Yellow }\end{array}$ & Green & White & Blue \\
\hline 0.5 in. diameter & $\begin{array}{l}\text { Immediate } \\
\text { action; unsatis- } \\
\text { factory or } \\
\text { hazardous } \\
\text { condition }\end{array}$ & $\begin{array}{l}\text { Impending or } \\
\text { unsatisfactory } \\
\text { condition } \\
\text { requiring alert- } \\
\text { ness or caution }\end{array}$ & $\begin{array}{l}\text { Equipment } \\
\text { operating or } \\
\text { condition } \\
\text { satisfactory }\end{array}$ & $\begin{array}{l}\text { Neutral status } \\
\text { (action in } \\
\text { progress) }\end{array}$ & $\begin{array}{l}\text { Action in } \\
\text { progress; } \\
\text { standby }\end{array}$ \\
\hline $\begin{array}{l}1 \text { in. diameter, } \\
\text { flashing } 3-5 \text { sec. } \\
\text { (ON time should be } \\
\text { at least } 0.1 \text { sec and } \\
\text { slightly shorter } \\
\text { than OFF time.) }\end{array}$ & $\begin{array}{l}\text { Extreme } \\
\text { emergency }\end{array}$ & & & & \\
\hline $\begin{array}{l}1 \text { in. diameter, }{ }^{1} \\
\text { steady }\end{array}$ & & $\begin{array}{l}\text { Extreme } \\
\text { cautionary } \\
\text { conditions } \\
\text { indicating } \\
\text { impending } \\
\text { danger }\end{array}$ & & & \\
\hline
\end{tabular}

SEPARATING INFORMATION. Operator and maintainer information should not be combined in a single display unless the information content and format are well suited to, and time compatible for, both users (U.S. Department of Defense, 1981a).

WARNING LIGHTS. A warning device, such as legend lights, should tell the maintenance personnel what corrective action is needed. Such lights should be clearly labeled, with the labels adequately illuminated. The wording of the labels should clearly indicate what should be done (U.S. Army, 1972).

TESTING WARNING LIGHTS. A press-to-test capability should be provided so that maintenance personnel can rely on the operation of warning lights. As an alternative, each warning light could have two lamps in parallel so that if one burns out the other will still provide a warning signal (lbid.).

\subsubsection{DISPLAYS TO INDICATE EQUIPMENT FAILURE}

An indication of power failure should be provided so that failure of a display or its circuit is immediately apparent to the maintenance personnel.

TOLERANCE CONDITIONS. Displays should be provided to indicate when equipment has failed or is not operating within tolerance limits (U.S. Department of Defense, 1981a). When there are many lights on a single panel, a master light that indicates when any portion of the system is operating out of tolerance should be provided (U.S. Army, 1972).

AVOIDING IMPROPER ILLUMINATION. PrOvisions should be made to prevent direct or reflected light from making indicators appear illuminated when they are not or to appear extinguished when they are illuminated (U.S. Department of Defense, 1981a). 


\subsection{GUIDELINES FOR TACTILE SENSATION AND FEEDBACK}

One way in which the body receives information is through the cutaneous (skin) senses. Tactile (touch) sensations can provide important information for maintenance task performance especially in situations where tasks must be performed with a lack of visual cues. When controls or equipment used in these tasks are easily identified there is a decrease in improper control manipulation and in the time required to locate controls. Identification utilizing the concept of tactile displays is often accomplished with shape coding or size coding. It is important to recognize that tactile information must be perceptible to maintenance personnel wearing protective garments.

\section{PAOPER SIZING OF PROTECTIVE GARMENTS.} Protective clothing and breathing equipment should be compatible with body sizes and tasks to provide adequate tactile sensitivity and ability to see, reach, move, communicate, and hear (U.S. Nuclear Regulatory Commission, 1981).

HANDWEAR. Controls should be compatible with handwear that will be used in the anticipated environment. Unless otherwise specified, all dimensions cited in these guidelines are for bare hands and should be revised where necessary for use with gloves or mittens (U.S. Department of Defense, 1981a).

\subsubsection{INDICATING CONTROL ACTIVATION}

A positive indication of control activation such as snap feel, audible click, or association with visual or auditory display should be provided. Ganged knob configurations should not be used under conditions where heavy gloves must be worn (U.S. Department of Defense, 1981a).

\subsubsection{SHAPE CODING}

Shape coding provides for tactile identification of controls and handles. Shapes should be identifiable visually, and functional shapes that suggest the purpose of the control should be used where feasible. When shape coding is used, consideration should be given to the following factors:

coded features should not interfere with the ease of control manipulation;

shapes should be identifiable by the hand regardless of control position or orientation;

shapes should be tactually identifiable when gloves are worn;

a sufficient number of identifiable shapes should be provided to cover the expected number of controls requiring tactual identification;

shape coded knobs and handles should be positively and nonreversably attached to their shafts to preclude incorrect attachment upon replacement;

shapes should be associated with or resemble control function, and not an alternate function; and (U.S. Department of Defense, 1981a);

shapes should be easily distinguished from one another.

\subsubsection{SIZE CODING}

Controls can be coded by size, but when tactual information is the only means of identification, size coding is not as effective as shape coding and the usable sizes are limited. However, size coding can be superimposed on shape coding. The following factors should be considered when utilizing size coding:

no more than three different sizes should be used when coding controls for discrimination by absolute size; 
controls used for the same function on different items should be the same size;

when knob diameter is used as the coding parameter, differences in diameters shall not be less than 0.5 inches; and

when knob thickness is the coding parameter, differences in thicknesses shall not be less than 0.4 inches. (U.S. Department of Defense, 1981a).

\subsection{GUIDELINES FOR AUDITORY DISPLAYS}

The guidelines included in this section apply to auditory display problems encountered by nuclear power plant maintenance personnel. Additional sources should be accessed for more complete information pertaining to design recommendations for auditory displays (U.S. Department of Defense, 1981 a; Van Cott and Kinkade, 1972; Rankin et al., 1983; U.S. Nuclear Regulatory Commission, 1981).

ALARMS. Auditory signals are often used as alarms and warning devices to call attention to an urgent situation that may require immediate action. Many warning devices are used in everyday situations; others have been developed for special purposes. In selecting and designing signals for alarm and warning, sounds with frequencies between 200 and $5000 \mathrm{~Hz}$ (if possible between 500 and $3000 \mathrm{~Hz}$ ) should be used, because the normal human ear is most sensitive to this middle range (U.S. Air Force, 1980).

PREVENTING FALSE ALARM. In general, audio display devices and circuits should be designed so that false alarms are prevented. The audio display device and circuit should be designed to prevent the failure of signals in the event of system or equipment failure and vice versa. All audio displays should be equipped with circuit test devices or other means of operability testing (U.S. Department of Defense, 1981a).

\subsubsection{USE OF AUDITORY DISPLAYS}

Workers associate signals with their acoustic origin. Even though many ingenious visual displays for speech have been devised, none is likely to supplant the ear, except when deafness, intense noise, or other conditions prevent hearing.

PROVIDING AUDIO DISPLAYS. Audio displays should be provided for signals of acoustic origin, for warning signals, to supplement some visual displays, under conditions of limited vision or anoxia, and when signals need to be distinguished from noise.

SUPPLEMENTING VISUAL SIGNALS. To see a visual warning signal, a person must look, eyes open, in the general direction of the signal. When these conditions are not met, a visual warning signal does not "warn." Hearing, however, has no such limitation. It is omnidirectional and cannot be involuntarily shut off, as can vision. Auditory displays can often be used to supplement visual perception. For example, many complex tasks, such as piloting an airplane, demand so much attention to visual indicators that additional displays cannot be monitored. In such cases, auditory presentation can be used to supplement the overloaded visual channel.

LIMITED VISION. When information needs to be presented independently of the orientation of the head, or when a person's duties require movement or turning in different directions, visual presentation is undesirable. Auditory displays should be used when vision is limited or impossible as a result of darkness.

DISTINGUISHING SIGNALS FROM NOISE. When signals must be distinguished from noise, or when voice communication is necessary or desirable, auditory displays can be useful. The ear acts as a frequency analyzer, making it an effective detector of periodic signals in noise (U.S. Air Force, 1980; Van Cott and Kinkade, 1972; U.S. Department of Defense, 1981a). 


\subsubsection{CHOOSING VISUAL VS. AUDITORY DISPLAYS}

Some signals are better suited for auditory than for visual presentation and vice versa. Several illustrations are given in Table 9.8.

RESPONSE TYPE. Either auditory presentations or lights may be used for signals that have already been anticipated by the operator if the responses are discrete, short, and follow another presentation quickly (U.S. Army, 1972).

COMBINING SIGNALS. One audio signal may be used in conjunction with several visual displays, provided that immediate discrimination is not critical to personnel safety or system performance (U.S. Department of Defense, 1981a).

Table 9.8. Choice of Visual Versus Auditory Presentations (From U.S. Army, 1972)

\begin{tabular}{|c|c|c|}
\hline & $\begin{array}{l}\text { Auditory } \\
\text { Message } \\
\text { Indicated }\end{array}$ & $\begin{array}{c}\text { Visual } \\
\text { Message } \\
\text { Indicated }\end{array}$ \\
\hline \multirow[t]{5}{*}{ Message } & Simple & Complex \\
\hline & Short & Long \\
\hline & Not referred to later & Referred to later \\
\hline & $\begin{array}{l}\text { Deals with events } \\
\text { in time }\end{array}$ & $\begin{array}{l}\text { Deals with location } \\
\text { in space }\end{array}$ \\
\hline & $\begin{array}{l}\text { Calls for immediate } \\
\text { action }\end{array}$ & $\begin{array}{l}\text { Does not call for } \\
\text { immediate action }\end{array}$ \\
\hline $\begin{array}{l}\text { Sensory } \\
\text { Overload }\end{array}$ & Visual overburden & $\begin{array}{l}\text { Auditory } \\
\text { overburden }\end{array}$ \\
\hline $\begin{array}{l}\text { Receiving } \\
\text { Location }\end{array}$ & $\begin{array}{l}\text { Too bright; or, dark } \\
\text { adaptation is } \\
\text { necessary }\end{array}$ & Too noisy \\
\hline $\begin{array}{l}\text { Job } \\
\text { Requirements }\end{array}$ & $\begin{array}{l}\text { Technician must } \\
\text { move about } \\
\text { continually }\end{array}$ & $\begin{array}{l}\text { Technician may } \\
\text { remain in one } \\
\text { position }\end{array}$ \\
\hline
\end{tabular}

\subsubsection{CHOOSING SIGNAL TYPE}

When an audio presentation is necessary, the signal presented should conform to the guidelines in Table 9.9.

TONAL SIGNALS. Tonal signals rather than speech should be used when:

the message is extremely simple

the listener has had special training in the meaning of coded signals

the signal designates a point in time that has no absolute value

the message calls for immediate action

speech signals are overburdening the listener

security of the message is important

speech will mask other communication or annoy other listeners

conditions are unfavorable for receiving speech messages. (U.S. Air Force, 1980; Van Cott and Kinkade, 1972).

LIMITATIONS ON NUMBERS OF TONES. The number of different types of tones that can be recognized over long periods of time is no more than six, and is probably closer to three or four (U.S. Air Force, 1980; Van Cott and Kinkade, 1972).

VERBAL SIGNALS. Speech rather than tonal signals should be used when:

flexibility of communication is necessary

it is necessary to be able to identify the source of the message

the listener has had no special training in the meaning of coded signals

rapid two-way exchanges of information are necessary

the message deals with a future event requiring some preparation

stress might cause the listener to "forget" the meaning of the code

the number of tone signals exceeds the discriminative capacity of the listener. 


\section{Information Needs}

Table 9.9. Functional Evaluation of Audio Signals (From U.S. Department of Defense, 1981a)

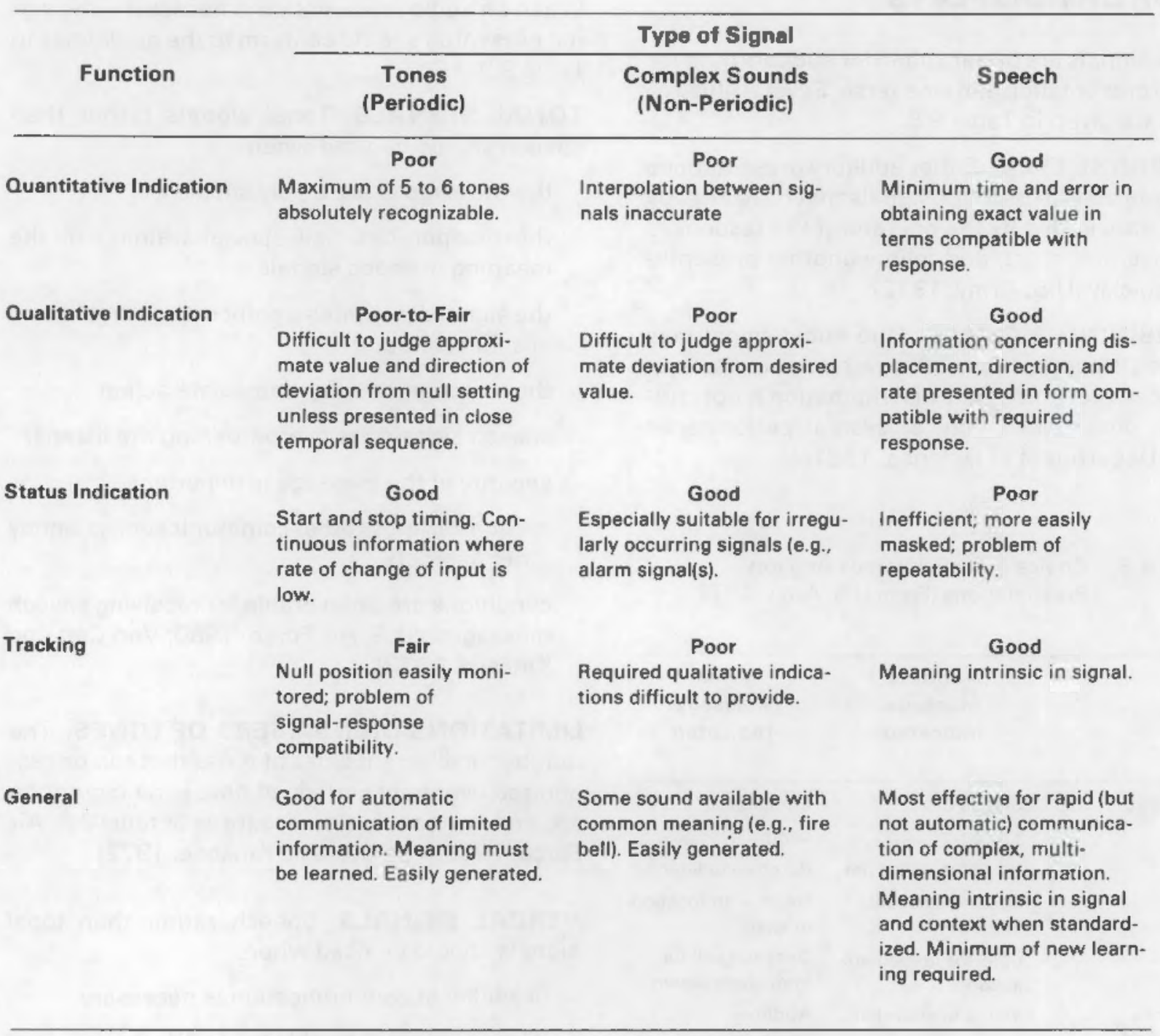




\subsubsection{PLANNING ALARM AND WARNING SIGNALS}

Recommendations for auditory alarm and warning devices are presented in Table 9.10. The principal characteristics and special features of different types of auditory alarm and warning devices are presented in Table 9.11.

Table 9.10. Design Recommendations for Warning Devices (From VanCott and Kinkade, 1972 and U.S. Army, 1972)

\begin{tabular}{|c|c|}
\hline Condition & Design Recommendations \\
\hline $\begin{array}{l}\text { Distance to listener is } \\
\text { great }\end{array}$ & $\begin{array}{l}\text { Use high intensities; avoid high } \\
\text { frequencies }\end{array}$ \\
\hline $\begin{array}{l}\text { Sound must bend } \\
\text { around obstacles and } \\
\text { pass through } \\
\text { partitions }\end{array}$ & Use low frequencies \\
\hline $\begin{array}{l}\text { Background noise is } \\
\text { present }\end{array}$ & $\begin{array}{l}\text { Select alarm frequency in region } \\
\text { where the masking of noise is } \\
\text { minimal }\end{array}$ \\
\hline $\begin{array}{l}\text { Operator's attention is } \\
\text { demanded }\end{array}$ & $\begin{array}{l}\text { Modulate signal to give intermittent } \\
\text { beeps; or, modulate frequency to } \\
\text { make pitch rise and fall at a rate of } \\
\sim 1-3 \text { cps. }\end{array}$ \\
\hline $\begin{array}{l}\text { Action taken to warn- } \\
\text { ing warrants } \\
\text { recognition }\end{array}$ & $\begin{array}{l}\text { Provide signal with manual shutoff } \\
\text { so that sound continues until action } \\
\text { is taken. }\end{array}$ \\
\hline
\end{tabular}

DISTINCTIVE SIGNALS. Auditory presentations should be easily detectible. In addition, the signal should hold attention, should be distinctive, and should be quickly and accurately identifiable.

MAXIMUM SIGNAL INTENSITY. Auditory signal intensities should not exceed $90 \mathrm{~dB}$ (A), except for evacuation signals, which may be up to 115 $d B(A)$.

FREQUENCY. Alarms should be undulating or warbling tones with the sound at least $20 \mathrm{db}$ above threshold. A tone of lower frequency than the background noise should be used, but frequencies below $500 \mathrm{~Hz}$. should not be used.

SIGNAL INTERPRETATION. Signals that need to be interpreted during the performance of a repetitive task should be avoided, as should separate auditory channels used by different personnel.

BREVITY. The initial sound in a warning system should be as brief as possible to reduce the need for overlapping or simultaneously monitoring reception.

MONITORING. Simultaneous monitoring of two or more auditory channels should be required only when each channel contains information directed toward a single operation and when none of the information is contradictory (U.S. Army, 1972). 
Table 9.11. Characteristics and Special Features of Alarms (From U.S. Army, 1972)

\begin{tabular}{|c|c|c|c|c|c|}
\hline Alarm & Intensity & Frequency & $\begin{array}{l}\text { Attention } \\
\text { Getting } \\
\text { Ability }\end{array}$ & $\begin{array}{l}\text { Noise } \\
\text { Penetration } \\
\text { Ability }\end{array}$ & Special Features \\
\hline $\begin{array}{l}\text { Diaphone } \\
\text { (foghorn) }\end{array}$ & Very high & Very low & Good & $\begin{array}{l}\text { Poor in low frequency } \\
\text { noise } \\
\text { Good in high frequency } \\
\text { noise }\end{array}$ & \\
\hline Horn & High & Low to high & Good & Good & $\begin{array}{l}\text { Can be designed to beam } \\
\text { sound directionally }\end{array}$ \\
\hline & & & & & $\begin{array}{l}\text { Can be rotated to get } \\
\text { wide coverage }\end{array}$ \\
\hline Whistle & High & Low to high & $\begin{array}{l}\text { Good if } \\
\text { intermittent }\end{array}$ & $\begin{array}{l}\text { Good if frequency is } \\
\text { properly chosen }\end{array}$ & $\begin{array}{l}\text { Can be made directional } \\
\text { by reflectors }\end{array}$ \\
\hline Siren & High & Low to high & $\begin{array}{l}\text { Very good if } \\
\text { pitch rises } \\
\text { and falls }\end{array}$ & $\begin{array}{l}\text { Very good with rising and } \\
\text { falling frequency }\end{array}$ & $\begin{array}{l}\text { Can be coupled to horn } \\
\text { for directional } \\
\text { transmission }\end{array}$ \\
\hline Bell & Medium & $\begin{array}{l}\text { Medium to } \\
\text { high }\end{array}$ & Good & Good in frequency noise & $\begin{array}{l}\text { Can be provided with } \\
\text { manusl shutoff to insure } \\
\text { alarm until action is } \\
\text { taken }\end{array}$ \\
\hline Buzzer & $\begin{array}{l}\text { Low to } \\
\text { medium }\end{array}$ & $\begin{array}{l}\text { Low to } \\
\text { medium }\end{array}$ & Good & $\begin{array}{l}\text { Fair if spectrum is suited } \\
\text { to background } \\
\text { noise }\end{array}$ & $\begin{array}{l}\text { Can be provided with } \\
\text { manual shutoff to insure } \\
\text { alarm until action is } \\
\text { taken }\end{array}$ \\
\hline $\begin{array}{l}\text { Chimes and } \\
\text { gong }\end{array}$ & $\begin{array}{l}\text { Low to } \\
\text { medium }\end{array}$ & $\begin{array}{l}\text { Low to } \\
\text { medium }\end{array}$ & Fair & $\begin{array}{l}\text { Fair if spectrum is suited } \\
\text { to background } \\
\text { noise }\end{array}$ & \\
\hline Oscillator & $\begin{array}{l}\text { Low to } \\
\text { medium }\end{array}$ & $\begin{array}{l}\text { Medium to } \\
\text { high }\end{array}$ & $\begin{array}{l}\text { Good if } \\
\text { intermittent }\end{array}$ & $\begin{array}{l}\text { Good if frequency is } \\
\text { properly chosen }\end{array}$ & $\begin{array}{l}\text { Can be presented over } \\
\text { intercom system }\end{array}$ \\
\hline
\end{tabular}


APPENDIX A

ANTHROPOMETRY 


\section{Appendix A ANTHROPOMETRY}

The material in this section has been adapted in large part from Military Standard 1472C: Human Engineering Design Criteria for Military Systems, Equipment and Facilities (U.S. Department of Defense, 1981).

Appropriate form and sizing insure accommodation, compatibility, operability, and maintainability by the user population. Generally, form and size should be based upon limits set by critical body dimensions ranging from the 5 th percentile female to the 95th percentile male (Figures A.1-A.4 and Tables A.1-A.4). For any body dimension, the 5 th percentile value indicates that five percent of the population will be equal to or smaller than that value, and 95 percent will be larger; conversely, the 95th percentile values indicate that 95 percent of the population will be equal to or smaller than that value and five percent will be larger. Therefore, accommodation of the range from the 5 th to 95 th percentile will theoretically provide coverage for 90 percent of the user population. Where two or more dimensions are involved, appropriate design parameters, appropriate multivariate data and techniques should be utilized. Use of anthropometric data should take the following factors into consideration:

the nature, frequency, and difficulty of tasks to be performed by the wearer of the equipment

the position of the body during performance of these tasks

mobility or flexibility demands imposed by the tasks

increments in critical dimensions imposed by the need to compensate for obstacles, projections, etc.

increments in critical dimensions imposed by protective clothing or equipment, packages, lines, padding, etc.

\section{A.1 ANTHROPOMETRIC DATA}

The anthropometric data shown in Figures A.1-A.3 and Tables A.1-A.3 are for nude body measurements, compiled and collated from several sources. The data on ground troops came from measurements of 6682 U.S. Army men and 2008
U.S. Marines, taken in 1966. Measurements of 287 U.S. Army men, taken in 1977, are also included. The data on aviators came from measurements of 1482 U.S. Army aviation personnel, taken in 1970; 1549 U.S. Navy pilots, taken in 1964; and 2420 U.S. Air Force flying personnel, taken in 1967. The data on military women came from measurements of 1300 U.S. Army WAC personnel and Army nurses, measured in 1977, and 1905 U.S. Air Force WAF personnel and Air Force nurses, measured in 1968. Blanks in the tables indicate that data are not available for those dimensions. Summary statistics for selected body size dimensions of nuclear power plant personnel were developed by the Electric Power Research Institute (EPRI); and are included in Figure A.4 and Table A.4. These data are based on extrapolations of data contained in Tables A.1 through A.3 (Parris and McConville, 1981). Technical reports should be consulted for definitions of specified measurements, methods of data collection and more detailed anthropometric data (see references); more specific or definitive data should be obtained for the user population of interest.

\section{A.1.1 DATA LIMITATIONS}

Because the anthropometric data presented here represent nude body measurements, suitable allowances should be made for clothing, protective equipment, and other items that are worn or carried.

\section{A.1.2 CLEARANCE, LIMITING AND ADJUSTABLE DIMENSIONS}

CLEARANCE DIMENSIONS. Clearance dimensions for passageways and accesses should be based upon 95th percentile values of applicable male body dimensions and in no case should the minimum width of any exit be less than 28 in. (NFPA, 1981; also see 29 CFR 1910.37 (d)(6)).

LIMITING DIMENSIONS. Reaching distance, control movement, displays, test points, handrails, etc.) that restrict or are limited by extensions of the body should be based upon the 5 th percentile values for applicable female body dimensions. 
Table A.1. Body Dimensions (in.), 5th and 95th Percentile (from U.S. Department of Defense, 1981 a) (Refer to Figure A.1)

\begin{tabular}{|c|c|c|c|c|c|c|}
\hline & \multicolumn{2}{|c|}{$\begin{array}{c}\text { GROUND TROOPS } \\
\text { Percentile }\end{array}$} & \multicolumn{2}{|c|}{$\begin{array}{l}\text { AVIATORS } \\
\text { Percentile }\end{array}$} & \multicolumn{2}{|c|}{$\begin{array}{l}\text { WOMEN } \\
\text { Percentile }\end{array}$} \\
\hline & 5th & 95th & 5 th & 95th & 5 th & 95th \\
\hline Weight (lb) & 122.4 & 201.9 & 133.1 & 211.6 & 102.3 & 164.3 \\
\hline \multicolumn{7}{|l|}{ Standing body dimensions } \\
\hline 1. Stature & 64.1 & 73.1 & 64.6 & 73.9 & 60.0 & 68.5 \\
\hline 2. Eye height (standing) & 59.5 & 68.2 & 59.9 & 69.0 & 55.5 & 63.9 \\
\hline 3. Shoulder (acromiale) height & 52.6 & 60.7 & 52.5 & 60.9 & 48.4 & 56.6 \\
\hline 4. Chest (nipple) height* & 46.4 & 53.7 & 47.5 & 54.5 & 43.0 & 50.3 \\
\hline 5. Elbow (radiale) height & 39.8 & 46.4 & 41.3 & 47.2 & 37.4 & 43.6 \\
\hline 6. Fingertip (dactylion) height & - & - & 24.2 & 28.8 & - & - \\
\hline 7. Waist height & 38.0 & 45.3 & 38.4 & 45.3 & 36.6 & 43.4 \\
\hline 8. Crotch height & 30.0 & 36.1 & 29.4 & 36.2 & 26.8 & 33.0 \\
\hline 9. Gluteal furrow height & 28.8 & 34.5 & 29.4 & 34.7 & 26.2 & 31.9 \\
\hline 10. Kneecap height & 18.7 & 23.1 & 18.4 & 22.8 & 17.2 & 20.7 \\
\hline 11. Calf height & 12.2 & 16.0 & 12.2 & 15.5 & 11.4 & 14.4 \\
\hline 12. Functional reach & 28.6 & 35.8 & 28.8 & 34.3 & 25.2 & 31.7 \\
\hline 13. Functional reach, extended & 33.2 & 39.8 & 32.4 & 38.3 & 28.9 & 36.5 \\
\hline \multicolumn{7}{|l|}{ Seated body dimensions } \\
\hline 14. Vertical arm reach, sitting & 50.6 & 58.2 & 52.8 & 60.3 & 46.2 & 54.9 \\
\hline 15. Thigh clearance height & - & - & 4.9 & 7.4 & 4.1 & 6.9 \\
\hline 16. Sitting height, erect & 32.9 & 38.2 & 33.7 & 38.8 & 31.1 & 35.8 \\
\hline Sitting height, relaxed & 32.1 & 37.3 & 32.9 & 38.0 & 30.5 & 35.3 \\
\hline 17. Eye height, sitting erect & 28.3 & .33 .3 & 30.0 & 33.9 & 26.6 & 31.2 \\
\hline Eye height, sitting relaxed & 27.6 & 32.5 & 28.2 & 33.1 & 26.1 & 30.7 \\
\hline 18. Mid-shoulder height & 22.3 & 26.7 & 23.0 & 27.3 & 21.2 & 24.6 \\
\hline 19. Shoulder height, sitting & 21.3 & 25.7 & 21.5 & 25.9 & 29.6 & 23.7 \\
\hline 20. Shoulder-elbow length & 13.1 & 15.8 & 13.1 & 15.6 & 12.1 & 14.4 \\
\hline 21. Elbow rest height & 6.9 & 11.0 & 7.4 & 11.6 & 6.4 & 10.6 \\
\hline 22. Elbow-fingertip length & 17.3 & 20.5 & 17.6 & 20.4 & 15.7 & 18.7 \\
\hline 23. Elbow-grip length & 12.5 & 15.1 & 12.8 & 14.9 & 11.6 & 14.0 \\
\hline 24. Popliteal height & 15.6 & 19.7 & 15.1 & 18.8 & 15.0 & 18.0 \\
\hline 25. Knee height, sitting & 19.6 & 23.7 & 19.3 & 23.6 & 18.5 & 21.8 \\
\hline 26. Buttock-popliteal length & 17.9 & 21.5 & 17.7 & 21.5 & 17.1 & 20.7 \\
\hline 27. Buttock-heel length & - & - & 18.4 & 22.2 & - & - \\
\hline 28. Functional leg iength & 43.5 & 50.3 & 40.9 & 47.4 & 39.2 & 46.7 \\
\hline 29. Buttock-knee length & 21.6 & 25.9 & 22.0 & 25.8 & 20.9 & 24.9 \\
\hline
\end{tabular}




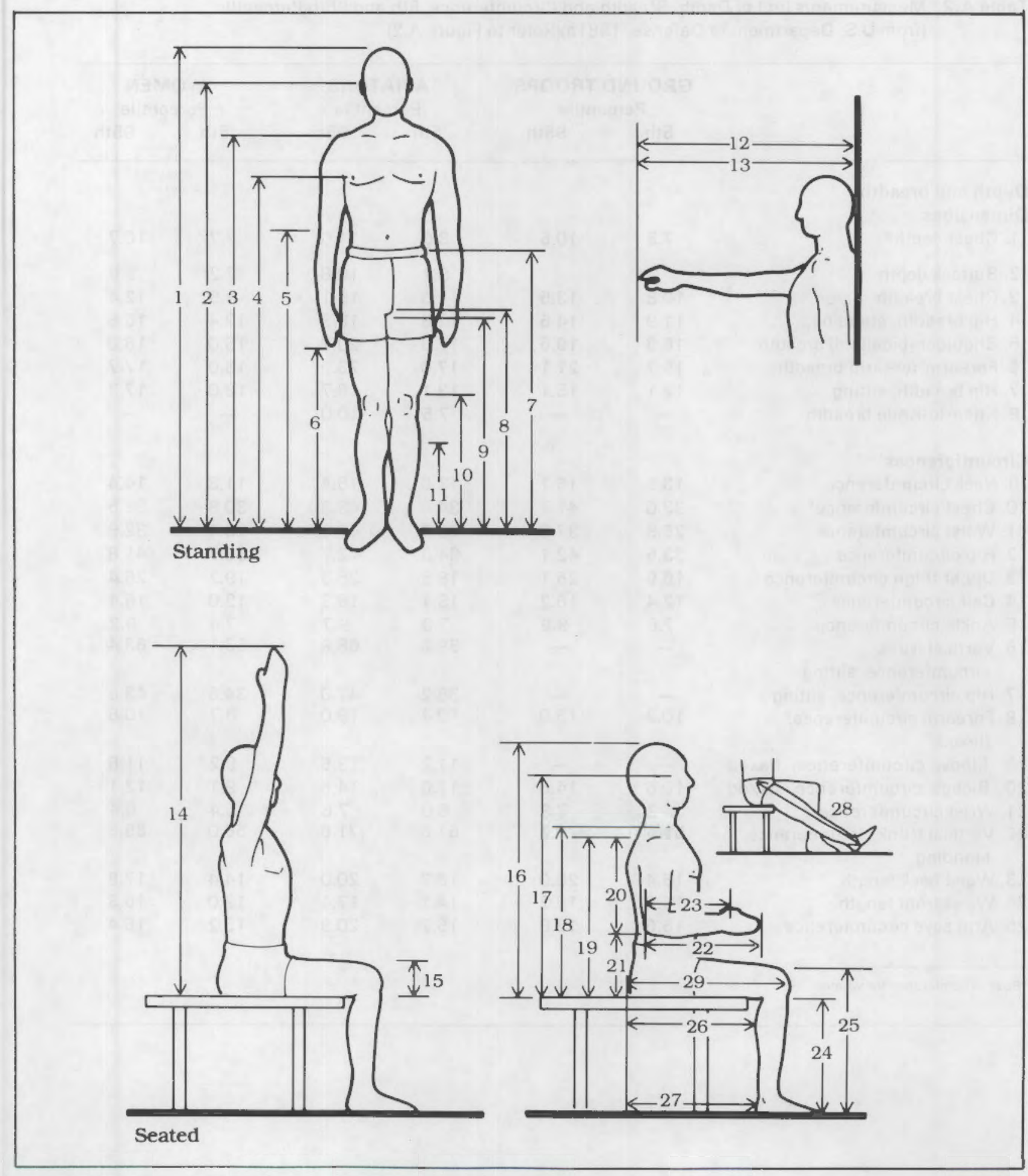

Figure A.1 Body Dimensions (from U.S. Department of Defense, 1981 a) 
Table A.2. Measurements (in.) of Depth, Breadth and Circumference, 5th and 95th Percentile (from U.S. Department of Defense, 1981 akRefer to Figure A.2)

\begin{tabular}{|c|c|c|c|c|c|c|}
\hline & \multicolumn{2}{|c|}{$\begin{array}{l}\text { GROUND TROOPS } \\
\text { Percentile }\end{array}$} & \multicolumn{2}{|c|}{$\begin{array}{l}\text { AVIATORS } \\
\text { Percentile }\end{array}$} & \multicolumn{2}{|c|}{$\begin{array}{l}\text { WOMEN } \\
\text { Percentile }\end{array}$} \\
\hline & 5 th & 95th & 5th & 95th & 5 th & 95th \\
\hline \multicolumn{7}{|l|}{ Depth and breadth } \\
\hline 1. Chest depth* & 7.5 & 10.5 & 8.0 & 11.0 & 7.7 & 10.7 \\
\hline 2. Buttock depth & & & 8.2 & 10.8 & 7.2 & 9.6 \\
\hline 3. Chest breadth & 10.8 & 13.5 & 11.5 & 15.1 & 9.9 & 12.4 \\
\hline 4. Hip breadth, standing & 11.9 & 14.5 & 12.5 & 15.3 & 12.4 & 15.6 \\
\hline 5. Shoulder (bideltoid) breadth & 16.3 & 19.6 & 17.0 & 20.7 & 15.0 & 18.0 \\
\hline 6. Forearm-forearm breadth & 15.7 & 21.1 & 17.0 & 23.9 & 13.0 & 17.7 \\
\hline 7. Hip breadth, sitting & 12.1 & 15.1 & 13.1 & 16.7 & 13.0 & 17.3 \\
\hline 8. Knee-to-Knee breadth & - & - & 7.5 & 10.0 & - & - \\
\hline \multicolumn{7}{|l|}{ Circumferences } \\
\hline 9. Neck circumference & 13.5 & 16.1 & 13.6 & 16.4 & 11.8 & 14.4 \\
\hline 10. Chest circumference* & 33.0 & 41.7 & 34.4 & 43.3 & 30.8 & 39.5 \\
\hline 11. Waist circumference & 26.9 & 37.6 & 28.9 & 40.0 & 23.4 & 32.9 \\
\hline 12. Hip circumference & 33.5 & 42.1 & 34.3 & 42.7 & 33.7 & 41.8 \\
\hline 13. Upper thigh circumference & 16.9 & 25.1 & 19.5 & 26.3 & 19.2 & 25.4 \\
\hline 14. Calf circumference & 12.4 & 16.2 & 13.1 & 16.3 & 12.0 & 15.4 \\
\hline 15. Ankle circumference & 7.6 & 9.9 & 7.9 & 9.7 & 7.4 & 9.2 \\
\hline $\begin{array}{l}\text { 16. Vertical trunk } \\
\text { circumference, sitting }\end{array}$ & - & - & 59.2 & 68.9 & 53.1 & 63.4 \\
\hline 17. Hip circumference, sitting & - & - & 38.2 & 47.0 & 34.5 & 43.6 \\
\hline $\begin{array}{l}\text { 18. Forearm circumference, } \\
\text { flexed }\end{array}$ & 10.3 & 13.0 & 10.4 & 13.0 & 8.7 & 10.8 \\
\hline 19. Elbow circumference, flexed & - & - & 11.2 & 13.5 & 9.2 & 11.8 \\
\hline 20. Biceps circumference, flexed & 10.6 & 14.6 & 11.0 & 14.5 & 9.1 & 12.1 \\
\hline 21. Wrist circumference & 6.2 & 7.3 & 6.0 & 7.6 & 5.4 & 6.4 \\
\hline $\begin{array}{l}\text { 22. Vertical trunk circumference, } \\
\text { standing }\end{array}$ & 59.3 & 70.3 & 61.6 & 71.6 & 56.0 & 65.5 \\
\hline 23. Waist back length & 15.4 & 20.0 & 16.7 & 20.0 & 14.4 & 17.9 \\
\hline 24. Waist front length & 14.2 & 18.2 & 14.1 & 17.4 & 12.0 & 16.3 \\
\hline 25. Arm scye circumference & 15.6 & 19.8 & 15.7 & 20.9 & 13.2 & 16.4 \\
\hline "Bust circumference for women & & & & & & \\
\hline
\end{tabular}




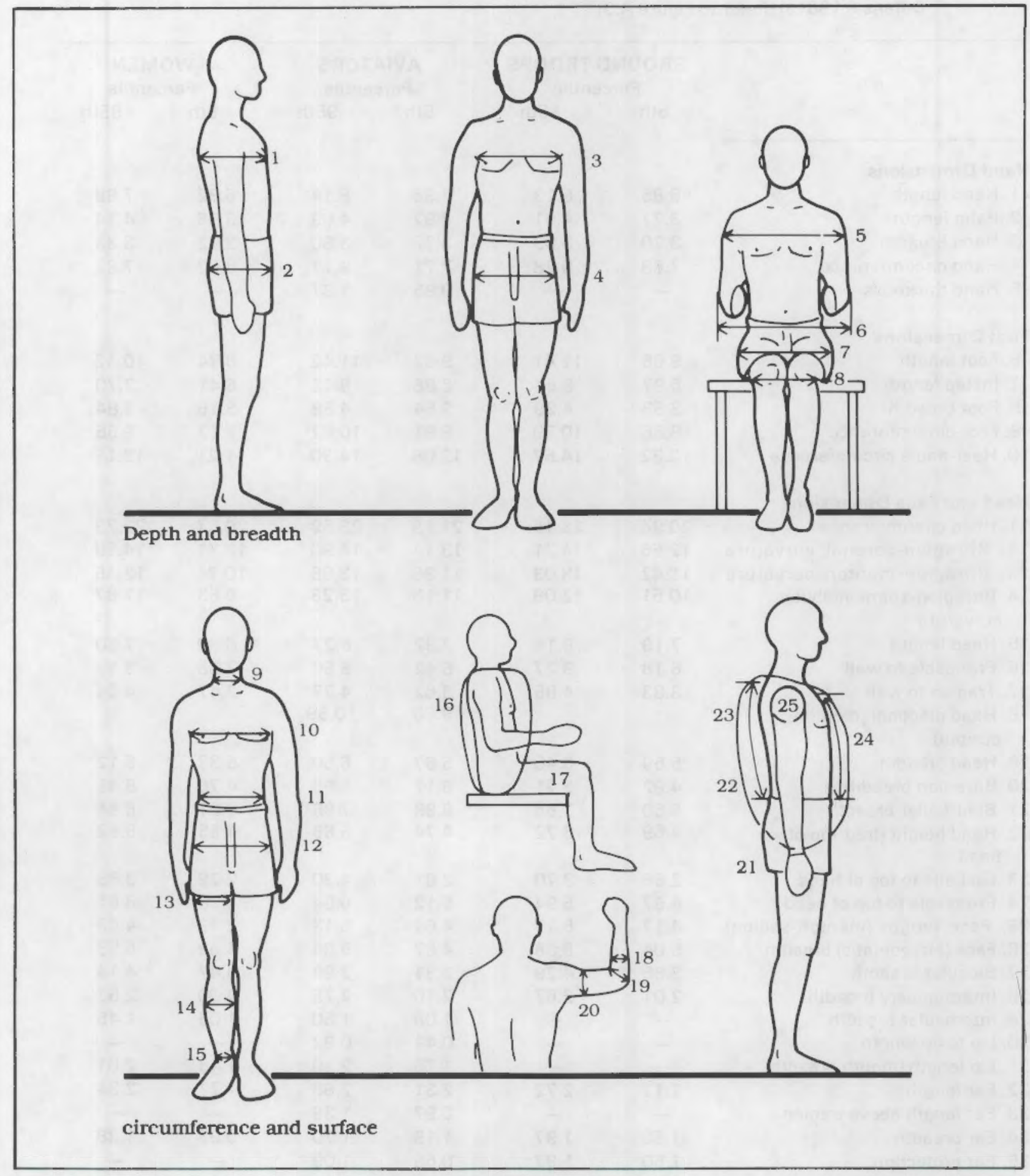

Figure A.2. Depth, Breadth, Circumference and Surface Measurements (from U.S. Department of Defense, 1981 a) 
Table A.3. Hand, Foot, Head and Face Dimensions (in.), 5th and 95th Percentile (from U.S. Department of Defense, 1981 a) (Refer to Figure A.3)

\begin{tabular}{|c|c|c|c|c|c|c|}
\hline & \multicolumn{2}{|c|}{$\begin{array}{c}\text { GROUND TROOPS } \\
\text { Percentile }\end{array}$} & \multicolumn{2}{|c|}{$\begin{array}{l}\text { AVIATORS } \\
\text { Percentile }\end{array}$} & \multicolumn{2}{|c|}{$\begin{array}{l}\text { WOMEN } \\
\text { Percentile }\end{array}$} \\
\hline & 5th & 95th & 5 th & 95th & 5 th & 95th \\
\hline \multicolumn{7}{|l|}{ Hand Dimensions } \\
\hline 1. Hand length & 6.85 & 8.13 & 6.98 & 8.14 & 6.32 & 7.89 \\
\hline 2. Palm length & 3.77 & 4.61 & 3.92 & 4.69 & 3.56 & 4.24 \\
\hline 3. Hand breadth & 3.20 & 3.83 & 3.22 & 3.80 & 2.72 & 3.33 \\
\hline 4. Hand circumference & 7.68 & 9.28 & 7.71 & 9.11 & 6.62 & 7.82 \\
\hline 5. Hand thickness & - & - & 0.95 & 1.37 & - & - \\
\hline \multicolumn{7}{|l|}{ Foot Dimensions } \\
\hline 6. Foot length & 9.65 & 11.41 & 9.62 & 11.42 & 8.74 & 10.42 \\
\hline 7. Instep length & 6.97 & 8.54 & $6.8 \mathrm{~B}$ & 8.42 & 6.41 & 7.70 \\
\hline 8. Foot breadth & 3.53 & 4.29 & 3.54 & 4.58 & 3.16 & 3.84 \\
\hline 9. Foot circumference & 8.B6 & 10.79 & 8.91 & 10.62 & 8.17 & 9.65 \\
\hline 10. Heel-angle circumference & 12.32 & 14.57 & 12.08 & 14.30 & 11.21 & 13.11 \\
\hline \multicolumn{7}{|l|}{ Head and Face Dimensions } \\
\hline 11. Head circumference & 20.94 & 23.16 & 21.18 & 23.59 & 20.57 & 22.73 \\
\hline 12. Bitragion-coronal curvature & 12.56 & 14.21 & 13.14 & 14.90 & 12.31 & 14.29 \\
\hline 13. Bitragion-menton curvature & 11.42 & 13.03 & 11.86 & 13.66 & 10.74 & 12.45 \\
\hline $\begin{array}{l}\text { 14. Bitragion-submandibular } \\
\text { curvature }\end{array}$ & 10.51 & 12.09 & 11.18 & 13.23 & 9.63 & 11.37 \\
\hline 15. Head length & 7.19 & 8.14 & 7.32 & 8.27 & 6.80 & 7.80 \\
\hline 16. Pronasale to wall & 8.18 & 9.27 & 8.42 & 9.50 & 7.88 & 9.15 \\
\hline 17. Tragion to wall & 3.33 & 4.95 & 3.62 & 4.77 & 3.47 & 4.64 \\
\hline $\begin{array}{l}\text { 18. Head diagonal (menton- } \\
\text { occiput) }\end{array}$ & & & 9.60 & 10.59 & & \\
\hline 19. Head breadth & 5.59 & 6.40 & 5.67 & 6.50 & 5.33 & 6.12 \\
\hline 20. Bitragion breadth & 4.92 & 5.71 & 5.17 & 5.98 & 4.76 & 5.45 \\
\hline 21. Biauricular breadth & 6.50 & 7.64 & 6.89 & 7.95 & 5.61 & 6.84 \\
\hline $\begin{array}{l}\text { 22. Head height (trag-top of } \\
\text { head }\end{array}$ & 4.69 & 5.72 & 4.74 & 5.69 & 4.55 & 5.62 \\
\hline 23. Glabella to top of head & 2.56 & 3.70 & 2.81 & 4.30 & 2.79 & 3.88 \\
\hline 24. Pronasale to top of head & 4.57 & 5.94 & 5.12 & 6.54 & 4.70 & 6.61 \\
\hline 25. Face length (menton-sellion) & 4.17 & 5.17 & 4.04 & 5.13 & 3.79 & 4.63 \\
\hline 26. Face (bizygomatic) breadth & 5.04 & 5.88 & 4.87 & 5.94 & 4.69 & 5.53 \\
\hline 27. Biocular breadth & 3.66 & 4.29 & 3.31 & 3.99 & 3.47 & 4.14 \\
\hline 28. Interpupillary breadth & 2.01 & 2.67 & 2.10 & 2.75 & 2.00 & 2.57 \\
\hline 29. Interocular breadth & - & - & 1.08 & 1.50 & 1.05 & 1.45 \\
\hline 30. Lip to lip length & - & - & 0.41 & 0.92 & - & - \\
\hline 31. Lip length (mouth breadth) & - & - & 1.76 & 2.30 & 1.46 & 2.01 \\
\hline 32. Ear length & 2.17 & 2.72 & 2.31 & 2.88 & 1.77 & 2.34 \\
\hline 33. Ear length above tragion & - & - & 0.97 & 1.36 & - & - \\
\hline 34. Ear breadth & 1.50 & 1.97 & 1.19 & 1.70 & 0.95 & 1.38 \\
\hline 35. Ear protection & 1.50 & 1.97 & 0.65 & 1.09 & - & - \\
\hline
\end{tabular}




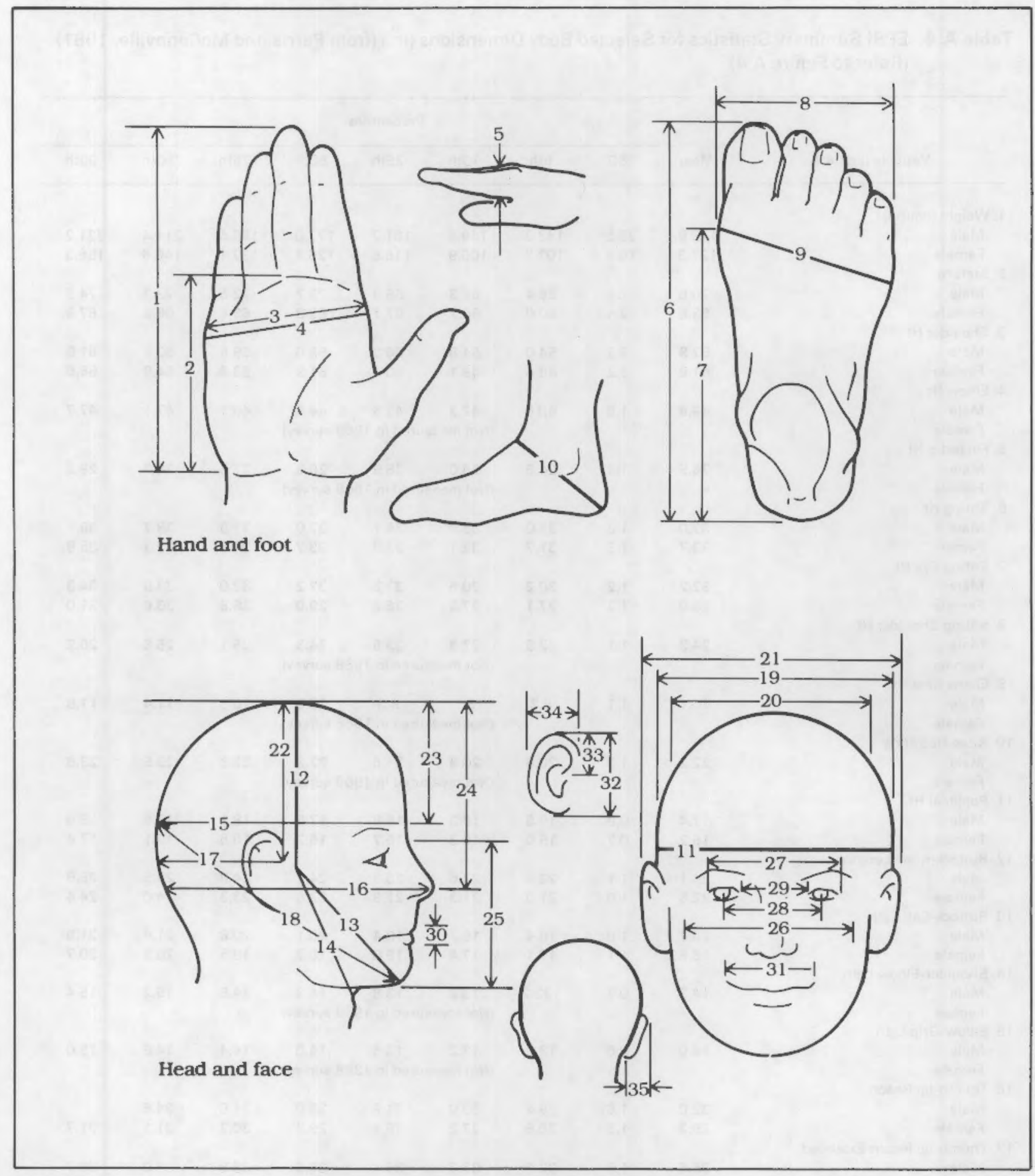

Figure A.3. Measurements of Hand, Foot, Head and Face Dimensions (from U.S. Department of Defense, 1981a) 
Table A.4. EPRI Summary Statistics for Selected Body Dimensions (in.) (from Parris and McConnville, 1981) (Refer to Figure A.4)

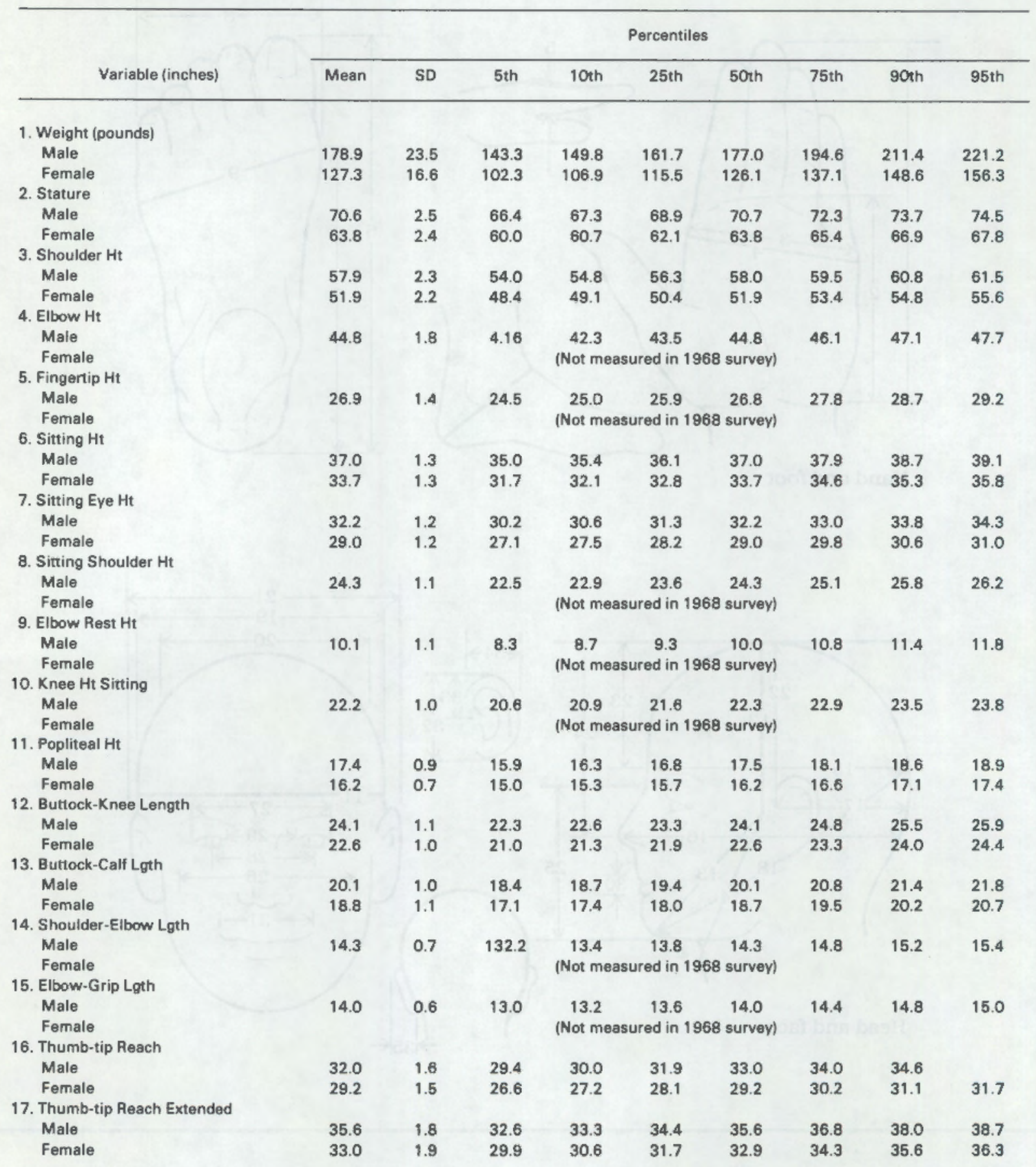


Table A.4. (Continued)

\begin{tabular}{|c|c|c|c|c|c|c|c|c|c|}
\hline \multirow[b]{2}{*}{ Variable (inches) } & \multicolumn{9}{|c|}{ Percentiles } \\
\hline & Mean & SD & 5 th & $10 \mathrm{rh}$ & 25th & 50 th & 75 th & 90th & 95th \\
\hline \multicolumn{10}{|l|}{ 18. Shoulder Breadth } \\
\hline Male & 19.1 & 1.1 & 17.5 & 17.8 & 18.4 & 19.1 & 19.8 & 20.5 & 21.0 \\
\hline Female & 16.5 & 0.9 & 15.1 & 15.4 & 15.9 & 16.4 & 17.1 & 17.7 & 18.1 \\
\hline \multicolumn{10}{|l|}{ 19. Hip Breadth } \\
\hline Male & 14.0 & 0.8 & 12.8 & 13.1 & 13.5 & 14.0 & 14.6 & 15.1 & 15.5 \\
\hline Female & 13.8 & 0.9 & 12.4 & 12.7 & 13.2 & 13.7 & 14.3 & 14.9 & 15.3 \\
\hline \multicolumn{10}{|l|}{ 20. Hip breacth Seated } \\
\hline Male & 15.1 & 1.0 & 13.6 & 13.9 & 14.4 & 15.0 & 15.7 & 16.4 & 16.8 \\
\hline Female & 15.0 & 1.1 & 13.3 & 13.7 & 14.3 & 15.0 & 15.7 & 16.5 & 17.0 \\
\hline \multicolumn{10}{|l|}{ 21. Forearm to Forearm Breadth } \\
\hline Male & 21.6 & 1.5 & 19.1 & 19.6 & 20.5 & 21.5 & 22.6 & 23.6 & 24.2 \\
\hline Female & \multicolumn{9}{|c|}{ (Not measured in 1968 survey) } \\
\hline
\end{tabular}

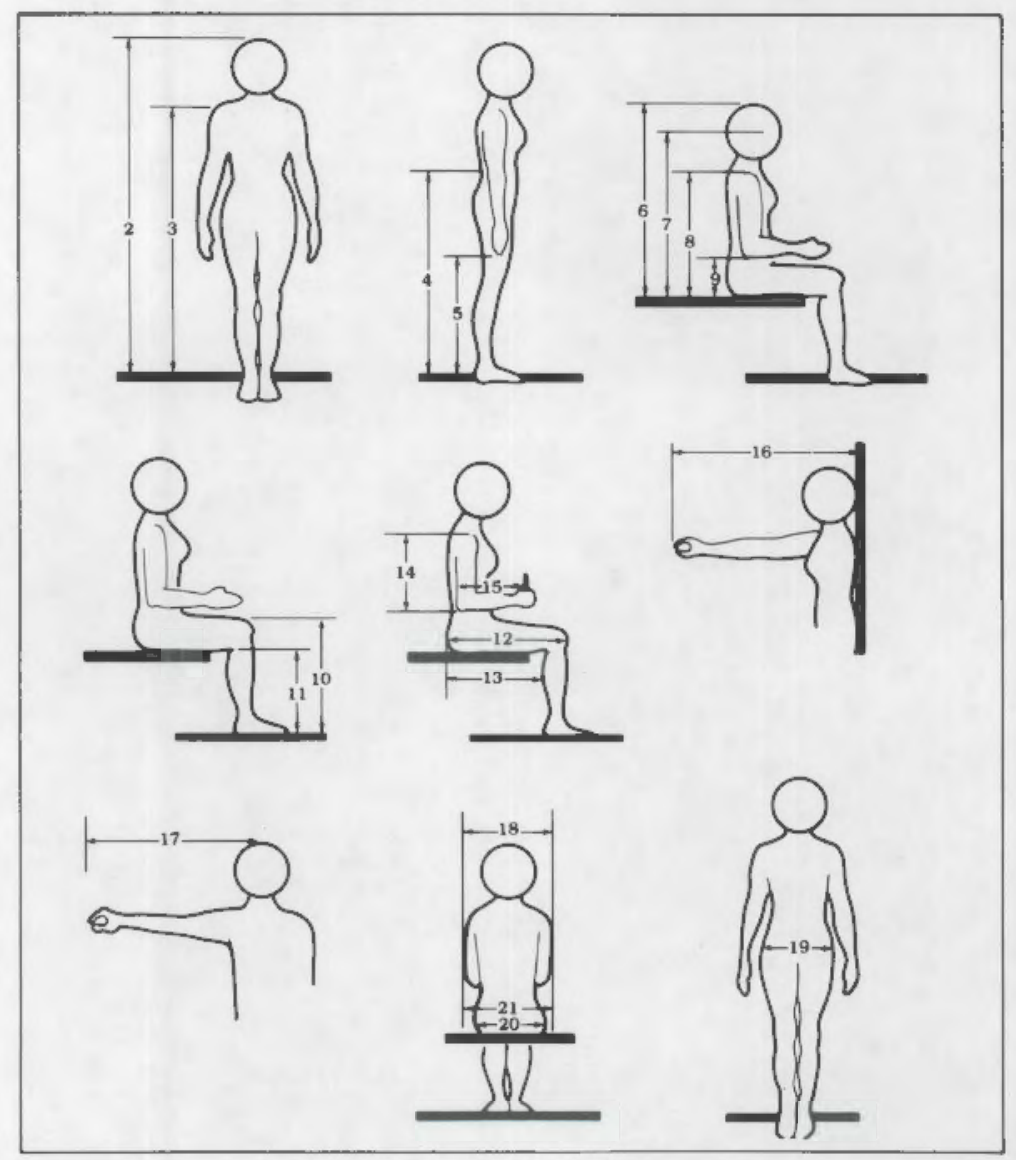

Figure A.4. Definitions of Measurements for Selected Body Dimensions (from Parris and McConnville, 1981) 
ADJUSTABLE DIMENSIONS. Seats, restraint systems, safety harnesses, belts, controls, or any equipment that must be adjusted for the comfort or performance of the individual user should be adjustable over the range of the appropriate 5 th to 95th percentile values.

\section{A.1.3 CLOTHING AND PERSONAL EQUIPMENT}

Clothing and personal equipment (including protective or specialized equipment worn or carried by the individual) should be of a form and size to accommodate body dimensions ranging from the 5 th through the 95th percentile. Where two or more dimensions are used simultaneously as design parameters, appropriate multivariate data and techniques should be utilized. (See references.)

\section{A.2 SPECIAL POPULATIONS}

Where equipment will be used by personnel whose body dimensions fall outside 5 through 95 th percentile range, appropriate anthropometric data should be used in establishing criteria for the form and size. (See references.) 


\section{APPENDIX B}

FORCE APPLICATION 


\section{Appendix B FORCE APPLICATION}

Specific force application guidelines are included for reference in designing or modifying equipment controls or moveable modules.

\section{B.1 HORIZONTAL PUSH-PULL FORCES}

Manual horizontal push-pull forces needed to set an object in motion or to sustain an object over a short period of time should not exceed values presented in Table B.1, illustrated in Figure B.1. The values shown in Table B.1 apply to males only and should be modified (reduced by one-third) for females. In addition, values apply only when a suitable surface for force exertion is supplied (see Section 5.6.1).

\section{B.2 VERTICALPUSH-PULL FORCES}

Manual push and pull forces needed for vertical movement should not exceed values given for the 5 th percentile peak (Table B.2 and Figure B.2). The

Table B.1. Maximum Design Values for Horizontal Push and Pull Forces for Males (From U.S. Department of Defense, 1981a) (refer to Figure B.1)

\begin{tabular}{lc}
\hline $\begin{array}{c}\text { Condition } \\
\text { ( } \mu \text { : Coefficient of Friction) }\end{array}$ & $\begin{array}{c}\text { (Minimum) } \\
\text { Horizontal Force (Ib) }\end{array}$ \\
\hline Traction & 25 \\
Low, $0.2<\mu<0.3$ (A-C) & 45 \\
Med, $\mu \sim 0.6$ (A-C) & 70 \\
High, $\mu>0.9$ (A-C) & \\
Foot rest & 110 \\
$20-70$ in. from panel (D-F) & $165^{*}$ \\
$23-43$ in. from panel (F) & \\
Braced Against Wall & $55^{*}$ \\
$20-60$ in. (G) (one hand) & 110 \\
$20-70$ in. (G-1) (G, two hands) & $165^{*}$ \\
$23-43$ in. (F) &
\end{tabular}

"Push only; all other values are for push and pull.

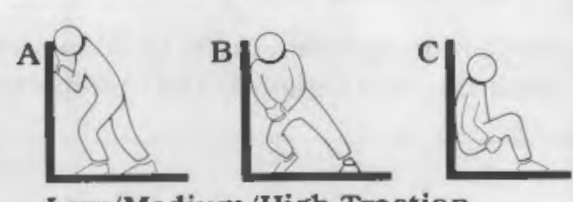

Low/Medium/High Traction
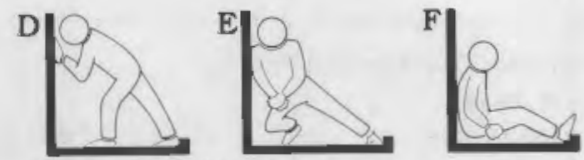

Use of Footrest
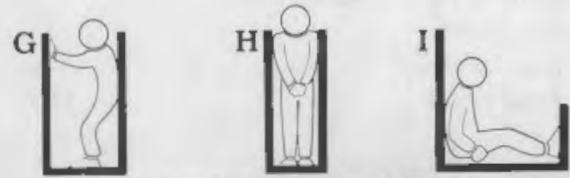

Braced Against Vertical Wall

Figure B.1. Push Force Conditions

values shown in Table B.2 are based on static strength measurements of 349 Army women and 102 Army men dressed in normal indoor apparel (U.S. Department of Defense, 1981a).

\section{B.3 ARM, HAND AND THUMB- FINGER CONTROL FORCES}

Maximum forces for arm, hand and thumb-finger controls are given in Figure B.3, specified in Table B.3. These forces should be adjusted downward by one-third for females (U.S. Department of Defense, 1981a).

\section{B.4 FOOT CONTROL FORCES}

A maximum push force exerted by the leg is a function of the thigh and knee angle. Figure B.4 illustrates a limiting knee angle of approximately 160 degrees to produce a maximum push value (U.S. Department of Defense, 1981 a). 


\section{Force Application}

Table B.2. Static Muscle Strength (lb) for Men and Women in the 5th and 95th Percentile (From U.S. Department of Defense, 1981 a)(refer to Figure B.2)

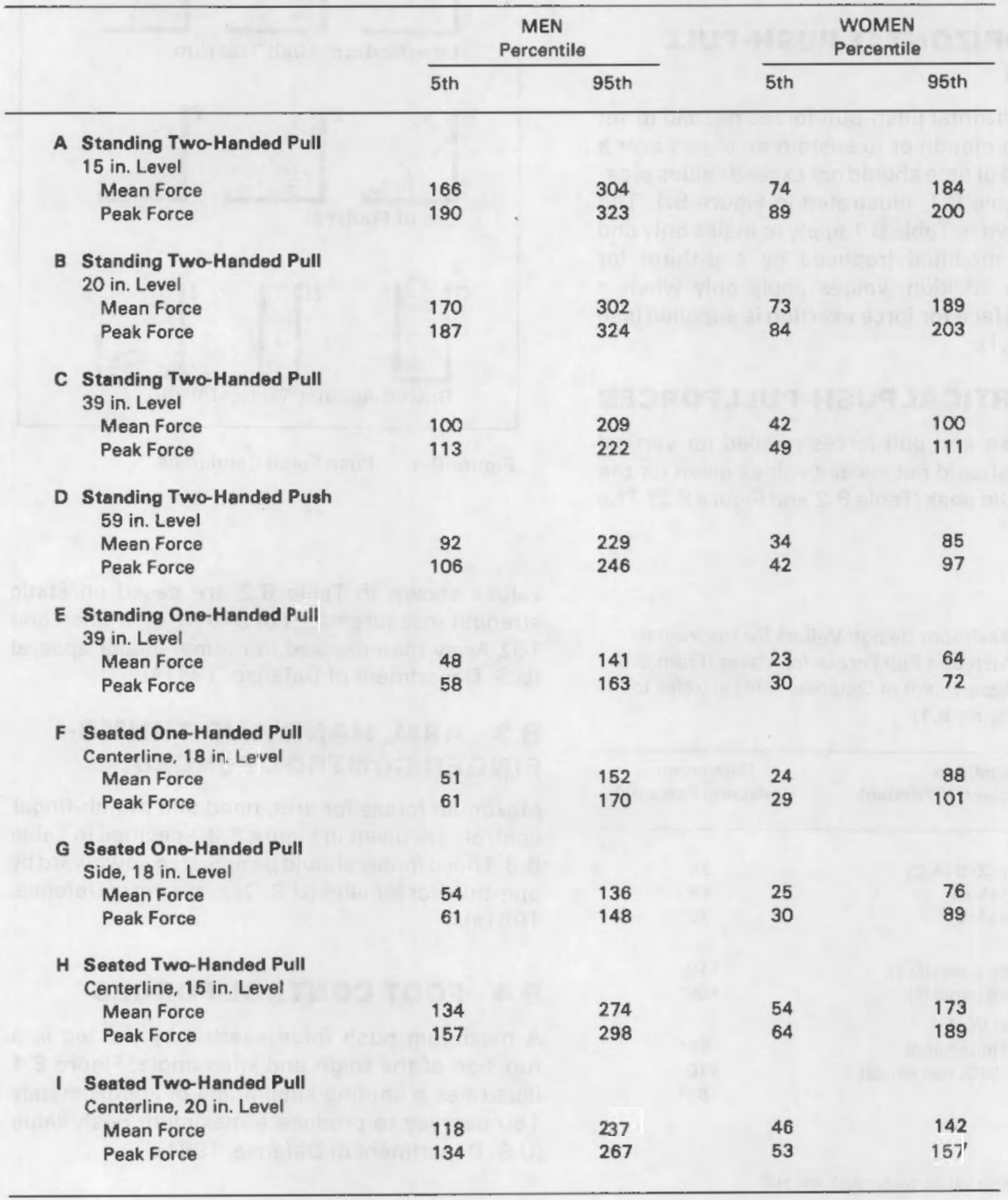




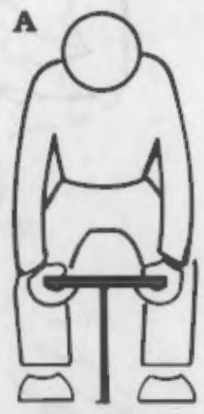

Feet, 18" apart; $18^{\prime \prime}$ long handle; Pulling, using arms, shoulders and legs

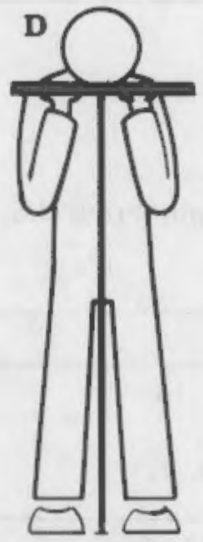

Feet, 18" apart: 18" long handle; Pushing. using arms and shoulders

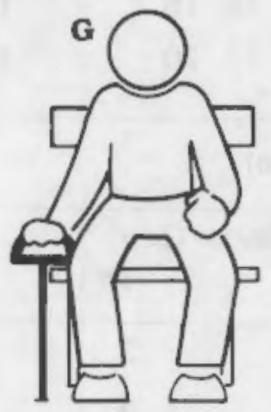

Feet, 22" apart: Dominant hand grasping D-ring; Pulling, while keeping shoulders square

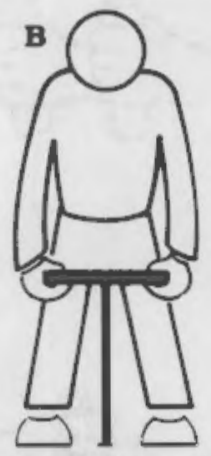

Feet, 18" apart: 18" long handle: Pulling, using arms and shoulders

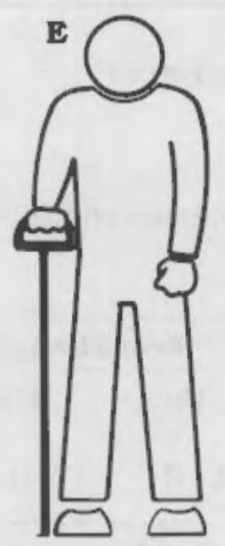

Feet, 6" apart: Dominant hand grasping D-ring; Pulling, whlle keeping shoulders square

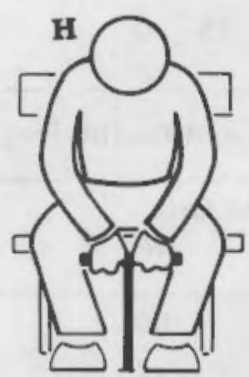

Feet, 22" apart; 6" long handle; Pulling, using arms and shoulders: keeping arms off thighs

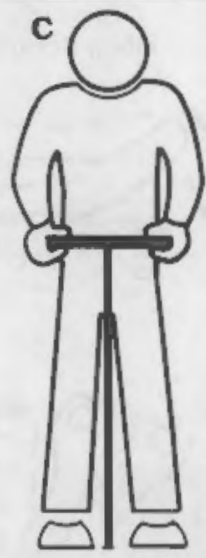

Feet. 18" apart: $18^{\prime \prime}$ long handle; Pulling. using arms

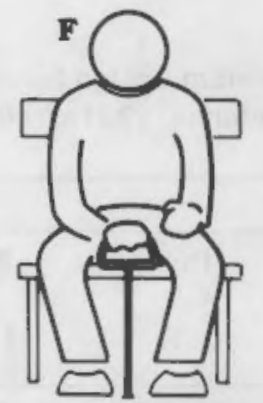

Feet, 22" apart: Dominant hand grasping D-rng: Pulling, while keeping shoulders square

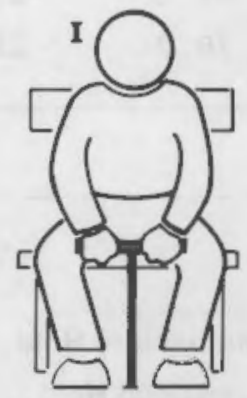

Feet 22 " apart: 6 "long handle; Pulling, using arms and shoulders; Keeping arms off thighs

Figure B.2. Body Conditions for Studies on Static Muscle Strength 


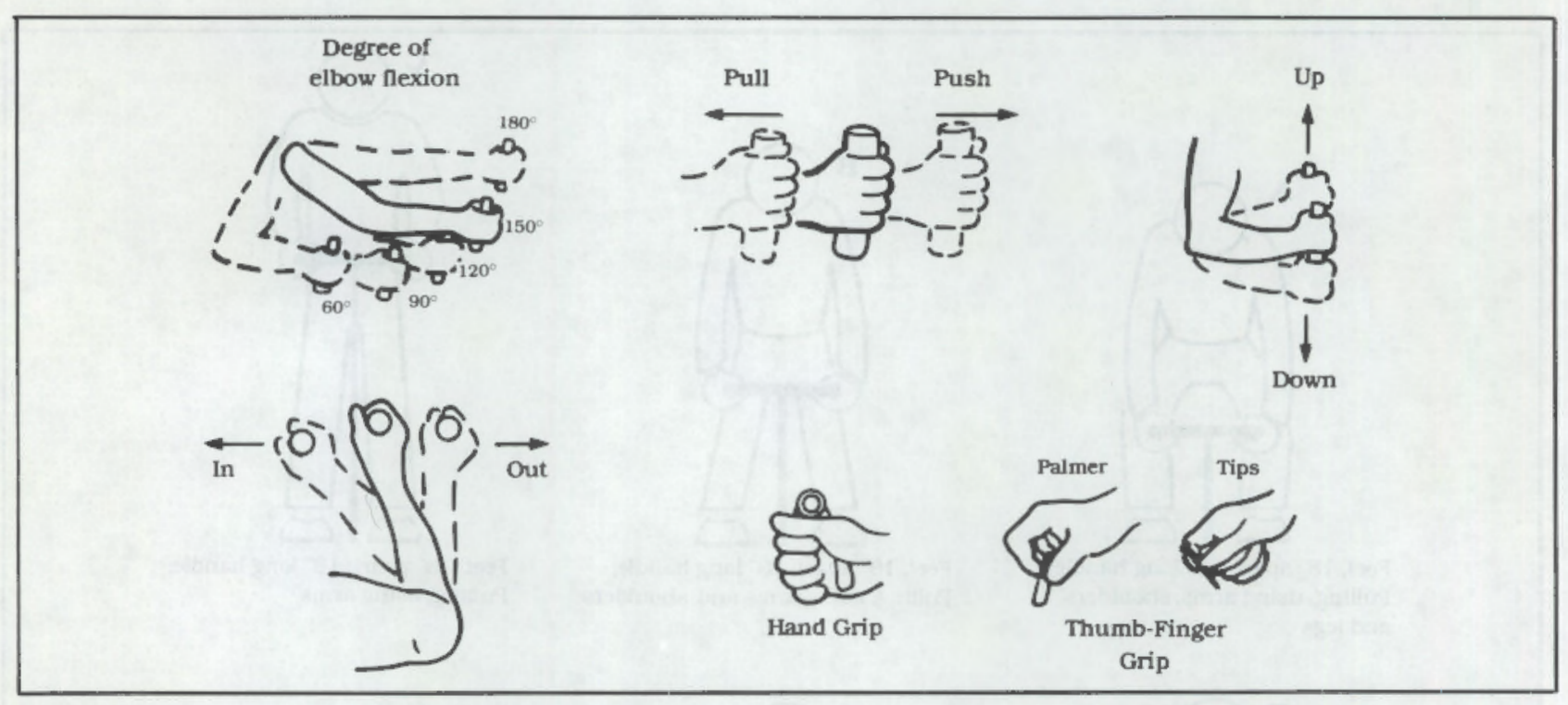

Figure B.3 Use of Arm, Hand and Thumb-Finger Forces

Table B.3. Maximum Design Force Values for Arm, Hand and Thumb-Finger Strength (From U.S. Department of Defense, 1981a)(refer to Figure B.3)

\begin{tabular}{|c|c|c|c|c|c|c|c|c|c|c|c|c|}
\hline \multirow[b]{2}{*}{$\begin{array}{l}\text { Elbow } \\
\text { Flexion } \\
\text { (degree) }\end{array}$} & \multicolumn{12}{|c|}{ Arm Strength (Lb) } \\
\hline & & R & & & & Ip & $\begin{array}{c}\text { Dow } \\
\text { L }\end{array}$ & & & & $\mathbf{L}$ & $\mathbf{R}$ \\
\hline 180 & 50 & 52 & 42 & 50 & 9 & 14 & 13 & 17 & 13 & 20 & 8 & 14 \\
\hline 150 & 42 & 56 & 30 & 42 & 15 & 18 & 18 & 20 & 15 & 20 & 8 & 15 \\
\hline 120 & 34 & 42 & 26 & 36 & 17 & 24 & 21 & 26 & 20 & 22 & 10 & 15 \\
\hline 90 & 32 & 37 & 22 & 36 & 17 & 20 & 21 & 26 & 16 & 18 & 10 & 16 \\
\hline 60 & 26 & 24 & 22 & 34 & 15 & 20 & 18 & 20 & 17 & 20 & 12 & 17 \\
\hline
\end{tabular}

Hand, and Thumb-Finger Strength (Lb)

\begin{tabular}{|c|c|c|c|c|}
\hline & \multicolumn{2}{|c|}{ Hand Grip } & \multicolumn{2}{|c|}{ Thumb-Finger Grip } \\
\hline & $\mathbf{L}$ & $\mathbf{R}$ & Palmer & Tips \\
\hline Momentary Hold & 56 & 59 & 13 & 3 \\
\hline Sustained Hold & 33 & 35 & 8 & 8 \\
\hline$L=$ Left, $R=$ Right & & & & \\
\hline
\end{tabular}




\section{B.5 RESISTANCES FOR SPECIFIC CONTROLS}

Recommended resistances for specific controls are included in Tables B.4 through B.13, with illustrations in Figures B.5 to B.12.

ROTARY KNOBS. The optimum resistance for continuous adjustment rotary knobs should be determined in accordance with the general criteria in U.S. Air Force (1980), Par 3.3. Preferably, moderate viscous damping should be incorporated and inertial and static resistance should be avoided. Sufficient resistance should be provided so that inadvertent touching of the knob will neither activate the control nor change its setting (see U.S. Air Force, 1980 DN 2D2, Par 4.4.3). While no practical minimum resistance is necessary for adequate operator performance, the minimum amount to incorporate in a given knob in terms of potential jarring, vibrations, or other operating conditions should be determined. Torque should not exceed 4-1/2 in.-oz $(0.0318 \mathrm{~N}-\mathrm{m})$ for small knobs 1 in. $(25.4 \mathrm{~mm})$ or less in diameter, or $6 \mathrm{in}$ - $-\mathrm{oz}(0.042 \mathrm{~N}-\mathrm{m})$ for larger knobs. Where applicable, knobs should be coded in terms of characteristic dynamic properties (i.e., "feel"), including type and amount of resistance, etc. (see U.S. Air Force, 1980, DN 2D4, Part 4 and U.S. Army, 1972, 9-5.)

HANDWHEELS. Control dimensions, resistance, displacement and separation between edges of adjacent handwheels should conform to the criteria in Table B.4 (Ibid.).

In general, inertia for handwheels that move through small arcs should be minimized, but high inertia should be provided when it is desirable to maintain wheel rotation without the continual application of force (e.g., spinning a valve control to its OFF position). For one-hand operation, incorporate between 5 and $30 \mathrm{lb}(2.27$ to $13.61 \mathrm{~kg})$ of resistance, measured in terms of linear force applied to a point on the circumference of the wheel. Within this range, resistance should increase in relation to the size of the wheel in order to maintain proper "feel." For two-hand operation, do not exceed a maximum of $50 \mathrm{lb}(22.68 \mathrm{~kg})$ for handwheels mounted in either vertical or upright horizontal position, or a maximum of $20 \mathrm{lb}(9.07 \mathrm{~kg})$ if the handwheel must be mounted in an overhead horizontal position (U.S. Air Force, 1980).

FOOT OPERATED SWITCHES AND PEDALS. Dimensions, resistance and displacement of footoperated switches and pedals should conform to the criteria illustrated in Figure B.5 and Table B.5. Although not recommended (i.e., only one switch per $\mathrm{ft}$. is preferred), when one $\mathrm{ft}$. is required to operate more than one switch, such switches should be at least 3 in. (75 $\mathrm{mm}$ ) apart horizontally; $8 \mathrm{in} .(200 \mathrm{~mm}$ ) apart vertically (U.S. Department of Defense, 1981 a).

PUSHBUTTONS. The control dimensions, resistance, displacement and separation between adjacent edges of the pushbuttons that form keyboards should conform to the criteria indicated in Figure B.6 and Table B.6. For a given keyboard, these criteria should be uniform for all individual keys. For those applications where the operator has to wear arctic mittens (trigger finger), the minimum key size should be $0.75 \mathrm{in} .(19 \mathrm{~mm})$. Other parameters of bare-handed operation remain unchanged (see Table B.7) (lbid.).

TOGGLE SWITCHES. Dimensions, resistance, displacement, and separation between adjacent edges of toggle switches should conform to the criteria illustrated in Figure B.7 and Table B.B. Resistance should gradually increase, then drop when the switch snaps into position. It should be impossible to stop the switch between positions (lbid.).

ROCKER SWITCHES. Dimensions, resistance, displacement and separation between centers of rocker switches should conform to the criteria illustrated in Figure B.8 and Table B.9. Resistance should gradually increase, then drop when the switch snaps into position. As with toggle switches, operators should not be able to stop switches between positions (lbid.). 


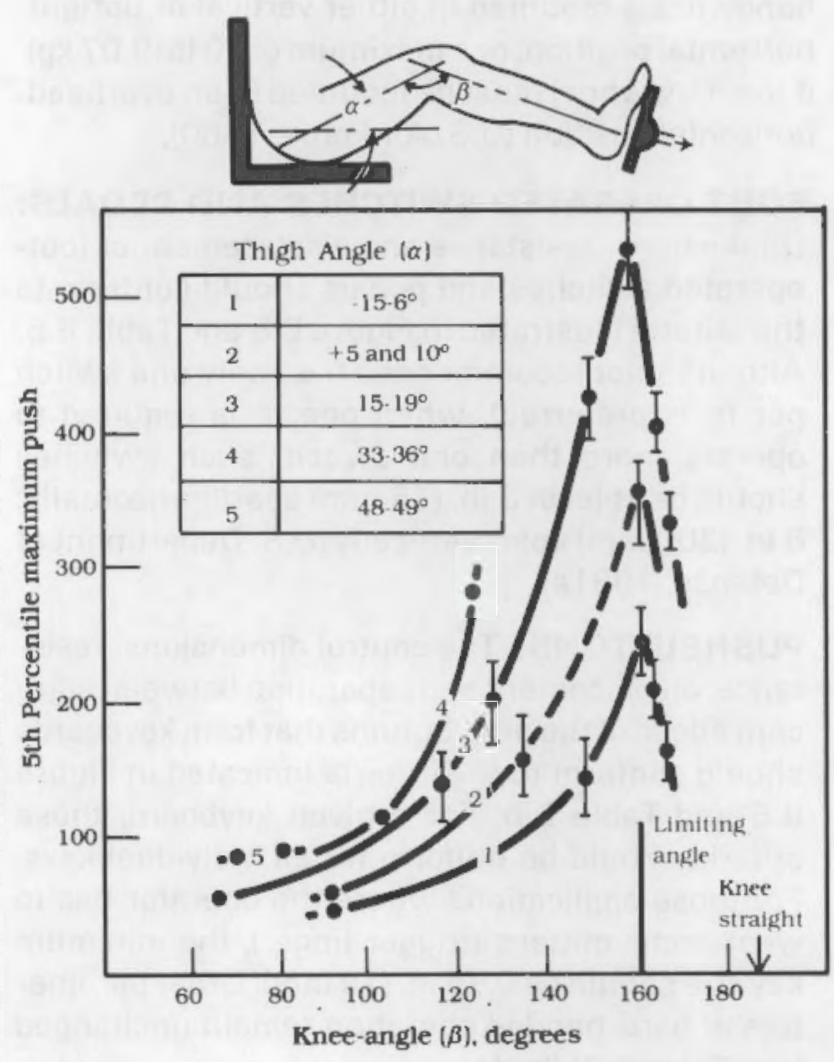

Figure B.4. Leg Strength as a Function of Knee and Thigh Angles (from U.S. Department of Defense, 1981 a)

Table B.4. Design Criteria for Handwheels (From U.S. Department of Defense, 1981a)

\begin{tabular}{|c|c|c|c|c|c|}
\hline & Application Crituris & Dismeter & $\underset{\text { Diammer }}{\text { Rim }}$ & $\begin{array}{c}\text { Min. Hand } \\
\text { Clamerance } \\
\text { (Around } \\
\text { Pim] }\end{array}$ & $\begin{array}{l}\text { Sopuration } \\
\text { (EIbow } \\
\text { Elbow } \\
\text { Clearanca) }\end{array}$ \\
\hline $\begin{array}{ll}00 & 0 \\
00 & 0\end{array}$ & $\begin{array}{l}\text { Continuous adjust- } \\
\text { ment for alternate } \\
\text { slewing/precise } \\
\text { positioning, using } \\
\text { display reference. } \\
\text { Resistance low (e.g. } \\
\text { below }\{25 \text { lb\} }\end{array}$ & $B^{* \prime} \cdot 20^{\prime \prime}$ & $3 / 4 " 11 / 4 "$ & $3^{\prime \prime}$ & $28 "$ \\
\hline & $\begin{array}{l}\text { Continuous lock- } \\
\text { unlock operation }\end{array}$ & $\begin{array}{c}8 * \text { for } 5 \mathrm{lb} \\
\text { to } \\
20 \text { for } 35 \mathrm{lb}\end{array}$ & $3 / 4^{\prime \prime}-11 / 4^{\prime \prime}$ & 3" & $28 *$ \\
\hline & High torque valves & $8 "-16^{\prime \prime}$ for overhead & $3 / 4 *-1 / / 4 *$ & 3" & $28^{*}$ \\
\hline & & $\begin{array}{l}8^{\prime \prime}-20 \text { " for other } \\
\text { positions }\end{array}$ & & & \\
\hline & & $\begin{array}{l}12 "-60 " \text { above } \\
\text { standing surface }\end{array}$ & & & \\
\hline
\end{tabular}



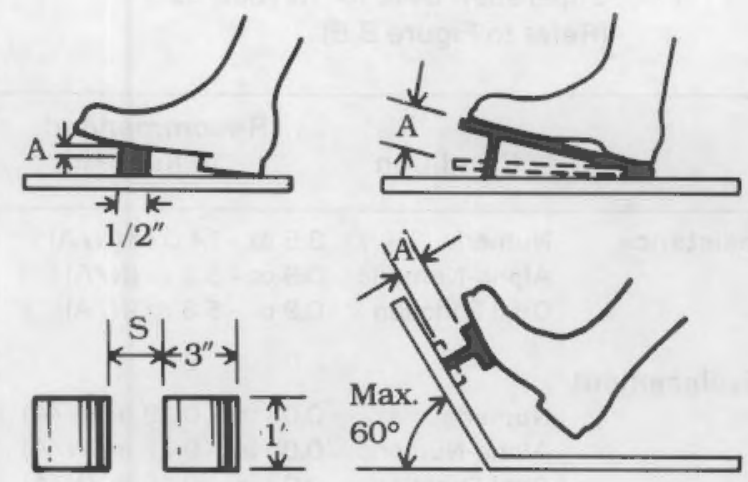

Figure B.5. Foot Operated Switches and Pedals

Table B.5. Resistance, Displacement and Separation Data for Foot-Operated Switches and Pedals ${ }^{1.2}$ (From U.S. Department of Defense, 1981 a) (refer to Figure 8.5)

\begin{tabular}{|c|c|c|c|}
\hline & \multirow[b]{2}{*}{ Condition } & \multicolumn{2}{|c|}{ Recommended Values ${ }^{1.2}$} \\
\hline & & $\begin{array}{l}\text { Foot-Operated } \\
\text { Switches }\end{array}$ & Pedals \\
\hline \multirow[t]{4}{*}{ Resistance } & Foot will NOT rest on Control (Pedal) & $4 \mathrm{lb}-20 \mathrm{lb}(\mathrm{N} / \mathrm{A})$ & $4 \mathrm{lb}-20 \mathrm{lb}(\mathrm{N} / \mathrm{A})$ \\
\hline & Foot WILL rest on Control (Pedal) & $10 \mathrm{lb}-20 \mathrm{lb}(\mathrm{N} / \mathrm{A})$ & $10 \mathrm{lb}-20 \mathrm{lb}(\mathrm{N} / \mathrm{A})$ \\
\hline & Ankle Flexion Only & & $N / A-10 \mathrm{lb}(\mathrm{N} / \mathrm{A})$ \\
\hline & Total Leg Movement & & $10 \mathrm{lb}-180 \mathrm{lb}(\mathrm{N} / \mathrm{A})$ \\
\hline Displacement & Normal Operation & $1 / 2$ in. $-2-1 / 2$ in. (N/A) & $1 / 2 \mathrm{in.}-2-1 / 2 \mathrm{in}$. (N/A) \\
\hline \multirow[t]{3}{*}{ A } & Heavy Boots & 1 in. $-2-1 / 2$ in. (N/A) & 1 in. $-2-1 / 2$ in. (N/A) \\
\hline & Ankle Flexion Only & 1 in. $-2-1 / 2$ in. (N/A) & 1 in. $-2-1 / 2$ in. (N/A) \\
\hline & Total Leg Movement & 1 in. -4 in. (N/A) & 1 in. -7 in. (N/A) \\
\hline Separation & One Foot Random & & 4 in. $-N / A(6$ in.) \\
\hline $\mathbf{s}$ & One Foot Sequential & & 2 in. $-N / A(4$ in.) \\
\hline $\begin{array}{l}\text { 'Values shown are m } \\
{ }^{2} \mathrm{~N} / \mathrm{A}=\text { Not Available }\end{array}$ & naximum (preferred) in units indicated. & & \\
\hline
\end{tabular}




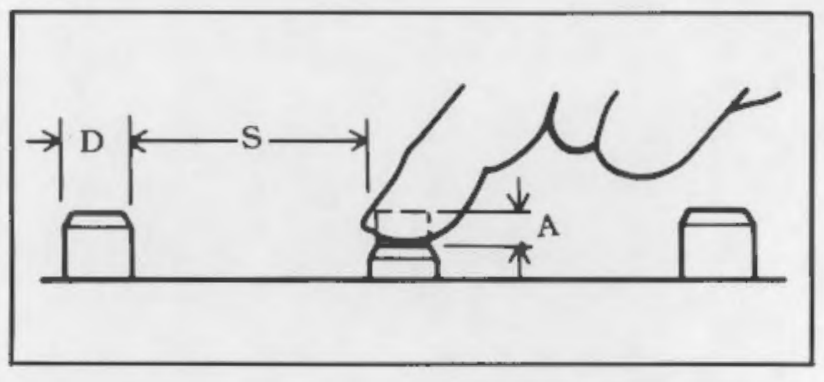

Figure B.6. Finger and Hand-Operated Pushbuttons

Table B.6. Resistance, Displacement and Separation Data for Pushbuttons, Finger or Hand Operated'.2 (From U.S. Department of Defense, 1981 a) (Refer to Figure B.6)

\begin{tabular}{cll}
\hline & \multicolumn{1}{c}{ Condition } & \multicolumn{1}{c}{$\begin{array}{c}\text { Recommended } \\
\text { Velues }\end{array}$} \\
\hline Resistance
\end{tabular}

Table B.7. Resistance, Displacement and Separation Data for Keyboards ${ }^{1.2}$ (Refer to Figure B.6)

\begin{tabular}{|c|c|c|}
\hline & Condition & $\begin{array}{l}\text { Recommended } \\
\text { Values }\end{array}$ \\
\hline Resistance & $\begin{array}{l}\text { Numeric } \\
\text { Alpha-Numeric } \\
\text { Dual Function }\end{array}$ & $\begin{array}{l}3.5 \mathrm{oz}-14.0 \mathrm{oz} \text { (N/A) } \\
0.9 \mathrm{oz}-5.3 \mathrm{oz} \text { (N/A) } \\
0.9 \mathrm{oz}-5.3 \mathrm{oz}(\mathrm{N} / \mathrm{A})\end{array}$ \\
\hline Displaceme & $\begin{array}{l}\text { Numeric } \\
\text { Alpha-Numeric } \\
\text { Dual Function }\end{array}$ & $\begin{array}{l}0.03 \mathrm{in.}-0.19 \mathrm{in} .(\mathrm{N} / \mathrm{A}) \\
0.05 \mathrm{in} .-0.25 \mathrm{in} \text {. (N/A) } \\
0.03 \mathrm{in.}-0.19 \mathrm{in} \text {. (N/A) }\end{array}$ \\
\hline Separation & $\begin{array}{l}\text { BetweenAdjacent } \\
\text { Key Tops }\end{array}$ & $0.25 \mathrm{in.}-\mathrm{N} / \mathrm{A}(0.25 \mathrm{in}$.) \\
\hline $\begin{array}{c}\text { Diameter } \\
\text { D }\end{array}$ & $\begin{array}{l}\text { Bare handed } \\
\text { Arctic mittens }\end{array}$ & $\begin{array}{l}0.385 \text { in. }-0.75 \text { in. }(0.5 \mathrm{in.}) \\
0.75 \text { in. }-\mathrm{N} / \mathrm{A}(0.75 \mathrm{in} .)\end{array}$ \\
\hline \multicolumn{3}{|c|}{$\begin{array}{l}\text { 'Values shown are minimum - maximum (preferred) in units } \\
\text { indicated. } \\
{ }^{2} \mathrm{~N} / \mathrm{A}=\text { Not available. }\end{array}$} \\
\hline
\end{tabular}


Bare Flnger $1 / 2^{\prime \prime}-2^{\prime \prime}$

Heavy Handwear $11 / 2^{\prime \prime}-2^{\prime \prime}$

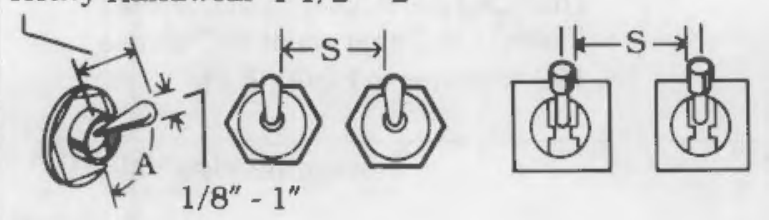

Figure B.7. Toggle Switches

Table B.8. Resistance, Displacement and Separation Data for Toggle Switches ${ }^{1,2}$ (From U.S. Department of Defense, 1981 a) (refer to Figure B.7)

\begin{tabular}{|c|c|c|}
\hline & Condition & $\begin{array}{c}\text { Recommended } \\
\text { Values }\end{array}$ \\
\hline Resistance & $\begin{array}{l}\text { Small Switch } \\
\text { Large Switch }\end{array}$ & $\begin{array}{l}10 \mathrm{oz}-16 \mathrm{oz}(\mathrm{N} / \mathrm{A}) \\
10 \mathrm{oz}-40 \mathrm{oz}(\mathrm{N} / \mathrm{A})\end{array}$ \\
\hline $\begin{array}{c}\text { Displacement } \\
\text { A }\end{array}$ & $\begin{array}{l}2 \text { position } \\
3 \text { position }\end{array}$ & $\begin{array}{l}30^{\circ}-60^{\circ}(\mathrm{N} / \mathrm{A}) \\
17^{\circ}-30^{\circ}\left(25^{\circ}\right)\end{array}$ \\
\hline Separation & Single Finger, Bare & $3 / 4$ in. $-N / A(2$ in.) \\
\hline \multirow[t]{3}{*}{$\mathbf{s}$} & $\begin{array}{l}\text { Using a Lever Lock } \\
\text { Toggle Switch }\end{array}$ & 1 in. $-N / A(2$ in. $)$ \\
\hline & $\begin{array}{l}\text { Single Finger, } \\
\text { Sequential } \\
\text { Operation }\end{array}$ & $1 / 2$ in. $-N / A(1$ in.) \\
\hline & $\begin{array}{l}\text { Simultaneous } \\
\text { Operation, } \\
\text { Different Fingers }\end{array}$ & $5 / 8$ in. $-N / A(3 / 4$ in. $)$ \\
\hline \multicolumn{3}{|c|}{$\begin{array}{l}\text { 'Values shown are minimum - maximum (preferred) in units } \\
\text { indicated. }\end{array}$} \\
\hline \multicolumn{3}{|c|}{${ }^{2} N / A=$ Not available } \\
\hline
\end{tabular}
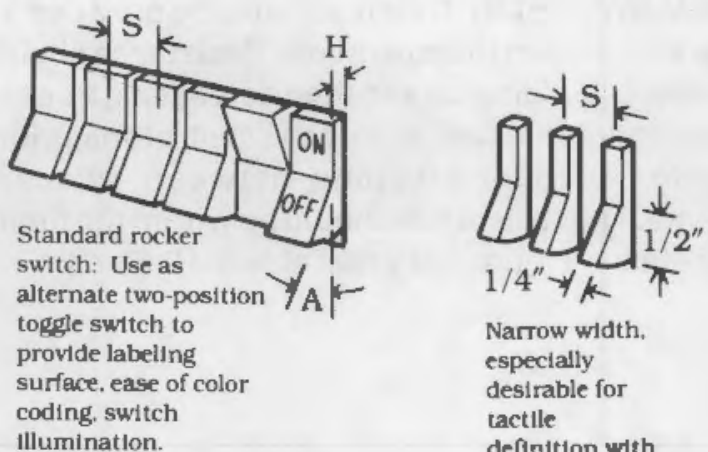

Narrow width. especially desirable for tactlle definition with gloves.
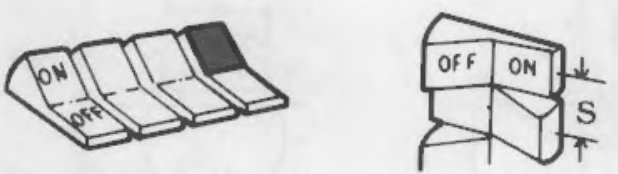

Alternate (contrast)

color for ON versus

OFF. Illuminated ON

desirable as second

feedback cue.

Figure B.8. Rocker Switches

Table B.9. Resistance, Displacement and Separation Data for Rocker Switches ${ }^{1,2}$ (From U.S. Department of Defense, 1981a) (refer to Figure B.8)

\begin{tabular}{|c|c|c|}
\hline & Condition & $\begin{array}{l}\text { Recommended } \\
\text { Values }^{1,2}\end{array}$ \\
\hline Resistance & - & $10 \mathrm{oz}-40 \mathrm{oz}$ (N/A) \\
\hline Displacement & $\begin{array}{l}\text { Depression (H) } \\
\text { Angle (A) }\end{array}$ & $\begin{array}{l}1 / 8 \text { in. }-N / A(N / A) \\
30^{\circ}-N / A(N / A)\end{array}$ \\
\hline $\begin{array}{l}\text { Separation, } \\
\text { Center to } \\
\text { Center } \\
\text { S }\end{array}$ & $\begin{array}{l}\text { Bare Hand } \\
\text { Gloved Hand }\end{array}$ & $\begin{array}{l}3 / 4 \text { in. } \cdot N / A(N / A) \\
1-1 / 4 \text { in. }-N / A(N / A)\end{array}$ \\
\hline \multicolumn{3}{|c|}{$\begin{array}{l}{ }^{1} \text { Values shown are minimum-maximum (preferred) in units } \\
\text { indicated. }\end{array}$} \\
\hline
\end{tabular}


THUMBWHEELS. Detents should be provided for discrete position thumbwheels. Resistance should be elastic, building up and then decreasing as each detent is approached, so that the control snaps into position without stopping between adjacent detents. The resistance should be within the limits indicated in Figure B.9 and Table B.10 (Ibid.).

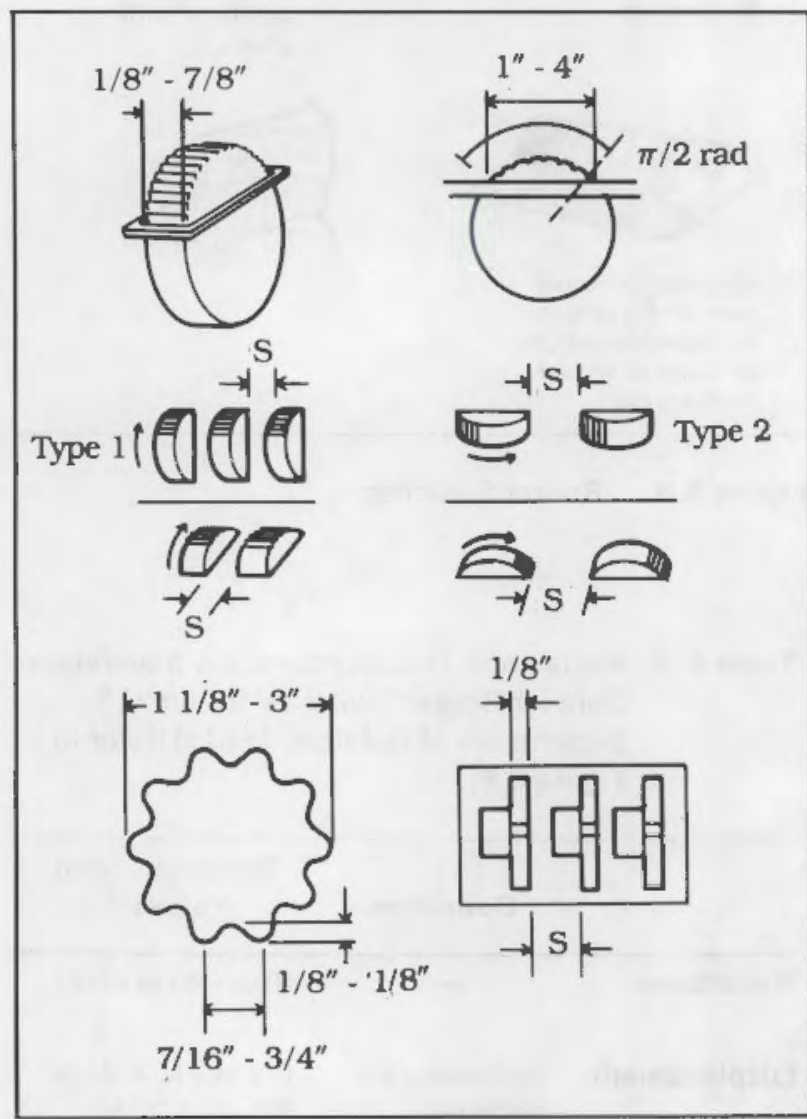

Figure B.9. Discrete Thumbwheel and Thumbwheel Adjustment Controls
Table B.10. Resistance and Separation Data for Discrete Thumbwheel Control and Thumbwheel Adjustment Controls ${ }^{1,2}$ (From U.S. Department of Defense, 1981 a)(Refer to Figure B.9)

\begin{tabular}{|c|c|c|c|}
\hline & \multirow[b]{2}{*}{ Condition } & \multicolumn{2}{|c|}{ Recommended Values ${ }^{1,2}$} \\
\hline & & $\begin{array}{c}\text { Discrete } \\
\text { Thumbwheels }\end{array}$ & $\begin{array}{c}\text { Thumbwheel } \\
\text { Adjustment } \\
\text { Controls }\end{array}$ \\
\hline Resistance & - & $60 z-20 o z$ & N/A -12 oz \\
\hline \multirow{3}{*}{$\begin{array}{c}\text { Separation } \\
\mathbf{S}\end{array}$} & - & $13 / 32$ in. $-N / A$ & - \\
\hline & Type $1^{3}$ & - & 1 in. $-N / A$ \\
\hline & Type $2^{4}$ & - & $2 \mathrm{in.}-\mathrm{N} / \mathrm{A}$ \\
\hline \multicolumn{4}{|c|}{$\begin{array}{l}1 \text { Values shown are minimum - maximum in units indicated. } \\
{ }^{2} N / A=\text { Not available. } \\
{ }^{3} \text { Add } 1 / 2 \text { in. for gloves. } \\
{ }^{4} \text { Add } 1 \text { in. for gloves. }\end{array}$} \\
\hline
\end{tabular}


KNOBS. Resistance should conform to requirements illustrated in Figure B.10 and Table B.11. Knobs should be serrated. Fine serrations should be used on precise adjustment knobs; coarse serrations on gross adjustment knobs (lbid.).

LEVERS. The resistance incorporated in levers should be within the limits indicated in Figure B.11 and Table B.12 measured as linear force applied to a point on the handle. (NOTE: The right hand can supply slightly more force than the left, but the difference is not significant. The same amount of push-pull force can be applied when the control is along the median plane of the body as when it is directly in front of the arm, $7 \mathrm{in}$. (180 mm) from the median plane. When the control is placed in front of the opposite (unused) arm, only 75 percent as much force can be applied. When the control is 10 to 19 in. (250 to $480 \mathrm{~mm}$ ) forward of the neutral seat reference point, twice as much push-pull force can be applied with two hands as with one hand. Outside this range, two-hand operation becomes less effective (lbid.).

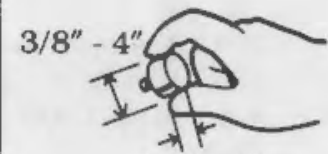

$1 / 2^{\prime \prime}-1^{\prime \prime}$

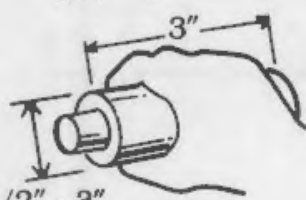

$11 / 2^{\prime \prime}-3^{\prime \prime}$

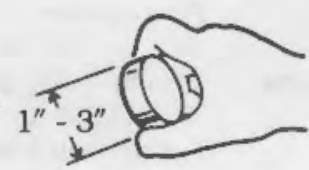

Separation

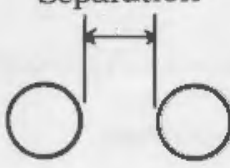

Figure B.10. Knobs
Table B.11. Torque and Separation Data for Knobs ${ }^{1.2}$ (From U.S. Department of Defense, 1981 a) (Refer to Figure B.10)

\begin{tabular}{|c|c|c|}
\hline & Condition & $\begin{array}{c}\text { Recommended } \\
\text { Values }^{1,2}\end{array}$ \\
\hline \multirow[t]{2}{*}{ Torque } & $\begin{array}{l}\text { Knob Diameter } \\
\leq 1 \text { in. }\end{array}$ & $N / A-4-1 / 2$ in. $-0 z$ (N/A) \\
\hline & $\begin{array}{l}\text { Knob Diameter } \\
>1 \text { in. }\end{array}$ & $N / A-6$ in. $-0 z$ (N/A) \\
\hline \multirow[t]{2}{*}{ Separation } & $\begin{array}{l}\text { One hand } \\
\text { individually }\end{array}$ & 1 in. $-N / A(2$ in.) \\
\hline & $\begin{array}{l}\text { Two hands } \\
\text { simultaneously }\end{array}$ & 2 in. - N/A (5 in.) \\
\hline \multicolumn{3}{|c|}{$\begin{array}{l}\text { 'Values shown are minimum - maximum (preferred) in units } \\
\text { indicated. } \\
{ }^{2} \text { N/A = Not available. }\end{array}$} \\
\hline
\end{tabular}

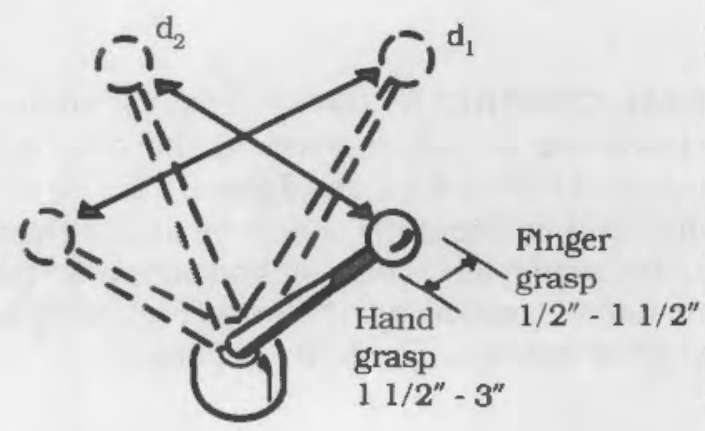

Figure B.11. Levers 
Table B.12. Resistance, Displacement and Separation Data for Levers ${ }^{1,2}$ (From U.S. Department of Defense, 1981 a) (Refer to Figure B.11)

\begin{tabular}{|c|c|c|}
\hline & Condition & $\begin{array}{c}\text { Recommended } \\
\text { Values }^{1,2}\end{array}$ \\
\hline Resistance & $\begin{array}{l}\text { One hand, } d_{1} \\
\text { One hand, } d_{2} \\
\text { Two hands, } d_{1} \\
\text { Two hands, } d_{2}\end{array}$ & $\begin{array}{l}2 \mathrm{lb}-30 \mathrm{lb}(N / A) \\
2 \mathrm{lb}-20 \mathrm{lb}(N / A) \\
2 \mathrm{lb}-50 \mathrm{lb}(N / A) \\
2 \mathrm{lb}-30 \mathrm{lb}(N / A)\end{array}$ \\
\hline Displacement & $\begin{array}{l}\text { Forward, } d_{1} \\
\text { Lateral, } d_{2}\end{array}$ & $\begin{array}{l}\text { N/A }-14 \mathrm{in.}(\mathrm{N} / \mathrm{A}) \\
\mathrm{N} / \mathrm{A}-38 \mathrm{in} .(\mathrm{N} / \mathrm{A})\end{array}$ \\
\hline \multirow[t]{2}{*}{ Separation } & $\begin{array}{l}\text { One Hand, } \\
\text { Random }\end{array}$ & 2 in. $-N / A(4$ in.) \\
\hline & $\begin{array}{l}\text { Two Hands, } \\
\text { Simultaneously }\end{array}$ & 3 in. - N/A (5 in) \\
\hline \multicolumn{3}{|c|}{$\begin{array}{l}1 \text { Values shown are minimum - maximum (preferred) in units } \\
\text { indicated. }\end{array}$} \\
\hline
\end{tabular}

BALL CONTROLS. Dimensions, resistance and clearances should conform to the criteria illustrated in Figure B.12 and Table B.13. The smaller diameter ball controls should be used only where space availability is very limited and when there is no need for precision. Preferred mounting is on a shelf or desk top (Figure B.12) (lbid.).

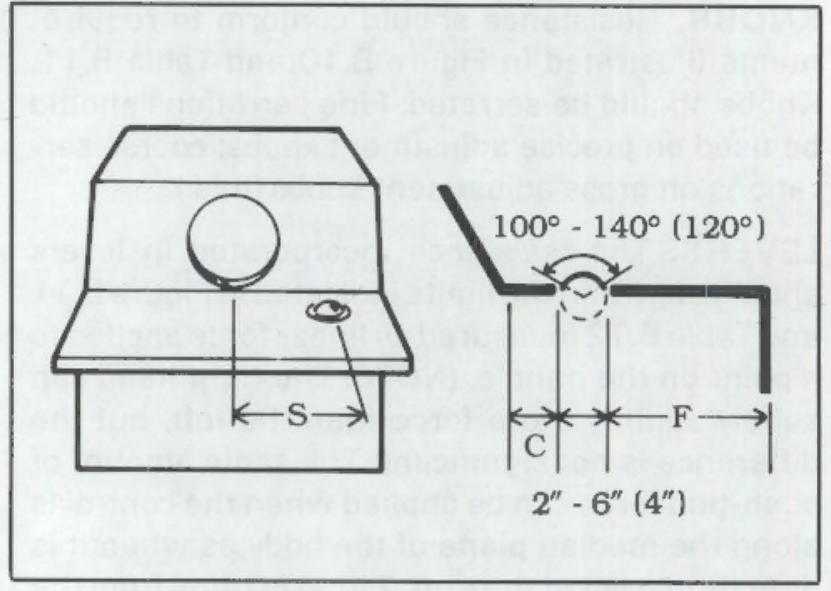

Figure B.12. Ball Controls

Table B.13. Resistance and Clearance Data for Ball Controls $^{1.2}$ (From U.S. Department of Defense, 1981 a) (Refer to Figure B.12)

\begin{tabular}{|c|c|c|}
\hline & Condition & $\begin{array}{l}\text { Recommended } \\
\text { Values }^{1,2}\end{array}$ \\
\hline Resistance & $\begin{array}{l}\text { Precision Required } \\
\text { Vibration or } \\
\text { Acceleration }\end{array}$ & $\begin{array}{l}\text { N/A }-3.6 \text { oz }(1.1 \mathrm{oz}) \\
\text { N/A }-6 \text { oz (N/A) }\end{array}$ \\
\hline Clearance & $\begin{array}{l}\text { Display to Ball (S) } \\
\text { Around Ball (C) } \\
\text { Falf to Shelf Front (F) }\end{array}$ & $\begin{array}{l}0-12-5 / 8 \text { in. (N/A) } \\
2 \text { in. }-N / A(N / A) \\
4-3 / 4 \text { in. }-9-3 / 4 \text { in. } \\
\text { (N/A) }\end{array}$ \\
\hline \multicolumn{3}{|c|}{$\begin{array}{l}\text { 'Values shown are minimum-maximum (preferred) in units } \\
\text { indicated. }\end{array}$} \\
\hline
\end{tabular}




\section{REFERENCES AND RELATED SOURCES}

American Conference of Governmental Industrial Hygienists (ACGIH). 1983. TLV's Threshold Limit Values for Chemical Substances in the Work Environment Adopted by ACGIH for 1983-84. ACGIH, 6500 Glenway Ave., Bldg. D-5, Cincinnati, Ohio 452II.

American Conference of Governmental Industrial Hygienists (ACGIH). 1980. Industrial Ventilation. A Manual of Recommended Practice. ACGIH Committee on Industrial Ventilation, P.O. Box 16153 , Lansing, Michigan 4890 I.

American National Standards Institute (ANSI). 1981. Scheme for the Identification of Piping Systems. ANSI A13.1-1981. American Society of Mechanical Engineers, New York.

American National Standards Institute (ANSI). 1980. Practices for Respiratory Protection. ANSI Z88.2-1980. American National Standards Institute, New York, New York.

American National Standards Institute (ANSI). 1979. Practice for Industrial Lighting. ANSI/IES RP-7-1979. American National Standards Institute, New York, New York.

American National Standards Institute (ANSI). 1976. Preferred Frequencies and Band Numbers for Acoustical Measurements. ANSI S1.6 1967. American National Standards Institute, New York, New York.

American National Standards Institute (ANSI). 1974. American National Standard in Protective Coating in the Nuclear Industry. ANSI N512-1974. American National Standards Institute, New York, New York.

American National Standards institute (ANSI). 1967 Fundamenta/Specification of Safety Colors for CIE Standards Source "C." ANSI Z53.1-1967. American National Standards Institute, New York, New York.

American National Standards Institute (ANSI). Concrete Radiation Shields. ANSI N101.6. American National Standards Institute, New York, New York.

American National Standards Institute (ANSI). Standard for NPP Air Cleaning Units and Components. ANSI N509. American National Standards Institute, New York, New York.
American National Standards Institute (ANSI). Standard for Testing of Nuclear Air Cleaning Systems. American National Standards Institute, New York, New York. ,

American Society of Heating, Refrigerating and Air-Conditioning (ASHRAE). 1977. ASHRAE Handbook and Product Directory (1977 Fundamentals Volume.) American Society of Heating, Refrigerating and Air-Conditioning. New York.

Badalamente, R.V., W.8. Ashton, A.D. Chockie, C.H. Imhoff, and D. Truby. 1982. Recommended Program for the Development of Maintenance Guidelines for Nuclear Power Plants. PNL-4475. Prepared for the United States Nuclear Regulatory Commission by the Pacific Northwest Laboratory, Richland, WA.

Chaffin, D.B. 1975. Low Back Stresses. IN: Ghista. Applications of Biomechanics. Marcel Dekkar, New York.

Chaffin, D.8., G.D. Herrin, W.M. Keyserling and B.A. Fecht. 1978. Biomechanica/ Strength Prediction Model: Guidelines for the Job Analyst. Department of Industrial and Operations Engineering, University of Michigan.

Clayton, G.D., and F.E. Clayton (eds.). 1978. Patty's Industrial Hygiene and Toxicology. Third edition. Five Volumes. John Wiley and Sons, New York, New York.

Code of Federal Regulations. Title 10, Part 20. (Cited in text as 10 CFR 20.) Government Printing Office, Washington, D.C.

Code of Federal Regulations. Title 29, Part 1910. (Cited in text as 29 CFR 1910.) Government Printing Office, Washington, D.C.

Douglas, D.D., A.L. Hack, B.J. Held and W.H. Revoir. 1976. Respirator Manual. LA-6370-M. Prepared for the U.S. Department of Energy by Los Alamos National Laboratory, Los Alamos, New Mexico.

Folley, J.D., Jr., and J.W. Altman. 1956. Guide to Design of Electronic Equipment for Maintainability. Air Research and Development Command, 56218, Department of the Air Force, Washington, D.C.

Higgins, L.R., and L.C. Morrow, eds. 1977. Maintenance Engineering Handbook. Third Edition. McGraw-Hill, New York, New York. 


\section{References and Related Sources}

Illuminating Engineering Society (IES). 1981. Lighting Handbook (Application Volume.) Illuminating Engineering Society, New York.

International Standardization Organization (ISO) Guide to the Evaluation of Human Exposure to Whole Body Vibration. ISO DIS 2631.

Konz, Stephan. 1979. Work Design. Grid Publishing, Columbus, Ohio.

Kroemer, K.H.E. 1970. Human Strength: Terminology, Measurement and Interpretation of Data. Human Factors 12(3):297-313.

Looram, M.E., J.H. Bickford, J.L. Seminara and J.R. Leth. 1981. A Study of Bolting Problems, Tools and Practices in the Nuclear Industry. EPRI NP-2174. The Electric Power Research Institute, Palo Alto, CA.

Mackison, F.W., R.S. Stricoff and L.J. Partridge, Jr. (eds.). 1981. NIOSH/OSHA Occupational Health Guidelines for Chemical Hazards. National Institute of Occupational Safety and Health and Occupational Safety and Health Administration, Washington, D.C.

Mackworth, N.H. 1950. Researches on the Measurement of Human Performance. Medical Research Council (Great Britain), Special Report Series 268, 1950. Reprinted in H.W. Sinaiko (ed.). 1961. Selected Papers on Human Factors in the Design and Use of Control Systems. Dover Publications, Inc., New York.

McCormick, E.J., and M.S. Sanders. 1982. Human Factors in Engineering. McGraw Hill, New York.

Meister, D., and D.J. Sullivan. 1969. Guide to Human Engineering Design for Visual Displays. NR 196-080. Office of Naval Research, Washington, D.C.

Murach, E. 1976. Maintenance Activities Leading to Commercial Operation of Nuclear Generating Station. IN: Proceedings of the Topical Meeting on Nuclear Power Plant Construction Licensing and Startup in American Nuclear Society, Hindsdale, IL.

Ref-2
Murrell, K.F.H. 1969. Ergonomics: Man in His Working Environment. Chapman and Hall, London.

National Fire Protection Association, Inc. (NFPA). 1981. Life Safety Code. 1981. NFPA 101, National Fire Protection Association, Inc., Batterymarch Mark, Quincy, MA 02269.

Nertney, R.J., and M.G. Bullock. 1976. Human Factors in Design. ERDA-76-452. Energy Research Development Administration (now Department of Energy), Washington, D.C.

Occupational Safety and Health Administration (OSHA). 1980. Noise Control: A Guide for Workers and Employers. U.S. Department of Labor, Washington, D.C.

Oliver, J.A., J.E. Baker and J.W. Roth. 1981. Assessment of the Use of Human Factors in the Design of Fossil-Fired Steam Generating System. EPRI-CS-1760. Electric Power Research Institute, Palo Alto, CA.

Pacific Northwest Laboratory. 1980. Safety Guides. PNL-MA-43, Pacific Northwest Laboratory, Richland, WA.

Pacific Northwest Laboratory. 1970. Radiological Design Criteria. PNL-MA-3, Pacific Northwest Laboratory, Richland, WA.

Parris, H.L., and J.T. McConville. 1981. Anthropometric Data Base for Power Plant Design. EPRI NP-1918-SR. The Electric Power Research Institute, Palo Alto, CA.

Pigford, T.H. 1981. The Management of Nuclear Safety: A Review of TMI After Two Years. Nuclear News, 41-48.

Pritchard, John A. 1977. A Guide to IndustrialRespiratory Protection. Prepared for the U.S. Department of Energy by Los Alamos National Laboratory, Los Alamos, New Mexico. 
Rankin, W.L., E.G. Duvernoy, K.R. Ames, M.H. Morgenstern and R.J. Eckenrode. 1983. NearTerm Improvements for Nuclear Power Plant ControlRoom Annunciator Systems. BHARC-400/83/ 004, PNL-4662, NuReg/CR-3217. Battelle Human Affairs Research Center, Pacific Northwest Laboratory, Seattle, WA.

Rigby, L.V., J.I. Cooper and W.A. Spickard. 1961. Guide to Integrated System Design for Maintainability. ASD Tech Report 61-424/AD271477. Aeronautical Systems Division of the United States Air Force, Washington, D.C.

Rogovin, M., and G.T. Frampton, Jr. 1979. Three Mile /sland: A Report to the Commissioners and to the Public. NUREG/CR-1250, U.S. Nuclear Regulatory Commission, Washington, D.C.

Sandia Laboratories. 1978. Short Course Information on Human Factors in Environment, Safety and Health, sponsored by the United States Department of Energy, held in Richland, WA, Nov. 28-30.

Seeman, J.S., F.H. Smith and D.D. Meuller. 1966. A Technique to Investigate Space Maintenance Tasks. Report No. AMRL-TR-66-32, Aerospace Medical Research Laboratories, Wright-Patterson Air Force Base, OH.

Seminara, J.L. 1982. Human Factors Methods for Assessing and Enhancing Power Plant Maintainability. EPRI NP-2360. The Electric Power Research Institute, Palo Alto, CA.

Seminara, J.L., S.K. Eckert, S. Seidenstein, W.R. Gonsalez, R.L. Stempson and S.O. Parsons. 1979. Human Factors Methods for Nuclear ControlRoom Design. EPRI NP-1118-SY. Electric Power Research Institute, Palo Alto, CA.

Seminara, J.L., and S.O. Parsons. 1981. Human Factors Review of Power Plant Maintainability. EPRI NP-1567. The Electric Power Research Institute, Palo Alto, CA.

Swain, A.D. 1975. Preliminary Human Factors Analysis of Zion Nuclear Power Plant. SAND 76 0324, NUREG 76-6503. Prepared for the U.S. Nuclear Regulatory Commission by Sandia Laboratories, Los Alamos, New Mexico.
Swain, A.D., and H.E. Guttman. 1980. Handbook of Human Reliability Analysis with Emphasis on Nuclear Power Plant Applications. NUREG/CR1278 (draft). U.S. Nuclear Regulatory Commission, Washington, D.C.

Topmiller, D.A. 1964. A Factor-Analytic Approach to Human Engineering Analysis and Prediction of System Maintainability. Report No. AMRL-TR-64115. Aero Medical Research Labs., WPAFB, OH.

United States Air Force. 1980. AFSC Design Handbook 1-3, Human Factors Engineer. Third Edition, Rev. 1. AFSC DH 1-3. United States Department of the Air Force, Washington, D.C.

United States Air Force. 1978. AFSC Design Handbook 1-9; Maintainability. AFSC DH 1-9. United States Department of the Air Force, Washington, D.C.

United States Air Force. 1973. Hazardous Noise Exposure. U.S. Air Force Regulation 161-35. United States Department of the Air Force, Washington, D.C.

United States Army. 1972. Maintainability Guide for Design. AMCP 706-134. Army Material Command, United States Army, Washington, D.C.

United States Army Missile Command. 1965. Maintainability Engineering Guide. RC-S-65-2. United States Army Missile Command, Washington, D.C.

United States Department of Defense. 1979, Noise Limits for Army Material. MIL-STD-1474B. United States Department of Defense, Washington, DC.

United States Department of Defense. 1977. Military Standard System Safety Program Requirements. MIL-STD-882A. U.S. Department of Defense, Washington, D.C.

United States Department of Defense. 1966. Maintainability Program Requirements MIL-STD-470, United States Department of Defense, Washington, D.C. 
United States Department of Defense. 1981a. Military Standard 1472C: Human Engineering Design Criteria for Military Systems, Equipment Facilities. MILSTD-1472C. United States Department of Defense, Washington, D.C.

United States Department of Defense. 1981b. Military Handbook 759A. United States Department of Defense, Washington, D.C.

United States Department of Energy. 1981. Chapter XI, Requirements for Radiation Protection. DOE 5480.1 Chg 6, United States Department of Energy, Washington, D.C.

U.S. Nuclear Regulatory Commission. 1983. Generic Implications of ATWS Events at the Salem Nuclear Power Plant. NUREG-1000, Vol. 1. United States Nuclear Regulatory Commission, Washington, D.C.
U.S. Nuclear Regulatory Commission. 1982. NRC Report on the January 25, 1982 Steam Generator Tube Rupture at the R.E. Ginna Nuclear Power Plant. NUREG-0909. United States Nuclear Regulatory Commission.

U.S. Nuclear Regulatory Commission. 1981. Guidelines for Control Room Design Review. NUREG-0700. United States Nuclear Regulatory Commission, Washington, D.C.

Van Cott, H.P., and R.G. Kinkade (eds.). 1972. Human Engineering Guide to Equipment Design. American Institute for Research, Washington, D.C.

Webster, J.C., and E.R. Rubin. 1962. Noise Attenuation of Car Protection Devices. Sound 1:34-36.

Winslow, C.E.A. 1942. Physiological Influence of Atmospheric Humidity: Second Report of the ASHVE Technical Advisory Committee on Physiological Reactions. Transactions of the ASHVE 48:317-326. 


\section{DISTRIBUTION}

No. of

Copies

\section{OFFSITE}

4 Dr. Dennis Serig

U.S. Nuclear Regulatory Commission

Division of Human Factors Safety

Air Rights III Building

Mailstop AR-5209

Washington, DC 20555

U.S. Nuclear Regulatory Commission Division of Technical Information and Document Control

7920 Norfolk Avenue

Bethesda, MD 20014
No. of

Copies

ONSITE

41 Pacific Northwest Laboratory

R.V. Badalamente (30)

D.E. Blahnik

J.D. Eklund

B.A. Fecht

R.D. Widrig

Publishing Coordination (5)

Technical Information (2)

Human Affairs Research Center

M.H. Morgenstern 


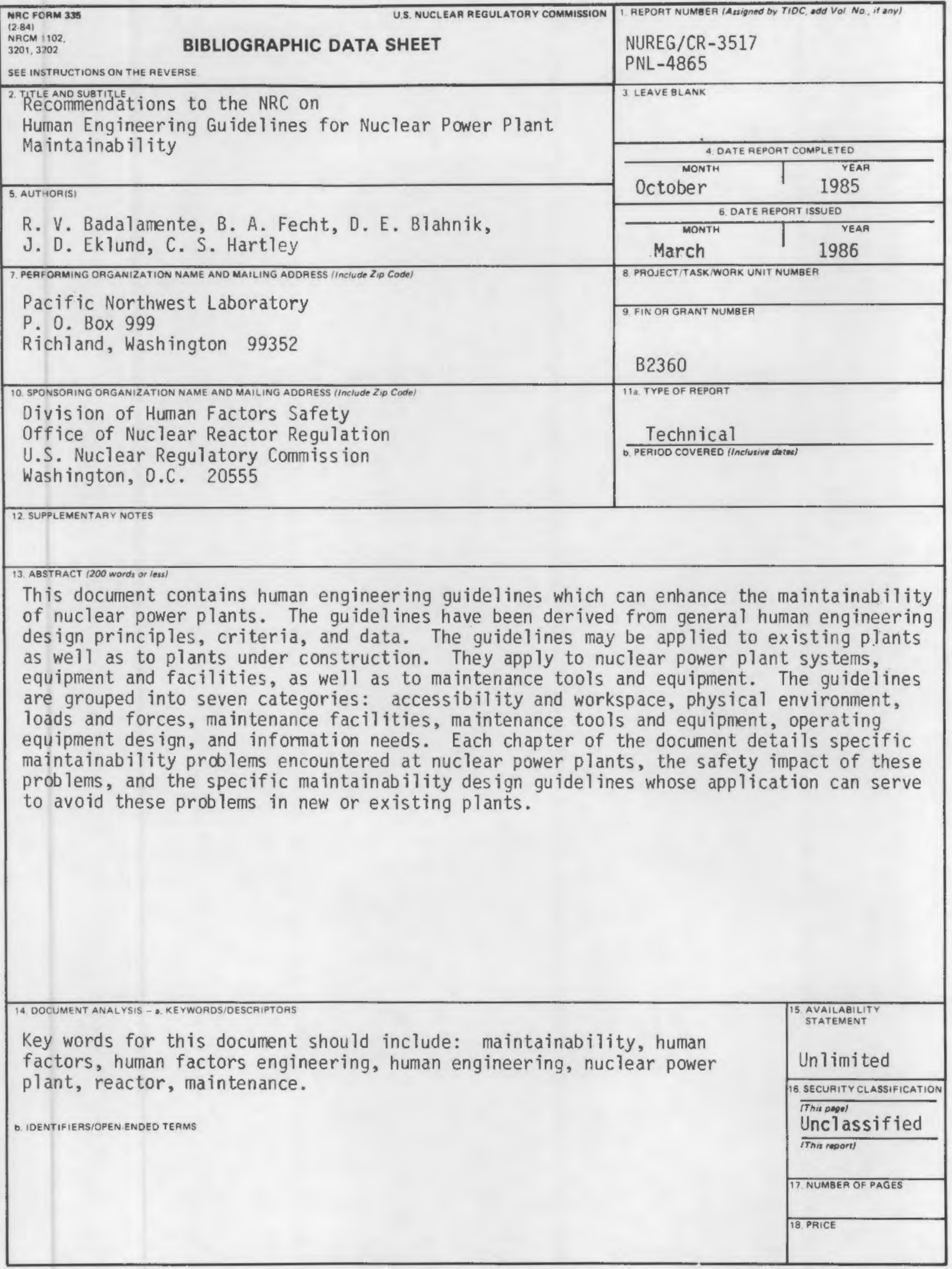


